NOTE TO USERS

This reproduction is the best copy available.

(B)

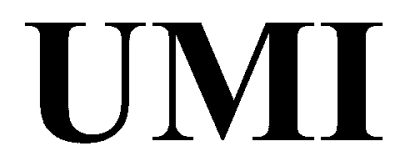





\title{
Analysis of Collision Trends and Safety Engineering Countermeasures on Canadian Roads
}

\author{
Submitted by \\ Leanna Belluz
}

A thesis submitted to the Faculty of Graduate Studies and Research in partial fulfillment of the requirements for the degree of Master of Applied Science

Department of Civil and Environmental Engineering Carleton University

Ottawa, Ontario

(C) Leanna Belluz 2008

The Master of Applied Science in Civil Engineering Program is a joint program with the University of Ottawa, administered by the Ottawa-Carleton Institute for Civil Engineering 


$\begin{array}{ll}\begin{array}{l}\text { Library and } \\ \text { Archives Canada }\end{array} & \begin{array}{l}\text { Bibliothèque et } \\ \text { Archives Canada }\end{array} \\ \begin{array}{l}\text { Published Heritage } \\ \text { Branch }\end{array} & \begin{array}{l}\text { Direction du } \\ \text { Patrimoine de l'édition }\end{array} \\ \begin{array}{l}\text { 395 Wellington Street } \\ \text { Ottawa ON K1A 0N4 } \\ \text { Canada }\end{array} & \begin{array}{l}\text { 395, rue Wellington } \\ \text { Ottawa ON K1A 0N4 } \\ \text { Canada }\end{array}\end{array}$

Your file Votre référence ISBN: 978-0-494-44029-2

Ourfile Notre référence

ISBN: 978-0-494-44029-2

NOTICE:

The author has granted a nonexclusive license allowing Library and Archives Canada to reproduce, publish, archive, preserve, conserve, communicate to the public by telecommunication or on the Internet, loan, distribute and sell theses worldwide, for commercial or noncommercial purposes, in microform, paper, electronic and/or any other formats.

The author retains copyright ownership and moral rights in this thesis. Neither the thesis nor substantial extracts from it may be printed or otherwise reproduced without the author's permission.
AVIS:

L'auteur a accordé une licence non exclusive permettant à la Bibliothèque et Archives Canada de reproduire, publier, archiver, sauvegarder, conserver, transmettre au public par télécommunication ou par l'Internet, prêter, distribuer et vendre des thèses partout dans le monde, à des fins commerciales ou autres, sur support microforme, papier, électronique et/ou autres formats.

L'auteur conserve la propriété du droit d'auteur et des droits moraux qui protège cette thèse. $\mathrm{Ni}$ la thèse ni des extraits substantiels de celle-ci ne doivent être imprimés ou autrement reproduits sans son autorisation.
In compliance with the Canadian Privacy Act some supporting forms may have been removed from this thesis.

While these forms may be included in the document page count, their removal does not represent any loss of content from the thesis.
Conformément à la loi canadienne sur la protection de la vie privée, quelques formulaires secondaires ont été enlevés de cette thèse.

Bien que ces formulaires aient inclus dans la pagination, il n'y aura aucun contenu manquant.

\section{Canada}




\begin{abstract}
The objective of this thesis was to analyze Canadian collision data from 1984 to 2004 on a national and regional level, identify trends and priority areas where improvements are required, and recommend specific road safety engineering countermeasures that would improve road safety in Canada. The collision analysis found that the majority of collision types showed a decreasing trend. Higher decreases were associated with fatal collisions rather than injury collisions. Three major collision types identified as still being problem areas and requiring further improvement were collisions on undivided roads, collisions on rural roads where the speed limit was 80 or $90 \mathrm{~km} / \mathrm{h}$, and run off the road collisions. Some of the more effective measures to address the priority areas were found to be median barriers, rumble strips, improved roadway lighting, converting undivided highways to a divided highway, and wider clear zones.
\end{abstract}




\section{Acknowledgements}

I would like to thank Dr. Yasser Hassan for his patience and commitment to the thesis, Transport Canada for partially funding my graduate studies, and the Evaluation and Data Systems Group within the Road Safety and Motor Vehicle Regulation

Directorate of Transport Canada for giving me access to the Traffic Accident Information Database and for answering my questions along the way. 


\section{Table of Contents}

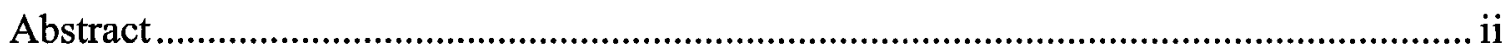

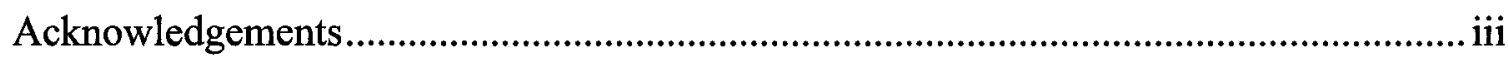

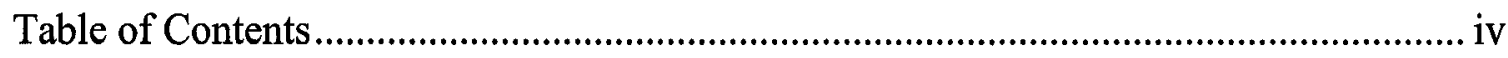

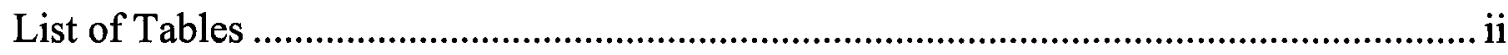

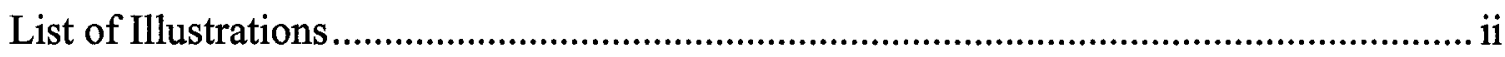

Chapter 1: Introduction and Methodology ..................................................................... 1

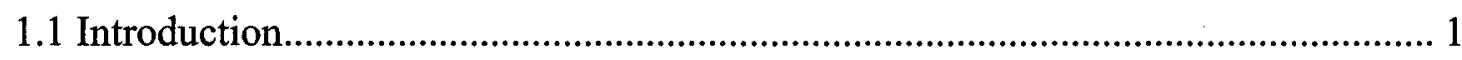

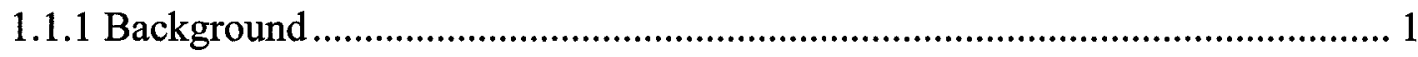

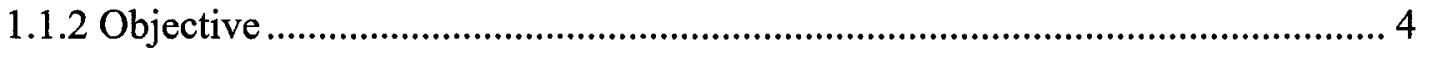

1.1 .3 Scope

1.1.4 Thesis Organization and Writing Style .............................................................. 5

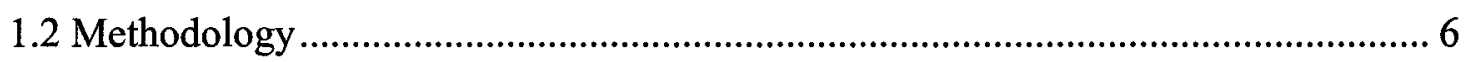

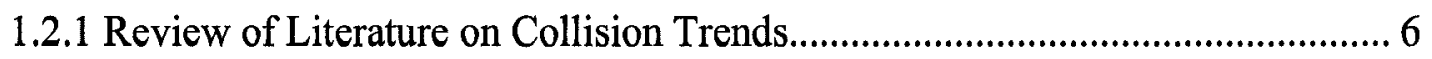

1.2.2 Data Extraction ......................................................................................... 7

1.2.3 Data Analysis ............................................................................................. 8

1.2.4 Review of Literature on the Impact of Safety Countermeasures...................... 11

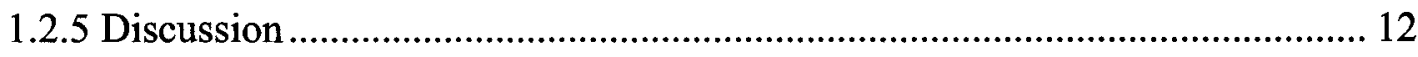

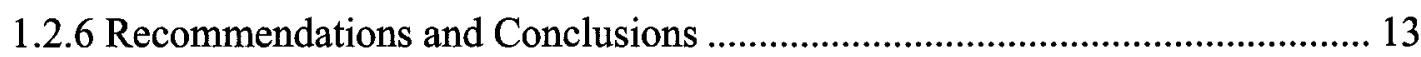

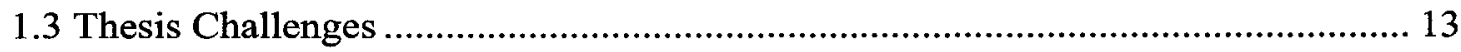

Chapter 2: Review of Literature on Collision Trends.................................................... 16

Chapter 3: Collision Trend Analysis Results................................................................. 24

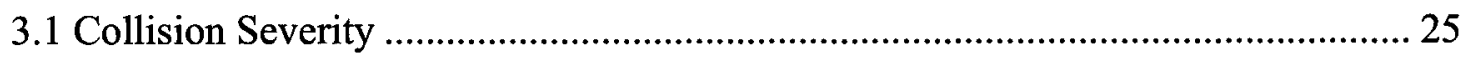




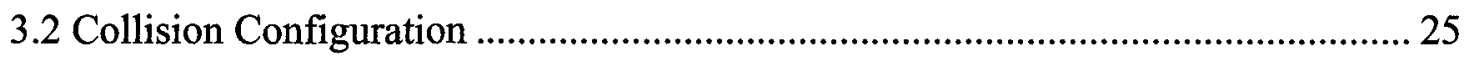

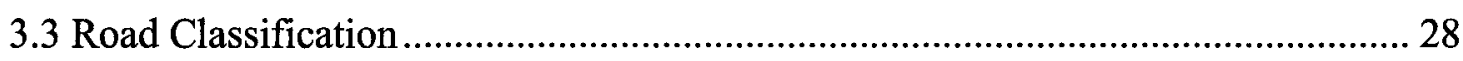

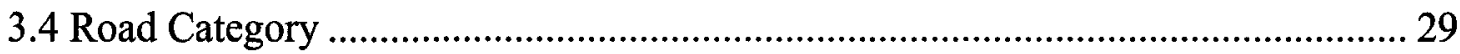

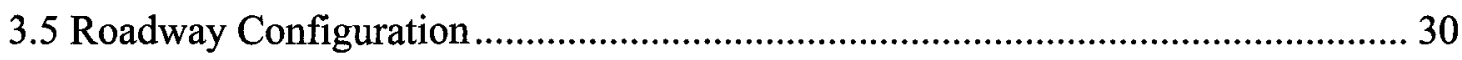

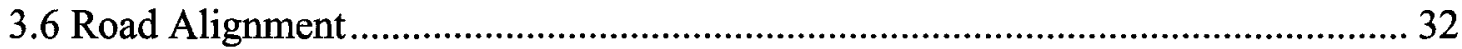

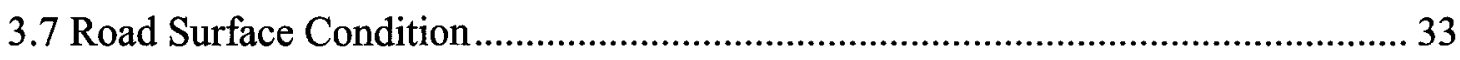

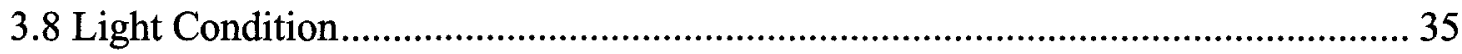

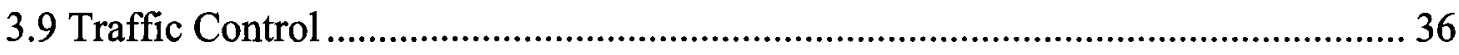

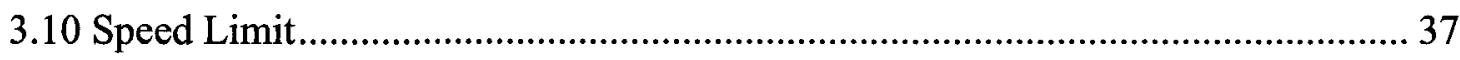

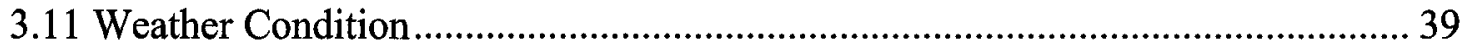

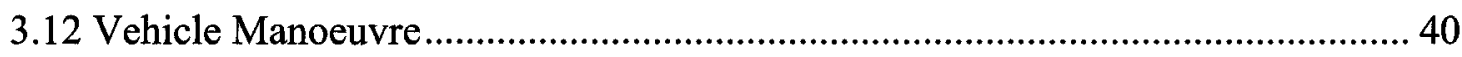

3.13 Vehicle Type

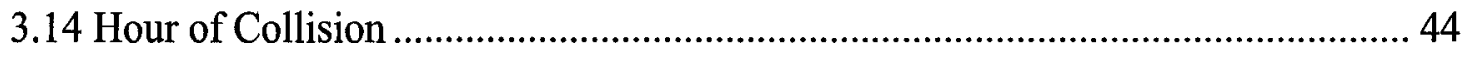

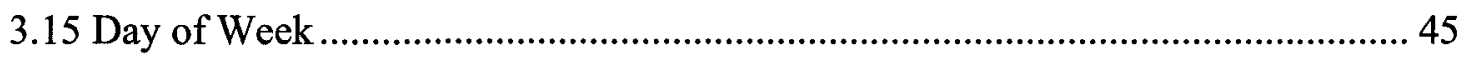

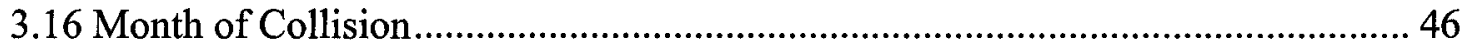

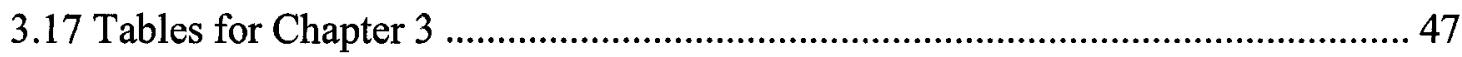

3.18 Figures for Chapter 3 ................................................................................... 56

Chapter 4: Review of Literature on the Impact of Safety Countermeasures ................... 114

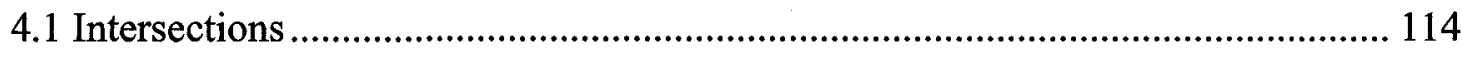

4.1.1 Channelization ........................................................................................ 115

4.1.2 Railway Crossing Warning Devices ............................................................ 118

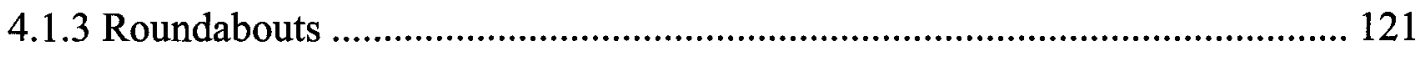

4.1.4 Left-Turn Accommodations at Signalized Intersections ................................ 127 


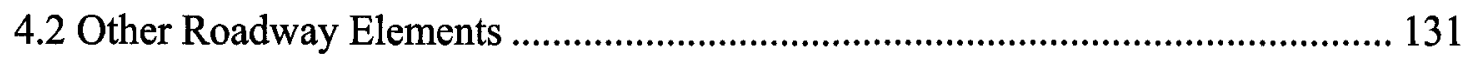

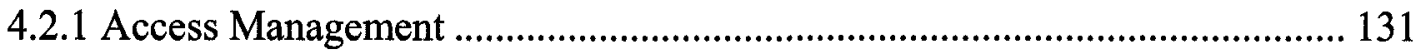

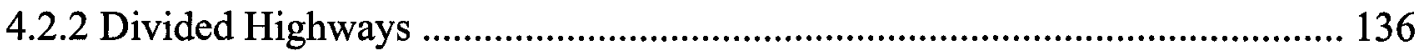

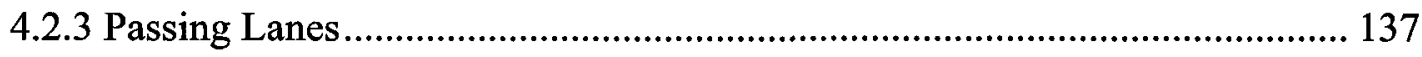

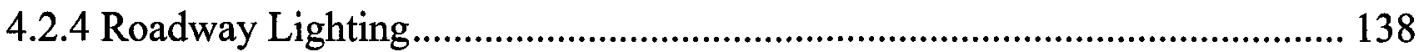

4.2.5 Horizontal Curve Flattening .......................................................................... 140

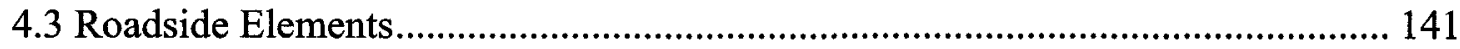

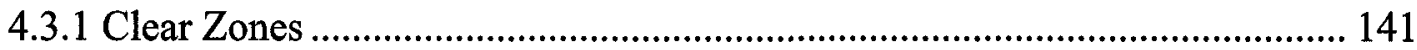

4.3.2 Shoulder Rumble Strips ........................................................................... 143

4.3.3 Energy-Absorbing Barrier End Treatments ………................................... 148

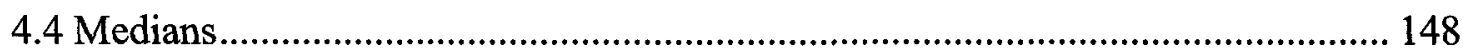

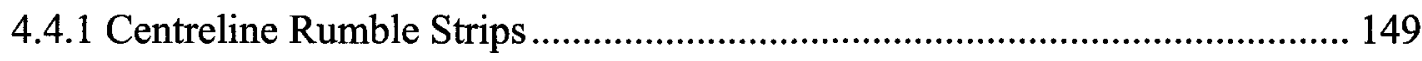

4.4.2 Two-Way Left Turn Lanes ........................................................................... 150

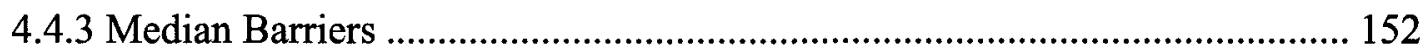

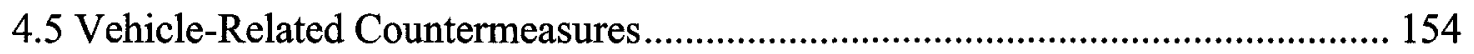

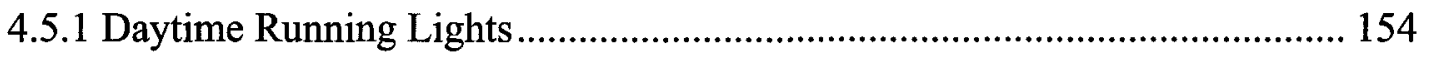

4.5.2 Electronic Stability Control ......................................................................... 156

4.5.3 Centre High Mounted Stop Lamps ................................................................ 159

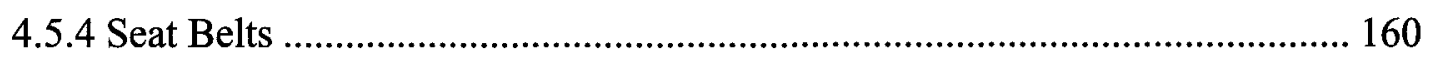

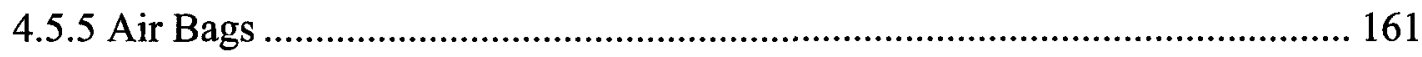

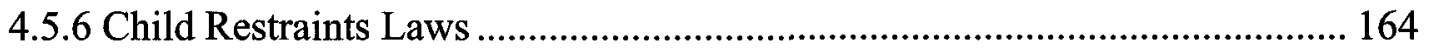

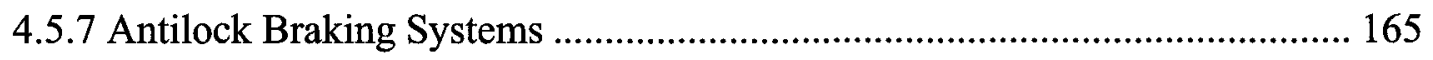

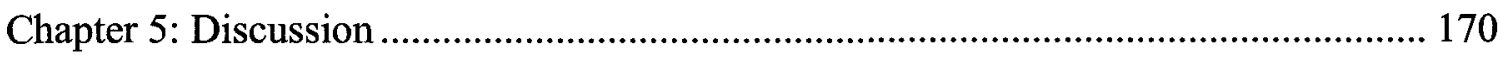


5.1 Countermeasures Affecting National Road Safety Trends.................................... 170

5.2 Regional Trend Discussion Based on Analysis ................................................... 176

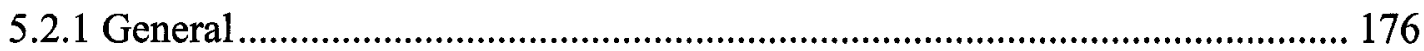

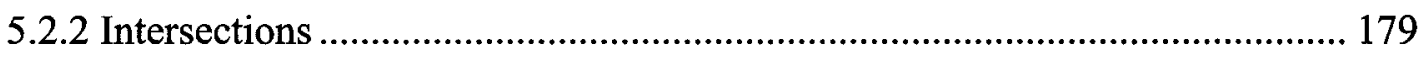

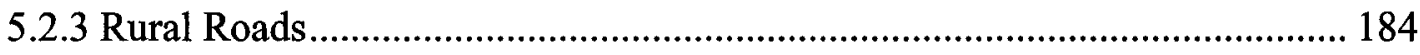

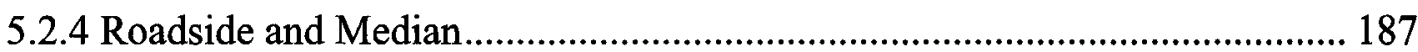

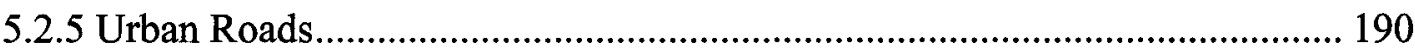

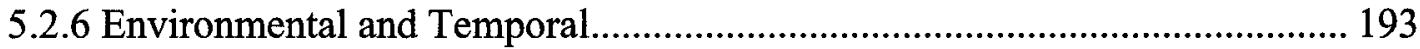

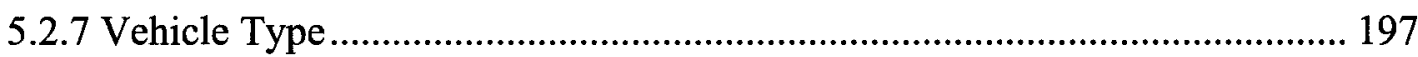

Chapter 6: Recommendation and Conclusions ......................................................... 200

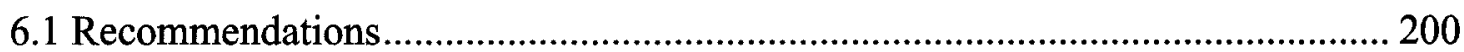

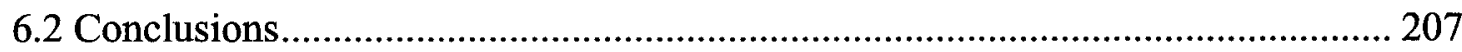

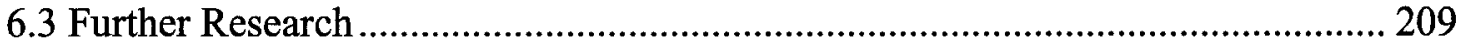

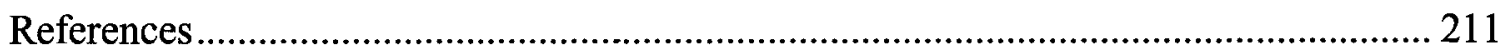




\section{List of Tables}

Table 1.1: Provinces and Territories Included in Analysis Per Data Element.................... 9

Table 3.1: Percentage of Collisions By Region for Collision Severity Values. ............... 47

Table 3.2: Percentage Change in Collision Rates By Region for Collision Severity Values

Between 1984 and 2004

Table 3.3: Percentage of Collisions By Region for Collision Configuration Values....... 47

Table 3.4: Percentage Change in Collision Rates By Region For Collision Configuration

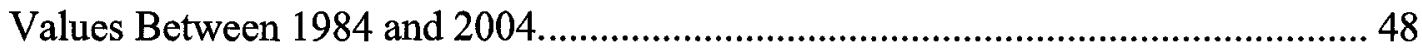

Table 3.5: Percentage of Collisions By Region For Road Classification Values............. 48

Table 3.6: Percentage Change in Collision Rates By Region for Road Classification

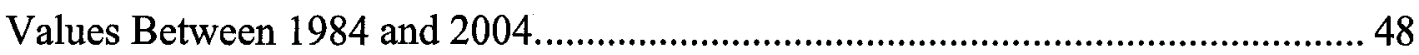

Table 3.7: Percentage of Collisions By Region For Road Category Values. .................... 49

Table 3.8: Percentage Change in Collision Rates By Region For Road Category Values

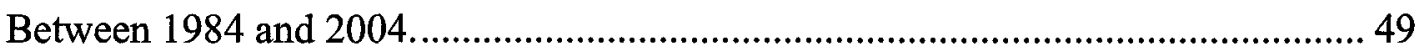

Table 3.9: Percentage of Collisions By Region For Road Configuration Values. ........... 49

Table 3.10: Percentage Change in Collision Rates By Region For Road Configuration

Values Between 1984 and 2004......................................................................... 49

Table 3.11: Percentage of Collisions By Region for Road Alignment Values.................. 50

Table 3.12: Percentage Change in Collision Rates By Region For Road Alignment

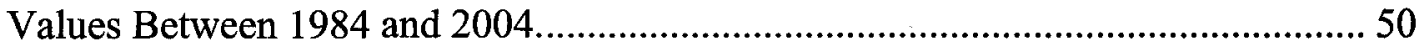

Table 3.13: Percentage of Collisions By Region for Road Surface Condition Values..... 50

Table 3.14: Percentage Change in Collision Rates For Road Surface Condition Values. 51

Table 3.15: Percentage of Collisions By Region for Light Condition Values................... 51 
Table 3.16: Percentage Change in Collisions By Region For Light Condition Values

Between 1984 and 2004 51

Table 3.17: Percentage of Collisions By Region For Traffic Control Values. 52

Table 3.18: Percentage Change in Collisions By Region For Traffic Control Values Between 1984 and 2004 52

Table 3.19: Percentage of Collisions By Region For Speed Limit Values........................ 52 Table 3.20: Percentage Change in Collisions By Region for Speed Limit Values Between 1984 and 2004. 53

Table 3.21: Percentage of Collisions By Region For Weather Condition Values. 53

Table 3.22: Percentage Change in Collisions By Region For Weather Condition Values Between 1984 and 2004 53

Table 3.23: Percentage of Vehicles Involved in Collisions By Region For Vehicle Manoeuvre Values. 54

Table 3.24: Percentage Change in Vehicles Involved in Collision Rates By Region For Vehicle Manoeuvre Values Between 1984 and 2004. 54

Table 3.25: Percentage of Vehicles Involved in Collisions By Region For Vehicle Type Values. 55

Table 3.26: Percentage Change in Vehicles Involved in Collision Rates By Region For Vehicle Type Values Between 1984 and 2004. 55

Table 4.1: Percent Reduction in Collisions After Installation of Roundabouts, (Robinson et al. 2000). 124

Table 4.2: Percent Reduction in Crashes After Installation of Roundabouts, (Jacquemart 2004) 126 
Table 4.3: Reduction in Collisions From Increased Clear Zones, (Ogden 1996)........... 143 


\section{List of Illustrations}

Figure 1.1: Distribution of the Number of Fatal and Injury Collisions Per Region. ........ 10

Figure 3.1: Fatal Collisions Per 10,000 Motor Vehicles Registered By Year................... 56

Figure 3.2: Injury Collisions Per 10,000 Motor Vehicles Registered By Year................ 56

Figure 3.3: Percentage of Fatal Collisions for Collision Configuration Values................ 57

Figure 3.4: Percentage of Injury Collisions for Collision Configuration Values............. 57

Figure 3.5: Fatal Hit Object/Person Collisions Per 10,000 Motor Vehicles Registered By

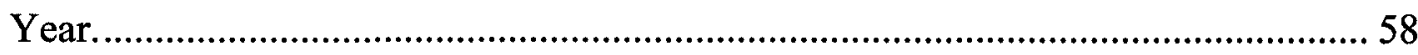

Figure 3.6: Fatal Head-On Collisions Per 10,000 Motor Vehicles Registered By Year. 58

Figure 3.7: Fatal Right-Turn Collisions Per 10,000 Motor Vehicles Registered By Year.

Figure 3.8: Fatal Left-Turn Collisions Per 10,000 Motor Vehicles Registered By Year. 59

Figure 3.9: Fatal Rear-End Collisions Per 10,000 Motor Vehicles Registered By Year.. 60

Figure 3.10: Fatal Run Off Left Shoulder Collisions Per 10,000 Motor Vehicles

Registered By Year.

Figure 3.11: Fatal Run Off Right Shoulder Collisions Per 10,000 Motor Vehicles

Registered By Year.

Figure 3.12: Injury Hit Object/Person Collisions Per 10,000 Motor Vehicles Registered

By Year.

Figure 3.13: Injury Head-On Collisions Per 10,000 Motor Vehicles Registered By Year.

Figure 3.14: Injury Right-Turn Collisions Per 10,000 Motor Vehicles Registered By

Year. 
Figure 3.15: Injury Left-Turn Collisions Per 10,000 Motor Vehicles Registered By Year.

Figure 3.16: Injury Rear-End Collisions Per 10,000 Motor Vehicles Registered By Year.

Figure 3.17: Injury Run Off Left Shoulder Collisions Per 10,000 Motor Vehicles

Registered By Year. 64

Figure 3.18: Injury Run Off Right Shoulder Collisions Per 10,000 Motor Vehicles

Registered By Year. 64

Figure 3.19: Percentage of Fatal Collisions for Road Classification Values. 65

Figure 3.20: Percentage of Injury Collisions for Road Classification Values. 65

Figure 3.21: Fatal Urban Collisions Per 10,000 Motor Vehicles Registered By Year.... 66

Figure 3.22: Fatal Rural Collisions Per 10,000 Motor Vehicles Registered By Year..... 66

Figure 3.23: Injury Urban Collisions Per 10,000 Motor Vehicles Registered By Year... 67

Figure 3.24: Injury Rural Collisions Per 10,000 Motor Vehicles Registered By Year. ... 67

Figure 3.25: Percentage of Fatal Collisions for Road Category Values. ......................... 68

Figure 3.26: Percentage of Injury Collisions for Road Category Values. ....................... 68

Figure 3.27: Fatal Divided Road Collisions Per 10,000 Motor Vehicles Registered By

Year.

Figure 3.28: Fatal Undivided Road Collisions Per 10,000 Motor Vehicles Registered By

Year.

Figure 3.29: Injury Divided Road Collisions Per 10,000 Motor Vehicles Registered By

Year. 
Figure 3.30: Injury Undivided Road Collisions Per 10,000 Motor Vehicles Registered By Year. 70

Figure 3.31: Percentage of Fatal Collisions for Road Configuration Values. .................. 71

Figure 3.32: Percentage of Injury Collisions for Road Configuration Values. ................. 71 Figure 3.33: Fatal Intersection Collisions Per 10,000 Motor Vehicles Registered By Year. 72

Figure 3.34: Fatal Non-Intersection Collisions Per 10,000 Motor Vehicles Registered By Year. 72

Figure 3.35: Injury Intersection Collisions Per 10,000 Motor Vehicles Registered By

Year 73

Figure 3.36: Injury Non-Intersection Collisions Per 10,000 Motor Vehicles Registered By Year. 73

Figure 3.37: Percentage of Fatal Collisions for Road Alignment Values.......................... 74

Figure 3.38: Percentage of Injury Collisions for Road Alignment Values....................... 74

Figure 3.39: Fatal Straight and Level Road Collisions Per 10,000 Motor Vehicles

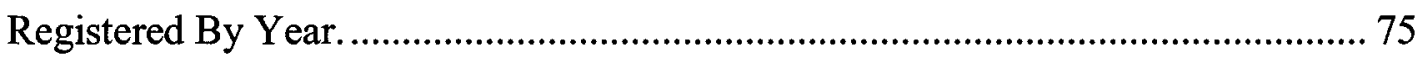

Figure 3.40: Fatal Curved Road Collisions Per 10,000 Motor Vehicles Registered By Year. 75

Figure 3.41: Fatal Collisions that Occurred at a Gradient Per 10,000 Motor Vehicles

Registered By Year. 76

Figure 3.42: Injury Straight and Level Road Collisions Per 10,000 Motor Vehicles

Registered By Year. 76 
Figure 3.43: Injury Curved Road Collisions Per 10,000 Motor Vehicles Registered By Year.

Figure 3.44: Injury Collisions that Occurred on a Gradient Per 10,000 Motor Vehicles Registered By Year 77

Figure 3.45: Percentage of Fatal Collisions for Road Surface Condition Values. ........... 78

Figure 3.46: Percentage of Injury Collisions for Road Surface Condition Values........... 78

Figure 3.47: Fatal Collisions On Dry, Normal Roads Per 10,000 Motor Vehicles Registered. 79

Figure 3.48: Fatal Collisions On Wet Roads Per 10,000 Motor Vehicles Registered By

Year 79

Figure 3.49: Fatal Collisions On Winter Condition Roads Per 10,000 Motor Vehicles

Registered By Year. 80

Figure 3.50: Injury Collisions On Dry, Normal Roads Per 10,000 Motor Vehicles

Registered By Year. 80

Figure 3.51: Injury Collisions On Wet Roads Per 10,000 Motor Vehicles Registered By Year 81

Figure 3.52: Injury Collisions On Winter Condition Roads Per 10,000 Motor Vehicles

Registered By Year. 81

Figure 3.53: Percentage of Fatal Collisions for Light Condition Values. 82

Figure 3.54: Percentage of Injury Collisions for Light Condition Values. 82

Figure 3.55: Fatal Collisions That Occurred During Daylight Per 10,000 Motor Vehicles Registered By Year. 83 
Figure 3.56: Fatal Collisions That Occurred While It Was Dark Per 10,000 Motor

Vehicles Registered By Year. 83

Figure 3.57: Injury Collisions That Occurred During Daylight Per 10,000 Motor Vehicles Registered By Year. 84

Figure 3.58: Injury Collisions That Occurred While It Was Dark Per 10,000 Motor Vehicles Registered By Year. 84

Figure 3.59: Percentage of Fatal Collisions for Traffic Control Values. 85

Figure 3.60: Percentage of Injury Collisions for Traffic Control Values. 85

Figure 3.61: Fatal Collisions That Occurred Where There Was No Control Present Per 10,000 Motor Vehicles Registered By Year. 86

Figure 3.62: Fatal Collisions That Occurred At Traffic Signals Per 10,000 Motor

Vehicles Registered By Year. 86

Figure 3.63: Fatal Collisions That Occurred At Stop Signs Per 10,000 Motor Vehicles Registered By Year 87

Figure 3.64: Injury Collisions That Occurred Where There Was No Control Present Per 10,000 Motor Vehicles Registered By Year. 87

Figure 3.65: Injury Collisions That Occurred At Traffic Signals Per 10,000 Motor Vehicles Registered By Year. 88

Figure 3.66: Injury Collisions That Occurred At Stop Signs Per 10,000 Motor Vehicles

Registered By Year. 88

Figure 3.67: Percentage of Fatal Collisions for Speed Limit Values. 89

Figure 3.68: Percentage of Injury Collisions for Speed Limit Values. 89 
Figure 3.69: Fatal Collisions That Occurred Where the Speed Limit was $40 \& 50 \mathrm{~km} / \mathrm{h} \mathrm{Per}$ 10,000 Motor Vehicles Registered By Year. 90

Figure 3.70: Fatal Collisions That Occurred Where the Speed Limit was $60 \& 70 \mathrm{~km} / \mathrm{h}$ Per 10,000 Motor Vehicles Registered By Year. 90

Figure 3.71: Fatal Collisions That Occurred Where the Speed Limit was $80 \& 90 \mathrm{~km} / \mathrm{h}$ Per 10,000 Motor Vehicles Registered By Year. 91

Figure 3.72: Fatal Collisions That Occurred Where the Speed Limit was $100 \& 110 \mathrm{~km} / \mathrm{h}$ Per 10,000 Motor Vehicles Registered By Year. 91

Figure 3.73: Injury Collisions That Occurred Where the Speed Limit was $40 \& 50 \mathrm{~km} / \mathrm{h}$ Per 10,000 Motor Vehicles Registered By Year. 92

Figure 3.74: Injury Collisions That Occurred Where the Speed Limit was $60 \& 70 \mathrm{~km} / \mathrm{h}$

Per 10,000 Motor Vehicles Registered By Year. 92

Figure 3.75: Injury Collisions That Occurred Where the Speed Limit was $80 \& 90 \mathrm{~km} / \mathrm{h}$ Per 10,000 Motor Vehicles Registered By Year.

Figure 3.76: Injury Collisions That Occurred Where the Speed Limit was $100 \& 110 \mathrm{~km} / \mathrm{h}$ Per 10,000 Motor Vehicles Registered By Year. 93

Figure 3.77: Percentage of Fatal Collisions for Weather Condition Values...................... 94

Figure 3.78: Percentage of Injury Collisions for Weather Condition Values.................... 94

Figure 3.79: Fatal Collisions That Occurred When the Weather was Clear Per 10,000

Motor Vehicles Registered By Year. 95

Figure 3.80: Fatal Collisions That Occurred When it was Raining Per 10,000 Motor Vehicles Registered By Year. 
Figure 3.81: Fatal Collisions That Occurred When it was Snowing Per 10,000 Motor

Vehicles Registered By Year. 96

Figure 3.82: Injury Collisions That Occurred When the Weather was Clear Per 10,000 Motor Vehicles Registered By Year. 96

Figure 3.83: Injury Collisions That Occurred When it was Raining Per 10,000 Motor Vehicles Registered By Year. 97

Figure 3.84: Injury Collisions That Occurred When it was Snowing Per 10,000 Motor Vehicles Registered By Year. 97

Figure 3.85: Percentage of Vehicles Involved in Fatal Collisions for Vehicle Manoeuvre

Values. 98

Figure 3.86: Percentage of Vehicles Involved in Injury Collisions for Vehicle Manoeuvre Values. 98

Figure 3.87: Vehicles Involved in Fatal Collisions While They Were Travelling Straight Ahead Per 10,000 Motor Vehicles Registered By Year. 99

Figure 3.88: Vehicles Involved in Fatal Collisions While They Were Turning Left Per 10,000 Motor Vehicles Registered By Year. 99

Figure 3.89: Vehicles Involved in Fatal Collisions While They Were Turning Right Per 10,000 Motor Vehicles Registered By Year. 100 Figure 3.90: Vehicles Involved in Fatal Collisions While They Were Changing Lanes Per 10,000 Motor Vehicles Registered By Year. 100

Figure 3.91: Vehicles Involved in Fatal Collisions While They Were Overtaking Another Vehicle Per 10,000 Motor Vehicles Registered By Year. 101 
Figure 3.92: Vehicles Involved in Injury Collisions While They Were Travelling Straight Ahead Per 10,000 Motor Vehicles Registered By Year. 101

Figure 3.93: Vehicles Involved in Injury Collisions While They Were Turning Left Per 10,000 Motor Vehicles Registered By Year. 102

Figure 3.94: Vehicles Involved in Injury Collisions While They Were Turning Right Per 10,000 Motor Vehicles Registered By Year. 102

Figure 3.95: Vehicles Involved in Injury Collisions While They Were Changing Lanes Per 10,000 Motor Vehicles Registered By Year. 103

Figure 3.96: Vehicles Involved in Injury Collisions While They Were Overtaking Another Vehicle Per 10,000 Motor Vehicles Registered By Year. 103

Figure 3.97: Percentage of Vehicles Involved in Fatal Collisions for Vehicle Type

Values. 104

Figure 3.98: Percentage of Vehicles Involved in Injury Collisions for Vehicle Type Values. 104

Figure 3.99: Automobiles Involved in Fatal Collisions Per 10,000 Motor Vehicles Registered By Year. 105

Figure 3.100: Bicycles Involved in Fatal Collisions Per 10,000 Motor Vehicles Registered By Year. 105

Figure 3.101: Motorcycles Involved in Fatal Collisions Per 10,000 Motor Vehicles

Registered By Year. 106

Figure 3.102: Pick-Up Trucks Involved in Fatal Collisions Per 10,000 Motor Vehicles Registered By Year. 106 
Figure 3.103: Tractor Trailers Involved in Fatal Collisions Per 10,000 Motor Vehicles

Registered By Year. 107

Figure 3.104: Trucks $>4536$ kg Involved in Fatal Collisions Per 10,000 Motor Vehicles Registered By Year. 107

Figure 3.105: Automobiles Involved in Injury Collisions Per 10,000 Motor Vehicles Registered By Year. 108

Figure 3.106: Bicycles Involved in Injury Collisions Per 10,000 Motor Vehicles Registered By Year. 108

Figure 3.107: Motorcycles Involved in Injury Collisions Per 10,000 Motor Vehicles

Registered By Year. 109

Figure 3.108: Pick-Up Trucks Involved in Injury Collisions Per 10,000 Motor Vehicles

Registered By Year. 109

Figure 3.109: Tractor Trailers Involved in Injury Collisions Per 10,000 Motor Vehicles Registered By Year. 110

Figure 3.110: Trucks $>4536 \mathrm{~kg}$ Involved in Injury Collisions Per 10,000 Motor Vehicles Registered By Year. 110

Figure 3.111: Percentage of Fatal Collisions for Hour of Collision Values.................... 111

Figure 3.112: Percentage of Injury Collisions for Hour of Collision Values. ................. 111

Figure 3.113: Percentage of Fatal Collisions for Day of Week Values........................... 112

Figure 3.114: Percentage of Injury Collisions for Day of Week Values......................... 112

Figure 3.115: Percentage of Fatal Collisions for Month of Collision Values. ................ 113

Figure 3.116: Percentage of Injury Collisions for Month of Collision Values................ 113

Figure 4.1: Conflicts at Signalized Intersections (Robinson et al. 2000)....................... 122 
Figure 4.2: Conflicts at Roundabouts (Robinson et al. 2000).................................. 123

Figure 5.1: Road Safety Countermeasure Timeline............................................. 173

Figure 5.2: Fatalities Per 10,000 Motor Vehicles Registered By Year. ....................... 173

Figure 5.3: Injuries Per 10,000 Motor Vehicles Registered By Year.......................... 174 


\section{Chapter 1: Introduction and Methodology}

\subsection{Introduction}

\subsubsection{Background}

Currently, about 2,500 fatal collisions involving 2,900 fatalities and about 145,000 injury collisions involving approximately 15,000 serious injuries and 200,000 injuries in total occur on Canadian roads each year (Transport Canada 2007). These collisions cause stress and trauma to families and friends of victims and cost the economy billions of dollars. In order to determine why they are happening and what can be done to prevent them and/or reduce their severity, it is important to understand the characteristics of these collisions as they relate to the three primary components of the road system - the road, vehicle, and driver. Such analysis necessitates the collection of accurate collision data so that collision trends over time may be studied and road safety projects and programs may be conducted on emerging problems.

In 1996, Canada's Road Safety Vision 2001 was adopted by the Canadian Council of Motor Transport Administrators (CCMTA) and endorsed by all ministers of Transportation and Highway Safety with a goal of having the safest roads in the world (Canadian Council of Motor Transport Administrators and Transport Canada 2006). It was supported by all levels of government as well as key public and private sector stakeholders. Its strategic objectives were to raise public awareness of road safety issues, improve communication, cooperation and collaboration among road safety agencies, enhance enforcement measures, and improve national road safety data quality and 
collection. In 2000, CCMTA adopted Road Safety Vision 2010, a successor to the Road Safety Vision 2001 with the same goal and strategic objectives but which also included an overall national target along with sub-targets that could be monitored annually (Canadian Council of Motor Transport Administrators and Transport Canada 2006). The national target of Road Safety Vision 2010 is to decrease the number of road users killed or seriously injured by 30 percent during the 2008 to 2010 period compared with the 1996 to 2001 period and the sub-targets include the following:

- A 95 percent rate of seat belt wearing and proper use of appropriate child restraints by all motor vehicle occupants.

- A 40 percent decrease in the number of fatally or seriously injured unbelted occupants.

- A 40 percent decrease in the percentage of road users fatally or seriously injured in crashes involving drinking drivers.

- A 40 percent decrease in the number of road users fatally or seriously injured on rural roadways.

- A 20 percent decrease in the number of road users killed or seriously injured in speed- or intersection-related crashes.

- A 20 percent decrease in the number of road users killed or seriously injured in crashes involving commercial vehicles.

- A 20 percent decrease in the number of young drivers/riders killed or seriously injured in crashes. 
- A 30 percent decrease in the number of fatally or seriously injured vulnerable road users.

CCMTA has made some progress in monitoring and working towards the sub-targets within the Road Safety Vision 2010 by initiating and implementing activities such as conducting seat belt surveys, drinking driving campaigns, development of a strategy to manage vehicle-wildlife conflicts, tougher sanctions for speeding violations, expansion of red light camera programs, participating in and funding research aimed at the development of a North American fatigue management program for the motor carrier industry, and campaigns promoting bicycle helmet use and cycling rules. However, the implementation and promotion of road engineering safety countermeasures was not explicitly considered in Road Safety Vision 2010. Drivers are often blamed for making mistakes on the roadway and causing collisions, however, road safety engineers are becoming more aware of human perception, capabilities, and limitations and are starting to take these into consideration in the design of road infrastructure, making the road environment more forgiving and conforming to driver expectations. Some roadway safety documents published by the Transportation Association of Canada (TAC) are briefly mentioned in the Road Safety Vision 2010 Annual Reports but the engineering and infrastructure components of road safety were originally not considered priority in achieving the Road Safety Vision 2010 sub-targets.

Recently, a mid-term review of Road Safety Vision 2010 (Johnson and Howard 2007) was conducted and the results found that given the current state of collisions in Canada, it 
is not likely that Canada will reach its national target or its goal of having the safest roads in the world. Other countries that have road safety visions and have been more successful in achieving their target have a road safety system approach in place where resources are going towards initiatives related to education, enforcement, and engineering; addressing issues related to vehicle design, road user safety, and infrastructure elements. In the early years of Road Safety Vision 2010, Canada ranked fifth among countries of the Organization of Economic Cooperation and Development (OECD) in terms of the lowest rate of traffic collision deaths per population. However, in 2004, Canada ranked tenth (Canadian Council of Motor Transport Administrators and Transport Canada 2006). It has recently been recognized that road safety engineering and infrastructure elements play a significant role in saving lives on the road and that they should be incorporated into the initiatives working towards Road Safety Vision 2010. The two specific sub-targets related to rural roads and speed and intersections have the potential to benefit greatly from infrastructure/engineering initiatives.

\subsubsection{Objective}

The objective of this thesis is to retrieve fatal and injury collision data from Transport Canada's Traffic Accident Information Database (TRAID) for the years 1984 to 2004, analyze the data and identify trends, show how road safety countermeasures have influenced the trends over the study years, determine priority areas where improvement is required, and recommend specific road safety engineering countermeasures that would help Canada work towards meeting its goal of having the 
safest roads in the world. Countermeasures that may contribute to the two sub-targets related to rural roads and speed and intersections will be explicitly considered.

\subsubsection{Scope}

This thesis will cover a literature review of studies conducted in Canada and internationally related to collision trend analysis. The trends identified within specific data elements in the collision analysis will include as many provinces and territories as possible for which information is available. National collision trends found in the analysis will be compared with regional trends. A second literature review will identify infrastructure and vehicle engineering countermeasures that have been implemented primarily in North America that have contributed to road safety over the years. Although the effects of education, enforcement, and economic factors on road safety are not within the main scope of this project, they will be considered implicitly in the qualitative explanation of the national trend lines. Recommendations of road engineering safety countermeasures linked with specific priority improvement topics will be identified that would contribute to Canada achieving it goal of having the safest roads in the world.

\subsubsection{Thesis Organization and Writing Style}

This thesis consists of five chapters. Chapter 1 includes background information on the status of road safety in Canada, the goals set out in Canada's Road Safety Vision 2010, the objectives and scope of this thesis, the methodology used, challenges faced, and the organization of the thesis report. Chapter 2 includes a summary of studies that have 
been conducted in Canada and internationally on collision trend analyses. Chapter 3 presents the results of the collision trend analysis and a description of any limitations associated with data availability for each province and territory. Chapter 4 includes a second review of literature related to road infrastructure and vehicle engineering countermeasures that have contributed to road safety within approximately the last 40 years. Chapter 5 includes a qualitative discussion and explanation of the collision trends identified in Chapter 3. Chapter 6 includes the identification of road engineering safety countermeasures that would contribute to addressing priority collision types, thesis conclusions, and future research needs.

This thesis was written using Carleton University guidelines and the Chicago Manual of Style. Also, the words "collision", "crash", and "accident" are used synonymously as well as "road" and "highway". The word "value" may refer to a number or to items within the data elements. For example, "snowing" is a value within the "weather" data element.

\subsection{Methodology}

\subsubsection{Review of Literature on Collision Trends}

A review of literature was conducted on studies related to collision trend analyses in Canada and internationally in order to determine if similar work has been done related to the objective of this thesis and whether any studies compared long-term collision trends in relation to road safety countermeasure implementation. Sources used to search for the references included the Internet, the National Transportation Library (TRIS), the 
Transport Canada Library, and Conference Proceedings of the Transportation Research Board, the Institute of Transportation Engineers, and the Transportation Association of Canada.

\subsubsection{Data Extraction}

The software program, Brio Intelligence Explorer was used to extract raw data from Transport Canada's Traffic Accident Information Database (TRAID). The data from TRIAD is provided to Transport Canada from every province and territory and includes fatal, injury, and property damage only collisions for the data elements listed on their individual collision report form. The years available in TRAID at the time of the collision analysis and of which were used in the thesis were from 1984 to 2004 . The primary data elements retrieved from TRAID for the analysis included those that would provide information about road characteristics, road engineering, road infrastructure, roadway hardware, and any others that would show collision trends and help in making recommendations on road engineering safety countermeasure implementation. These were Collision Severity, Collision Configuration, Road Classification, Road Category, Roadway Configuration, Road Alignment, Road Surface Condition, Light Condition, Traffic Control, Speed Limit, Weather Condition, Vehicle Manoeuvre, and Vehicle Type. The names for these data elements are from the TRAID Data Dictionary (Transport Canada 1995) and their definitions are included in Chapter 3 with their analyses. The data extraction was a time consuming task because each year of data was saved separately within the database. Therefore it was necessary to extract each year of data, within the 21 years, one at a time for each data element. 


\subsubsection{Data Analysis}

The raw data extracted from TRAID was transferred to Excel spreadsheets where pivot tables and pivot charts were developed to analyze the data more efficiently. Each primary data element was analyzed separately. Collisions with unknown values, which are those that were not filled out on the collision report form at the time of the collision, were not included in the analysis. Fatal and injury collisions were analyzed separately. Since not all provinces and territories collected the same data elements and values within the data elements from 1984 to 2004, limitations for each data element were identified. These limitations dictated which provinces and territories, which years, and which values within a specific data element would be included in the analysis. Table 1.1 summarizes the provinces and territories that were included or not included in the analysis of each data element. A " $\checkmark$ " indicates that the data was available for the analysis and an " $\mathrm{x}$ " indicates that it was not. Also, for most data elements, all years from 1984 to 2004 were included in the analysis with the exception of the year 1989 since Manitoba did not provide data to Transport Canada for that year. The exact limitations for each data element are described in more detail in Chapter 3. 
Table 1.1: Provinces and Territories Included in Analysis Per Data Element.

\begin{tabular}{|c|c|c|c|c|c|c|c|c|c|c|c|c|c|}
\hline 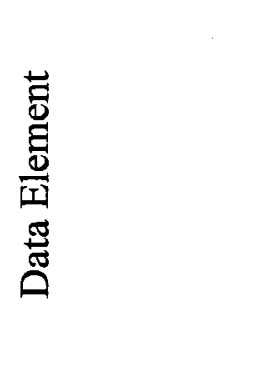 & 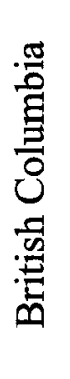 & 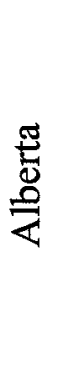 & 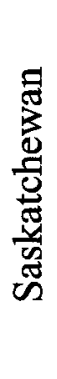 & 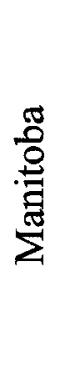 & 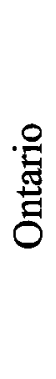 & 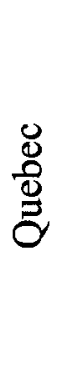 & 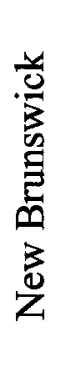 & 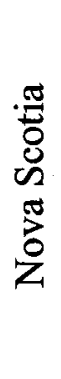 & 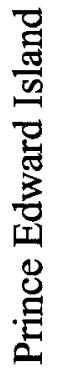 & 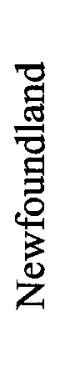 & 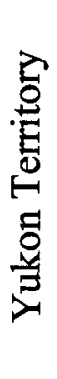 & 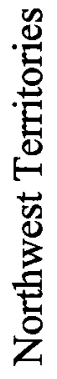 & 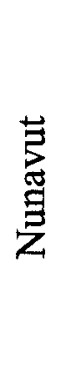 \\
\hline $\begin{array}{l}\text { Collision } \\
\text { Severity }\end{array}$ & $\checkmark$ & $\checkmark$ & $\checkmark$ & $\checkmark$ & $\checkmark$ & $\checkmark$ & $\checkmark$ & $\checkmark$ & $\checkmark$ & $\checkmark$ & $\checkmark$ & $\checkmark$ & $\checkmark$ \\
\hline $\begin{array}{l}\text { Collision } \\
\text { Configuration }\end{array}$ & $\checkmark$ & $\mathbf{x}$ & $\checkmark$ & $\checkmark$ & $\mathbf{x}$ & $\mathrm{x}$ & $\checkmark$ & $\checkmark$ & $\checkmark$ & $\checkmark$ & $\checkmark$ & $\mathrm{x}$ & $\mathrm{x}$ \\
\hline $\begin{array}{l}\text { Road } \\
\text { Classification }\end{array}$ & $\checkmark$ & $\mathbf{X}$ & $\checkmark$ & $\mathrm{x}$ & $\checkmark$ & $\checkmark$ & $\checkmark$ & $\checkmark$ & $\checkmark$ & $\checkmark$ & $\mathbf{x}$ & $\checkmark$ & $\checkmark$ \\
\hline $\begin{array}{l}\text { Road } \\
\text { Category }\end{array}$ & $\checkmark$ & $\mathrm{X}$ & $\mathrm{x}$ & $\checkmark$ & $\checkmark$ & $\mathrm{x}$ & $\mathrm{x}$ & $\mathbf{x}$ & $\mathbf{x}$ & $\mathrm{x}$ & $\checkmark$ & $\checkmark$ & $\checkmark$ \\
\hline $\begin{array}{l}\text { Roadway } \\
\text { Configuration }\end{array}$ & $\checkmark$ & $\mathrm{X}$ & $\checkmark$ & $\checkmark$ & $\checkmark$ & $\mathrm{x}$ & $\mathrm{X}$ & $\mathrm{x}$ & $\mathrm{X}$ & $\mathrm{x}$ & $\mathbf{x}$ & $\checkmark$ & $\checkmark$ \\
\hline $\begin{array}{l}\text { Road } \\
\text { Alignment }\end{array}$ & $\checkmark$ & $\mathrm{x}$ & $\checkmark$ & $\checkmark$ & $\checkmark$ & $\checkmark$ & $\checkmark$ & $\checkmark$ & $\checkmark$ & $\checkmark$ & $\checkmark$ & $\checkmark$ & $\checkmark$ \\
\hline $\begin{array}{l}\text { Road Surface } \\
\text { Condition }\end{array}$ & $\checkmark$ & $\mathbf{x}$ & $\checkmark$ & $\checkmark$ & $\checkmark$ & $\checkmark$ & $\checkmark$ & $\checkmark$ & $\checkmark$ & $\checkmark$ & $\checkmark$ & $\mathrm{x}$ & $\mathrm{x}$ \\
\hline $\begin{array}{l}\text { Light } \\
\text { Condition }\end{array}$ & $\checkmark$ & $\mathrm{x}$ & $\checkmark$ & $\checkmark$ & $\checkmark$ & $\checkmark$ & $\checkmark$ & $\checkmark$ & $\checkmark$ & $\checkmark$ & $\checkmark$ & $\checkmark$ & $\checkmark$ \\
\hline $\begin{array}{l}\text { Traffic } \\
\text { Control }\end{array}$ & $\checkmark$ & $\mathbf{X}$ & $\checkmark$ & $\checkmark$ & $\checkmark$ & $\checkmark$ & $\checkmark$ & $\checkmark$ & $\checkmark$ & $\checkmark$ & $\checkmark$ & $\checkmark$ & $\checkmark$ \\
\hline Speed Limit & $\checkmark$ & $\mathrm{x}$ & $\checkmark$ & $\checkmark$ & $\checkmark$ & $\checkmark$ & $\checkmark$ & $\checkmark$ & $\checkmark$ & $\checkmark$ & $\mathrm{x}$ & $\checkmark$ & $\checkmark$ \\
\hline $\begin{array}{l}\text { Weather } \\
\text { Condition }\end{array}$ & $\checkmark$ & $\mathrm{x}$ & $\checkmark$ & $\checkmark$ & $\checkmark$ & $\checkmark$ & $\checkmark$ & $\checkmark$ & $\checkmark$ & $\checkmark$ & $\checkmark$ & $\checkmark$ & $\checkmark$ \\
\hline $\begin{array}{l}\text { Vehicle } \\
\text { Manoeuvre }\end{array}$ & $\checkmark$ & $\mathrm{x}$ & $\checkmark$ & $\checkmark$ & $\checkmark$ & $\checkmark$ & $\checkmark$ & $\checkmark$ & $\checkmark$ & $\checkmark$ & $\checkmark$ & $\checkmark$ & $\checkmark$ \\
\hline Vehicle Type & $\checkmark$ & $\checkmark$ & $\checkmark$ & $\checkmark$ & $\checkmark$ & $\checkmark$ & $\checkmark$ & $\checkmark$ & $\checkmark$ & $\checkmark$ & $\checkmark$ & $\checkmark$ & $\checkmark$ \\
\hline $\begin{array}{l}\text { Hour of } \\
\text { Collision }\end{array}$ & $\checkmark$ & $\checkmark$ & $\checkmark$ & $\checkmark$ & $\checkmark$ & $\checkmark$ & $\checkmark$ & $\checkmark$ & $\checkmark$ & $\checkmark$ & $\checkmark$ & $\checkmark$ & $\checkmark$ \\
\hline Day of Week & $\checkmark$ & $\checkmark$ & $\checkmark$ & $\checkmark$ & $\checkmark$ & $\checkmark$ & $\checkmark$ & $\checkmark$ & $\checkmark$ & $\checkmark$ & $\checkmark$ & $\checkmark$ & $\checkmark$ \\
\hline $\begin{array}{l}\text { Month of } \\
\text { Collision }\end{array}$ & $\checkmark$ & $\checkmark$ & $\checkmark$ & $\checkmark$ & $\checkmark$ & $\checkmark$ & $\checkmark$ & $\checkmark$ & $\checkmark$ & $\checkmark$ & $\checkmark$ & $\checkmark$ & $\checkmark$ \\
\hline
\end{tabular}

The data was analyzed at a national level and then compared to four regions within Canada. The regions included Western Provinces (British Columbia, Alberta, 
Saskatchewan, and Manitoba), Ontario, Quebec, and Eastern Provinces (New Brunswick, Nova Scotia, Prince Edward Island, and Newfoundland). These regions were chosen based on geographic location and their total number of fatal and injury collisions combined over the study years. Figure 1.1 shows the distribution of fatal and injury collisions combined for each region. The Territories only represented 1 percent of all fatal and injury collisions in Canada and it was identified during the analysis that their sample size was not useful in comparing trends to other regions within Canada. Therefore, they were left out of the regional analysis. The Eastern Provinces, although only representing 7 percent of fatal and injury collisions in Canada were kept in the regional analysis because specific trends were identified.

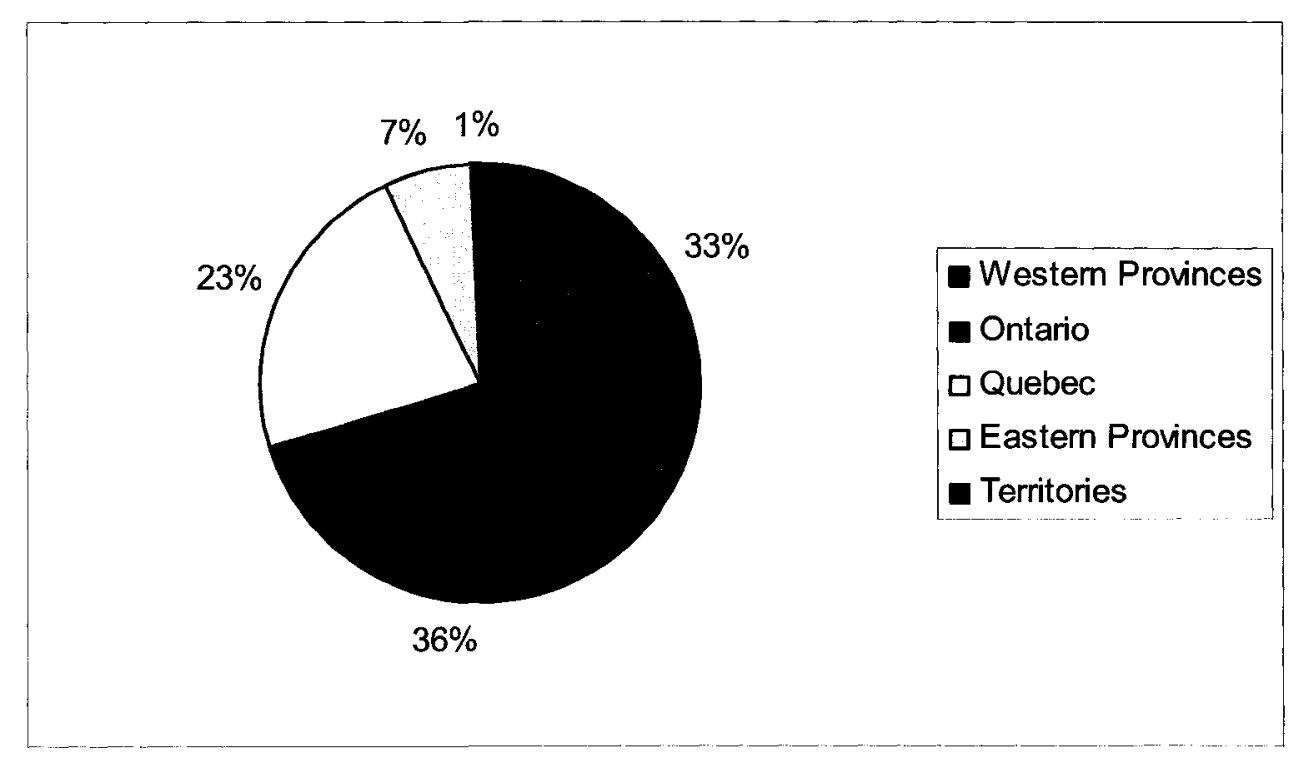

Figure 1.1: Distribution of the Number of Fatal and Injury Collisions Per Region.

The results for each primary data element for both the fatal and injury analyses included a definition of the data element and of the values within the data elements which 
were retrieved from the TRAID Data Dictionary (Transport Canada 1995) when available, a pie chart and written summary of the national percentage of collisions associated with each value overall throughout the years 1984 to 2004, a table comparing the national percentages with the regional percentages, and a written summary of the national change of collisions per 10,000 motor vehicles registered for each value from 1984 to 2004, and a table comparing these values with regional ones. Trend line graphs of the number of collisions per 10,000 motor vehicles registered per year for each value and for both fatal and injury collisions were also developed and included in Chapter 3. The national trend lines were graphed with the regional trend lines for comparison purposes.

The supporting data elements were not analyzed as deeply as the primary data elements because they did not play a significant part in the road safety engineering countermeasure implementation recommendations. They were included as supporting information only. Therefore, only pie charts and written national percentage distributions overall throughout the years 1984 to 2004 for each value within the data elements were included. All tables and figures associated with the collision analysis were placed at the end of Chapter 3.

\subsubsection{Review of Literature on the Impact of Safety Countermeasures}

A review of literature was conducted to identify the road engineering and vehicleengineering countermeasures that have contributed to road safety in Canada the most over the years and to show the extent to which they have improved road safety. During 
the course of gathering the research it was found that there were limited studies conducted and documented in Canada related to the effectiveness of road safety countermeasures, therefore this literature review includes research from throughout North America. It was assumed that the impact that countermeasures had in the U.S. would be similar to the impact they would have in Canada. Since there have been several road safety engineering countermeasures implemented in North America over the years, this literature review focuses on those that have been found to contribute the most to road safety based on information from Transport Canada's report "Roadway Safety Benchmarks Over Time" (Zein and Montufar 2003). Road safety experts in Canada and the U.S. identified the countermeasures in that report and the dates in which the countermeasures had been implemented in Canada was estimated. Although this thesis focuses mainly on road engineering and infrastructure countermeasures that have contributed to safety over the years, for a broader perspective, the literature review was expanded to include vehicle-engineering features that have contributed as well. The countermeasures are divided into sections, which include Intersections, Other Roadway Elements, Roadside Features, Medians, and Vehicle-Related Countermeasures. References were sought from the Internet, TRIS, the Transport Canada Library, and Conference Proceedings of the Transportation Research Board, the Institute of Transportation Engineers, and the Transportation Association of Canada.

\subsubsection{Discussion}

Multidisciplinary factors including road engineering, vehicle engineering, enforcement, education, and economic considerations which have influenced road safety 
in Canada is discussed and compared with national collision trends. A discussion of regional trends compared to national trends was included and divided into seven topic areas: general, intersections, rural roads, roadside and median, urban roads, environmental and temporal, and vehicle type.

\subsubsection{Recommendations and Conclusions}

Based on the analysis results, ten national priority areas were identified along with recommendations of road engineering safety countermeasures to address them in order to further road safety in Canada and help achieve the national road safety vision target. Regional issues that stood out from the national trends were also identified. Conclusions of the thesis were completed as well as recommendations for further research.

\subsection{Thesis Challenges}

The main challenge associated with this thesis was data quality. It was originally envisioned to include not only fatal and injury collisions in the study but also property damage only (PDO) collisions. However, it was found that the PDO collisions across Canada were not well represented. Some do not even get reported and are dealt with privately with the persons involved. The ones that are reported are not investigated and most of the information from the occurrence would come from the persons involved in the collisions. Since these persons may have their own motives for insurance companies to pay for the damages, there is a good possibility that the information received from those persons is inaccurate. Also, in British Columbia in 1996, changes took place in 
police reporting of collisions. Many police agencies changed their standards or practices for collision reporting, this resulted in fewer reported collisions overall, in particular those involving PDO collisions. Even though in more recent years, British Columbia has resumed their full submission of collision reports, the early changes resulted in the inability to make year-to-year comparisons of annual PDO collision statistics. In addition, for some data elements, Quebec for example did not collect PDO collisions at all.

Also, depending on the jurisdiction, different threshold values are used that determine whether a PDO collision should be reported or not. For example, one jurisdiction may use a threshold value of $\$ 700$ meaning that any PDO collision with damages that cost less than $\$ 700$ does not have to be reported. Another jurisdiction may use a threshold value of $\$ 1000$. It is not consistent across the country. These threshold values also changed within the study years by jurisdiction, which complicated the results even further and showed either steep increases or steep decreases in PDO collisions, not because the collisions were not occurring but because they were not being reported. Therefore in the end, it was decided to keep PDO collisions out of the analysis.

Another challenge was working with the data elements. Not all jurisdictions collected the same data elements or values within the data elements. This is a result of having different questions on collisions report forms, which are filled out by the police. Also, these collision report forms per jurisdiction changed within the study years so in some years for a specific jurisdiction they may not have collected a certain data element 
such as Road Category, however in later study years, they may have added it to their collision report form. Therefore, it was necessary to go through each value within each data element to determine which ones were collected for which years, which was a very time consuming task. In order to get a trend line from 1984 to 2004, it was necessary in some cases to leave out specific jurisdictions or years for specific data elements. 


\section{Chapter 2: Review of Literature on Collision Trends}

This literature review was conducted in order to find research that has been completed in Canada and internationally related to collision trend analysis and the effects that road safety countermeasures have had on historical increases and decreases of collision rates.

On a national level, Transport Canada publishes a brochure annually, which contains high-level collision statistics. The most recent one is the 2006 brochure (Transport Canada 2007). It has information on the number of fatal and injury collisions from 1987 to 2006 and other information such as the fatality rate per 10,000 motor vehicles registered and the number of motor vehicle registrations between 1987 and 2006. The brochure shows that the number of fatal collisions has decreased from 3,729 to 2,604 between 1987 and 2006 and personal injury collisions have decreased from 193,237 to 144,756 . The data for the brochure is provided to Transport Canada from the provincial jurisdictions on an annual basis, which is separate from the data provided for TRAID. Transport Canada also provides published updates on the progress of Canada's Road Safety Vision 2010. The most recent update is from 2005 (Canadian Council of Motor Transport Administrators and Transport Canada 2006). It outlines the target and sub-targets of the Vision, the progress made on them and the initiatives that are being undertaken in the country contributing to the progress. Some of the initiatives identified were child restraint and seat belt use campaigns in rural communities, tougher sanctions for speeding violations, variable message signs, police enforcement campaigns that target aggressive driving, expansion of red light camera programs, installation of roundabouts, 
installation of rumble strips, implementation of graduated licensing programs, and drinking and driving campaigns. However, the publication does not contain information on the progress being made by province or territory based on specific initiatives being undertaken in those jurisdictions. The information again is quite high-level and it is difficult to link specific road safety countermeasures with collision trends to determine how much of an effect each of them are having on the overall collision rates. In 2001, Transport Canada had published a study on collision trends in Canada from 1988 to 1997 (Transport Canada 2001). The data used for the study was retrieved from TRAID and contains fatal and injury collision trend data for various characteristics of collisions. However, there is no attempt to link the trends with road safety initiatives that have been implemented in Canada between 1988 and 1997 so it is difficult to gain perspective on the reasons for the trends identified. The first attempt to identify and measure road engineering safety countermeasures that have had an effect on national collision trends was a study completed in 2003 (Zein and Montufar 2003). The study was initiated by Transport Canada with a goal of identifying road engineering safety countermeasures that have been implemented in Canada in approximately the past 40 years, determine a date in which they started to be implemented in Canada, and estimate their safety effectiveness. Historically, vehicle safety improvements such as air bags and antilock braking systems and enforcement measures such as higher penalties for drinking and driving were measures that gained attention for improving road safety. This study put road engineering safety countermeasures in the limelight by recognizing that they have contributed to saving lives and injures on Canada roads over the years. The top five countermeasures that was found to contribute the most over the years to improve road 
safety were divided highways, intersection channelization, clear zone widening, breakaway devices and energy absorbing barrier end treatments.

British Columbia publishes collision statistics on police-attended injury and fatal collisions. Their latest report was completed in 2005 (British Columbia 2006). The data from this report was retrieved from British Columbia's Traffic Accident System, which compiles and maintains information on all traffic collisions in the province reported to the police. The province uses this data to determine collision trends over time and to identify problem factors. It is used to identify highway locations, which may require improvement, and to develop new policies and programs to reduce the frequency and severity of collisions in the province. The report does not contain collision statistics on property damage only collisions because of a lack of consistent reporting standards and practices by the police, as well as the lack of accuracy of self-reported collisions. The annual report mainly contains information for that one year so it would be necessary to review past annual reports to determine specific collision trends over time. Overall in 2005, the total reported number of fatally injured victims was 460, thirty more than 2004 . The number of people reported injured in 2005 was 28,752 compared to 29,201 in 2004. The reports are quite comprehensive and include collision statistics on a variety of collision characteristics such as environmental, speed related, collisions per road user type, and commercial vehicles. The Insurance Corporation of British Columbia also plays an important role in road safety. Through their $\$ 9$ million road improvement program, they analyze traffic problems and contribute money to road improvements that make roads in British Columbia safer for all users. ICBC conducts evaluations and cost 
benefit analyses on their road improvement progams which provides useful information on how effective specific road engineering safety countermeasures are in saving lives.

Alberta also publishes annual traffic collision statistics (Alberta 2007). The information in their report primarily contains only the one year of data, however for some types of collisions such as the number of motorcycles or trains involved in collisions it shows a trend of a few years. However, there is no indication in the report on the reasons for the trends. In 2004, the Alberta Motor Association published a report on traffic safety trends and key indicators (Anielski Management Incoporated 2004). The main goals of the report were to establish key indicators and trends in traffic safety to better measure and assess Alberta's progress, to provide a resource for traffic safety and injury control stakeholders in support of an evidence-based approach, and to set the stage for a vision of the provinces' traffic safety around which measureable goals and targets could be established. The study found that in 2002, 372 people were killed in collisions at a rate of 12.1 per 100,000 population. The traffic fatality rate had dropped 64 percent since their peak in 1979 and continues to decline. There were 28,989 people injured in collisions in 2002, which was the highest in Alberta's history. Injuries had increased by 55 percent and the injury rate per 100,000 population had increased by 32 percent from 1992 to 2002 . It was found that 80.4 percent of all collisions occurred in urban areas of Alberta while 19.6 percent occurred in rural areas, however, 70.5 percent of all fatal collisions occurred on rural roads. Collisions involving animals had increased 65 percent from 1991 to 2000 . The report also provides a discussion on what the trends mean and idenfies countermeasures that may have contributed to the trends. One of the factors 
identified as effecting the higher number of rural fatalities was the lower seat belt use in those areas. Recommendations on how to mitigate the animal strikes included the construction of underpasses and overpasses, wildlife relector devices, and high fencing. In one section of their report, it discusses how road design has contributed to road safety and recognizes that there has been an increasing trend of incorporating safety into road planning design and construction with greater effort in conducting road safety audits and in-service road safety reviews.

Ontario publishes an annual road safety report with collision statistics on a variety of collision types. Each report primarily contains data for that specific year. Comparisons are made with the previous year to determine the changes in collision rates. Their 2005 report (Ontario 2006) indicates that the fatality rate per 10,000 licensed drivers in Ontario was 0.87 , down 5 percent from 0.92 in 2004. Their number of fatalities on Ontario roads declined from 799 in 2004 to 766 in 2005 . Their number of minor injures from motor vehicle-related collisions also fell from 29,918 in 2004 to 29,518 in 2005 . The number of major injuries in collisions rose from 3,565 to 3,619. Also, in 2005, almost half of all the motor vehicle-related fatalities in Ontario involved drivers who were speeding or lost control of the vehicle. Their past experience showed that tougher sanctions for traffic offences have helped improve the aggressive driving problem.

The U.S. publishes collision statistics on an annual basis from data retrieved from their Fatality Analysis Reporting System and General Estimates System. The most recent 
report for 2006 (National Center for Statistics and Analysis 2008) indicates that fatal crashes decreased by 1.7 percent from 2005 to 2006 and that injury rates decreased by 5.6 percent. The first chapter of the report presents collision trends. Trends for fatal crashes and fatalities are presented from 1975 to 2006 . Trends for nonfatal crashes and injuries are presented from 1988 to 2006 . Their occupant fatality rate per 100,000 population, which declined by 22.7 percent from 1975 to 1992, decreased by 4.3 percent from 1992 to 2006 . Their occupant injury rate per 100,000 population, which declined by 13.6 percent from 1988 to 1992, decreased by 27.8 percent from 1992 to 2006 . Their nonoccupant fatality rate per 100,000 population declined by 51.9 percent from 1975 to 2006 and the nonoccupant injury rate per 100,000 population declined by 53.2 percent from 1988 to 2006 . There is however no indication in the report on the reasons for these collision trends and how road safety countermeasures may have had an influence. The U.S. conducted an additional study which was published in 2005 , comparing the characteristics of rural and urban collisions from 1994 to 2003 (Burgess 2005). The study found that there were approximately 42 percent more fatal crashes in rural areas compared to urban areas; however there were fewer vehicle kilometres travelled in rural areas than urban areas. In addition, fatal rural crashes were more likely to involve multiple fatalities, rollovers, and more trucks. The study also found that fatal rural crashes more often occurred on curved roadways and had greater vehicle damage. Headon collisions were more prevalent in rural areas than in urban areas and the length of time for emergency medical services to arrive at the scene is longer in rural areas than in urban areas. 
Great Britain publishes an annual report on their collision statistics. The report contains 50 data items collected for each collision, including the time and location of the collision, the types of vehicles involved, what they were doing at the time of the collision, as well as some information on the drivers and casualties involved. Part I of the most recent annual report with 2006 data (England Department of Transport 2007) presented trends for characterisics of collisions. They have been publishing these reports since 1951. At that time, there were 4.7 million vehicles in use and the police recorded 178,000 personal injury road collisions. In 2006 , the vehicle population was at 33 million and there were 189,000 injury collisions. Therefore, while the vehicle fleet increased sevenfold, the number of injury collisions increased by only a fifth. Between 1951 and 2006, 309,144 people were killed and 17.6 million persons were injured in collisions on British roads.

The Australian Government published a statistical report on road deaths in the country in 2006. (Australian Transport Safety Bureau 2007). The report showed that even through there is a long term downward trend in Australian road deaths, the number of deaths per annum had not changed much since 2003. In 2006, there were 1,601 persons killed in 1,456 road crashes, a 1.6 percent decrease from 2005. Between 2001 and 2006 , there was an average annual decrease of 1.7 percent in national road deaths. Between 2005 and 2006 the number of people killed per 100,000 Australian population decreased from 8.0 to 7.8 . 
New Zealand published a report on injury crashes in 2006 (Land Transport New Zealand 2007). Their historical figures in the report contain data as far back as 1951 . In 1951 their fatalities per 100,000 population was 14.8 and in 2006 it was 9.4. In 1951, their injuries per 100,000 population was 352 and in 2006 it was 367 . An additional report published by Austroads presents road safety facts for Australia and New Zealand (Austroads 2005). The most recent report from 2005, shows that in 2003, in Australia, the number of road deaths dropped to 1,621 and fell a further 25 in 2004 to 1,596 people killed annually on Australian roads. They attribute these reductions to a number of factors including compulsory fitting and wearing of seat belts, random breath testing, and national uniform speed limits backed by speed camera surveillance. In New Zealand, 461 people were killed in road crashes during 2003. The New Zealand death rate of 11.5 fatalities per 100,000 population is 40 percent higher than Australia's 8.2 deaths per 100,000 .

This literature review showed that there is a large amount of statistical collision data available and that some juridications publish trend data as well for comparison purposes. However, there is limited information on the factors that contributed to these trends and how much effect they have had on road safety from a historical perspective. Only one study (Zein and Montufar 2003) was found that attempted to show how road engineering safety countermeasures have influenced national collision trends. 


\section{Chapter 3: Collision Trend Analysis Results}

This chapter presents the results from the collision trend analysis. Each data element is defined based on definitions from the TRAID data dictionary (Transport Canada 1995). The data availability for each data element is discussed and when definitions of values within the data elements were available within the TRAID data dictionary, they were provided. National collision trend results are presented and compared with regional results though tables and figures found at the end of this Chapter. Only the primary data elements; which include Collision Severity, Collision Configuration, Road Classification, Road Category, Roadway Configuration, Road Alignment, Road Surface Condition, Light Condition, Traffic Control, Speed Limit, Weather Condition, Vehicle Manoeuvre, and Vehicle Type, are compared regionally. The supporting data elements, which include Hour of Collision, Day of Week, and Month of Collision are included only as supplementary information and were not analyzed as extensively. In many of the data elements, the value "Other" is included in the analysis. "Other" is used to represent values for that specific data element that were not explicitly analyzed because of unavailable data. Also, "Other" is often used on collision report forms when the collision represents another scenario other than the list of values provided. It was important to include this value in the analysis because they influence collision percentages.

It should be noted that this Chapter primarily includes the results of the analysis.

The discussion of the trends may be found in Chapter 5, which also includes the explanation of trends based on the countermeasures reviewed in Chapter 4 . 


\subsection{Collision Severity}

Collision Severity refers to the level of severity of the consequences of the collision. During the data extraction for this data element it was found that Manitoba data was not available for 1989 and Nunavut data was not available for 2001. Therefore, all provinces and territories were included in the analysis from 1984 to 2004, excluding 1989. The definitions associated with each of the values analyzed within the data element are shown below:

- Fatal - There is at least one death as the result of a traffic incident.

- Injury - There is at least one non-fatal injury as the result of a traffic incident.

The analysis found that nationally throughout the study years, 0.4 percent of collisions were fatal collisions and 24 percent were injury collisions. Table 3.1 shows how these percentages vary by region. From 1984 to 2004, fatal collisions per 10,000 motor vehicles registered decreased from 2.48 to 1.27 (49 percent) and injury collisions decreased from 114.72 to 78.12 ( 32 percent). Table 3.2 presents these percentages and compares them with regional trends. Figure 3.1 and 3.2 illustrate the national and regional trends by using line graphs.

\subsection{Collision Configuration}

Collision Configuration refers to the configuration of the involved vehicles just prior to the collision. During the data extraction for this data element it was found that 
Alberta did not collect data for this data element from 1984 to 1998, Manitoba data was not available for 1989, Ontario and Quebec collect limited values within the data element, the Northwest Territories did not collect data for this data element from 1984 to 1997, and Nunavut data was not available for 2001. Therefore, Alberta, Ontario, Quebec, Nunavut, and the Northwest Territories were excluded from the analysis and the years included in the analysis were from 1984 to 2004 excluding 1989. The definitions associated with each of the values within the data element are shown below.

- Hit Object/Person: One moving motor vehicle hit a person or object on the roadway. A parked car may be considered an object.

- Head-On: Two motor vehicles travelling parallel to each other but in opposite directions hit head-on.

- Left Turn: Two motor vehicles travelling in different directions and one motor vehicle turns left across opposing traffic.

- Right Turn: One motor vehicle travelling straight through comes in contract with another motor vehicle turning right from a side road.

- Rear-End: Two motor vehicles travelling in the same direction and one motor vehicle hits the other from behind.

- Run Off Left Shoulder: One moving motor vehicle ran off left shoulder

- Run Off Right Shoulder: One moving motor vehicle ran off right shoulder

The analysis found that, throughout the years, 10 percent of fatal collisions were hit object/person collisions, 20 percent were head-on collisions, 10 percent were right turn collisions, 4 percent were left turn collisions, 4 percent were rear-end collisions, 17 
percent were run off left shoulder collisions, and 18 percent were run off right shoulder collisions. For injury collisions, 5 percent were hit object/person collisions, 27 percent were rear-end collisions, 16 percent were right-turn collisions, 8 percent were left turn collisions, 5 percent were head-on collisions, 8 percent were run off left shoulder collisions, and 11 percent were run off right shoulder collisions. Figure 3.3 and 3.4 show these percentages in a chart and Table 3.3 show how these percentages compare on a regional level.

The analysis also found that for fatal collisions, from 1984 to 2004 , hit object/person collisions per 10,000 motor vehicles registered decreased from 0.22 to 0.13 (41 percent), head-on collisions per 10,000 motor vehicles registered decreased from 0.45 to 0.29 ( 36 percent), right turn collisions per 10,000 motor vehicles registered decreased from 0.23 to 0.11 ( 52 percent), left turn collisions per 10,000 motor vehicles registered remained constant, rear-end collisions per 10,000 motor vehicles registered decreased from 0.10 to 0.06 ( 40 percent), run off left shoulder collisions per 10,000 motor vehicles registered decreased from 0.40 to 0.26 ( 35 percent), and run off right shoulder collisions per 10,000 motor vehicles registered decreased from 0.41 to 0.28 ( 32 percent). For injury collisions, hit object/person collisions per 10,000 motor vehicles registered decreased from 5.68 to 4.18 ( 26 percent), head-on collisions per 10,000 motor vehicles registered decreased from 5.56 to 3.94 ( 29 percent), right turn collisions per 10,000 motor vehicles registered decreased from 16.74 to 8.42 (50 percent), left turn collisions per 10,000 motor vehicles registered increased from 6.11 to 8.32 ( 27 percent), rear-end collisions per 10,000 motor vehicles registered decreased from 19.39 to 19.02 ( 2 percent), run off left 
shoulder collisions per 10,000 motor vehicles registered decreased from 9.03 to 6.86 (24 percent), and run off right shoulder collisions per 10,000 motor vehicles registered decreased from 12.39 to 9.25 ( 25 percent). Table 3.4 compares these percentage changes by region and Figures 3.5 to 3.18 illustrate these trends in line graphs for each value within the data element and by region.

\subsection{Road Classification}

Road Classification is an indicator of population density; hence traffic density, adjacent to the collision site. During the data extraction for this data element it was found that Alberta data was not available from 1991 to 1998, Manitoba data was not available in 1989 and from 2002 to 2004, Yukon Territory data was not available from 1995 to 1997, and Nunavut data was not available for 2001. Therefore, Alberta, Manitoba, and the Yukon Territory were excluded from the analysis. All years from 1984 to 2004 were included in the analysis and the data elements analyzed were "Urban" and "Rural".

The analysis found that throughout the years, 35 percent of fatal collisions were urban collisions and 65 percent were rural. Also, 71 percent of injury collisions were urban collisions and 29 percent were rural. These percentages are illustrated in Figures 3.19 and 3.20 and the regional comparisons are found in Table 3.5.

The analysis also found that from 1984 to 2004 , fatal urban collisions per 10,000 motor vehicles registered decreased from 1.0 to 0.42 (58 percent) and fatal rural 
collisions per 10,000 motor vehicles registered decreased from 1.54 to 0.88 (47 percent). In addition, injury urban collisions per 10,000 motor vehicles registered decreased from 84.08 to 53.13 (37 percent) and injury rural collisions per 10,000 motor vehicles registered decreased from 36.16 to 23.67 (35 percent). Table 3.6 compares these percentage changes with regional ones and Figures 3.21 to 3.24 show these trends on line graphs with regional trends.

\subsection{Road Category}

Road Category refers to the general road design characteristics at the site of the collision. During the data extraction for this data element it was found that Alberta data was only available from 1991 to 2004 , Saskatchewan data was only available from 1991 to 2004 , Manitoba data was not available for 1989 , Quebec data was only available from 1984 to 1988 , New Brunswick data was only available from 1998 to 2004, Nova Scotia did not collect data for this data element, Prince Edward Island data was only available from 1997 to 2004, Newfoundland data was only available from 2000 to 2004, and Nunavut data was not available for 2001. Therefore, the provinces/territories included in the analysis were British Columbia, Manitoba, Ontario, Yukon Territory, Northwest Territories, and Nunavut. The years included in the analysis were 1984 to 2004 excluding 1989 and the values analyzed were "Divided" and "Undivided".

The analysis found that throughout the study years, 12 percent of fatal collisions occurred on divided roads and 83 percent occurred on undivided roads. Also, 14 percent of injury collisions occurred on divided roads and 79 percent occurred on undivided 
roads. These percentages are illustrated in Figures 3.25 and 3.26 and are compared to percentages regionally in Table 3.7 .

The analysis also found that from 1984 to 2004 , fatal collisions per 10,000 motor vehicles registered that occurred on divided roads decreased from 0.21 to 0.15 (29 percent) and fatal collisions per 10,000 motor vehicles registered that occurred on undivided roads decreased from 1.71 to 0.94 (45 percent). In addition, injury collisions per 10,000 motor vehicles registered that occurred on divided roads decreased from 16.45 to 12.05 (27 percent) and injury collisions per 10,000 motor vehicles registered that occurred on undivided roads decreased from 95.59 to 55.50 (42 percent). Table 3.8 compares these percentage changes by region and Figures 3.27 to 3.30 illustrate these trends on line graphs compared with regional trends.

\subsection{Roadway Configuration}

Roadway Configuration refers to the site of the collision. During the data extraction for this data element it was found that Alberta had several unknown collisions for this data element, Manitoba did not have data available for 1989, Quebec had limited values available for this data element from 1984 to 1987, Nova Scotia had limited values available from 1984 to 2002, Newfoundland had limited values available from 1984 to 1999, Prince Edward Island had limited values available from 1990 to 1995, New Brunswick had several unknown collisions, the Yukon Territory did not have data available for this data element from 1995 to 1997 , and Nunavut did not have data available for 2001. Therefore, Alberta, Quebec, Nova Scotia, Newfoundland, New 
Brunswick, Prince Edward Island, and the Yukon Territory were excluded from the analysis and the years included in the analysis were 1984 to 2004 excluding 1989 . The values included in the analysis were those that that were intersection related as well as the value "Non-Intersection" as defined below. All of the intersection-related values as shown below, were grouped together for the analysis so that they may be compared with the non-intersection related collisions.

- Intersection with at least two public roadways (uncontrolled)

- Intersection with traffic control (such as traffic signals or stop signs)

- Intersection with private driveway or laneway

- Non-intersections including mid-blocks and ramps

The analysis found that throughout the years, 63 percent of fatal collisions were non-intersection collisions and 32 percent were intersection-related collisions. Also, 38 percent of injury collisions were non-intersection collisions and 59 percent were intersection-related collisions. These percentages are illustrated in Figures 3.31 and 3.32 and compared with regional percentages in Table 3.9.

The analysis also found that from 1984 to 2004, fatal intersection collisions per 10,000 motor vehicles registered decreased from 0.66 to 0.38 ( 42 percent) and fatal nonintersection collisions per 10,000 motor vehicles registered decreased from 1.11 to 0.75 (32 percent). In addition, injury intersection collisions per 10,000 motor vehicles registered decreased from 66.79 to 43.99 (34 percent) and injury non-intersection 
collisions per 10,000 motor vehicles registered decreased from 45.39 to 29.73 (35 percent). These percentage changes are compared to regional ones in Table 3.10 and illustrated by using trend line graphs in Figures 3.33 to 3.36 .

\subsection{Road Alignment}

Road Alignment refers to the visual alignment of the roadway at the time of the collision. During the data extraction for this data element it was found that Alberta data was only available from 1991 to 2004, Manitoba data was not available for 1989, and Nunavut data was not available for 2001. Therefore, Alberta was left out of the analysis and the years included in the analysis were 1984 to 2004 excluding 1989 . The values within the data element included in the analysis were "Straight and Level", "Straight and Gradient", "Curved and Level", and "Curved and Gradient". For purposes of analysis, "Curved and Level" and "Curved and Gradient" were combined to determine the percentage of collisions that occurred on a curve and "Straight and Gradient" and "Curved and Gradient" were combined to determine the percentage of collisions that occurred on a gradient.

The analysis found that throughout the years, 55 percent of fatal collisions occurred on straight and level roads, 29 percent occurred on a curve, and 27 percent occurred on a gradient. Also, 72 percent of injury collisions occurred on straight and level roads, 15 percent occurred on a curve, and 19 percent occurred on a gradient. Figures 3.37 and 3.38 illustrated these percentages and Table 3.11 compares these percentages by region. 
The analysis also found that from 1984 to 2004, fatal collisions per 10,000 motor vehicles registered that occurred on straight and level roads decreased from 1.37 to 0.67 (51 percent), fatal collisions per 10,000 motor vehicles registered that occurred on curved roads decreased from 0.72 to 0.38 ( 47 percent), and fatal collisions per 10,000 motor vehicles registered that occurred on a gradient decreased from 0.67 to 0.34 ( 49 percent). In addition, injury collisions per 10,000 motor vehicles registered that occurred on straight and level roads decreased from 82.85 to 56.93 (31 percent), injury collisions per 10,000 motor vehicles registered that occurred on curved roads decreased from 18.72 to 10.92 (42 percent), and injury collisions per 10,000 motor vehicles registered that occurred on a gradient decreased from 22.94 to 13.05 (43 percent). Table 3.12 compares these percentage changes by region and Figures 3.39 to 3.44 illustrates these trends nationally and regionally by using line graphs for each value within the data element.

\subsection{Road Surface Condition}

Road Surface Condition refers to the construction and/or maintenance condition of the road. During the data extraction for this data element it was found that Alberta had limited values available for this data element, Manitoba data was not available for 1989 , the Northwest Territories had limited data available for this data element from 1984 to 1998, and Nunavut data was not available for 2001. Therefore, Alberta, the Northwest Territories, and Nunavut were left out of the analysis and the years included in the analysis were from 1984 to 2004 excluding 1989 . The values included in the analysis were "Dry, Normal", "Wet", "Snow (Loose)", “Ice (Packed Snow)", and "Slush". For 
purposes of analysis, "Snow (Loose)", "Ice (Packed Snow)", and "Slush" were combined to determine the percentage of collisions that occurred on winter condition roads.

The analysis found that throughout the years, 69 percent of fatal collisions occurred on dry, normal roads, 17 percent occurred on wet roads, and 13 percent occurred on winter condition roads. Also, 64 percent of injury collisions occurred on dry, normal roads, 22 percent occurred on wet roads, and 13 percent occurred on winter condition roads. Figures 3.45 and 3.46 illustrate these percentages and Table 3.13 compares them by region.

The analysis also found that from 1984 to 2004 , fatal collisions per 10,000 motor vehicles registered that occurred on dry roads decreased from 1.69 to 0.84 (50 percent), fatal collisions per 10,000 motor vehicles registered that occurred on wet roads decreased from 0.47 to 0.22 (53 percent), and fatal collisions per 10,000 motor vehicles registered that occurred on winter road conditions decreased from 0.30 to 0.16 (47 percent). In addition, injury collisions per 10,000 motor vehicles registered that occurred on dry roads decreased from 75.40 to 49.87 (34 percent), injury collisions per 10,000 motor vehicles registered that occurred on wet roads decreased from 27.72 to 15.36 (45 percent), and injury collisions per 10,000 motor vehicles registered that occurred on winter road conditions decreased from 16.19 to 12.40 (23 percent). Table 3.14 compares these percentage changes with regional ones and Figures 3.47 to 3.52 illustrates the trends nationally and regionally using line graphs for each value within the data element. 


\subsection{Light Condition}

Light Condition refers to the ambient light condition prevalent at the scene of the collision. During the data extraction for this data element it was found that Alberta data was not available from 1984 to 1998, Manitoba data was not available for 1989, and Nunavut data was not available for 2001. Therefore, Alberta was left out of the analysis and the years included in the analysis were 1984 to 2004 excluding 1989 . The values that were analyzed for this data element were "Day" and "Dark".

The analysis found that throughout the years, 51 percent of fatal collisions occurred during daylight and 35 percent occurred when it was dark. Also, 68 percent of injury collisions occurred during daylight and 19 percent occurred when it was dark. Figures 3.53 and 3.54 illustrate these percentages and Table 3.15 compares them with regional ones.

The analysis also found that from 1984 to 2004 , fatal collisions per 10,000 motor vehicles registered that occurred during daylight decreased from 1.15 to 0.67 (42 percent) and fatal collisions per 10,000 motor vehicles registered that occurred when it was dark decreased from 1.0 to 0.44 (56 percent). In addition, injury collisions per 10,000 motor vehicles registered that occurred during daylight decreased from 74.45 to 54.47 (27 percent) and injury collisions per 10,000 motor vehicles registered that occurred when it was dark decreased from 29.36 to 16.02 (45 percent). Table 3.16 shows these percentages compared to regional one and Figures 3.55 to 3.58 illustrate these trends nationally and regionally by using lines graphs per data element. 


\subsection{Traffic Control}

Traffic Control refers to the traffic control device or traffic control measure present at the collision site. During the data extraction for this data element it was found that Alberta had limited values available from 1984 to 1998, Manitoba data was not available for 1989, and Nunavut data was not available for 2001. Therefore, Alberta was left out of the analysis and the years included in the analysis were 1984 to 2004 excluding 1989. The values that were analyzed for this data element were "No Control Present", "Traffic Signals", and "Stop Signs".

The analysis found that throughout the years, 80 percent of fatal collisions occurred where there was no control present, 7 percent occurred at traffic signals, and 8 percent occurred at stop signs. Also, 62 percent of injury collisions occurred where there was no control present, 23 percent occurred at traffic signals, and 12 percent occurred at stop signs. Figures 3.59 and 3.60 illustrate these percentages and Table 3.17 compares them to regional one.

The analysis also found that from 1984 to 2004 , fatal collisions per 10,000 motor vehicles registered that occurred when no control was present decreased from 1.99 to 0.92 (54 percent), fatal collisions per 10,000 motor vehicles registered that occurred at traffic signals decreased from 0.13 to 0.10 ( 23 percent), and fatal collisions per 10,000 motor vehicles registered that occurred at stop signs decreased from 0.15 to 0.10 (33 percent). In addition, injury collisions per 10,000 motor vehicles registered that occurred when no control was present decreased from 78.52 to 42.90 (45 percent), injury collisions 
per 10,000 motor vehicles registered that occurred at traffic signals decreased from 21.17 to 19.10 (10 percent), and injury collisions per 10,000 motor vehicles registered that occurred at stop signs decreased from 13.39 to 8.49 ( 37 percent). Table 3.18 compares these percentage changes with regional ones and Figures 3.61 to 3.66 illustrates the national and regional trends for each value within the data element.

\subsection{Speed Limit}

Speed Limit refers to the posted speed limit at the collision site. During the data extraction for this data element it was found that Alberta did not collect this data element, Manitoba data was not available for 1989, Nova Scotia data was not available for 1995, Yukon Territory data was not available from 1990 to 1994, and Nunavut data was not available for 2001. Therefore, Alberta, and the Yukon Territory were left out of the analysis and the years included in the analysis were 1984 to 2004 excluding 1989 and 1995. The values that were analyzed for this data element were " 40 and $50 \mathrm{~km} / \mathrm{h}$ ", "60 and $70 \mathrm{~km} / \mathrm{h}$ ", "80 and $90 \mathrm{~km} / \mathrm{h}$ ", and "100 and $110 \mathrm{~km} / \mathrm{h}$ ". Although the speed limits were coded separately in the TRAID data dictionary, for purposes of analysis they were grouped in pairs. Speed limits such at $40 \mathrm{~km} / \mathrm{h}$ alone had limited data and did not show useful trends when analyzed alone. Also, by grouping the speed limits together, it was possible to compare the trends with the trends found in the Road Classification data element, which included the values "Urban" and "Rural".

The analysis found that throughout the years, 23 percent of fatal collisions occurred where the speed limit was 40 and $50 \mathrm{~km} / \mathrm{h}, 14$ percent occurred at 60 and 70 
$\mathrm{km} / \mathrm{h}, 49$ percent occurred at 80 and $90 \mathrm{~km} / \mathrm{h}$, and 13 percent occurred at 100 and 110 $\mathrm{km} / \mathrm{h}$. Also 54 percent of injury collisions occurred where the speed limit was 40 and 50 $\mathrm{km} / \mathrm{h}, 17$ percent occurred at 60 and $70 \mathrm{~km} / \mathrm{h}, 20$ percent occurred at 80 and $90 \mathrm{~km} / \mathrm{h}$, and 7 percent occurred at 100 and $110 \mathrm{~km} / \mathrm{h}$. Figures 3.67 and 3.68 illustrate these percentages and Table 3.19 compares them to regional percentages.

The analysis also found that from 1984 to 2004 , fatal collisions per 10,000 motor vehicles registered that occurred where the speed limit was 40 and $50 \mathrm{~km} / \mathrm{h}$ decreased from 0.66 to 0.25 ( 62 percent), fatal collisions per 10,000 motor vehicles registered that occurred where the speed limit was 60 and $70 \mathrm{~km} / \mathrm{h}$ decreased from 0.30 to 0.17 (43 percent), fatal collisions per 10,000 motor vehicles registered that occurred where the speed limit was 80 and $90 \mathrm{~km} / \mathrm{h}$ decreased from 1.17 to 0.54 (54 percent), and fatal collisions per 10,000 motor vehicles registered that occurred where the speed limit was 100 and $110 \mathrm{~km} / \mathrm{h}$ decreased from 0.24 to 0.20 (17 percent). In addition, injury collisions per 10,000 motor vehicles registered that occurred where the speed limit was 40 and 50 $\mathrm{km} / \mathrm{h}$ decreased from 63.14 to 37.72 (40 percent), injury collisions per 10,000 motor vehicles registered that occurred where the speed limit was 60 and $70 \mathrm{~km} / \mathrm{h}$ decreased from 17.46 to 13.28 ( 24 percent), injury collisions per 10,000 motor vehicles registered that occurred where the speed limit was 80 and $90 \mathrm{~km} / \mathrm{h}$ decreased from 25.18 to 13.32 (47 percent), and injury collisions per 10,000 motor vehicles registered that occurred where the speed limit was 100 and $110 \mathrm{~km} / \mathrm{h}$ increased from 6.24 to 6.96 (10 percent). Table 3.20 shows how these percentage changes compare per region and Figures 3.69 to 
3.76 illustrates these national and regional trends in line graphs per value within the data element.

\subsection{Weather Condition}

Weather Condition refers to the predominant weather condition prevalent at the scene of the collision. During the data extraction for this data element it was found that Alberta data was not available from 1984 to 1990, Manitoba data was not available for 1989, and Nunavut data was not available for 2001. Therefore, Alberta was left out of the analysis and the years included in the analysis were 1984 to 2004 excluding 1989. The values that were analyzed for this data element were "Clear", "Raining", and "Snowing".

The analysis found that throughout the years, 82 percent of fatal collisions occurred in clear weather, 9 percent occurred when it was raining, and 6 percent when it was snowing. Also, 80 percent of injury collisions occurred in clear weather, 12 percent occurred when it was raining, and 6 percent occurred when it was snowing. Figures 3.77 and 3.78 illustrate these percentages and Table 3.21 compares the percentages to regional ones.

The analysis also found that from 1984 to 2004 , fatal collisions per 10,000 motor vehicles registered that occurred when the weather was clear decreased from 2.05 to 0.99 (52 percent), fatal collisions per 10,000 motor vehicles registered that occurred when it was raining decreased from 0.24 to 0.13 (46 percent), and fatal collisions per 10,000 
motor vehicles registered that occurred when it was snowing decreased from 0.12 to 0.07 (42 percent). In addition, injury collisions per 10,000 motor vehicles registered that occurred when the weather was clear decreased from 96.61 to 62.06 (36 percent), injury collisions per 10,000 motor vehicles registered that occurred when it was raining decreased from 14.59 to 8.71 (40 percent), and injury collisions per 10,000 motor vehicles registered that occurred when it was snowing decreased from 6.23 to 5.38 (15 percent). Table 3.22 shows how these percentage changes compare at a regional level and Figures 3.79 to 3.84 illustrate the national and regional trends in line graphs per value within the data element.

\subsection{Vehicle Manoeuvre}

Vehicle Manoeuvre refers to the movement of the vehicle just prior to the collision. It is coded in TRAID as the number of vehicle involved in the collision per manoeuvre rather than the number of collisions. During the data extraction for this data element it was found that Alberta data was not available, Manitoba data was not available for 1989, and Nunavut data was not available for 2001. Therefore, Alberta was left out of the analysis and the years included in the analysis were 1984 to 2004 excluding 1989 . The values within the data element included in the analysis were "Going Straight Ahead", “Turning Left”, “Turning Right”, “Changing Lanes”, and "Overtaking”.

The analysis found that throughout the years, 78 percent of vehicles involved in fatal collisions were going straight ahead, 5 percent were turning left, 1 percent was turning right, 1 percent was changing lanes, and 3 percent were overtaking. Also, 60 
percent of vehicles involved in injury collisions were going straight ahead, 11 percent were turning left, 3 percent were turning right, 2 percent were changing lanes, and 1 percent was overtaking. These percentages are illustrated in Figures 3.85 and 3.86 and compared to regional percentages in Table 3.23.

The analysis also found that from 1984 to 2004, vehicles involved in fatal collisions per 10,000 motor vehicles registered that occurred when a vehicle was going straight ahead decreased from 3.09 to 1.59 ( 49 percent), vehicles involved in fatal collisions per 10,000 motor vehicles registered that occurred when a vehicle was turning left decreased from 0.18 to 0.11 ( 39 percent), vehicles involved in fatal collisions per 10,000 motor vehicles registered that occurred when a vehicle was turning right decreased from 0.04 to 0.01 (75 percent), vehicles involved in fatal collisions per 10,000 motor vehicles registered that occurred when a vehicle was changing lanes decreased from 0.05 to 0.03 ( 40 percent), and vehicles involved in fatal collisions per 10,000 motor vehicles registered that occurred when a vehicle was overtaking decreased from 0.12 to 0.04 (67 percent). In addition, vehicles involved in injury collisions per 10,000 motor vehicles registered that occurred when a vehicle was going straight ahead decreased from 130.85 to 82.59 ( 37 percent), vehicles involved in injury collisions per 10,000 motor vehicles registered that occurred when a vehicle was turning left decreased from 21.73 to 15.11 (30 percent), vehicles involved in injury collisions per 10,000 motor vehicles registered that occurred when a vehicle was turning right decreased from 6.35 to 4.34 (32 percent), vehicles involved in injury collisions per 10,000 motor vehicles registered that occurred when a vehicle was changing lanes decreased from 3.12 to 2.21 ( 29 percent), 
and vehicles involved in injury collisions per 10,000 motor vehicles registered that occurred when a vehicle was overtaking decreased from 3.11 to 1.30 (58 percent). These percentage changes are compared at the regional level in Table 3.24 and the trends are shown in line graphs nationally and regionally for each value within the data element in Figures 3.87 to 3.96 .

\subsection{Vehicle Type}

Vehicle Type refers to the description of the vehicle according to its general design characteristics. Similar to the Vehicle Manoeuvre data element, it is coded in TRAID by vehicles involved in collisions rather than the number of collisions. During the data extraction for this data element it was found that Manitoba data was not available for 1989 and Nunavut data was not available for 2001. Therefore, all provinces and territories were included in the analysis and the years included in the analysis were 1984 to 2004 excluding 1989 . The values within the data element included in the analysis were "Automobile", "Bicycle", "Motorcycle", "Pickup<4536 kg", "Tractor Trailer", and "Truck $>4536 \mathrm{~kg}$ ". The following vehicle type definitions were available from the TRAID Data Dictionary:

- Pickup <4536 kg: Light trucks and vans with a Gross Vehicle Weight Rating of less than $4536 \mathrm{~kg}$.

- Truck $>4536 \mathrm{~kg}$ : A truck designed primarily for the transportation of property or equipment, but does not include a trailer. This type of vehicle is also referred to as UNIT truck. Gross Vehicle Weight Rating of $4536 \mathrm{~kg}$ or more. 
- Tractor Trailer: Truck tractor and trailer(s). The truck is designed primarily for towing other vehicles (usually trailers) and not constructed for carrying any load other than a part of the weight of the load being towed.

The analysis found that throughout the years, 56 percent of vehicles involved in fatal collisions were automobiles, 2 percent were bicycles, 5 percent were motorcycles, 22 percent were pickup trucks $<4536 \mathrm{~kg}, 7$ percent were tractor trailers, and 4 percent were trucks $>4536 \mathrm{~kg}$. Also, 71 percent of vehicles involved in injury collisions were automobiles, 3 percent were bicycles, 3 percent were motorcycles, 17 percent were pickup $<4536 \mathrm{~kg}, 1$ percent were tractor trailers, and 2 percent were trucks $>4536 \mathrm{~kg}$. These percentages are illustrated in Figures 3.97 and 3.98 and compared with regional percentages in Table 3.25.

The analysis also found that from 1984 to 2004, automobiles involved in fatal collisions per 10,000 motor vehicles registered decreased from 2.27 to 1.07 (53 percent), bicycles involved in fatal collisions per 10,000 vehicles registered decreased from 0.10 to 0.03 (70 percent), motorcycles involved in fatal collisions per 10,000 motor vehicles registered decreased from 0.31 to 0.11 (65 percent), pick-up trucks $<4536 \mathrm{~kg}$ involved in fatal collisions per 10,000 motor vehicles registered decreased from 0.60 to 0.54 (10 percent), tractor trailers involved in fatal collisions per 10,000 motor vehicles registered decreased from 0.22 to 0.19 (14 percent), and trucks $>4536 \mathrm{~kg}$ involved in fatal collisions per 10,000 motor vehicles registered decreased from 0.10 to 0.08 ( 20 percent). In addition, automobiles involved in injury collisions per 10,000 motor vehicles registered 
decreased from 142.34 to 93.73 (34 percent), bicycles involved in injury collisions per 10,000 vehicles registered decreased from 8.45 to 4.25 ( 50 percent), motorcycles involved in injury collisions per 10,000 motor vehicles registered decreased from 11.05 to 3.08 ( 72 percent), pick-up trucks $<4536 \mathrm{~kg}$ involved in injury collisions per 10,000 motor vehicles registered increased from 21.95 to 30.26 ( 27 percent), tractor trailers involved in injury collisions per 10,000 motor vehicles registered decreased from 2.56 to 2.36 ( 8 percent), and trucks $>4536 \mathrm{~kg}$ involved in injury collisions per 10,000 motor vehicles registered increased from 2.20 to 2.78 ( 21 percent). These percentage changes are compared at the regional level in Table 3.26 and national and regional trends are shown on line graphs for each value within the data element in Figures 3.99 to 3.110.

\subsection{Hour of Collision}

Hour of Collision refers to the approximate hour of the day when the collision occurred. During the data extraction for this data element it was found that Manitoba data was not available for 1989 and Nunavut data was not available for 2001. Therefore, all provinces and territories were included in the analysis and the years included in the analysis were 1984 to 2004 excluding 1989. All hours of the day were included in the analysis.

The analysis found that throughout the years, 9 percent of fatal collisions occurred between 6:00 and 8:59 am, 10 percent occurred between 9:00 and 11:59 am, 13 percent occurred between 12:00 and 2:59 pm, 19 percent occurred between 3:00 and 5:59 pm, 16 percent occurred between 6:00 and 8:59 pm, 14 percent occurred between 9:00 and 11:59 
pm, 12 percent occurred between 12:00 and 2:59 am, and 7 percent occurred between 3:00 and 5:59 am. Also, 11 percent of injury collisions occurred between 6:00 and 8:59 am, 13 percent occurred between 9:00 and 11:59 am, 17 percent occurred between 12:00 and 2:59 pm, 24 percent occurred between 3:00 and 5:59 pm, 15 percent occurred between $6: 00$ and 8:59 pm, 10 percent occurred between 9:00 and 11:59 pm, 6 percent occurred between 12:00 and 2:59 am, and 4 percent occurred between 3:00 and 5:59 am. These percentages are illustrated in Figures 3.111 and 3.112.

\subsection{Day of Week}

Day of Week refers to the name of the weekday on which the collision occurred. During the data extraction for this data element it was found that Manitoba data was not available for 1989 and Nunavut data was not available for 2001. Therefore, all provinces and territories were included in the analysis and the years included in the analysis were 1984 to 2004 excluding 1989 . The values that were analyzed for this data element were "Sunday", "Monday", "Tuesday", “Wednesday", "Thursday", "Friday", and "Saturday".

The analysis found that throughout the years, 16 percent of fatal collisions occurred on Sunday, 12 percent occurred on Monday, 11 percent occurred on Tuesday, 12 percent occurred on Wednesday, 13 percent occurred on Thursday, 17 percent occurred on Friday, and 19 percent occurred on Saturday. Also, 12 percent of injury collisions occurred on Sunday, 13 percent occurred on Monday, 14 percent occurred on Tuesday, 14 percent occurred on Wednesday, 15 percent occurred on Thursday, 17 
percent occurred on Friday, and 15 percent occurred on Saturday. These percentages are illustrated in Figures 3.113 and 3.114.

\subsection{Month of Collision}

Month of Collision refers to the month in which the collision occurred. During the data extraction for this data element it was found that Manitoba data was not available for 1989 and Nunavut data was not available for 2001. Therefore, the years included in the analysis were 1984 to 2004 excluding 1989 . The values that were analyzed for this data element were "January", "February", "March", “April”, "May", “June”, “July”, “August”, “September", “October", "November", and "December”.

The analysis found that throughout the years, 7 percent of fatal collisions occurred in January, 6 percent occurred in February, 6 percent occurred in March, 6 percent occurred in April, 8 percent occurred in May, 10 percent occurred in June, 10 percent occurred in July, 12 percent occurred in August, 9 percent occurred in September, 9 percent occurred in October, 8 percent occurred in November, and 9 percent occurred in December. Also, 8 percent of injury collisions occurred in January, 7 percent occurred in February, 7 percent occurred in March, 7 percent occurred in April, 8 percent occurred in May, 9 percent occurred in June, 9 percent occurred in July, 9 percent occurred in August, 9 percent occurred in September, 9 percent occurred in October, 9 percent occurred in November, and 9 percent occurred in December. These percentages are illustrated in Figures 3.115 and 3.116. 


\subsection{Tables for Chapter 3}

Table 3.1: Percentage of Collisions By Region for Collision Severity Values.

\begin{tabular}{|l|l|l|l|l|l|}
\hline & National & $\begin{array}{l}\text { Western } \\
\text { Provinces }\end{array}$ & Ontario & Quebec & $\begin{array}{l}\text { Eastern } \\
\text { Provinces }\end{array}$ \\
\hline Fatal & 0.4 & 0.4 & 0.4 & 0.4 & 0.6 \\
\hline Injury & 24 & 19 & 34 & 22 & 22 \\
\hline
\end{tabular}

Table 3.2: Percentage Change in Collision Rates By Region for Collision Severity

Values Between 1984 and 2004.

\begin{tabular}{|l|l|l|l|l|l|}
\hline & National & $\begin{array}{l}\text { Western } \\
\text { Provinces }\end{array}$ & Ontario & Quebec & $\begin{array}{l}\text { Eastern } \\
\text { Provinces }\end{array}$ \\
\hline Fatal & -49 & -30 & -50 & -64 & -49 \\
\hline Injury & -32 & -12 & -48 & -35 & -21 \\
\hline
\end{tabular}

Table 3.3: Percentage of Collisions By Region for Collision Configuration Values.

\begin{tabular}{|l|l|l|l|l|}
\hline & & National & $\begin{array}{l}\text { Western } \\
\text { Provinces }\end{array}$ & $\begin{array}{l}\text { Eastern } \\
\text { Provinces }\end{array}$ \\
\hline \multirow{2}{*}{ Hit Object/Person } & Fatal & 17 & 6 & 20 \\
\cline { 2 - 5 } & Injury & 5 & 3 & 13 \\
\hline \multirow{3}{*}{ Head-On } & Fatal & 20 & 21 & 22 \\
\cline { 2 - 5 } & Injury & 5 & 5 & 5 \\
\hline Right Turn & Fatal & 10 & 11 & 6 \\
\cline { 2 - 5 } & Injury & 16 & 17 & 13 \\
\hline \multirow{2}{*}{ Left Turn } & Fatal & 4 & 4 & 5 \\
\cline { 2 - 5 } & Injury & 8 & 9 & 6 \\
\hline \multirow{2}{*}{ Rear End } & Fatal & 4 & 4 & 3 \\
\cline { 2 - 5 } & Injury & 27 & 26 & 21 \\
\hline \multirow{2}{*}{$\begin{array}{l}\text { Run Off Left } \\
\text { Shoulder }\end{array}$} & Fatal & 17 & 16 & 17 \\
\cline { 2 - 5 } $\begin{array}{l}\text { Run Off Right } \\
\text { Shoulder }\end{array}$ & Injury & 8 & 8 & 10 \\
\cline { 2 - 5 } & Fatal & 18 & 19 & 12 \\
\hline
\end{tabular}


Table 3.4: Percentage Change in Collision Rates By Region For Collision Configuration Values Between 1984 and 2004.

\begin{tabular}{|l|l|l|l|l|}
\hline & & National & $\begin{array}{l}\text { Western } \\
\text { Provinces }\end{array}$ & $\begin{array}{l}\text { Eastern } \\
\text { Provinces }\end{array}$ \\
\hline \multirow{2}{*}{ Hit Object/Person } & Fatal & -41 & -20 & -53 \\
\cline { 2 - 5 } & Injury & -26 & -10 & -40 \\
\hline \multirow{2}{*}{ Head-On } & Fatal & -36 & -33 & -38 \\
\cline { 2 - 5 } & Injury & -29 & -28 & -32 \\
\hline \multirow{2}{*}{ Right Turn } & Fatal & -52 & -48 & -69 \\
\cline { 2 - 5 } & Injury & -50 & -52 & -35 \\
\hline \multirow{2}{*}{ Left Turn } & Fatal & 0 & +38 & -40 \\
\cline { 2 - 5 } & Injury & +27 & +31 & -2 \\
\hline \multirow{2}{*}{ Rear End } & Fatal & -40 & -30 & -78 \\
\cline { 2 - 5 } & Injury & -2 & -8 & +29 \\
\hline \multirow{2}{*}{$\begin{array}{l}\text { Run Off Left } \\
\text { Shoulder }\end{array}$} & Fatal & -35 & -36 & -35 \\
\cline { 2 - 5 } & Injury & -24 & -22 & -30 \\
\hline Run Off Right & Fatal & -32 & -21 & -56 \\
\cline { 2 - 5 } Shoulder & Injury & -25 & -19 & -42 \\
\hline
\end{tabular}

Table 3.5: Percentage of Collisions By Region For Road Classification Values.

\begin{tabular}{|l|l|l|l|l|l|l|}
\hline & & National & $\begin{array}{l}\text { Western } \\
\text { Provinces }\end{array}$ & Ontario & Quebec & $\begin{array}{l}\text { Eastern } \\
\text { Provinces }\end{array}$ \\
\hline \multirow{2}{*}{ Urban } & Fatal & 35 & 35 & 32 & 41 & 26 \\
\cline { 2 - 7 } & Injury & 71 & 72 & 69 & 74 & 62 \\
\hline \multirow{2}{*}{ Rural } & Fatal & 65 & 65 & 68 & 59 & 74 \\
\cline { 2 - 7 } & Injury & 29 & 28 & 31 & 26 & 38 \\
\hline
\end{tabular}

Table 3.6: Percentage Change in Collision Rates By Region for Road Classification Values Between 1984 and 2004.

\begin{tabular}{|l|l|l|l|l|l|l|}
\hline & & National & $\begin{array}{l}\text { Western } \\
\text { Provinces }\end{array}$ & Ontario & Quebec & $\begin{array}{l}\text { Eastern } \\
\text { Provinces }\end{array}$ \\
\hline \multirow{2}{*}{ Urban } & Fatal & -58 & -35 & -53 & -73 & -52 \\
\cline { 2 - 7 } & Injury & -37 & -17 & -46 & -41 & -14 \\
\hline \multirow{2}{*}{ Rural } & Fatal & -47 & -22 & -49 & -59 & -48 \\
\cline { 2 - 7 } & Injury & -35 & -11 & -48 & -26 & -29 \\
\hline
\end{tabular}


Table 3.7: Percentage of Collisions By Region For Road Category Values.

\begin{tabular}{|l|l|l|l|l|}
\hline & & National & $\begin{array}{l}\text { Western } \\
\text { Provinces }\end{array}$ & Ontario \\
\hline \multirow{2}{*}{ Divided } & Fatal & 12 & 10 & 13 \\
\cline { 2 - 5 } & Injury & 14 & 17 & 13 \\
\hline \multirow{2}{*}{ Undivided } & Fatal & 83 & 80 & 85 \\
\cline { 2 - 5 } & Injury & 79 & 70 & 83 \\
\hline
\end{tabular}

Table 3.8: Percentage Change in Collision Rates By Region For Road Category

Values Between 1984 and 2004.

\begin{tabular}{|l|l|l|l|l|}
\hline & & National & $\begin{array}{l}\text { Western } \\
\text { Provinces }\end{array}$ & Ontario \\
\hline \multirow{2}{*}{ Divided } & Fatal & -29 & -25 & -32 \\
\cline { 2 - 5 } & Injury & -27 & -11 & -34 \\
\hline \multirow{2}{*}{ Undivided } & Fatal & -45 & -27 & -52 \\
\cline { 2 - 5 } & Injury & -42 & -22 & -49 \\
\hline
\end{tabular}

Table 3.9: Percentage of Collisions By Region For Road Configuration Values.

\begin{tabular}{|l|l|l|l|l|}
\hline & & National & $\begin{array}{l}\text { Western } \\
\text { Provinces }\end{array}$ & Ontario \\
\hline \multirow{2}{*}{ Intersection } & Fatal & 32 & 30 & 35 \\
\cline { 2 - 5 } & Injury & 59 & 54 & 63 \\
\hline \multirow{2}{*}{$\begin{array}{l}\text { Non- } \\
\text { Intersection }\end{array}$} & Fatal & 63 & 61 & 62 \\
\cline { 2 - 5 } & Injury & 38 & 40 & 36 \\
\hline
\end{tabular}

Table 3.10: Percentage Change in Collision Rates By Region For Road

Configuration Values Between 1984 and 2004.

\begin{tabular}{|l|l|l|l|l|}
\hline & & National & $\begin{array}{l}\text { Western } \\
\text { Provinces }\end{array}$ & Ontario \\
\hline \multirow{2}{*}{ Intersection } & Fatal & -42 & -17 & -53 \\
\cline { 2 - 5 } & Injury & -34 & -8 & -45 \\
\hline \multirow{2}{*}{$\begin{array}{l}\text { Non- } \\
\text { Intersection }\end{array}$} & Fatal & -32 & -2 & -47 \\
\cline { 2 - 5 } & Injury & -35 & -5 & -48 \\
\hline
\end{tabular}


Table 3.11: Percentage of Collisions By Region for Road Alignment Values.

\begin{tabular}{|l|l|l|l|l|l|l|}
\hline & & National & $\begin{array}{l}\text { Western } \\
\text { Provinces }\end{array}$ & Ontario & Quebec & $\begin{array}{l}\text { Eastern } \\
\text { Provinces }\end{array}$ \\
\hline \multirow{2}{*}{$\begin{array}{l}\text { Straight } \\
\text { and Level }\end{array}$} & Fatal & 55 & 51 & 62 & 55 & 42 \\
\cline { 2 - 7 } Curve & Injury & 72 & 67 & 77 & 72 & 57 \\
\cline { 2 - 7 } & Fatal & 29 & 32 & 22 & 31 & 35 \\
\hline \multirow{2}{*}{ Gradient } & Injury & 15 & 16 & 11 & 17 & 22 \\
\cline { 2 - 7 } & Fatal & 27 & 31 & 23 & 25 & 36 \\
\hline
\end{tabular}

Table 3.12: Percentage Change in Collision Rates By Region For Road Alignment

Values Between 1984 and 2004.

\begin{tabular}{|l|l|l|l|l|l|l|}
\hline & & National & $\begin{array}{l}\text { Western } \\
\text { Provinces }\end{array}$ & Ontario & Quebec & $\begin{array}{l}\text { Eastern } \\
\text { Provinces }\end{array}$ \\
\hline $\begin{array}{l}\text { Straight } \\
\text { and Level }\end{array}$ & Fatal & -51 & -31 & -46 & -66 & -56 \\
\cline { 2 - 7 } Curve & Injury & -31 & -27 & -42 & -36 & -13 \\
\cline { 2 - 7 } & Fatal & -47 & -14 & -53 & -62 & -47 \\
\hline \multirow{2}{*}{ Gradient } & Fatal & -42 & -15 & -61 & -40 & -29 \\
\cline { 2 - 7 } & Injury & -49 & -12 & -58 & -70 & -39 \\
\hline
\end{tabular}

Table 3.13: Percentage of Collisions By Region for Road Surface Condition Values.

\begin{tabular}{|l|l|l|l|l|l|l|}
\hline & & National & $\begin{array}{l}\text { Western } \\
\text { Provinces }\end{array}$ & Ontario & Quebec & $\begin{array}{l}\text { Eastern } \\
\text { Provinces }\end{array}$ \\
\hline \multirow{2}{*}{$\begin{array}{l}\text { Dry, } \\
\text { Normal }\end{array}$} & Fatal & 69 & 70 & 68 & 66 & 65 \\
\cline { 2 - 7 } & Injury & 64 & 60 & 66 & 64 & 60 \\
\hline \multirow{2}{*}{ Wet } & Fatal & 17 & 16 & 18 & 17 & 18 \\
\cline { 2 - 7 } & Injury & 22 & 24 & 22 & 20 & 20 \\
\hline $\begin{array}{l}\text { Winter } \\
\text { Road } \\
\text { Conditions }\end{array}$ & Fatal & 5 & 12 & 12 & 16 & 16 \\
\cline { 2 - 7 } & Injury & 5 & 15 & 11 & 16 & 19 \\
\hline
\end{tabular}


Table 3.14: Percentage Change in Collision Rates For Road Surface Condition Values.

\begin{tabular}{|l|l|l|l|l|l|l|}
\hline & & National & $\begin{array}{l}\text { Western } \\
\text { Provinces }\end{array}$ & Ontario & Quebec & $\begin{array}{l}\text { Eastern } \\
\text { Provinces }\end{array}$ \\
\hline $\begin{array}{l}\text { Dry, } \\
\text { Normal }\end{array}$ & Fatal & -50 & -24 & -95 & -64 & -47 \\
\cline { 2 - 7 } & Injury & -34 & -16 & -44 & -37 & -16 \\
\hline \multirow{2}{*}{ Wet } & Fatal & -53 & -35 & -50 & -66 & -55 \\
\cline { 2 - 7 } & Injury & -45 & -21 & -58 & -44 & -30 \\
\hline $\begin{array}{l}\text { Winter } \\
\text { Road } \\
\text { Conditions }\end{array}$ & Fatal & -47 & -23 & -38 & -65 & -41 \\
\cline { 2 - 7 } & Injury & -23 & -13 & -38 & -13 & -24 \\
\hline
\end{tabular}

Table 3.15: Percentage of Collisions By Region for Light Condition Values.

\begin{tabular}{|l|l|l|l|l|l|l|}
\hline & & National & $\begin{array}{l}\text { Western } \\
\text { Provinces }\end{array}$ & Ontario & Quebec & $\begin{array}{l}\text { Eastern } \\
\text { Provinces }\end{array}$ \\
\hline \multirow{2}{*}{ Day } & Fatal & 51 & 49 & 51 & 52 & 51 \\
\cline { 2 - 7 } & Injury & 68 & 65 & 68 & 65 & 67 \\
\hline \multirow{2}{*}{ Dark } & Fatal & 35 & 38 & 37 & 28 & 40 \\
\cline { 2 - 7 } & Injury & 19 & 21 & 20 & 15 & 26 \\
\hline
\end{tabular}

Table 3.16: Percentage Change in Collisions By Region For Light Condition Values

Between 1984 and 2004.

\begin{tabular}{|l|l|l|l|l|l|l|}
\hline & & National & $\begin{array}{l}\text { Western } \\
\text { Provinces }\end{array}$ & Ontario & Quebec & $\begin{array}{l}\text { Eastern } \\
\text { Provinces }\end{array}$ \\
\hline \multirow{2}{*}{ Day } & Fatal & -42 & -20 & -36 & -57 & -47 \\
\cline { 2 - 7 } & Injury & -27 & -10 & -40 & -37 & -7 \\
\hline \multirow{2}{*}{ Dark } & Fatal & -56 & -35 & -71 & -46 & -56 \\
\cline { 2 - 7 } & Injury & -45 & -27 & -76 & -43 & -44 \\
\hline
\end{tabular}


Table 3.17: Percentage of Collisions By Region For Traffic Control Values.

\begin{tabular}{|l|l|l|l|l|l|l|}
\hline & & National & $\begin{array}{l}\text { Western } \\
\text { Provinces }\end{array}$ & Ontario & Quebec & $\begin{array}{l}\text { Eastern } \\
\text { Provinces }\end{array}$ \\
\hline \multirow{2}{*}{$\begin{array}{l}\text { No } \\
\text { Control }\end{array}$} & Fatal & 80 & 84 & 76 & 84 & 82 \\
\cline { 2 - 7 } & Injury & 62 & 62 & 56 & 66 & 72 \\
\hline $\begin{array}{l}\text { Traffic } \\
\text { Signals }\end{array}$ & Fatal & 7 & 6 & 9 & 6 & 2 \\
\cline { 2 - 7 } & Injury & 23 & 22 & 27 & 10 & 12 \\
\hline $\begin{array}{l}\text { Stop } \\
\text { Signs }\end{array}$ & Fatal & 8 & 7 & 12 & 4 & 3 \\
\cline { 2 - 7 } & Injury & 12 & 11 & 14 & 20 & 7 \\
\hline
\end{tabular}

Table 3.18: Percentage Change in Collisions By Region For Traffic Control Values

Between 1984 and 2004.

\begin{tabular}{|l|l|l|l|l|l|l|}
\hline & & National & $\begin{array}{l}\text { Western } \\
\text { Provinces }\end{array}$ & Ontario & Quebec & $\begin{array}{l}\text { Eastern } \\
\text { Provinces }\end{array}$ \\
\hline $\begin{array}{l}\text { No } \\
\text { Control }\end{array}$ & Fatal & -54 & -40 & -51 & -68 & -37 \\
\cline { 2 - 7 } & Injury & -45 & -29 & -50 & -21 & +1 \\
\hline $\begin{array}{l}\text { Traffic } \\
\text { Signals }\end{array}$ & Fatal & -23 & +8 & -33 & -44 & -50 \\
\cline { 2 - 7 } & Injury & -10 & -52 & -22 & -23 & +35 \\
\hline $\begin{array}{l}\text { Stop } \\
\text { Signs }\end{array}$ & Fatal & -33 & 0 & -45 & -50 & -50 \\
\cline { 2 - 7 } & Injury & -37 & -29 & -50 & -27 & +2 \\
\hline
\end{tabular}

Table 3.19: Percentage of Collisions By Region For Speed Limit Values.

\begin{tabular}{|l|l|l|l|l|l|l|}
\hline & & National & $\begin{array}{l}\text { Western } \\
\text { Provinces }\end{array}$ & Ontario & Quebec & $\begin{array}{l}\text { Eastern } \\
\text { Provinces }\end{array}$ \\
\hline $\begin{array}{l}40 \& 50 \\
\mathrm{~km} / \mathrm{h}\end{array}$ & Fatal & 23 & 26 & 19 & 27 & 18 \\
\cline { 2 - 7 } & Injury & 54 & 59 & 49 & 60 & 53 \\
\hline $\begin{array}{l}60 \& 70 \\
\mathrm{~km} / \mathrm{h}\end{array}$ & Fatal & 14 & 14 & 16 & 11 & 15 \\
\cline { 2 - 7 } & Injury & 17 & 17 & 22 & 11 & 14 \\
\hline $\begin{array}{l}80 \& 90 \\
\mathrm{~km} / \mathrm{h}\end{array}$ & Fatal & 49 & 38 & 54 & 52 & 46 \\
\cline { 2 - 7 } & Injury & 20 & 16 & 20 & 20 & 25 \\
\hline $\begin{array}{l}100 \& 110 \\
\mathrm{~km} / \mathrm{h}\end{array}$ & Fatal & 13 & 19 & 11 & 9 & 19 \\
\cline { 2 - 7 } & Injury & 7 & 5 & 9 & 6 & 7 \\
\hline
\end{tabular}


Table 3.20: Percentage Change in Collisions By Region for Speed Limit Values

Between 1984 and 2004.

\begin{tabular}{|l|l|l|l|l|l|l|}
\hline & & National & $\begin{array}{l}\text { Western } \\
\text { Provinces }\end{array}$ & Ontario & Quebec & $\begin{array}{l}\text { Eastern } \\
\text { Provinces }\end{array}$ \\
\hline $\begin{array}{l}40 \& 50 \\
\mathrm{~km} / \mathrm{h}\end{array}$ & Fatal & -62 & -38 & -54 & -79 & -47 \\
\cline { 2 - 7 } & Injury & -40 & -21 & -51 & -45 & -17 \\
\hline $\begin{array}{l}60 \& 70 \\
\mathrm{~km} / \mathrm{h}\end{array}$ & Fatal & -43 & -19 & -41 & -56 & -65 \\
\cline { 2 - 7 } & Injury & -24 & -18 & -31 & -15 & -17 \\
\hline $\begin{array}{l}80 \& 90 \\
\mathrm{~km} / \mathrm{h}\end{array}$ & Fatal & -54 & -46 & -58 & -61 & -55 \\
\cline { 2 - 7 } & Injury & -47 & -34 & -58 & -41 & -44 \\
\hline $\begin{array}{l}100 \& 110 \\
\mathrm{~km} / \mathrm{h}\end{array}$ & Fatal & -17 & +37 & -20 & -62 & -21 \\
\cline { 2 - 7 } & Injury & +10 & +55 & -26 & +22 & +36 \\
\hline
\end{tabular}

Table 3.21: Percentage of Collisions By Region For Weather Condition Values.

\begin{tabular}{|l|l|l|l|l|l|l|}
\hline & & National & $\begin{array}{l}\text { Western } \\
\text { Provinces }\end{array}$ & Ontario & Quebec & $\begin{array}{l}\text { Eastern } \\
\text { Provinces }\end{array}$ \\
\hline \multirow{2}{*}{ Clear } & Fatal & 82 & 83 & 81 & 83 & 76 \\
\cline { 2 - 7 } & Injury & 80 & 81 & 78 & 82 & 78 \\
\hline \multirow{2}{*}{ Raining } & Fatal & 9 & 10 & 9 & 7 & 10 \\
\cline { 2 - 7 } & Injury & 12 & 14 & 13 & 10 & 11 \\
\hline \multirow{2}{*}{ Snowing } & Fatal & 6 & 4 & 7 & 9 & 7 \\
\cline { 2 - 7 } & Injury & 6 & 4 & 7 & 7 & 7 \\
\hline
\end{tabular}

Table 3.22: Percentage Change in Collisions By Region For Weather Condition

Values Between 1984 and 2004.

\begin{tabular}{|l|l|l|l|l|l|l|}
\hline & & National & $\begin{array}{l}\text { Western } \\
\text { Provinces }\end{array}$ & Ontario & Quebec & $\begin{array}{l}\text { Eastern } \\
\text { Provinces }\end{array}$ \\
\hline \multirow{2}{*}{ Clear } & Fatal & -52 & -27 & -52 & -67 & -32 \\
\cline { 2 - 7 } & Injury & -36 & -17 & -47 & -38 & -19 \\
\hline \multirow{2}{*}{ Raining } & Fatal & -46 & -25 & -47 & -56 & -66 \\
\cline { 2 - 7 } & Injury & -40 & -22 & -53 & -36 & -28 \\
\hline \multirow{2}{*}{ Snowing } & Fatal & -42 & +14 & -36 & -65 & 0 \\
\cline { 2 - 7 } & Injury & -15 & +2 & -25 & -8 & -16 \\
\hline
\end{tabular}


Table 3.23: Percentage of Vehicles Involved in Collisions By Region For Vehicle Manoeuvre Values.

\begin{tabular}{|l|l|l|l|l|l|l|}
\hline & & National & $\begin{array}{l}\text { Western } \\
\text { Provinces }\end{array}$ & Ontario & Quebec & $\begin{array}{l}\text { Eastern } \\
\text { Provinces }\end{array}$ \\
\hline $\begin{array}{l}\text { Going } \\
\text { Straight } \\
\text { Ahead }\end{array}$ & Fatal & 78 & 73 & 82 & 78 & 85 \\
\cline { 2 - 7 } & Injury & 60 & 58 & 59 & 65 & 64 \\
\hline $\begin{array}{l}\text { Turning } \\
\text { Left }\end{array}$ & Fatal & 5 & 5 & 5 & 5 & 4 \\
\cline { 2 - 7 } $\begin{array}{l}\text { Turning } \\
\text { Right }\end{array}$ & Fatal & 11 & 11 & 10 & 11 & 11 \\
\cline { 2 - 7 } & Injury & 3 & 1 & 1 & 1 & 1 \\
\hline \multirow{2}{*}{$\begin{array}{l}\text { Changing } \\
\text { Lanes }\end{array}$} & Fatal & 1 & 1 & 3 & 3 & 3 \\
\cline { 2 - 7 } & Injury & 2 & 1 & 2 & 1 & 1 \\
\hline Overtaking & Fatal & 3 & 2 & 3 & 3 & 1 \\
\cline { 2 - 7 } & Injury & 1 & 1 & 1 & 1 & 1 \\
\hline
\end{tabular}

Table 3.24: Percentage Change in Vehicles Involved in Collision Rates By Region

For Vehicle Manoeuvre Values Between 1984 and 2004.

\begin{tabular}{|l|l|l|l|l|l|l|}
\hline & & National & $\begin{array}{l}\text { Western } \\
\text { Provinces }\end{array}$ & Ontario & Quebec & $\begin{array}{l}\text { Eastern } \\
\text { Provinces }\end{array}$ \\
\hline $\begin{array}{l}\text { Going } \\
\text { Straight } \\
\text { Ahead }\end{array}$ & Fatal & -49 & -23 & -50 & -63 & -44 \\
\cline { 2 - 7 } & Injury & -37 & -20 & -48 & -37 & -24 \\
\hline $\begin{array}{l}\text { Turning } \\
\text { Left }\end{array}$ & Fatal & -39 & +7 & -36 & -61 & -81 \\
\cline { 2 - 7 } & Injury & -30 & -4 & -43 & -35 & -15 \\
\hline $\begin{array}{l}\text { Turning } \\
\text { Right }\end{array}$ & Fatal & -75 & -50 & -50 & -71 & -89 \\
\cline { 2 - 7 } & Injury & -32 & -7 & -38 & -45 & -18 \\
\hline $\begin{array}{l}\text { Changing } \\
\text { Lanes }\end{array}$ & Fatal & -40 & -67 & -33 & -33 & -100 \\
\cline { 2 - 7 } & Injury & -29 & -21 & -41 & +3 & -10 \\
\hline \multirow{2}{*}{ Overtaking } & Fatal & -67 & -57 & -58 & -68 & -64 \\
\cline { 2 - 7 } & Injury & -58 & -37 & -66 & -56 & -43 \\
\hline
\end{tabular}


Table 3.25: Percentage of Vehicles Involved in Collisions By Region For Vehicle

Type Values.

\begin{tabular}{|l|l|l|l|l|l|l|}
\hline & & National & $\begin{array}{l}\text { Western } \\
\text { Provinces }\end{array}$ & Ontario & Quebec & $\begin{array}{l}\text { Eastern } \\
\text { Provinces }\end{array}$ \\
\hline \multirow{2}{*}{ Automobile } & Fatal & 56 & 49 & 60 & 61 & 57 \\
\cline { 2 - 7 } & Injury & 71 & 68 & 73 & 72 & 71 \\
\hline \multirow{3}{*}{ Bicycle } & Fatal & 2 & 1 & 2 & 2 & 2 \\
\cline { 2 - 7 } & Injury & 3 & 3 & 3 & 5 & 2 \\
\hline \multirow{2}{*}{ Motorcycle } & Fatal & 5 & 4 & 5 & 5 & 5 \\
\cline { 2 - 7 } & Injury & 3 & 2 & 2 & 4 & 3 \\
\hline \multirow{2}{*}{$\begin{array}{l}\text { Pickup }<4536 \\
\text { kg }\end{array}$} & Fatal & 22 & 30 & 20 & 12 & 22 \\
\cline { 2 - 7 } & Injury & 17 & 22 & 17 & 10 & 20 \\
\hline $\begin{array}{l}\text { Tractor } \\
\text { Trailer }\end{array}$ & Fatal & 7 & 8 & 7 & 6 & 7 \\
\cline { 2 - 7 } & Injury & 1 & 1 & 1 & 1 & 1 \\
\hline \multirow{2}{*}{$\begin{array}{l}\text { Truck }>4536 \\
\text { kg }\end{array}$} & Fatal & 4 & 4 & 4 & 3 & 3 \\
\cline { 2 - 7 } & Injury & 2 & 2 & 1 & 2 & 1 \\
\hline
\end{tabular}

Table 3.26: Percentage Change in Vehicles Involved in Collision Rates By Region

For Vehicle Type Values Between 1984 and 2004.

\begin{tabular}{|l|l|l|l|l|l|l|}
\hline & & National & $\begin{array}{l}\text { Western } \\
\text { Provinces }\end{array}$ & Ontario & Quebec & $\begin{array}{l}\text { Eastern } \\
\text { Provinces }\end{array}$ \\
\hline \multirow{2}{*}{ Automobile } & Fatal & -53 & -40 & -54 & -65 & -48 \\
\cline { 2 - 7 } & Injury & -34 & -21 & -47 & -33 & -18 \\
\hline \multirow{2}{*}{ Bicycle } & Fatal & -70 & -40 & -70 & -76 & -50 \\
\cline { 2 - 7 } & Injury & -50 & -39 & -52 & -59 & -59 \\
\hline \multirow{2}{*}{ Motorcycle } & Fatal & -65 & -40 & -77 & -74 & -62 \\
\cline { 2 - 7 } & Injury & -72 & -57 & -83 & -74 & -67 \\
\hline \multirow{2}{*}{$\begin{array}{l}\text { Pickup }<4536 \\
\text { kg }\end{array}$} & Fatal & -10 & -5 & -20 & +61 & -41 \\
\cline { 2 - 7 } & Injury & +27 & +37 & -9 & +86 & +17 \\
\hline \multirow{2}{*}{$\begin{array}{l}\text { Tractor } \\
\text { Trailer }\end{array}$} & Fatal & -14 & 0 & -30 & +15 & -52 \\
\cline { 2 - 7 } & Injury & -8 & +10 & -36 & +32 & -18 \\
\hline \multirow{2}{*}{$\begin{array}{l}\text { Truck }>4536 \\
\text { kg }\end{array}$} & Fatal & -20 & -38 & 0 & +90 & -67 \\
\cline { 2 - 7 } & Injury & +21 & +18 & -18 & +88 & -28 \\
\hline
\end{tabular}




\subsection{Figures for Chapter 3}

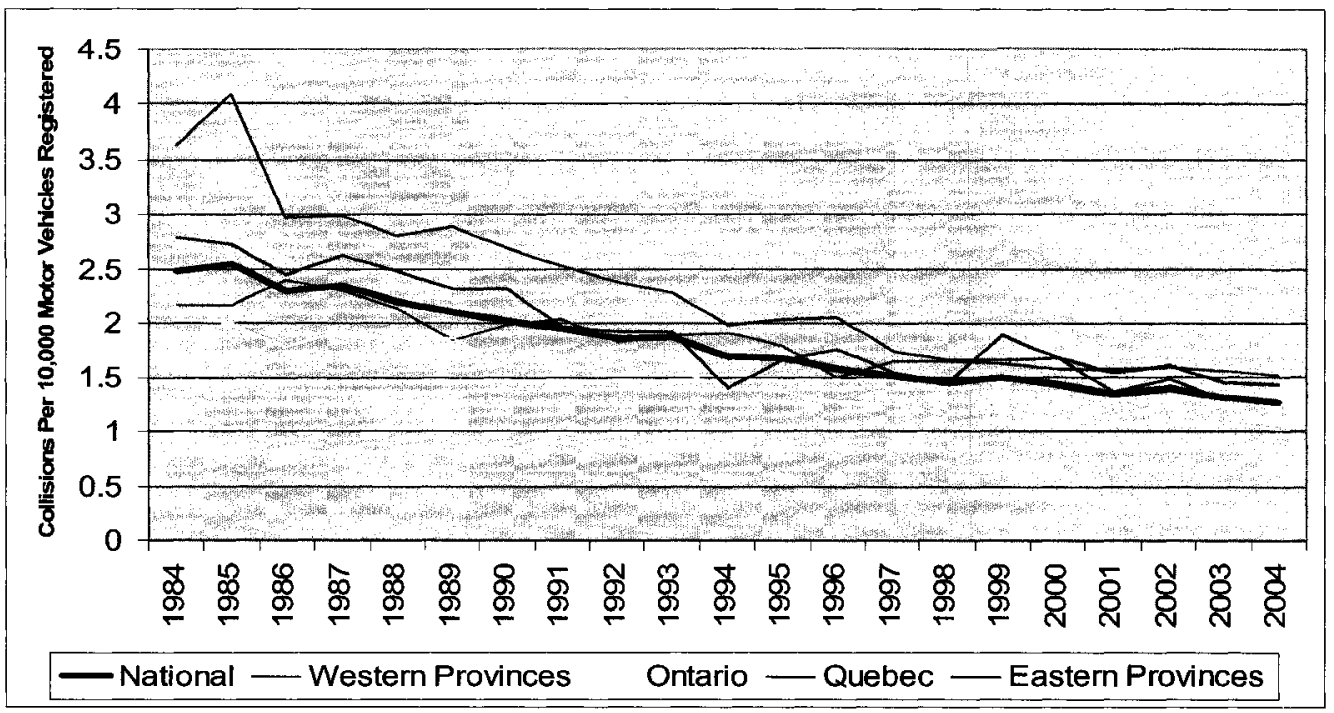

Figure 3.1: Fatal Collisions Per 10,000 Motor Vehicles Registered By Year.

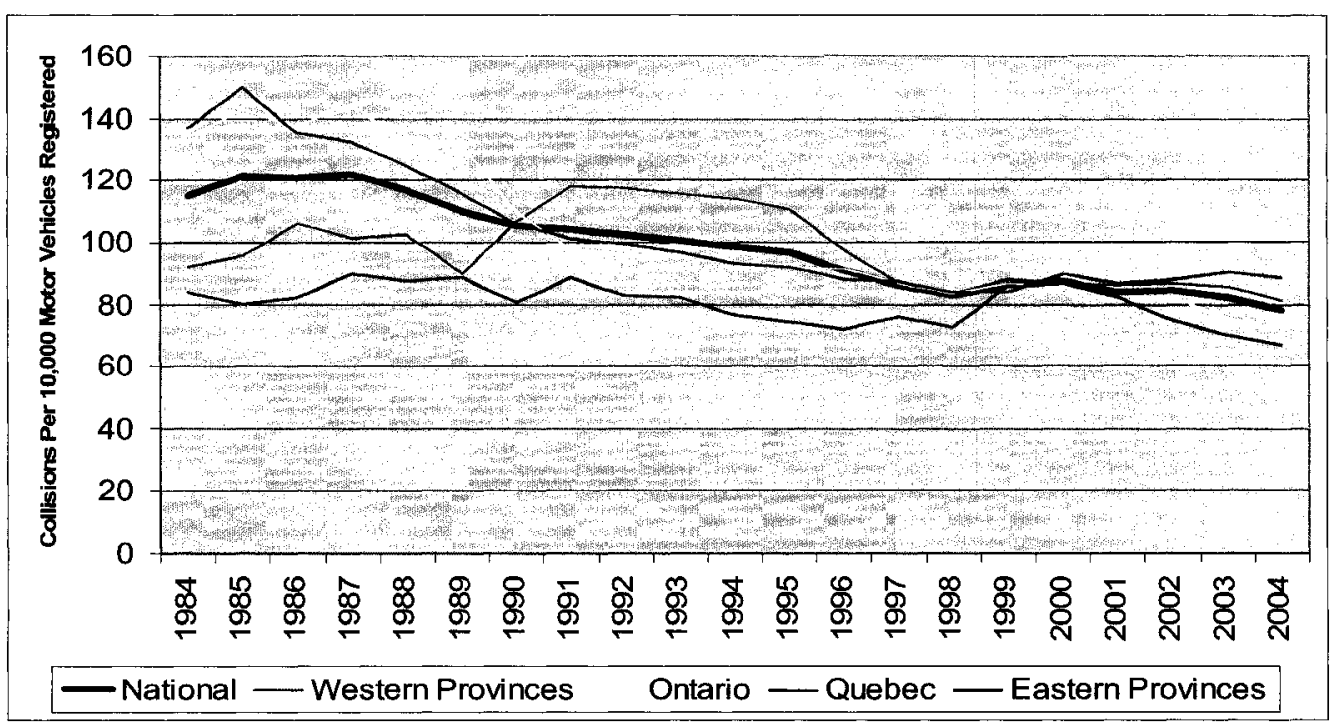

Figure 3.2: Injury Collisions Per 10,000 Motor Vehicles Registered By Year. 


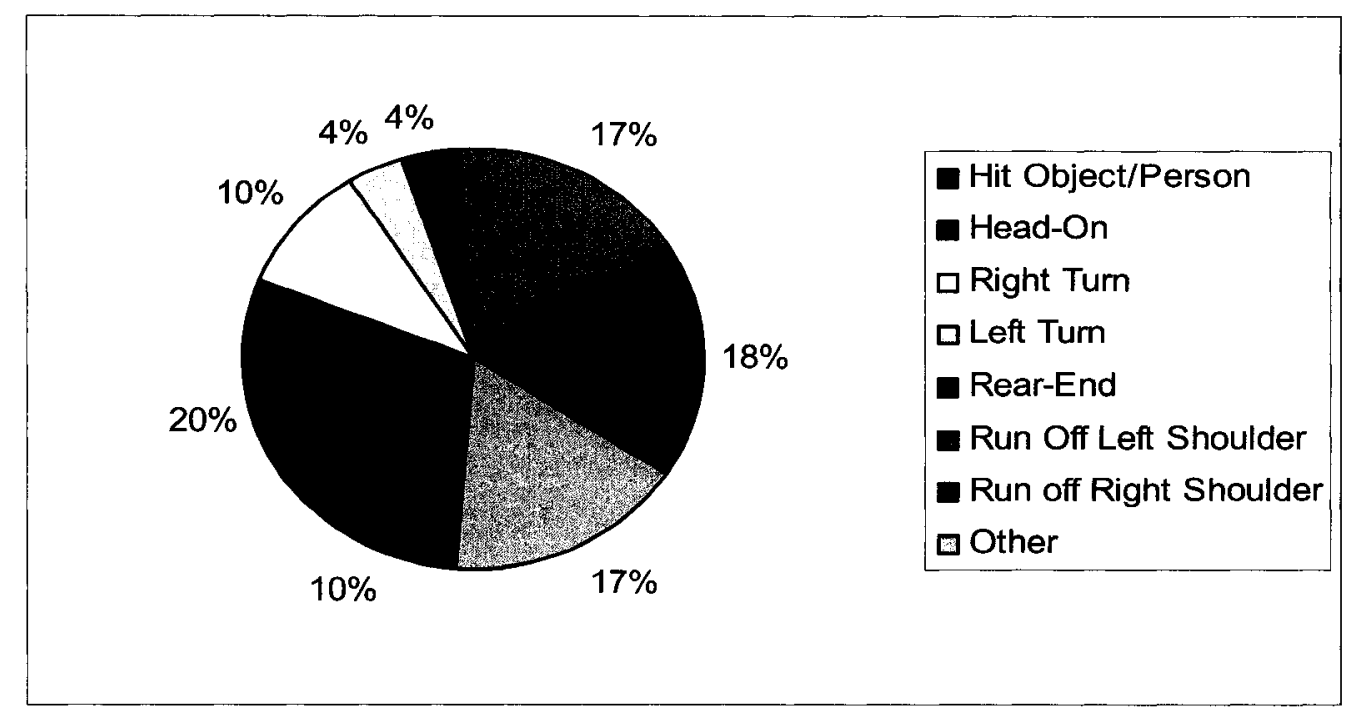

Figure 3.3: Percentage of Fatal Collisions for Collision Configuration Values.

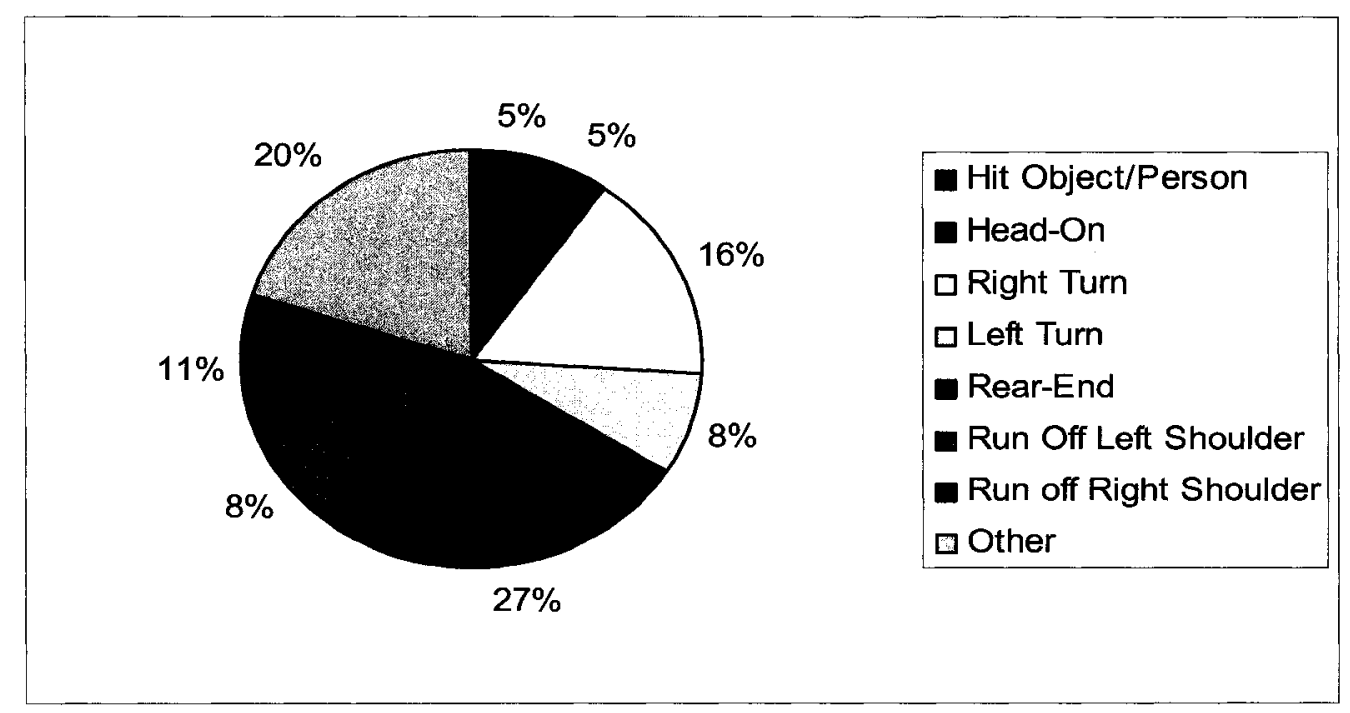

Figure 3.4: Percentage of Injury Collisions for Collision Configuration Values. 


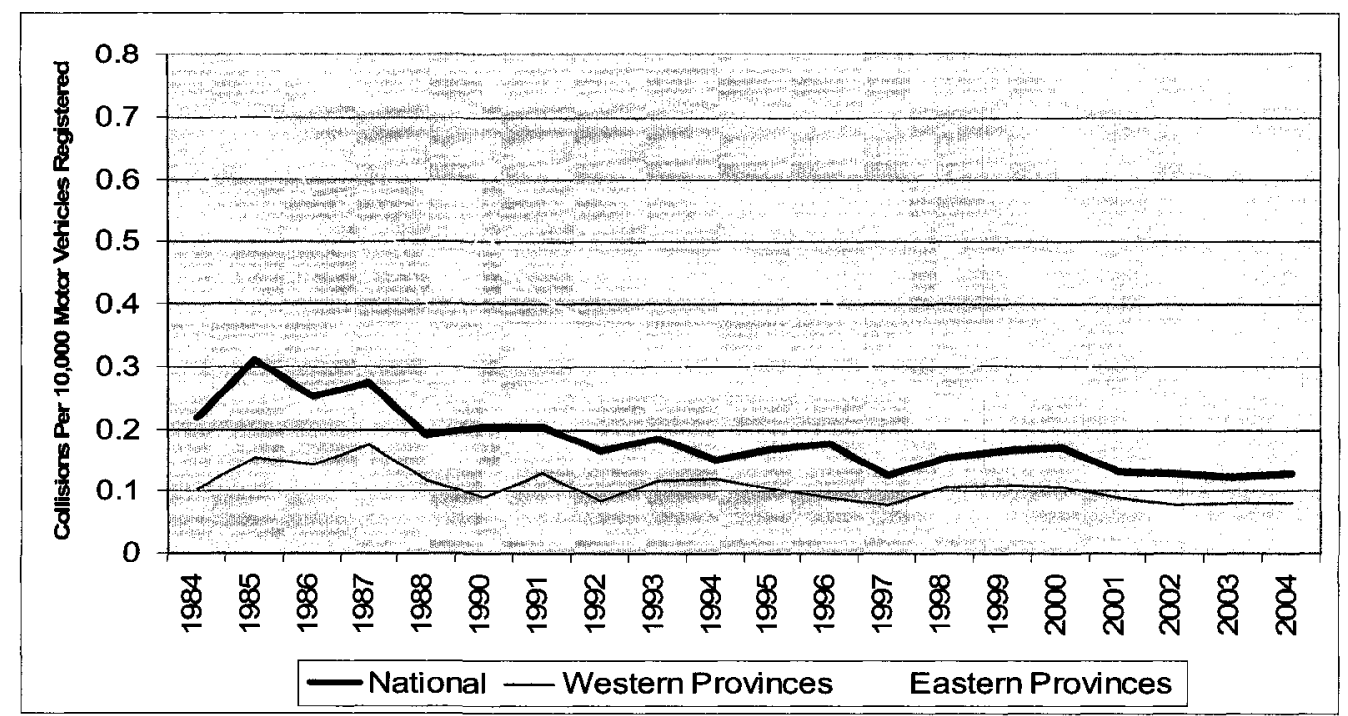

Figure 3.5: Fatal Hit Object/Person Collisions Per 10,000 Motor Vehicles Registered By Year.

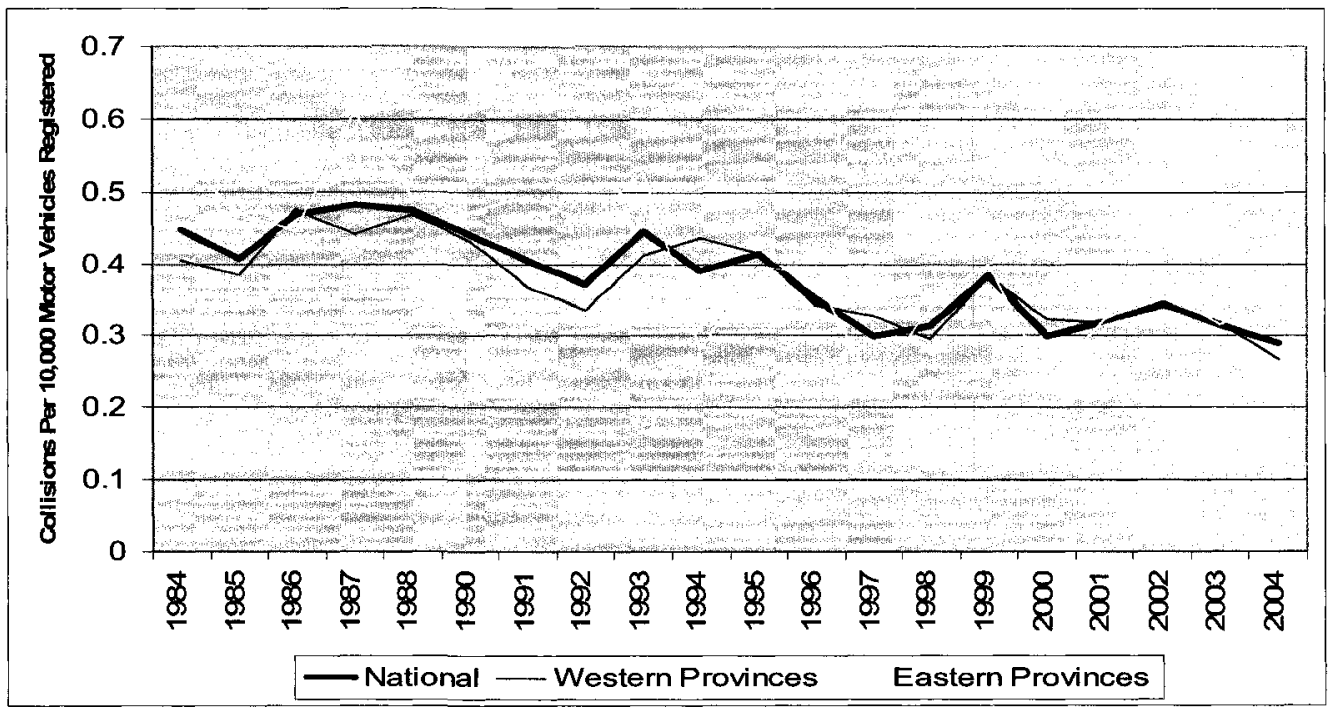

Figure 3.6: Fatal Head-On Collisions Per 10,000 Motor Vehicles Registered By Year. 


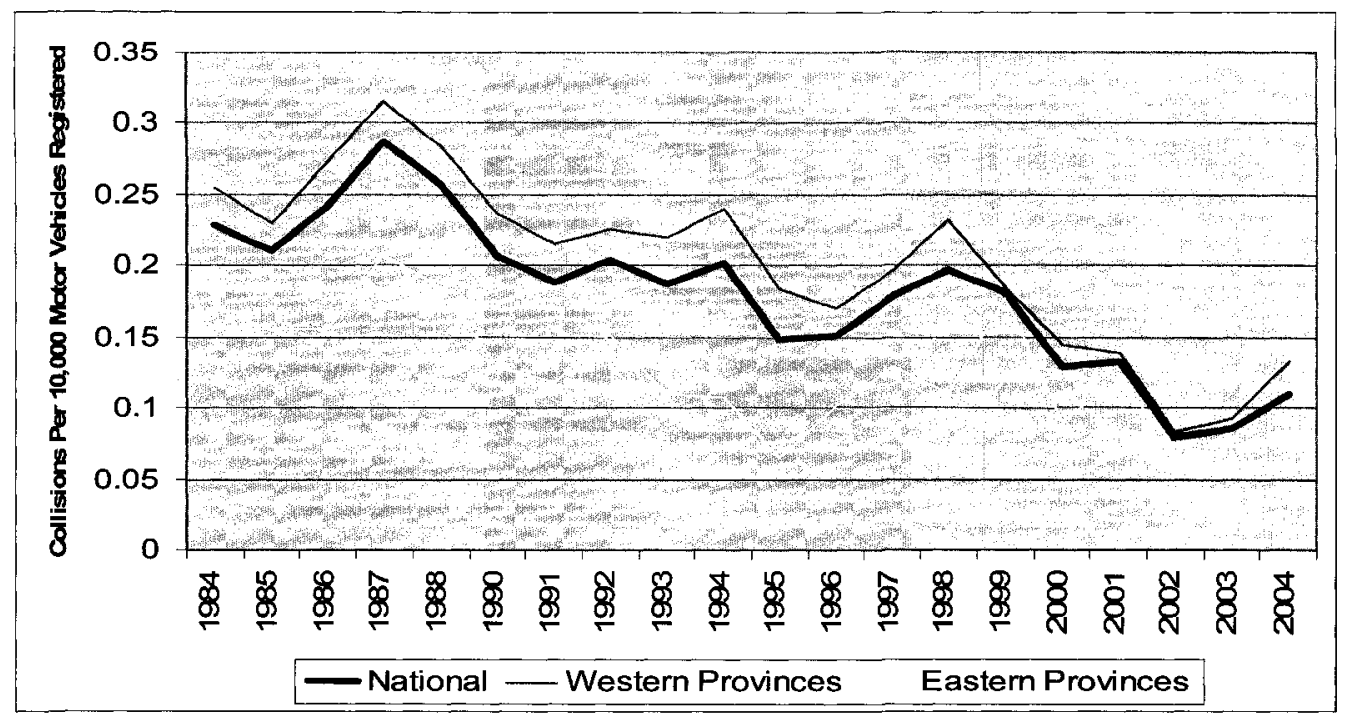

Figure 3.7: Fatal Right-Turn Collisions Per 10,000 Motor Vehicles Registered By Year.

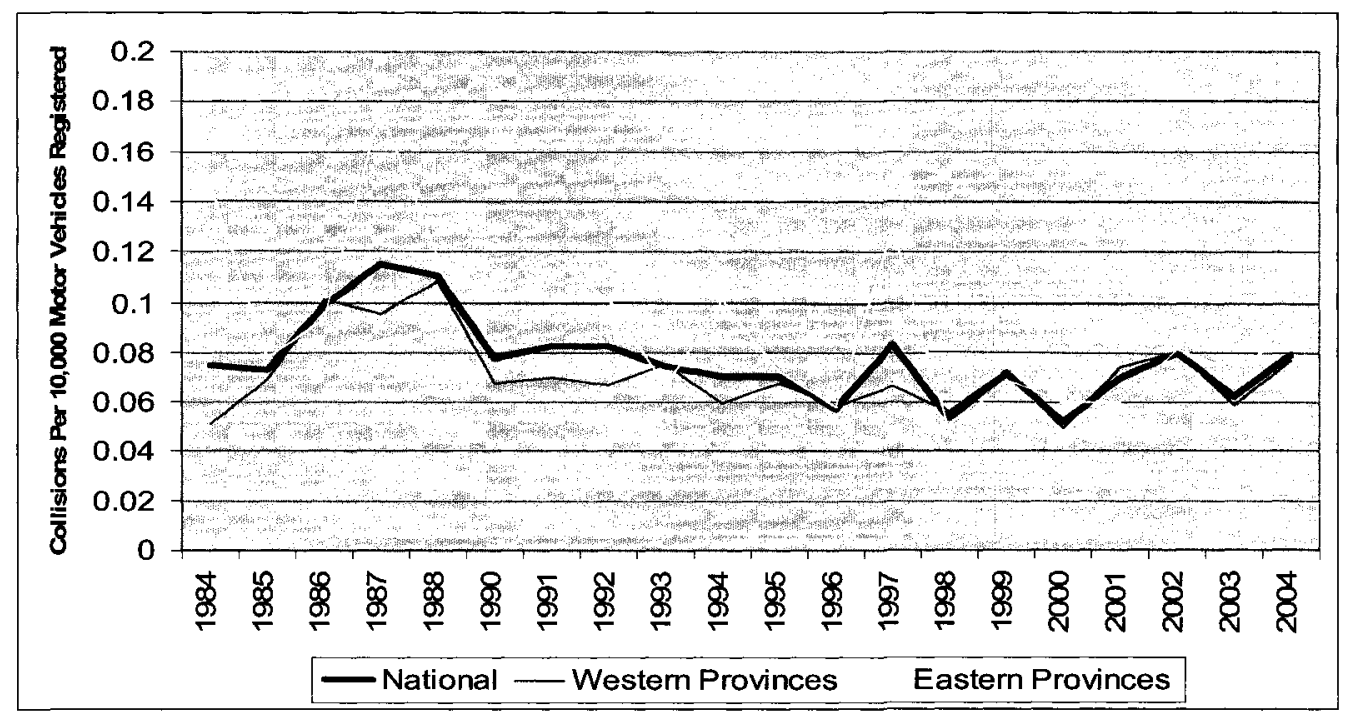

Figure 3.8: Fatal Left-Turn Collisions Per 10,000 Motor Vehicles Registered By Year. 


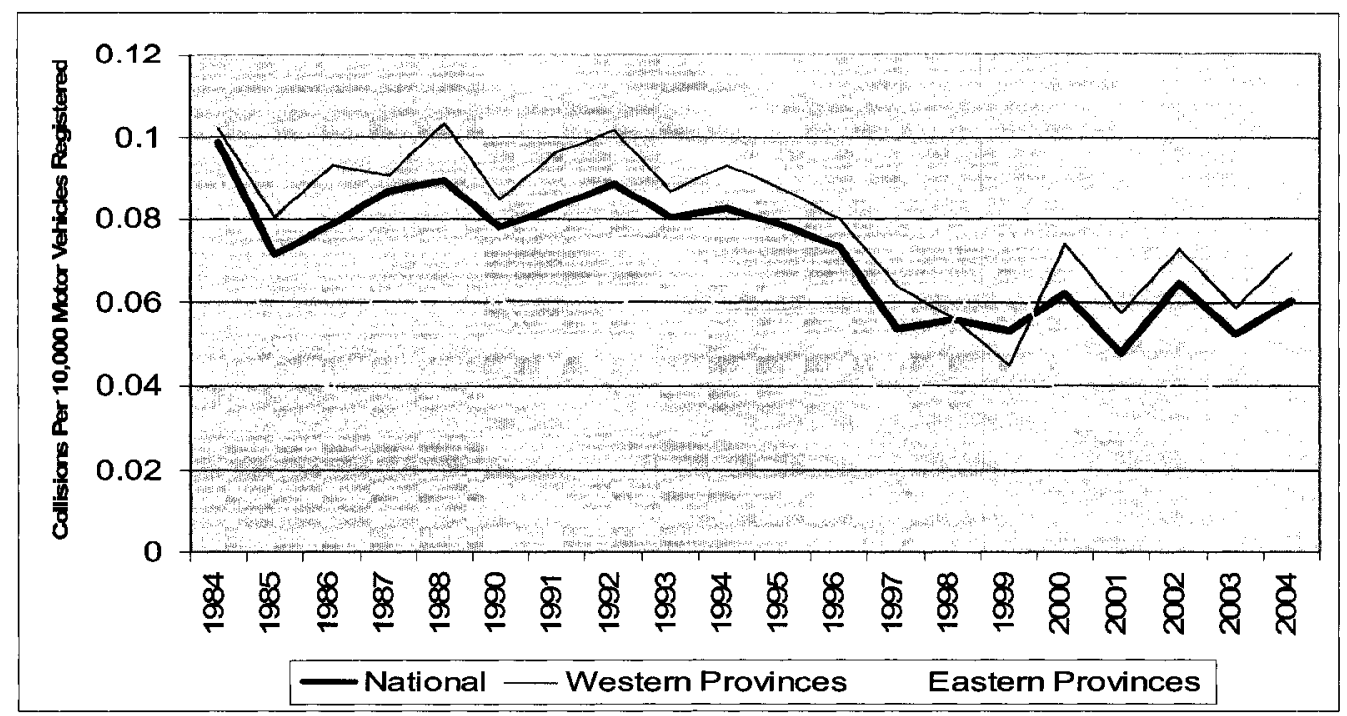

Figure 3.9: Fatal Rear-End Collisions Per 10,000 Motor Vehicles Registered By Year.

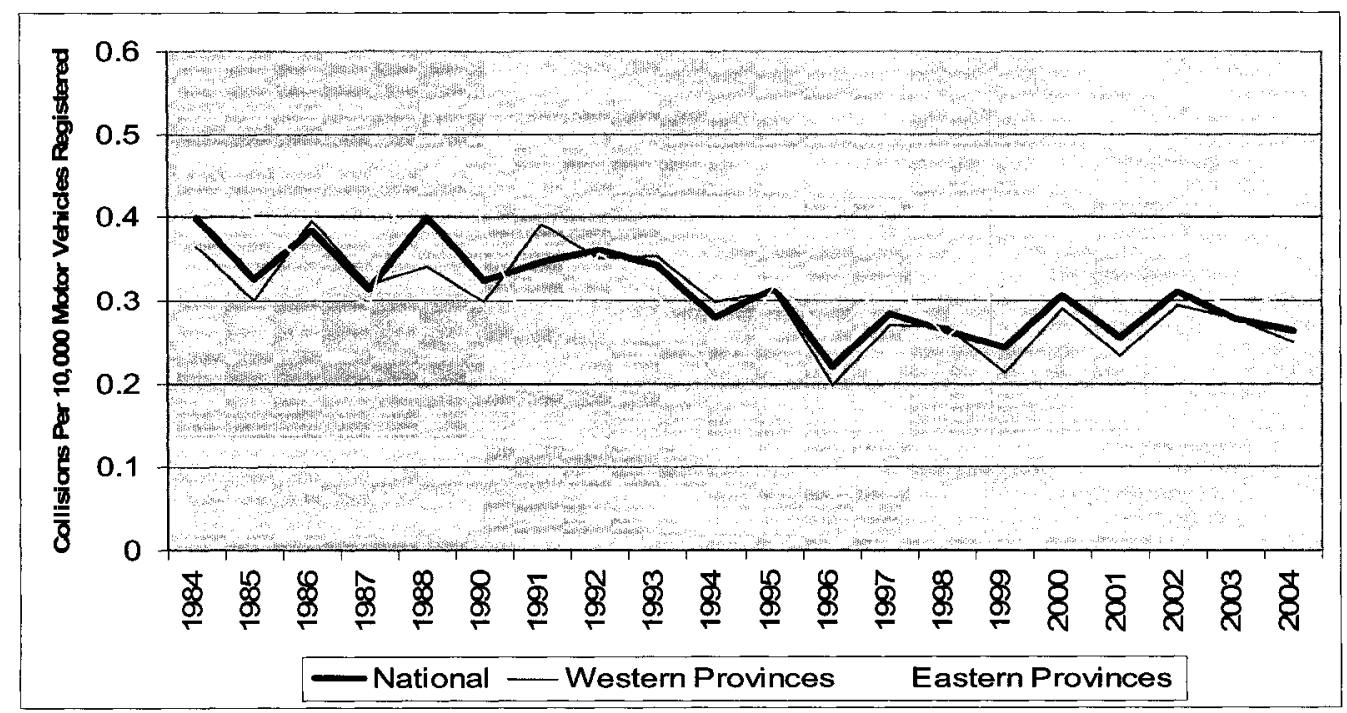

Figure 3.10: Fatal Run Off Left Shoulder Collisions Per 10,000 Motor Vehicles Registered By Year. 


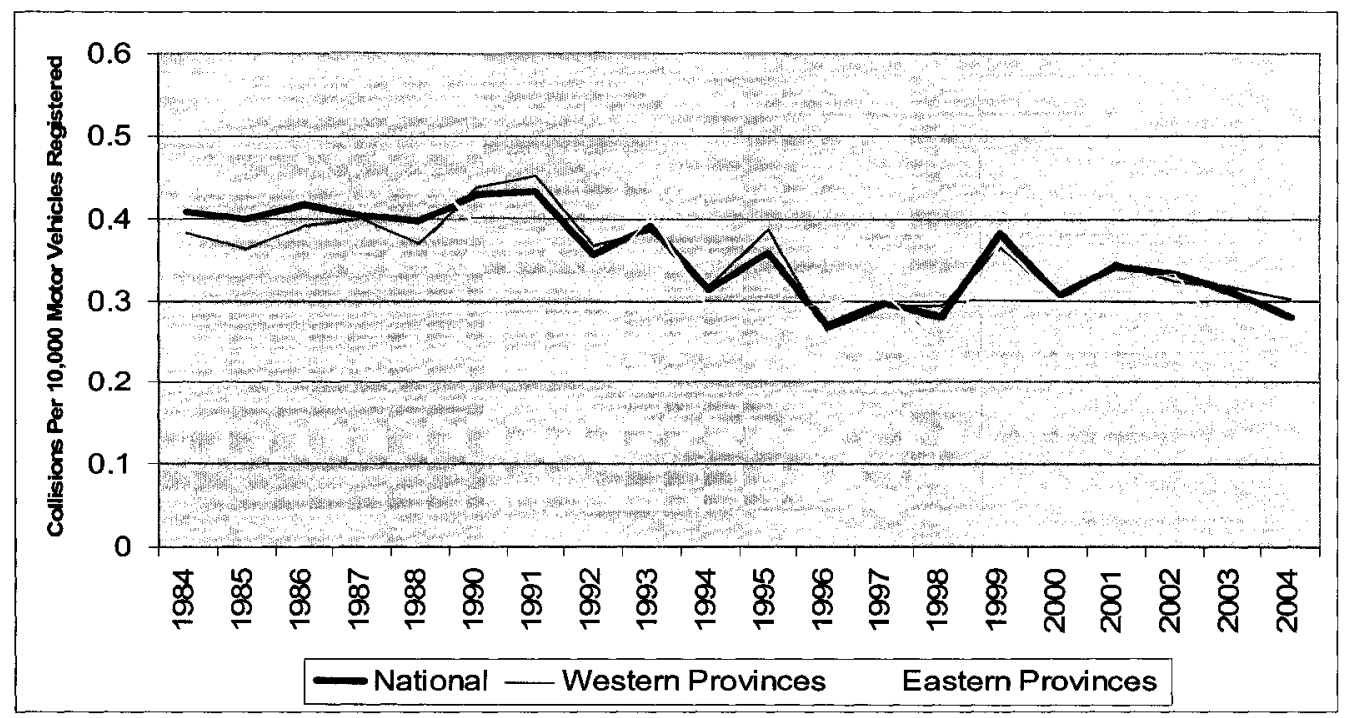

Figure 3.11: Fatal Run Off Right Shoulder Collisions Per 10,000 Motor Vehicles Registered By Year.

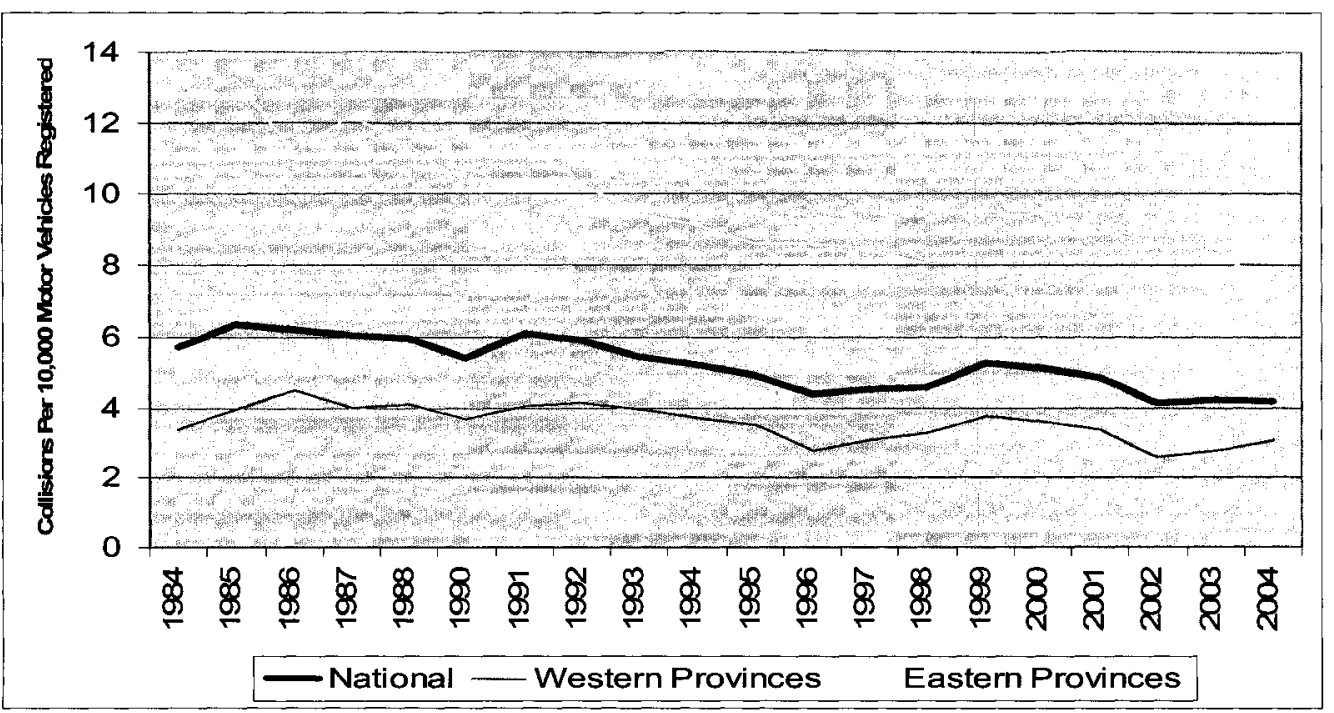

Figure 3.12: Injury Hit Object/Person Collisions Per 10,000 Motor Vehicles

\section{Registered By Year.}




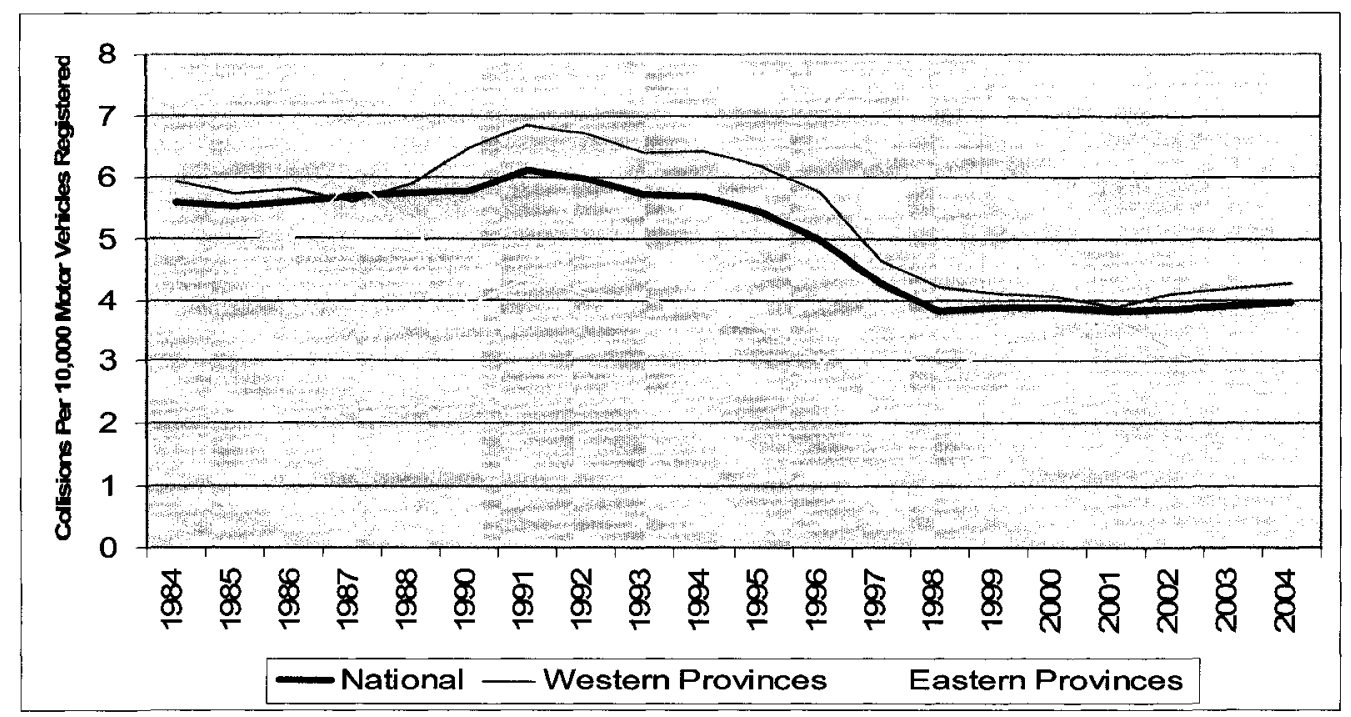

Figure 3.13: Injury Head-On Collisions Per 10,000 Motor Vehicles Registered By Year.

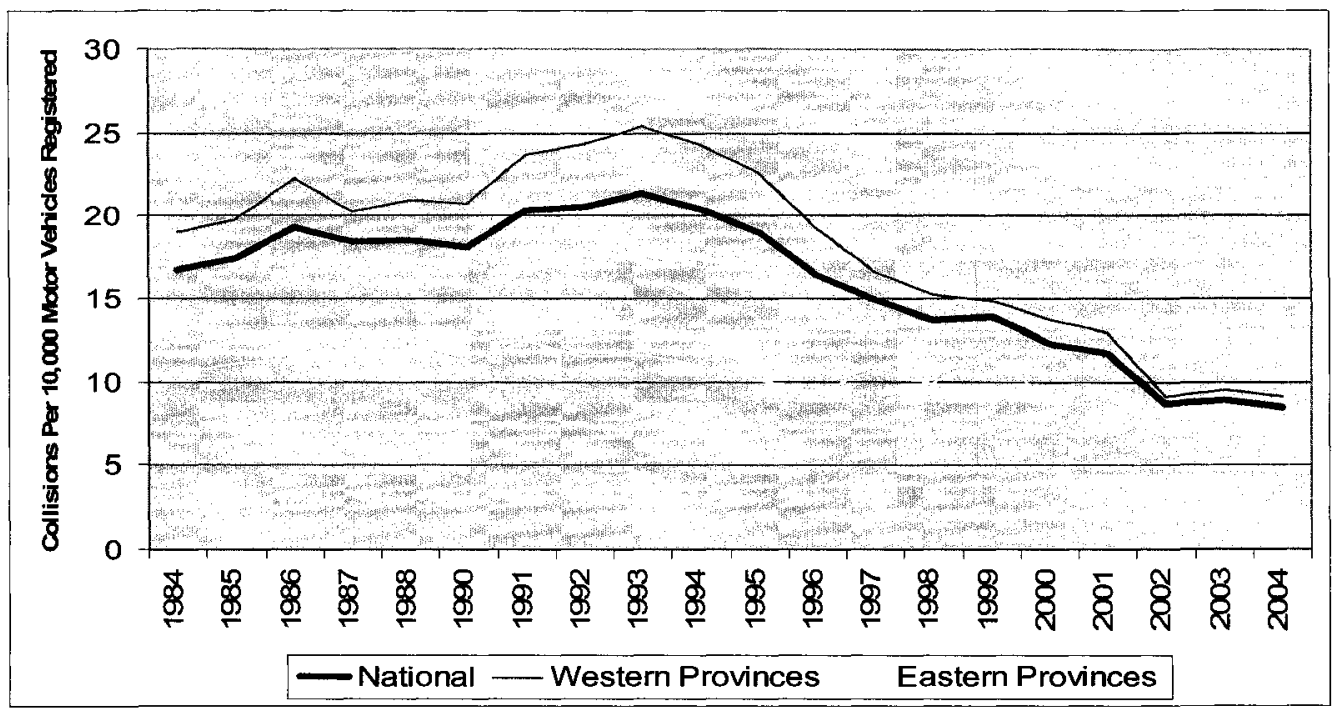

Figure 3.14: Injury Right-Turn Collisions Per 10,000 Motor Vehicles Registered By Year. 


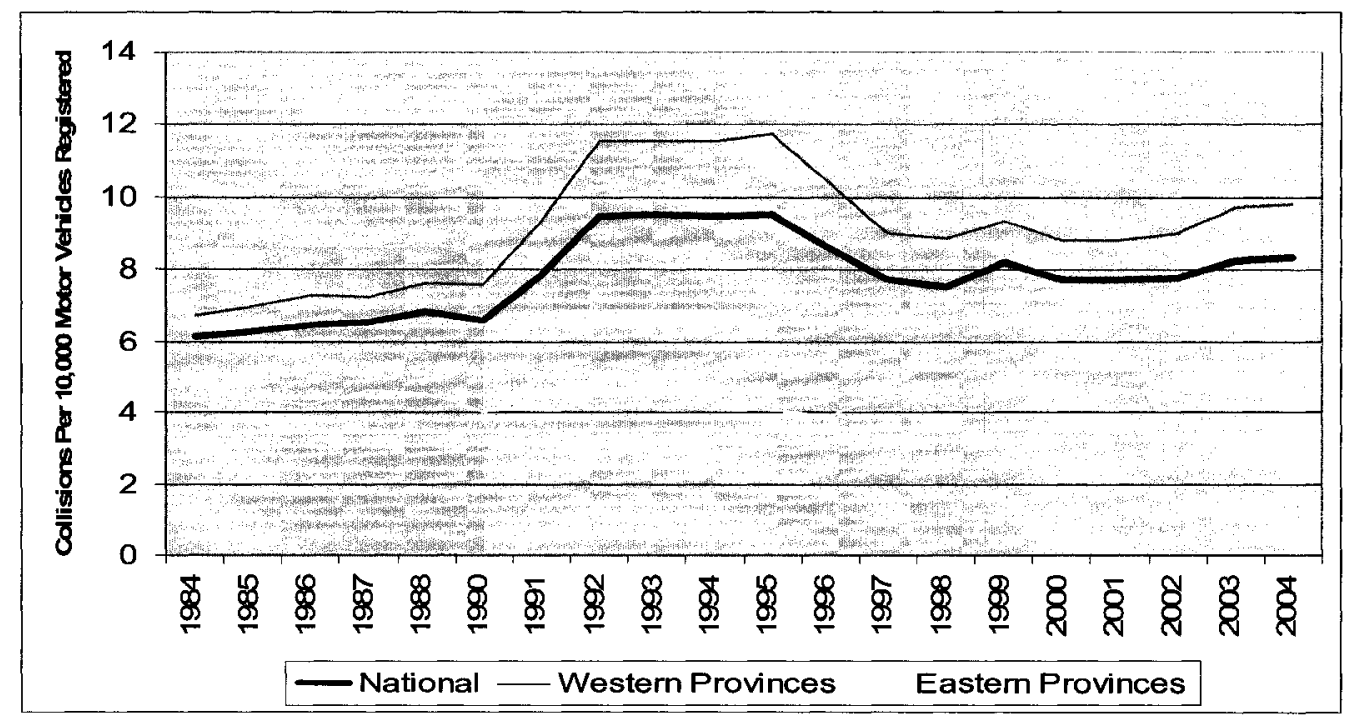

Figure 3.15: Injury Left-Turn Collisions Per 10,000 Motor Vehicles Registered By Year.

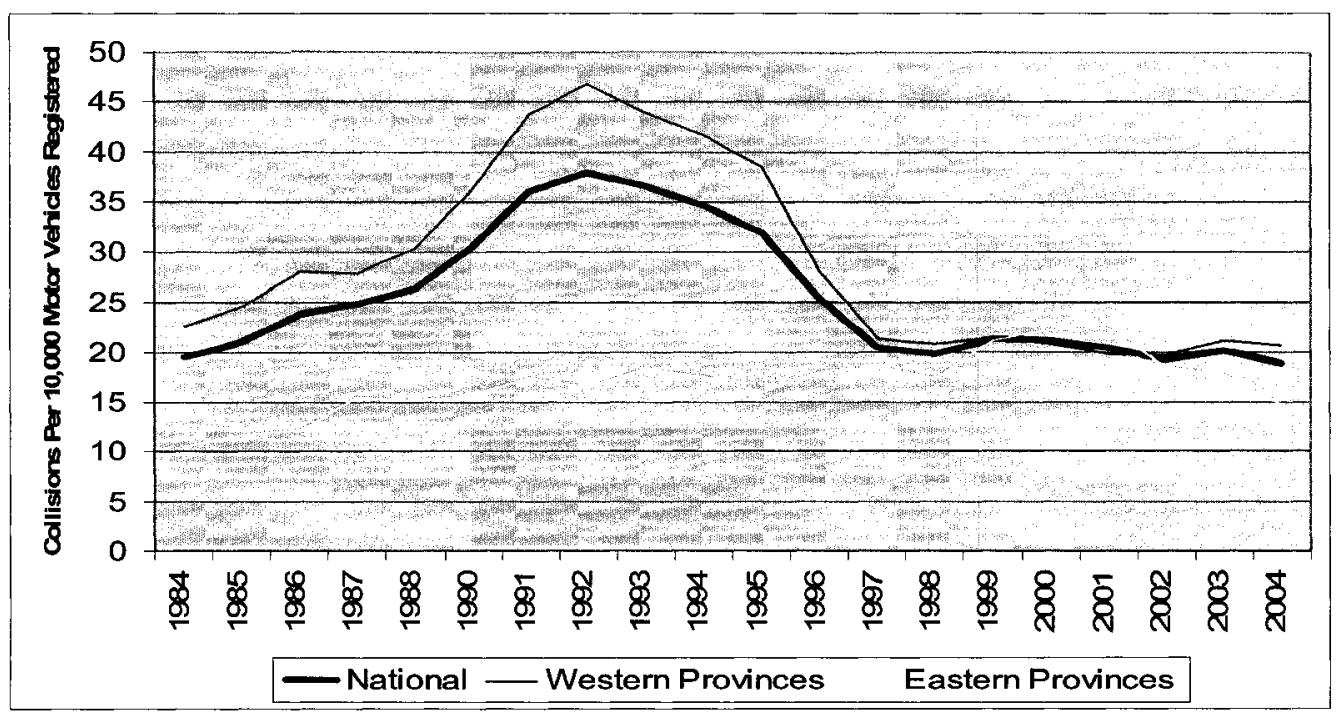

Figure 3.16: Injury Rear-End Collisions Per 10,000 Motor Vehicles Registered By Year. 


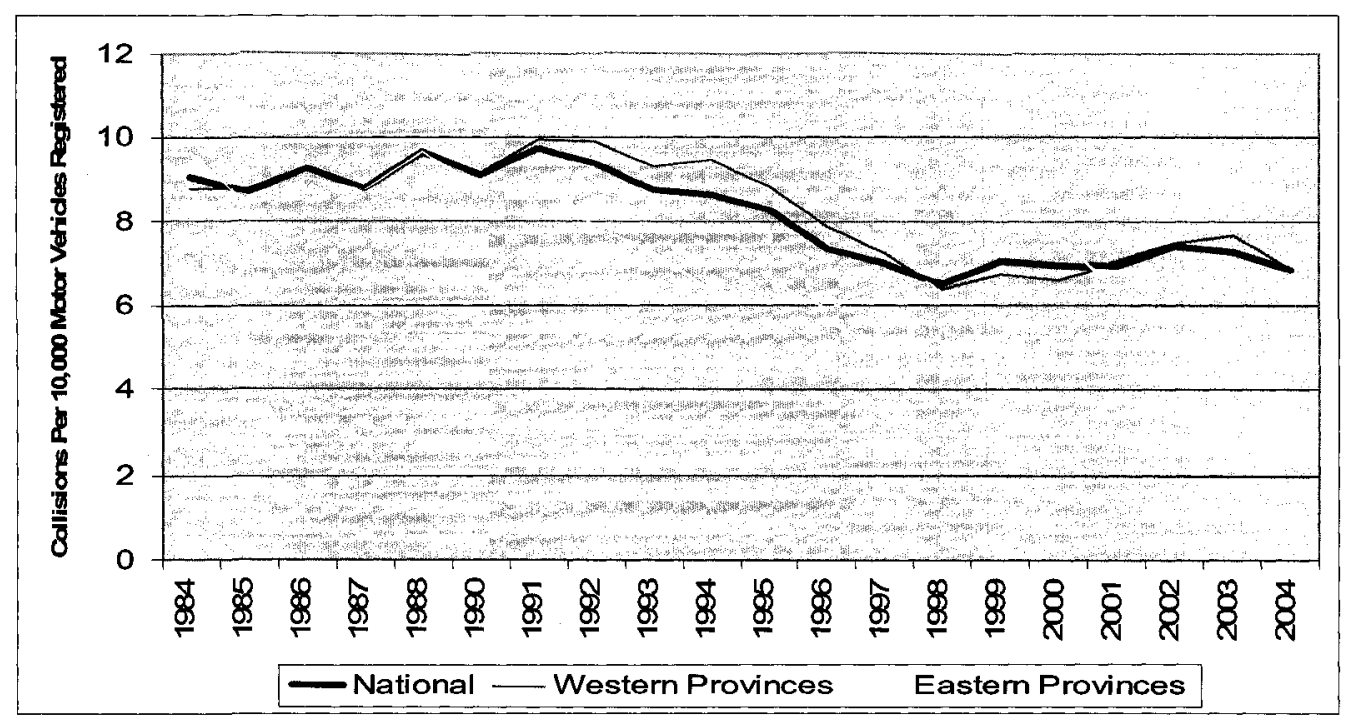

Figure 3.17: Injury Run Off Left Shoulder Collisions Per 10,000 Motor Vehicles Registered By Year.

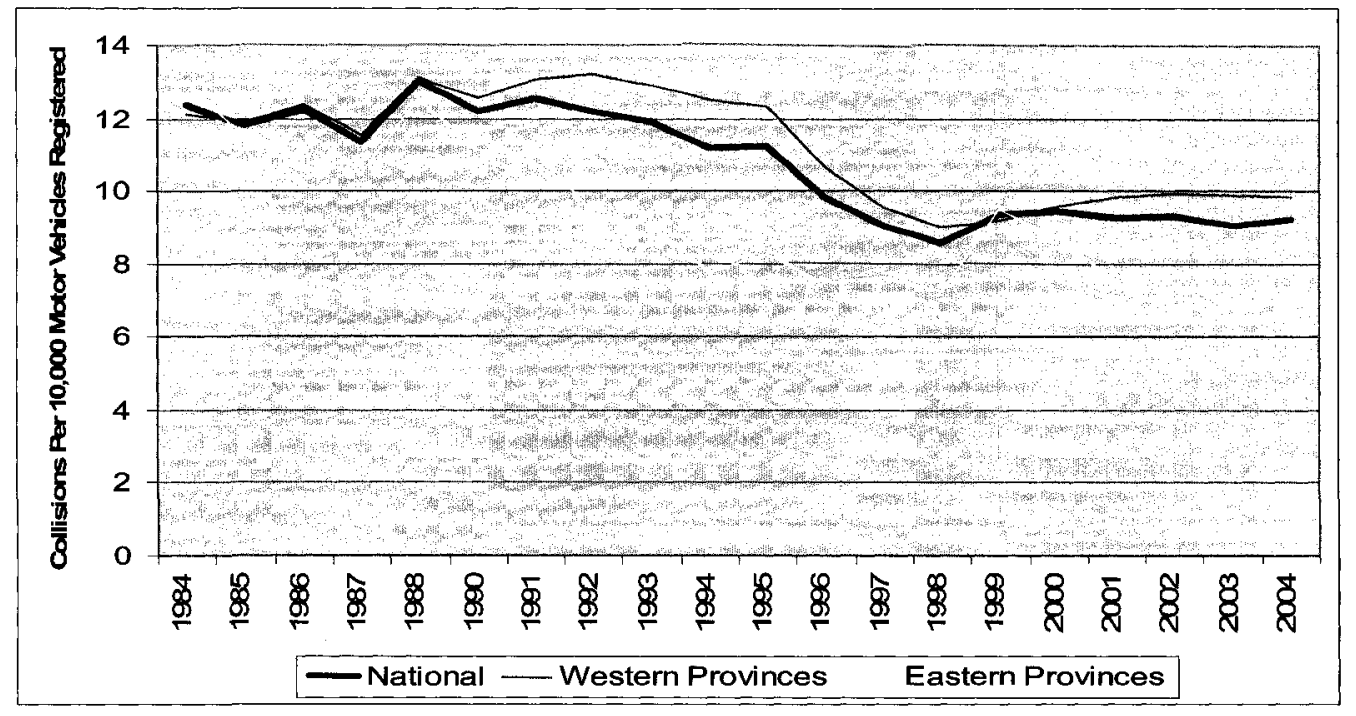

Figure 3.18: Injury Run Off Right Shoulder Collisions Per 10,000 Motor Vehicles Registered By Year. 


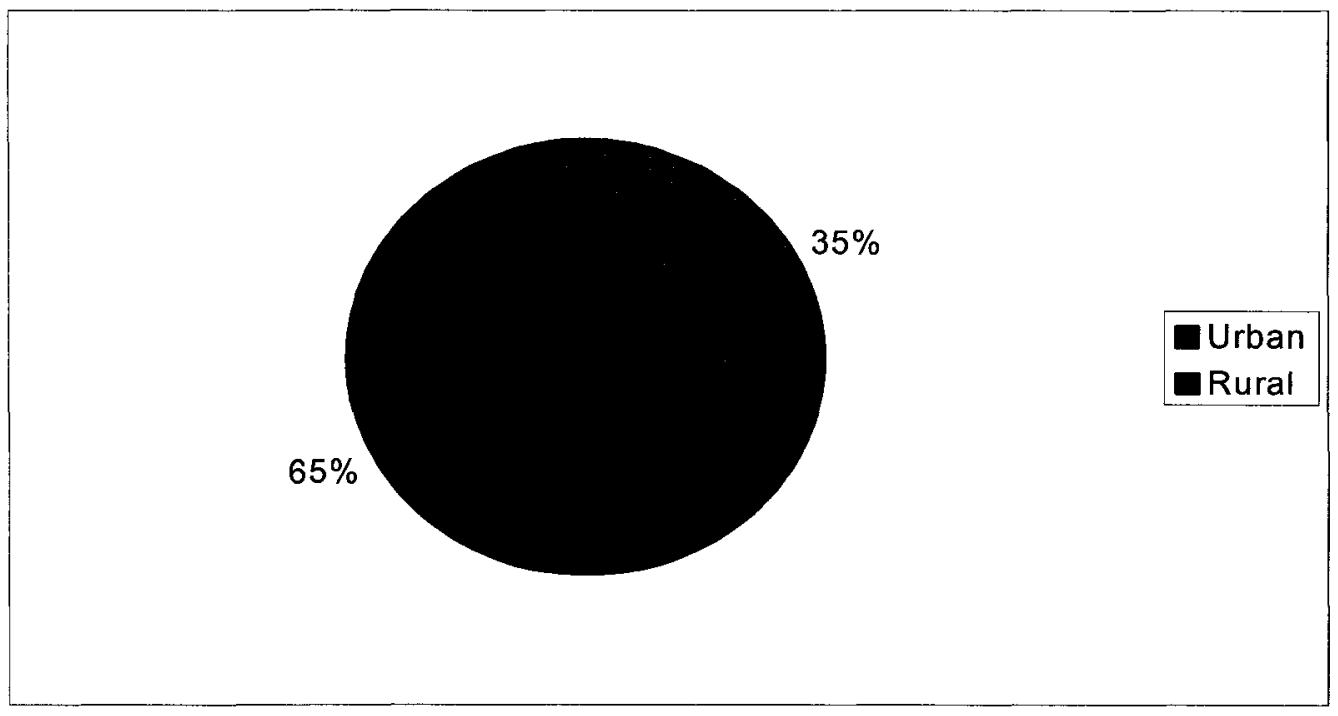

Figure 3.19: Percentage of Fatal Collisions for Road Classification Values.

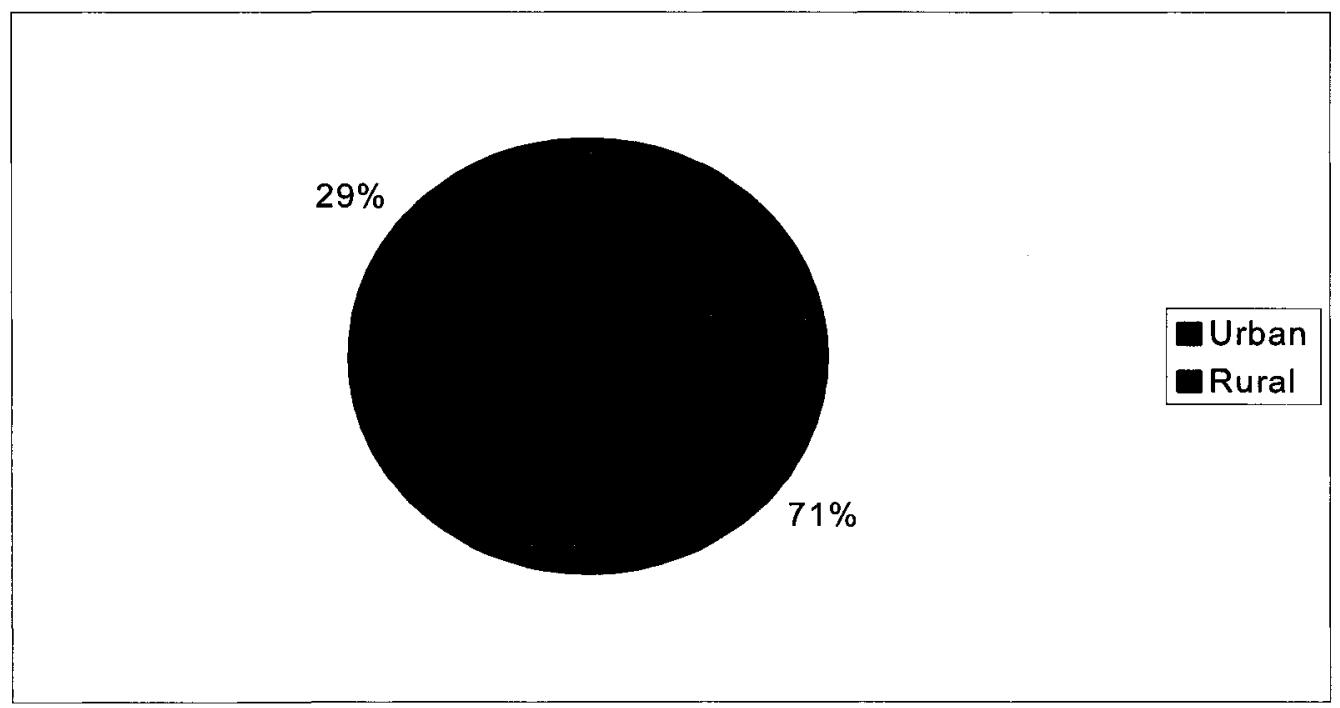

Figure 3.20: Percentage of Injury Collisions for Road Classification Values. 


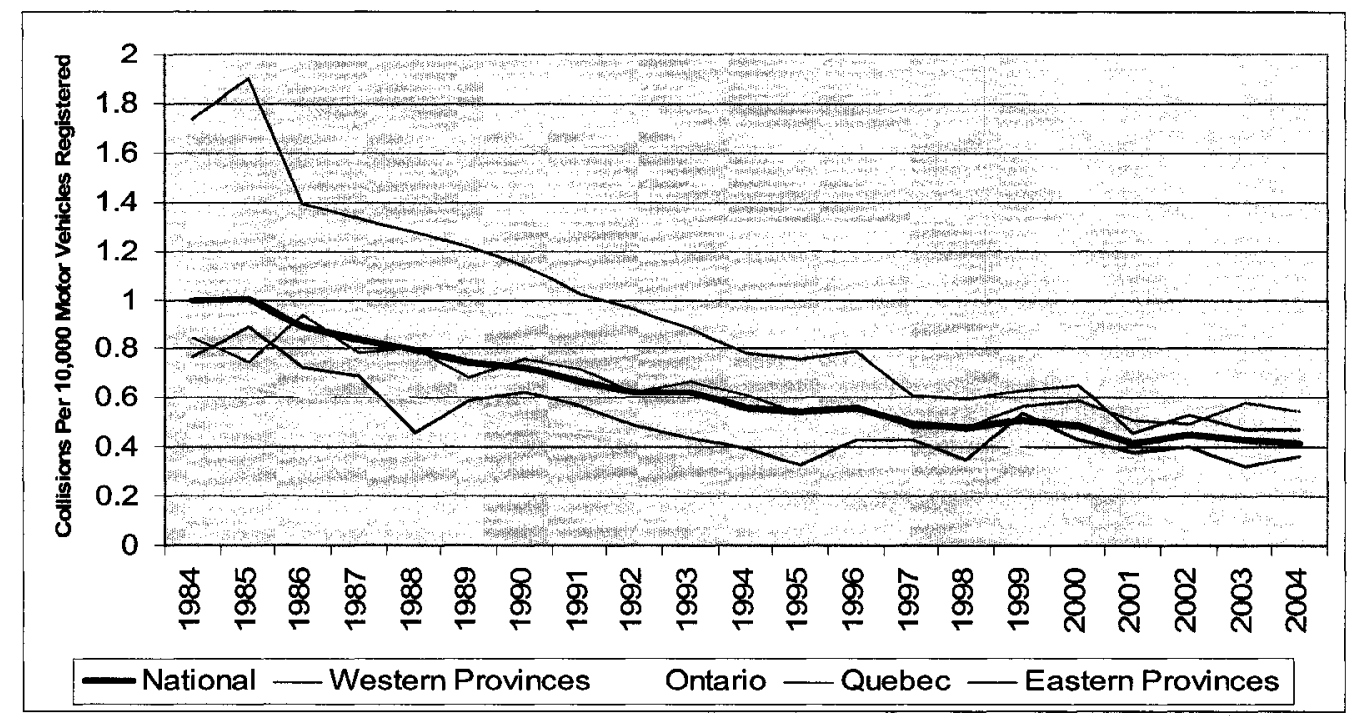

Figure 3.21: Fatal Urban Collisions Per 10,000 Motor Vehicles Registered By Year.

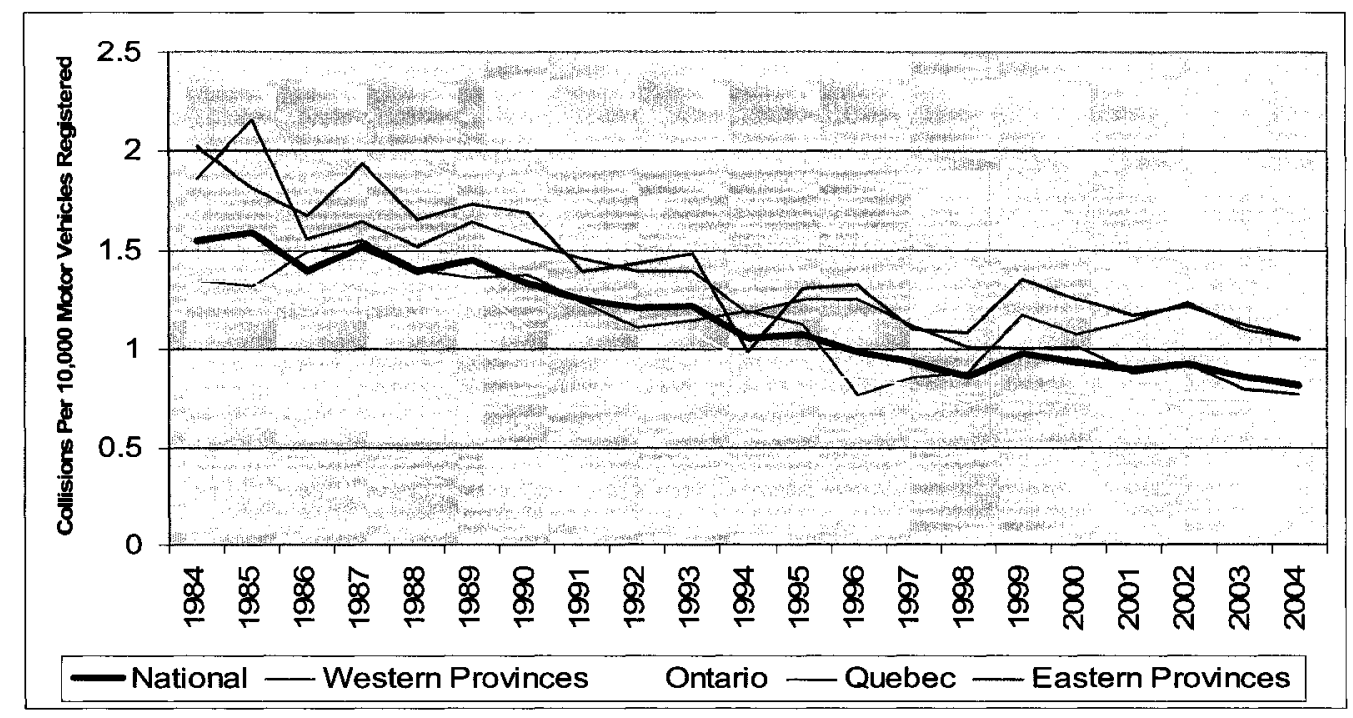

Figure 3.22: Fatal Rural Collisions Per 10,000 Motor Vehicles Registered By Year. 


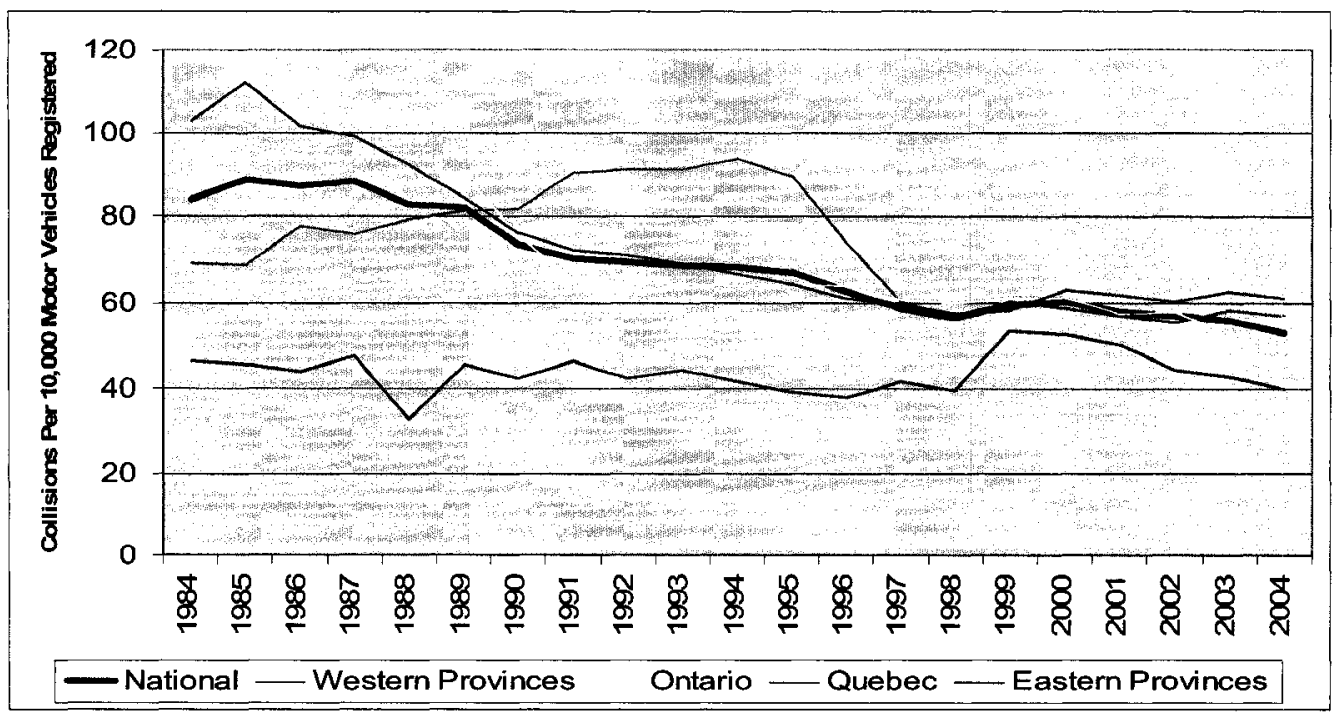

Figure 3.23: Injury Urban Collisions Per 10,000 Motor Vehicles Registered By Year.

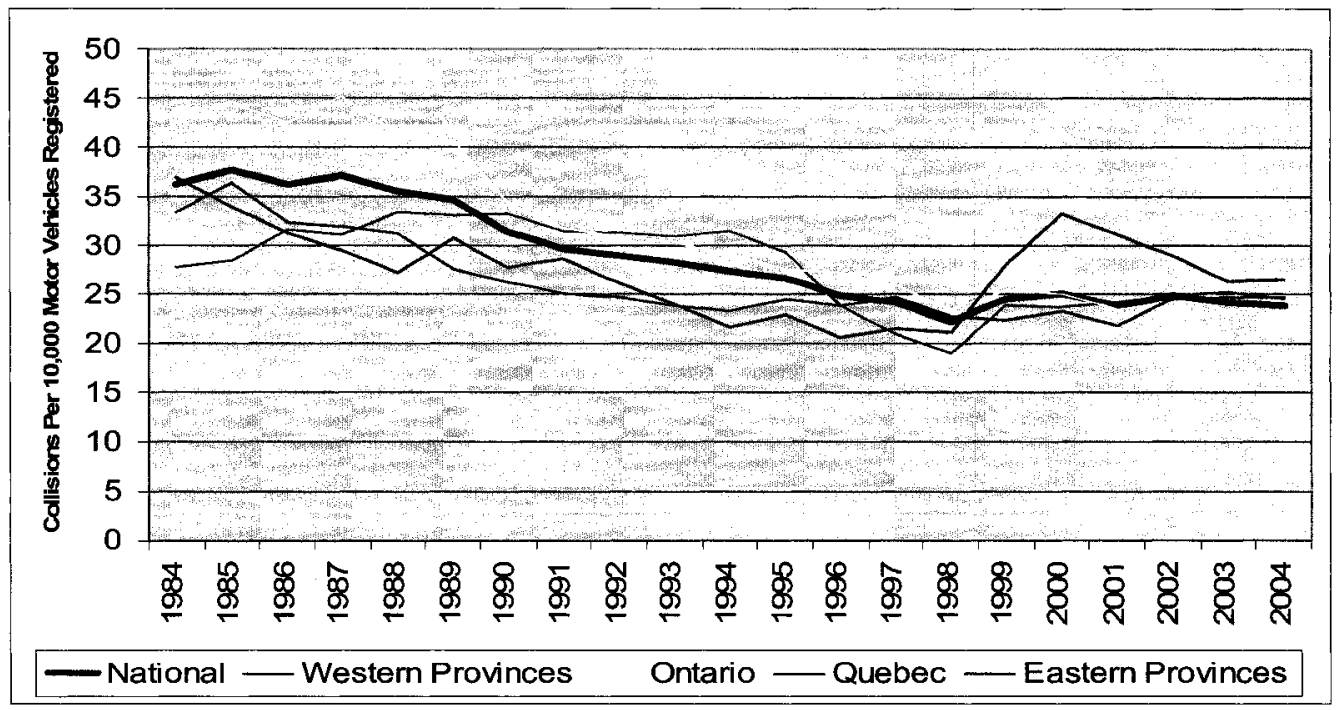

Figure 3.24: Injury Rural Collisions Per 10,000 Motor Vehicles Registered By Year. 


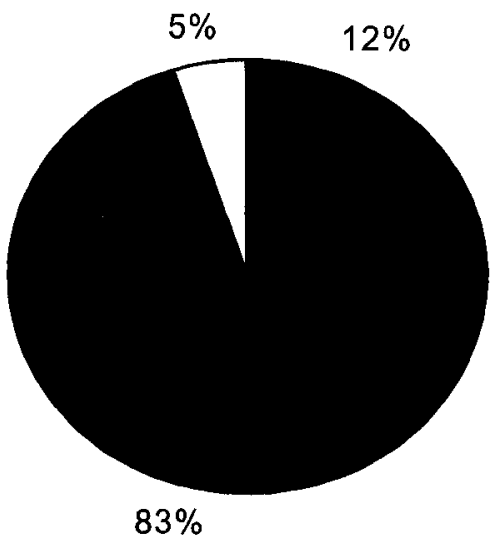

Divided

Undivided

口Other

Figure 3.25: Percentage of Fatal Collisions for Road Category Values.

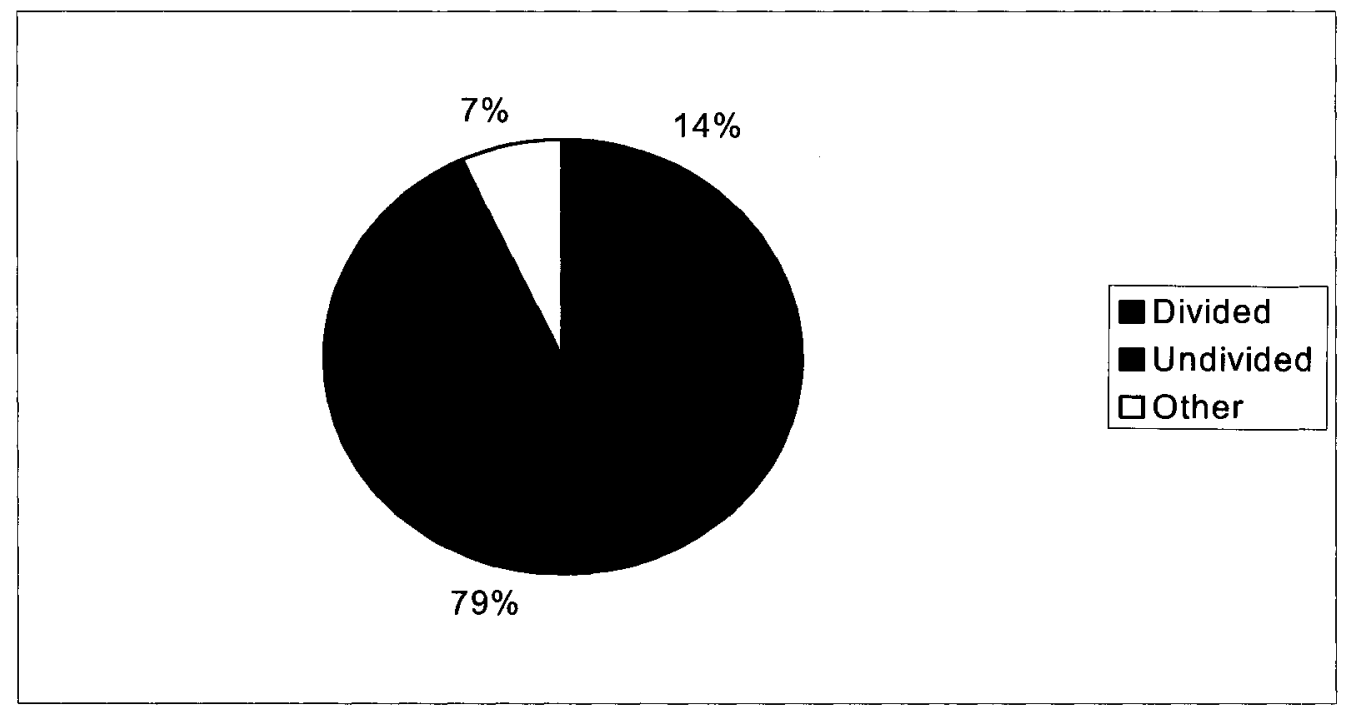

Figure 3.26: Percentage of Injury Collisions for Road Category Values. 


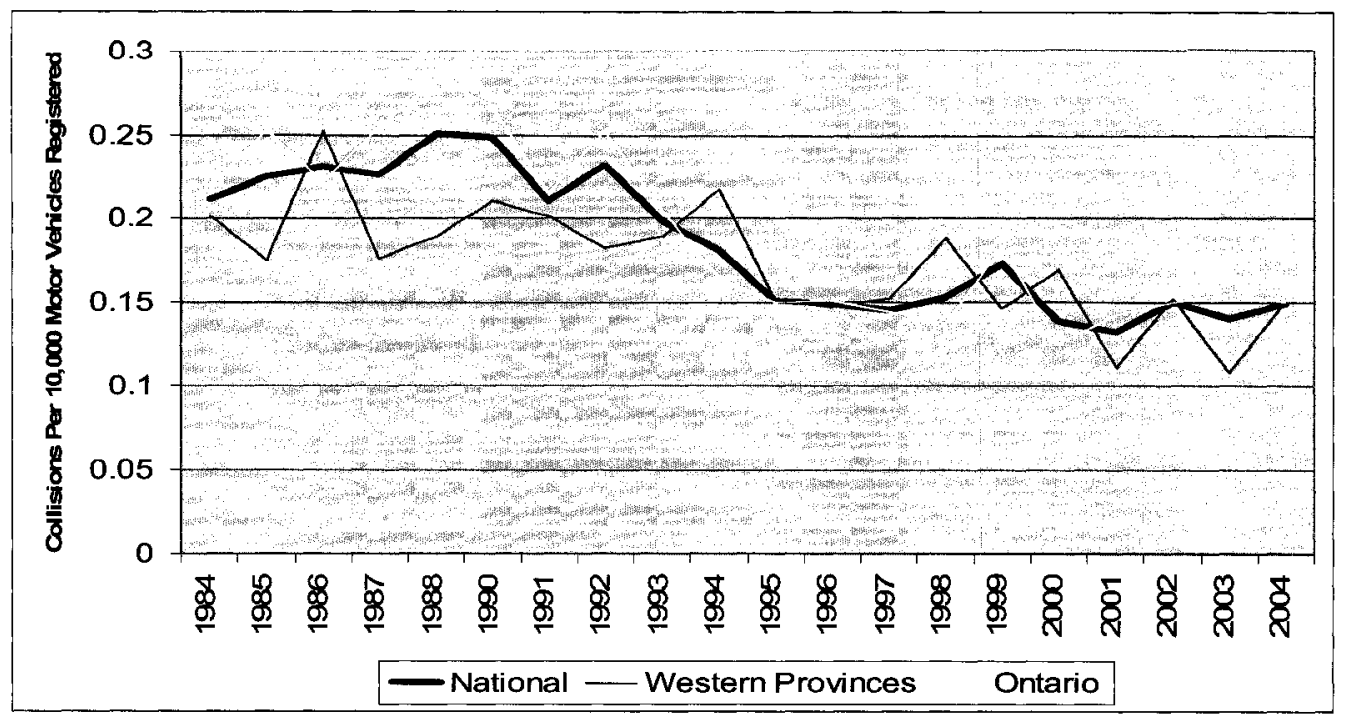

Figure 3.27: Fatal Divided Road Collisions Per 10,000 Motor Vehicles Registered By Year.

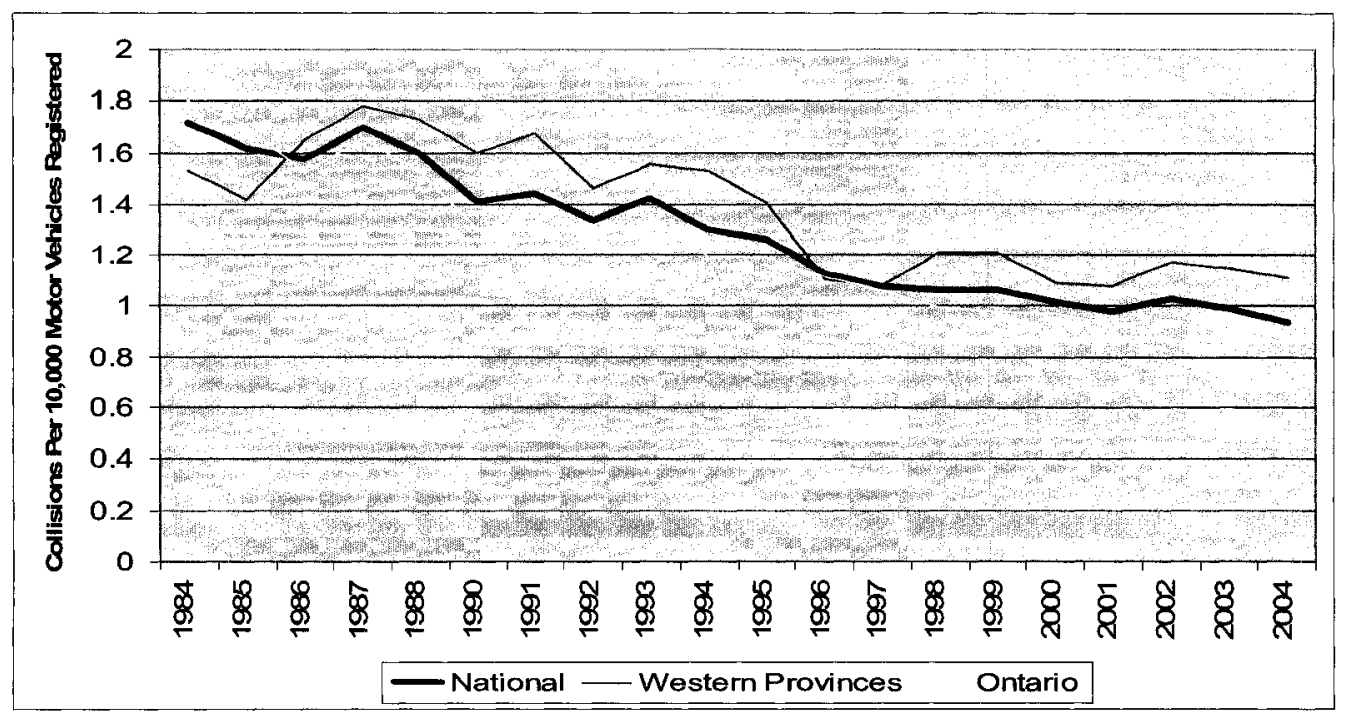

Figure 3.28: Fatal Undivided Road Collisions Per 10,000 Motor Vehicles Registered By Year. 


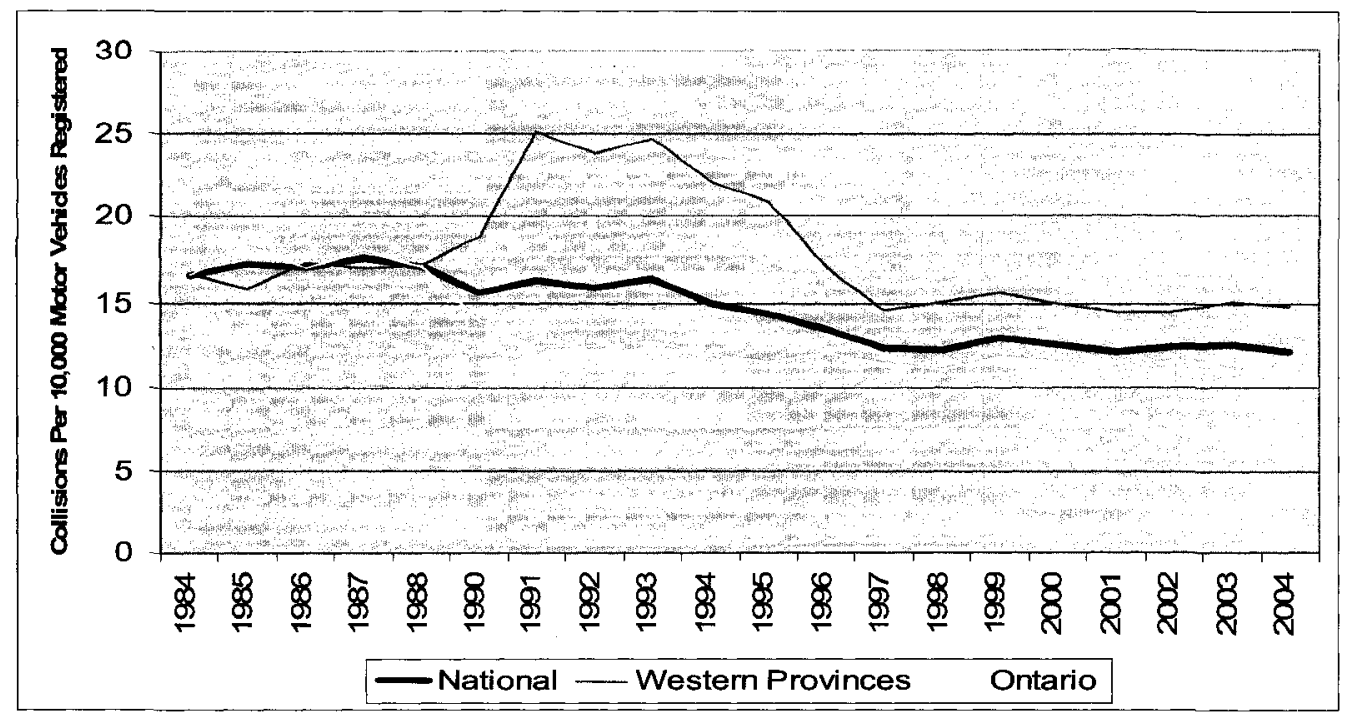

Figure 3.29: Injury Divided Road Collisions Per 10,000 Motor Vehicles Registered By Year.

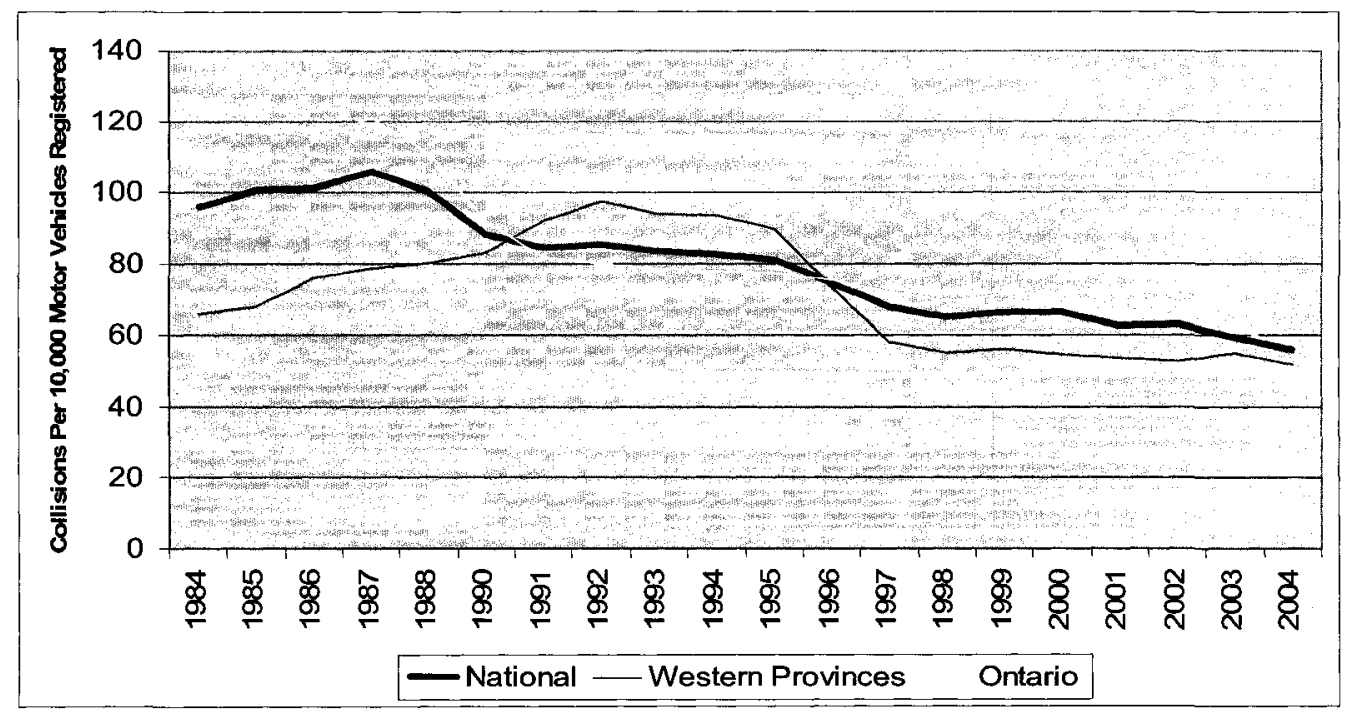

Figure 3.30: Injury Undivided Road Collisions Per 10,000 Motor Vehicles

\section{Registered By Year.}




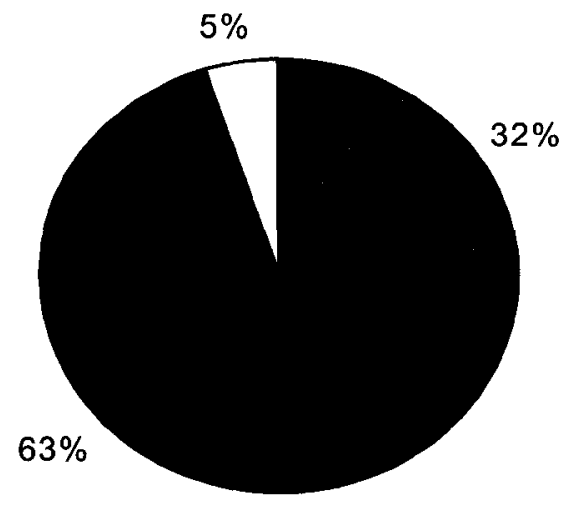

Intersection

Non-Intersection $\square$ Other

Figure 3.31: Percentage of Fatal Collisions for Road Configuration Values.

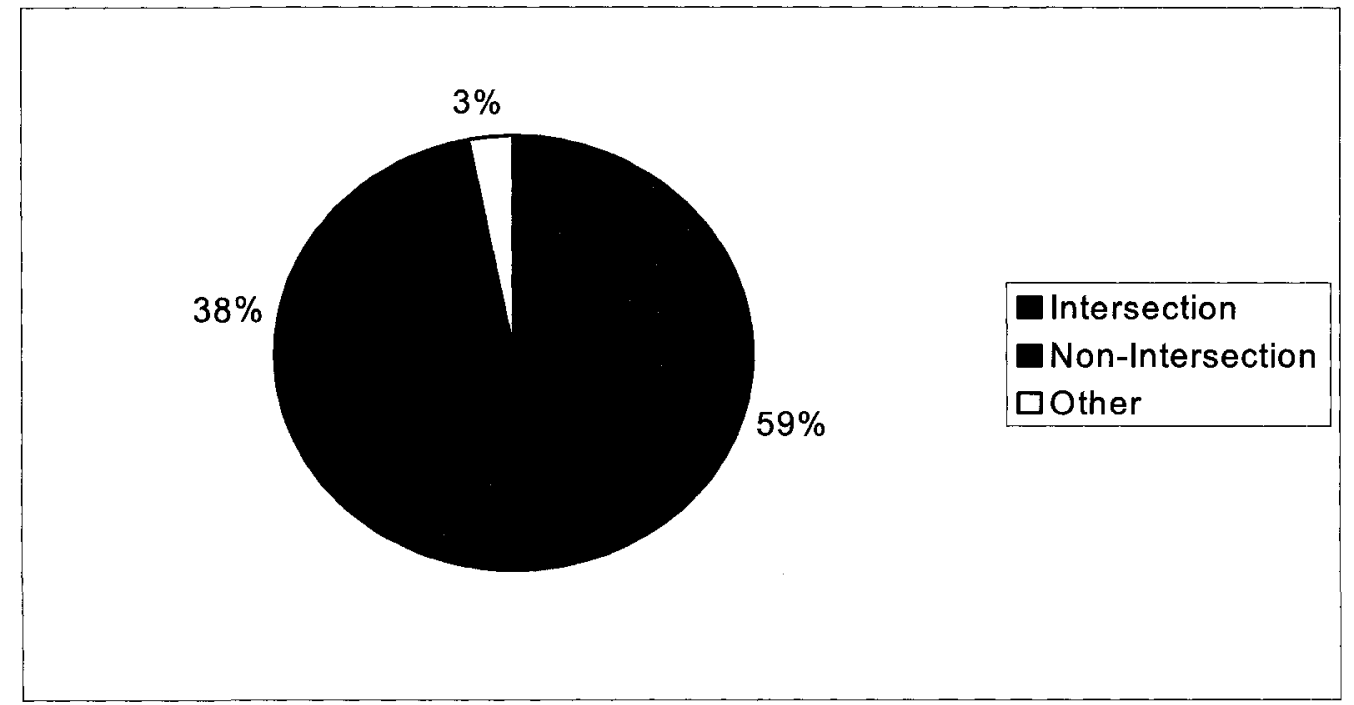

Figure 3.32: Percentage of Injury Collisions for Road Configuration Values. 


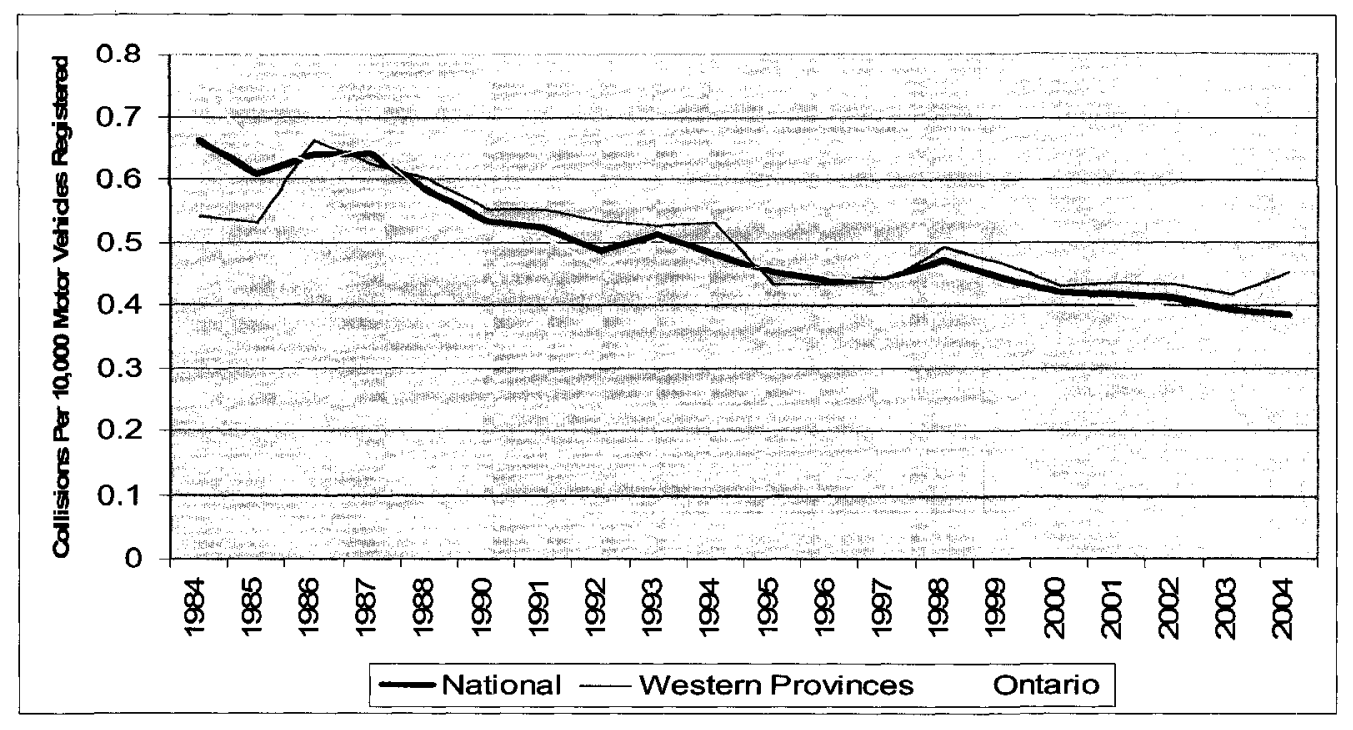

Figure 3.33: Fatal Intersection Collisions Per 10,000 Motor Vehicles Registered By Year.

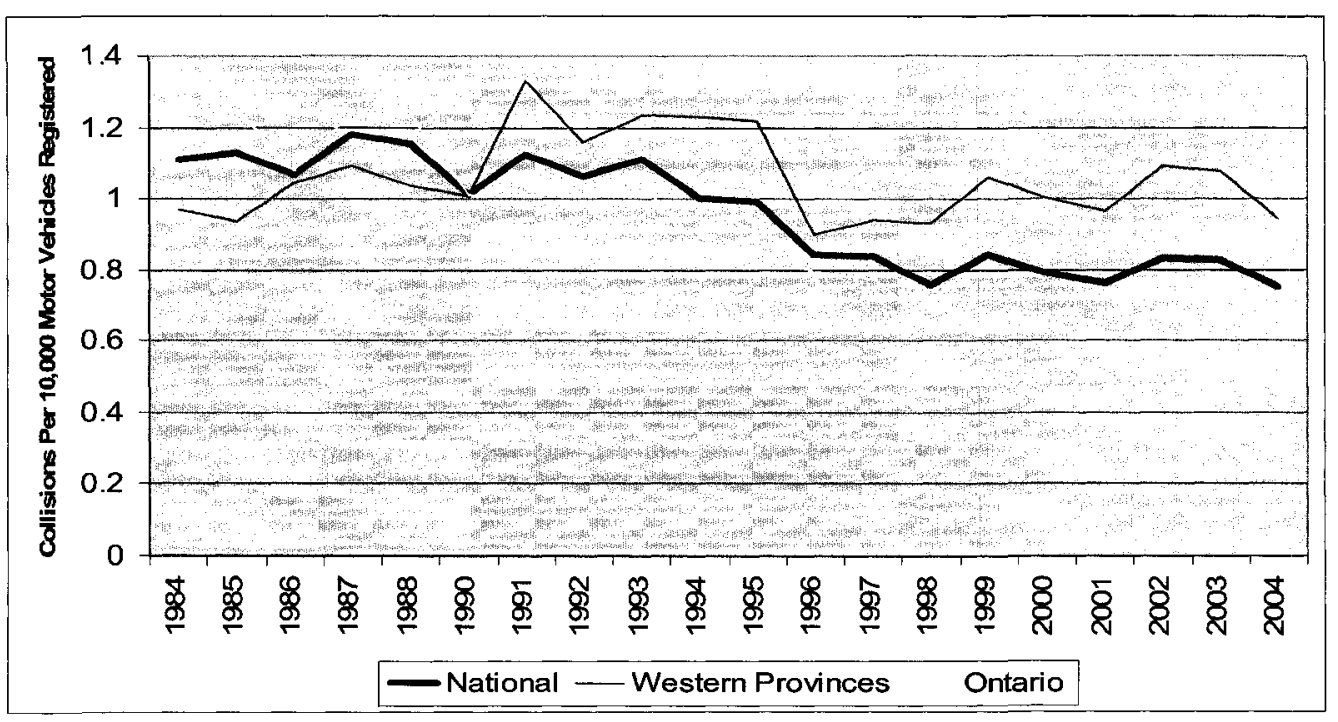

Figure 3.34: Fatal Non-Intersection Collisions Per 10,000 Motor Vehicles Registered By Year. 


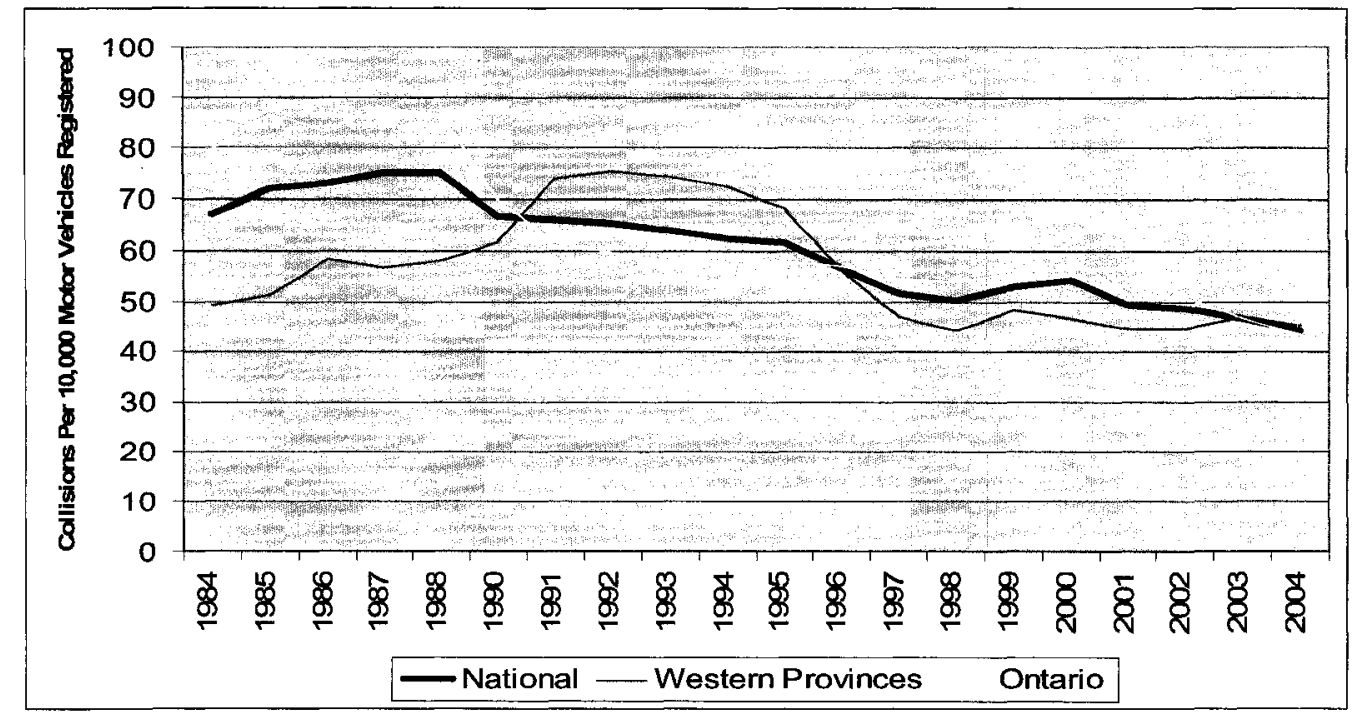

Figure 3.35: Injury Intersection Collisions Per 10,000 Motor Vehicles Registered By Year.

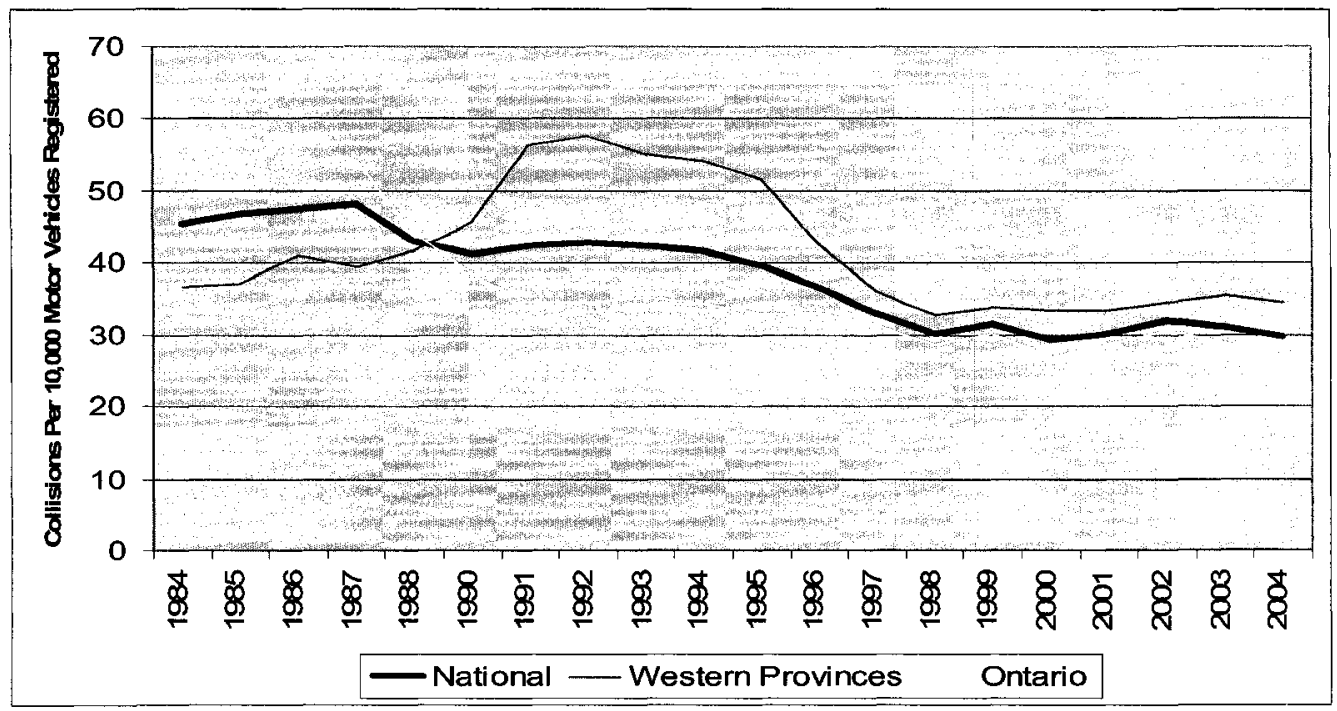

Figure 3.36: Injury Non-Intersection Collisions Per 10,000 Motor Vehicles Registered By Year. 


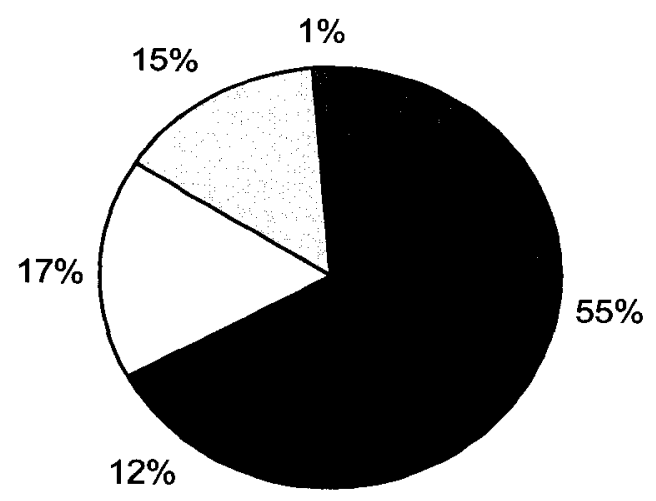

Straight and Level

- Curved and Gradient

$\square$ Curved and Level

$\square$ Straight and Gradient

- Other

Figure 3.37: Percentage of Fatal Collisions for Road Alignment Values.

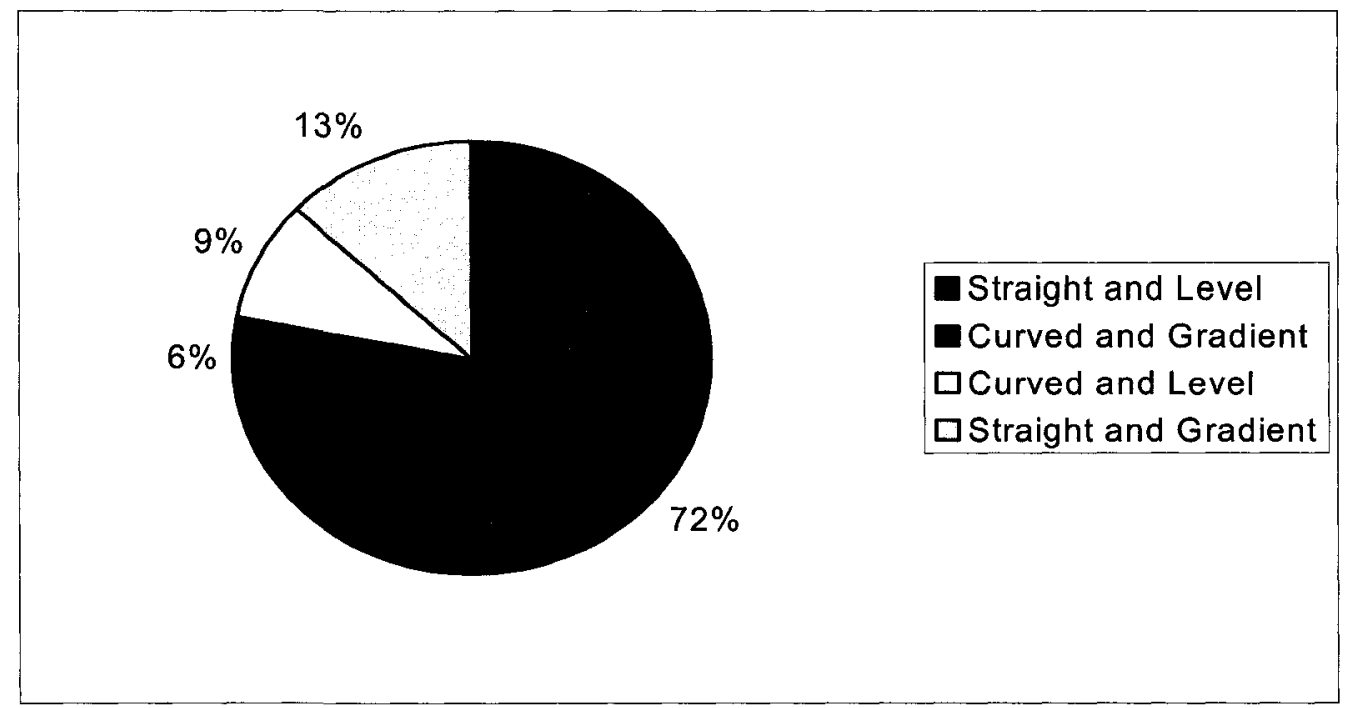

Figure 3.38: Percentage of Injury Collisions for Road Alignment Values. 


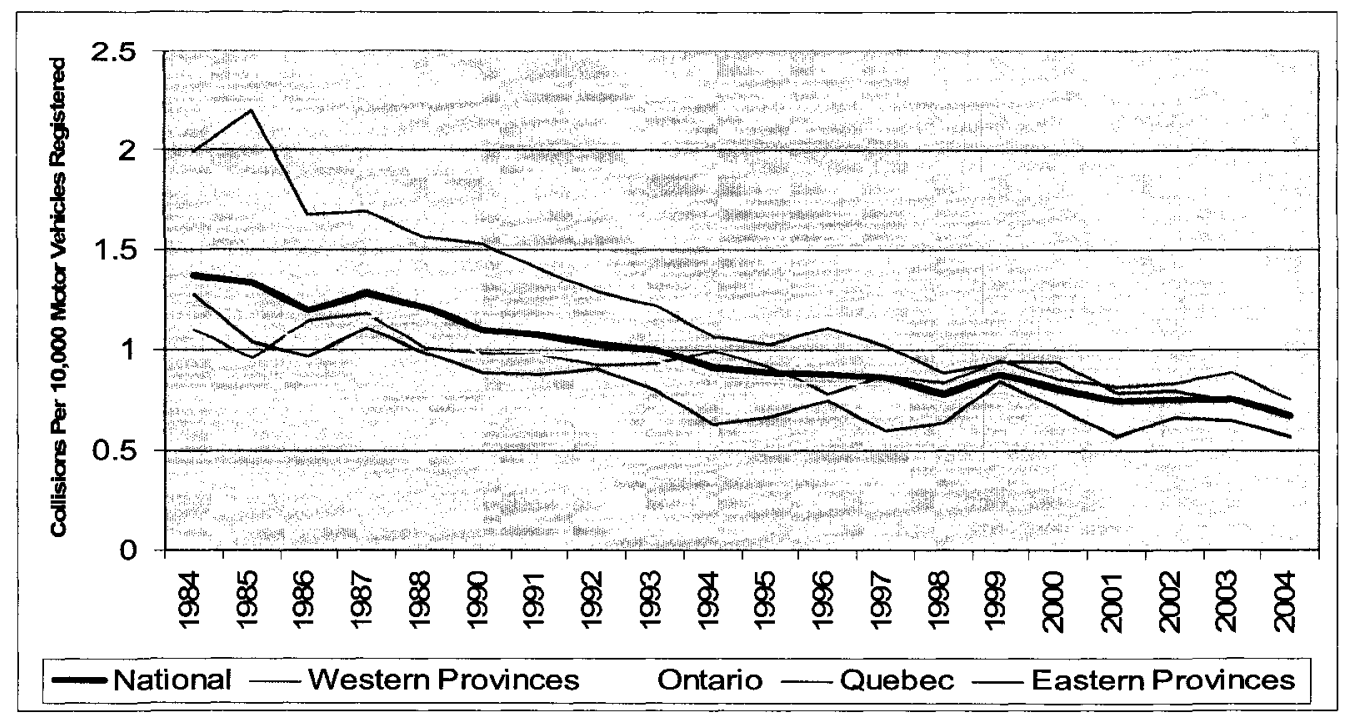

Figure 3.39: Fatal Straight and Level Road Collisions Per 10,000 Motor Vehicles

\section{Registered By Year.}

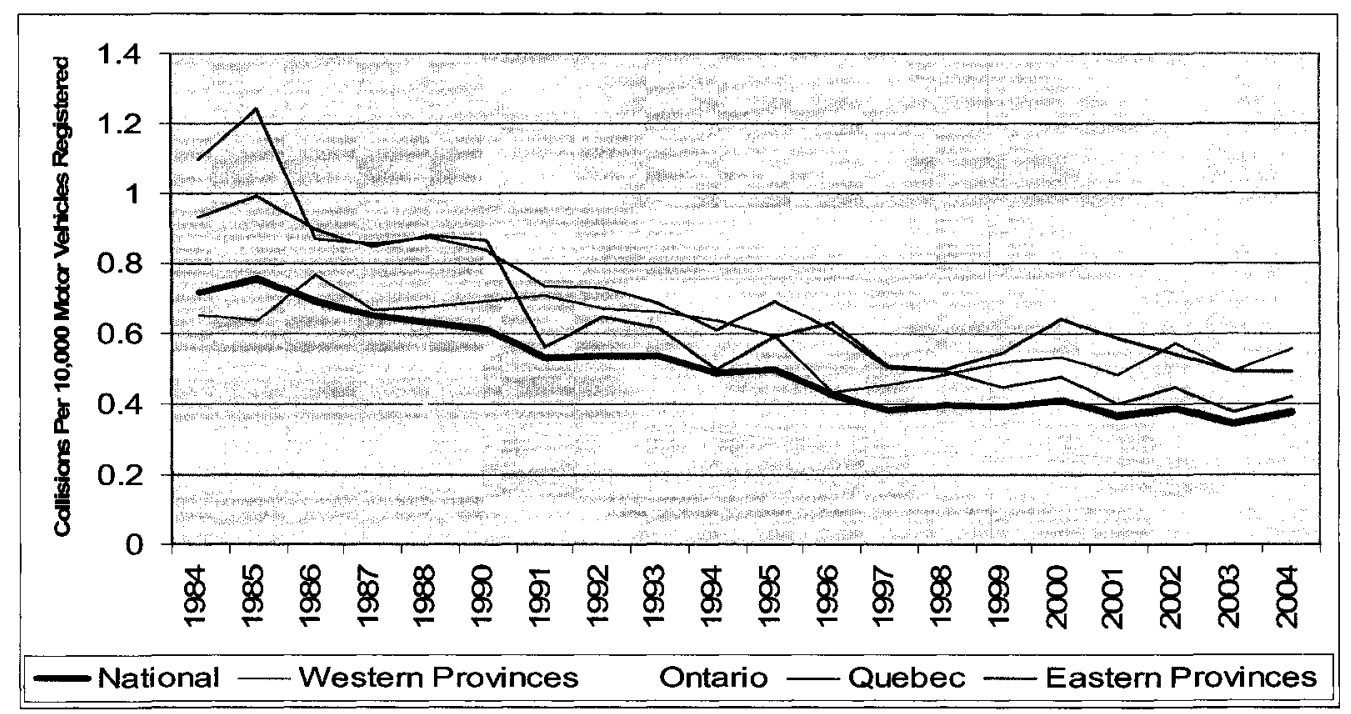

Figure 3.40: Fatal Curved Road Collisions Per 10,000 Motor Vehicles Registered By Year. 


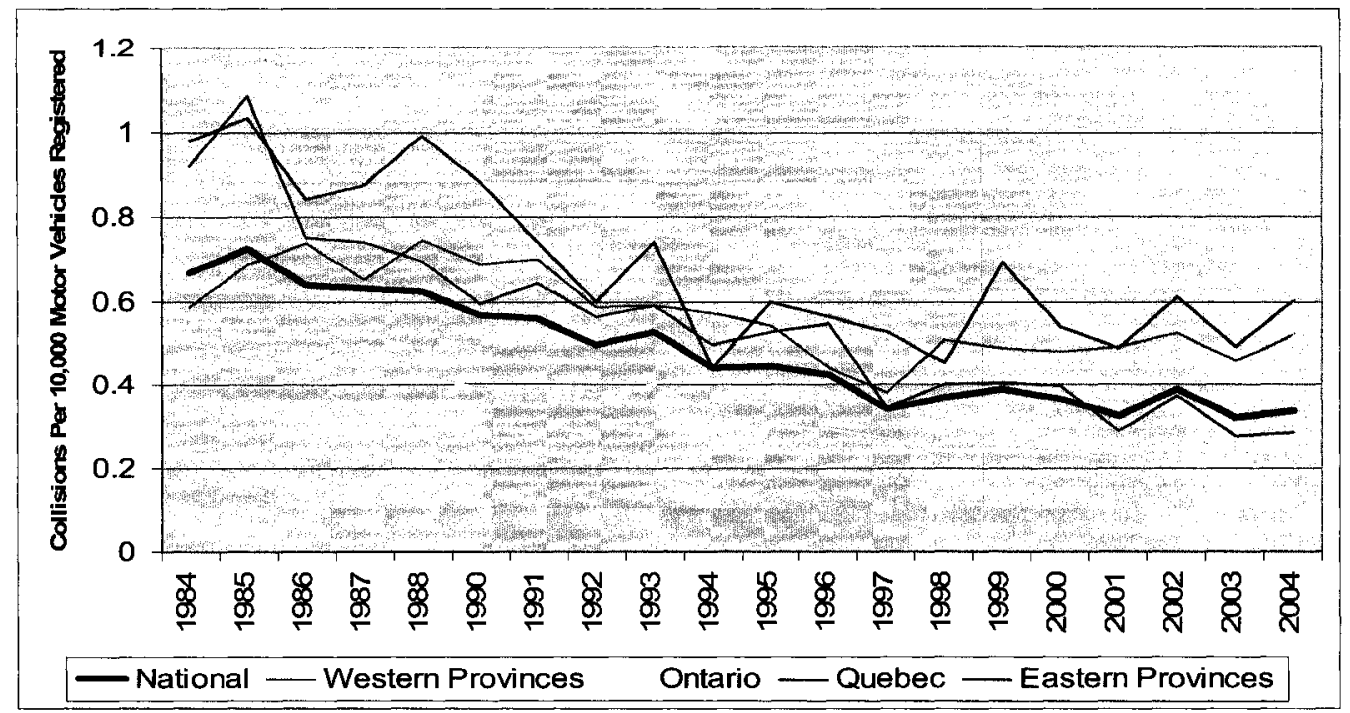

Figure 3.41: Fatal Collisions that Occurred at a Gradient Per 10,000 Motor Vehicles Registered By Year.

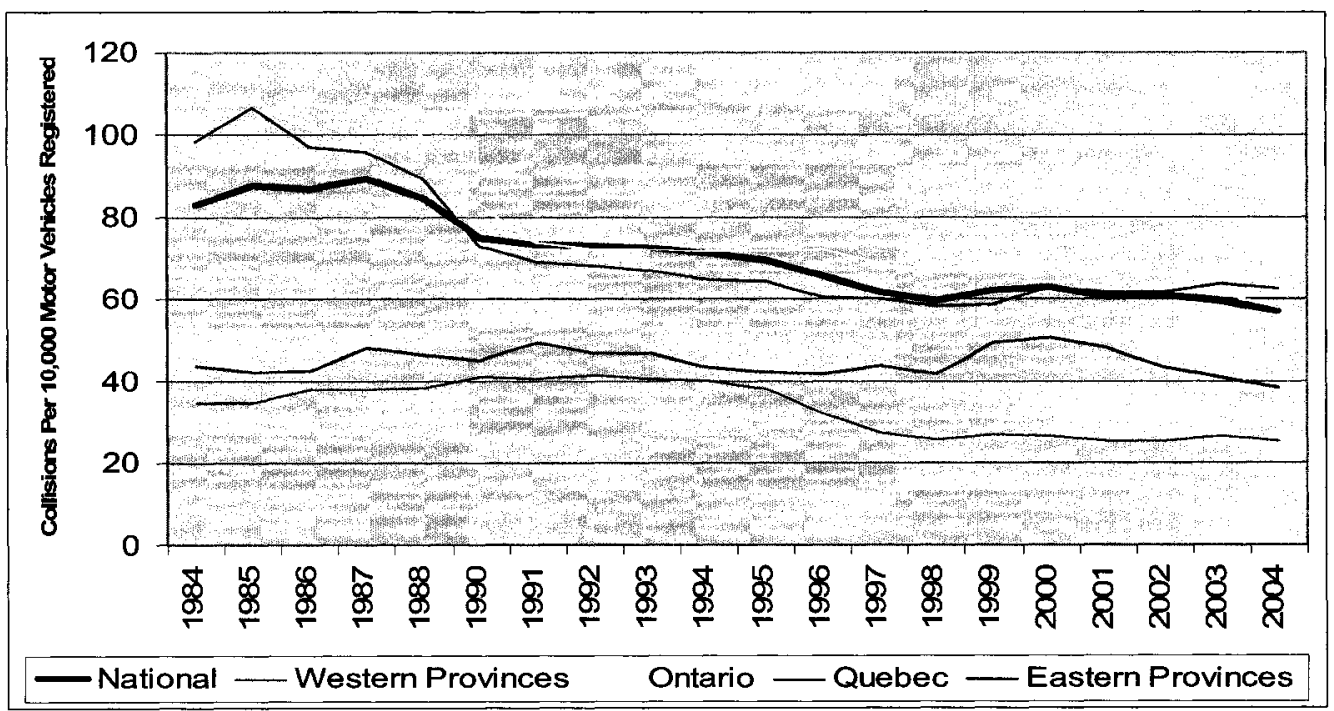

Figure 3.42: Injury Straight and Level Road Collisions Per 10,000 Motor Vehicles Registered By Year. 


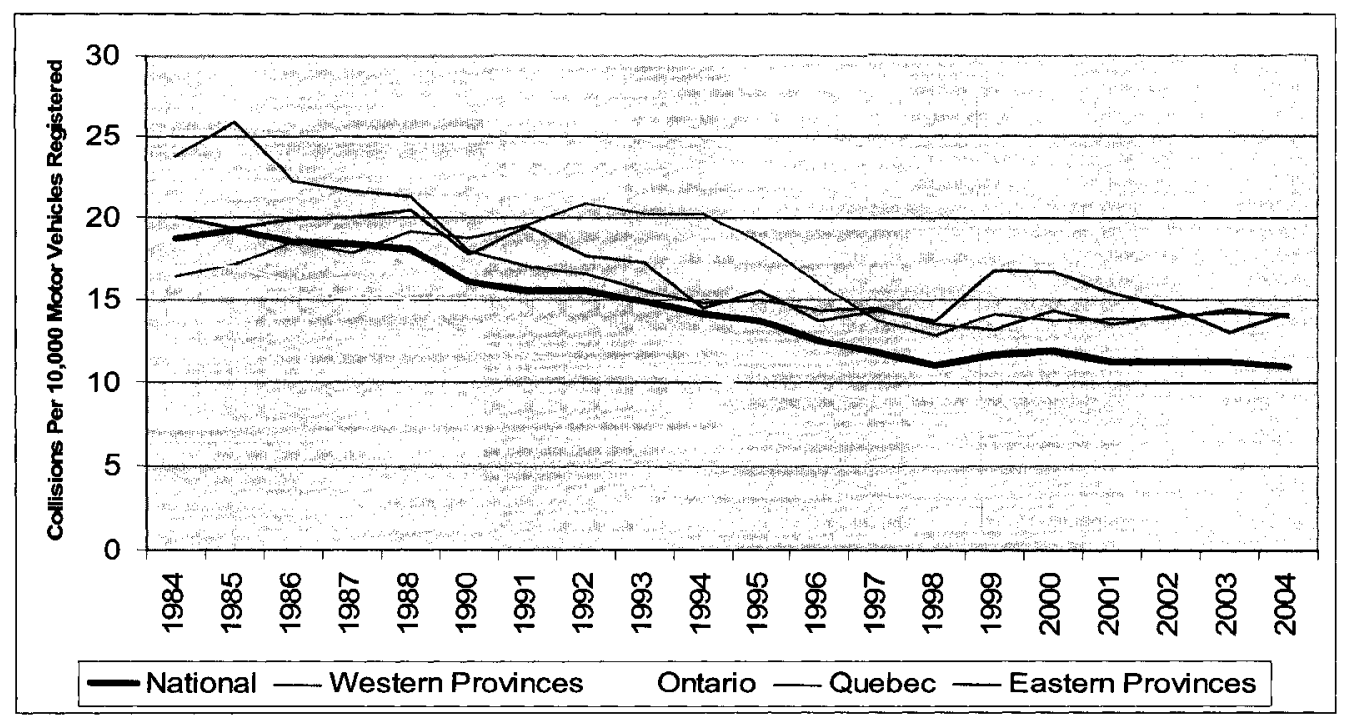

Figure 3.43: Injury Curved Road Collisions Per 10,000 Motor Vehicles Registered By Year.

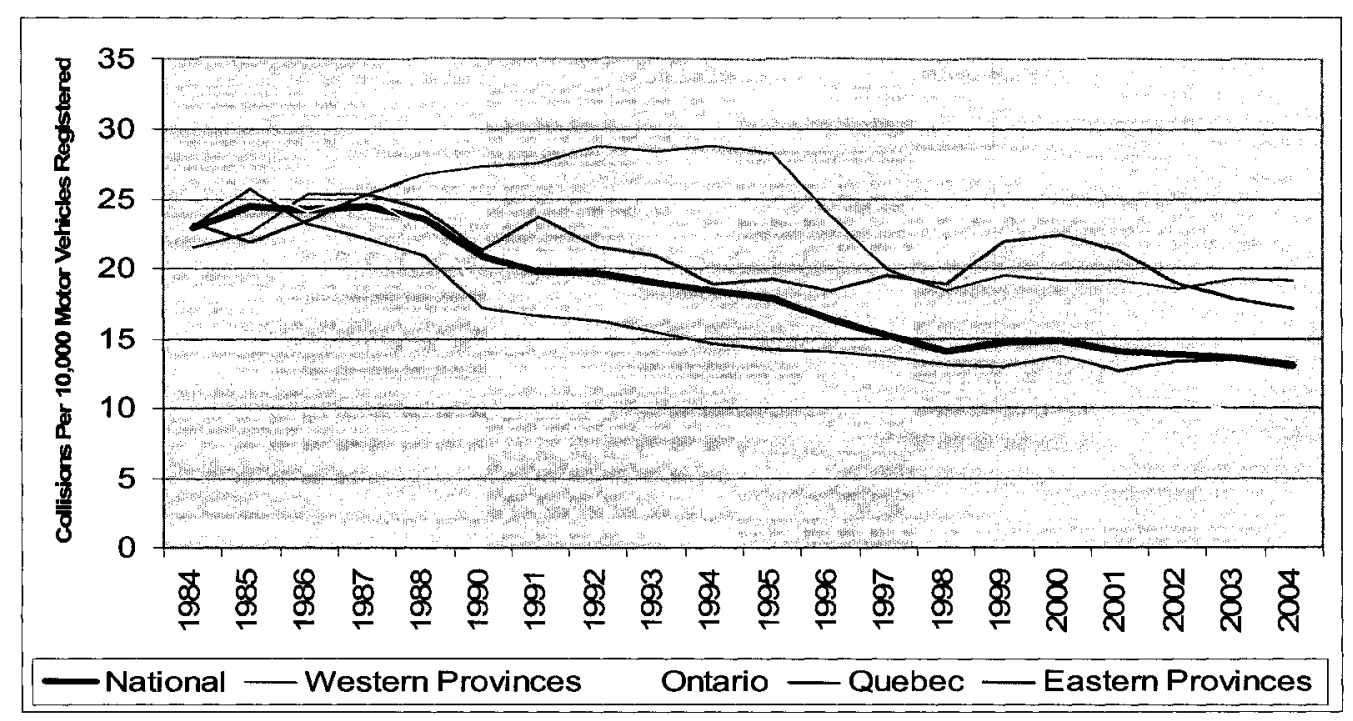

Figure 3.44: Injury Collisions that Occurred on a Gradient Per 10,000 Motor Vehicles Registered By Year. 


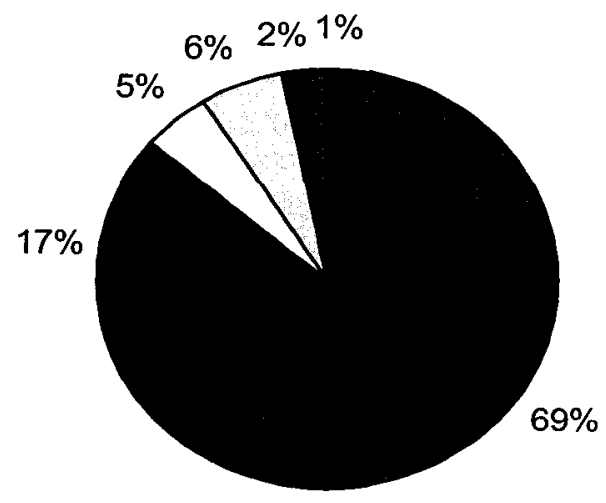

Dry, Normal

- Wet

$\square$ Snow (Loose)

$\square$ Ice (Packed Snow)

- Slush

- Other

Figure 3.45: Percentage of Fatal Collisions for Road Surface Condition Values.

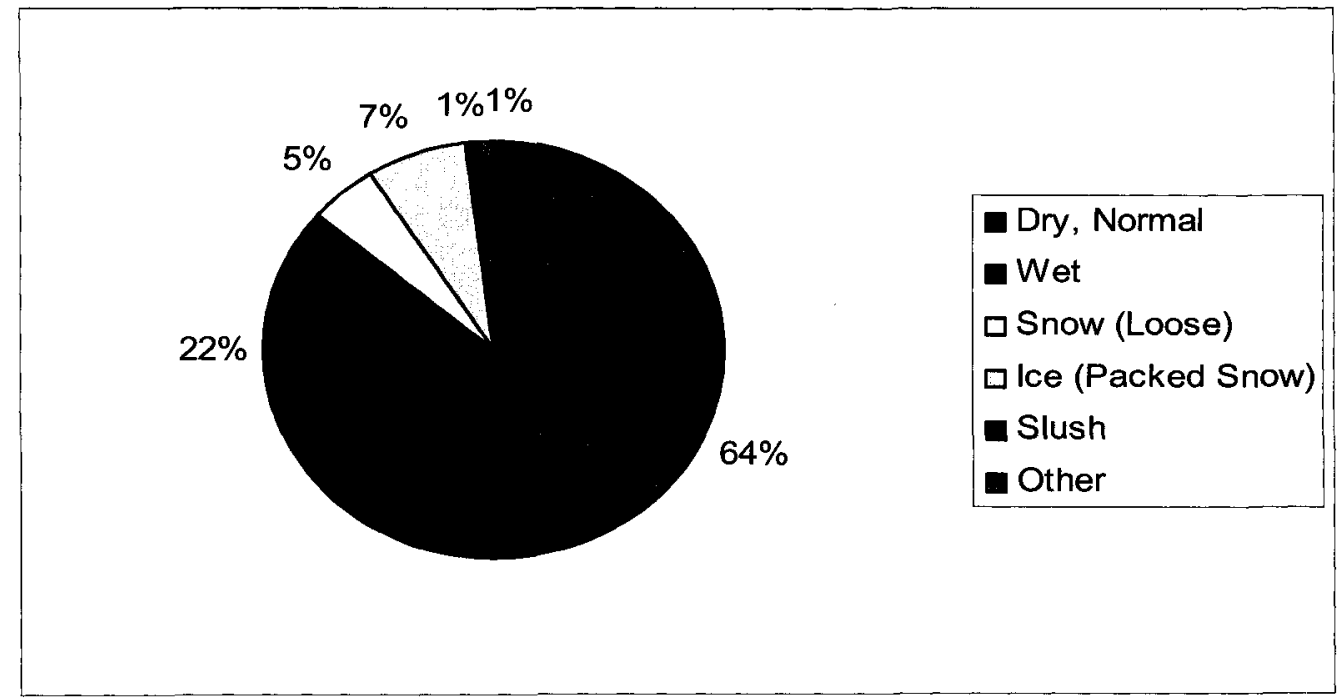

Figure 3.46: Percentage of Injury Collisions for Road Surface Condition Values. 


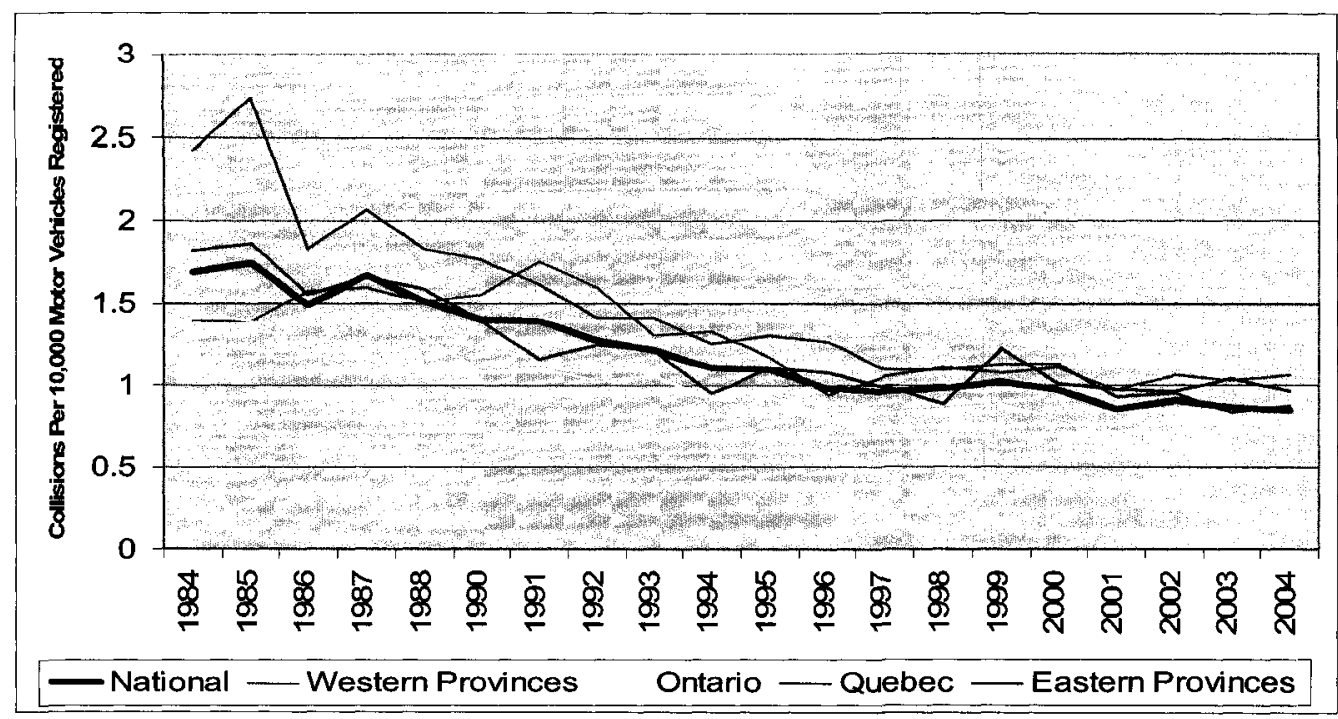

Figure 3.47: Fatal Collisions On Dry, Normal Roads Per 10,000 Motor Vehicles

\section{Registered.}

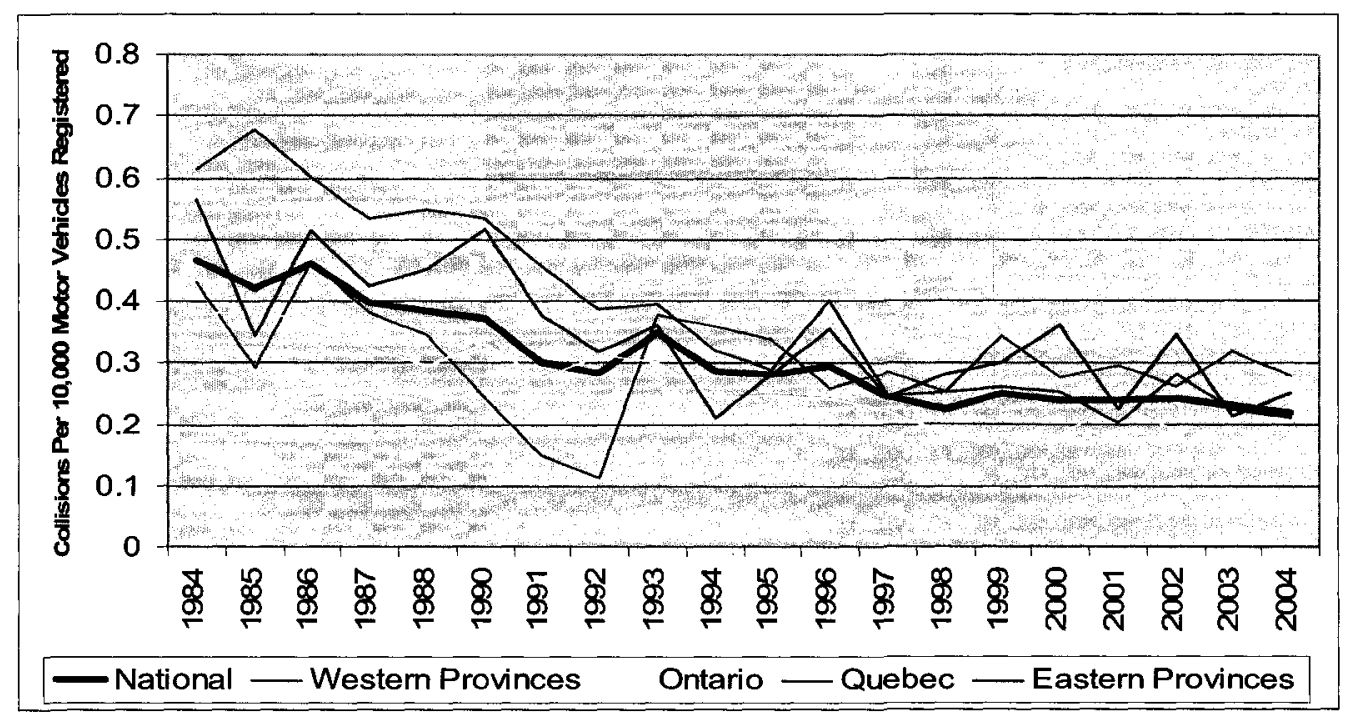

Figure 3.48: Fatal Collisions On Wet Roads Per 10,000 Motor Vehicles Registered By Year. 


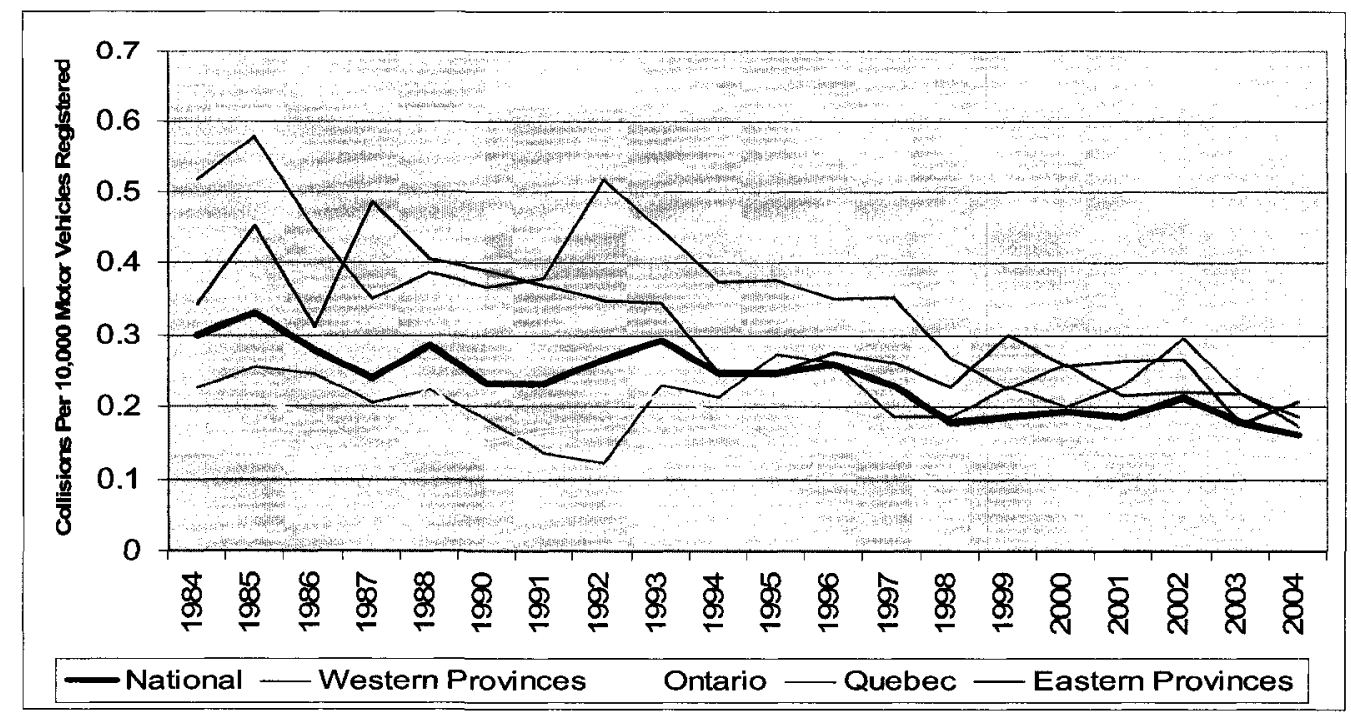

Figure 3.49: Fatal Collisions On Winter Condition Roads Per 10,000 Motor Vehicles Registered By Year.

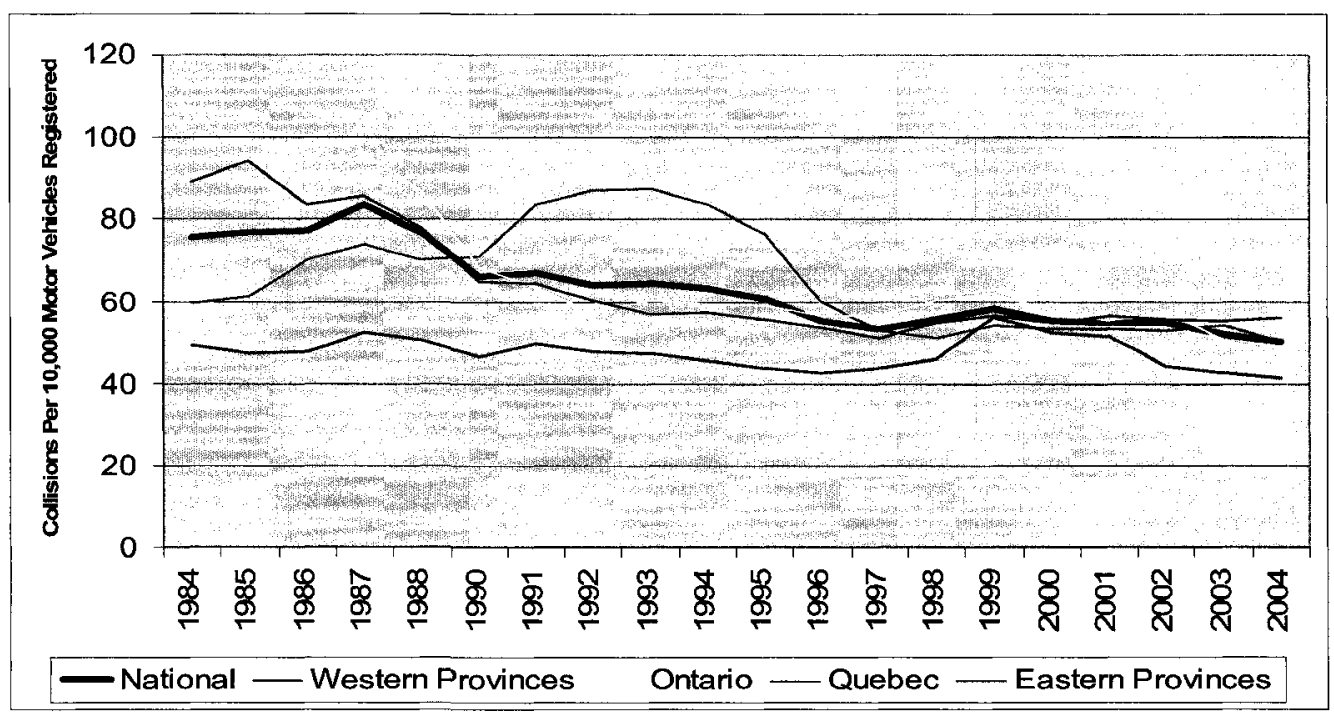

Figure 3.50: Injury Collisions On Dry, Normal Roads Per 10,000 Motor Vehicles

\section{Registered By Year.}




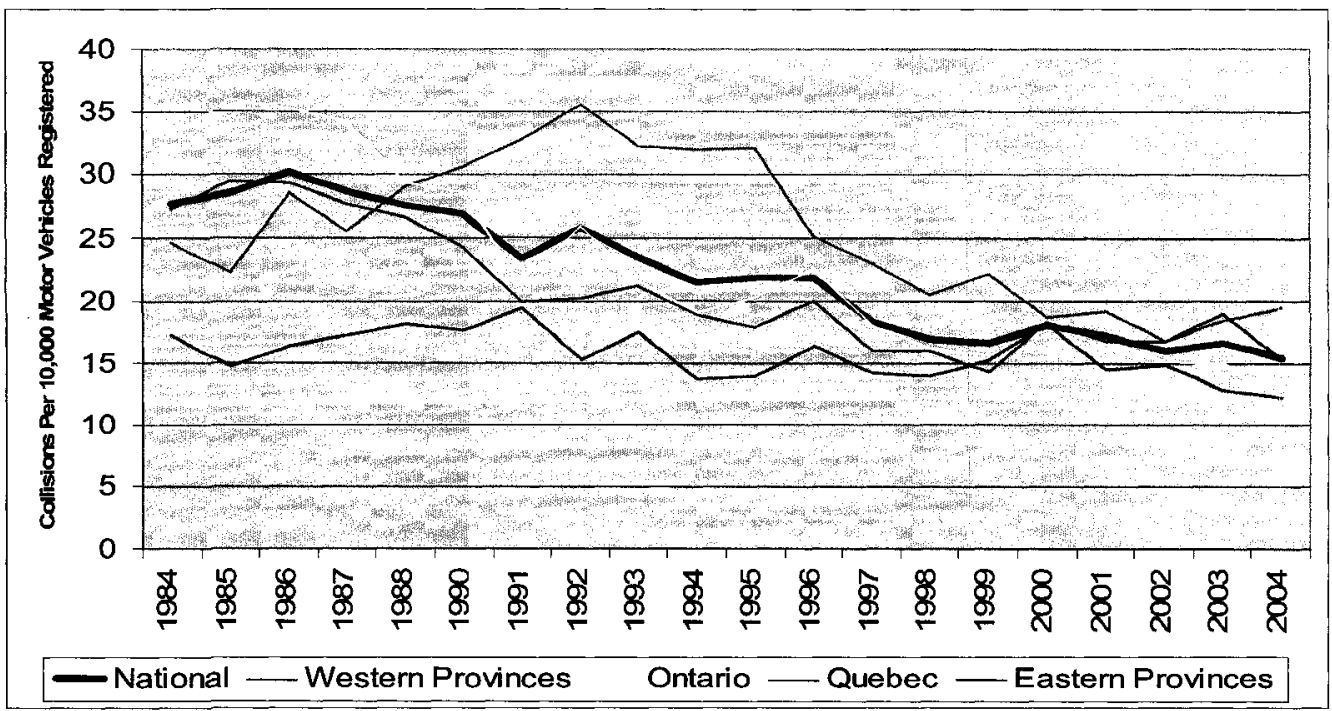

Figure 3.51: Injury Collisions On Wet Roads Per 10,000 Motor Vehicles Registered By Year.

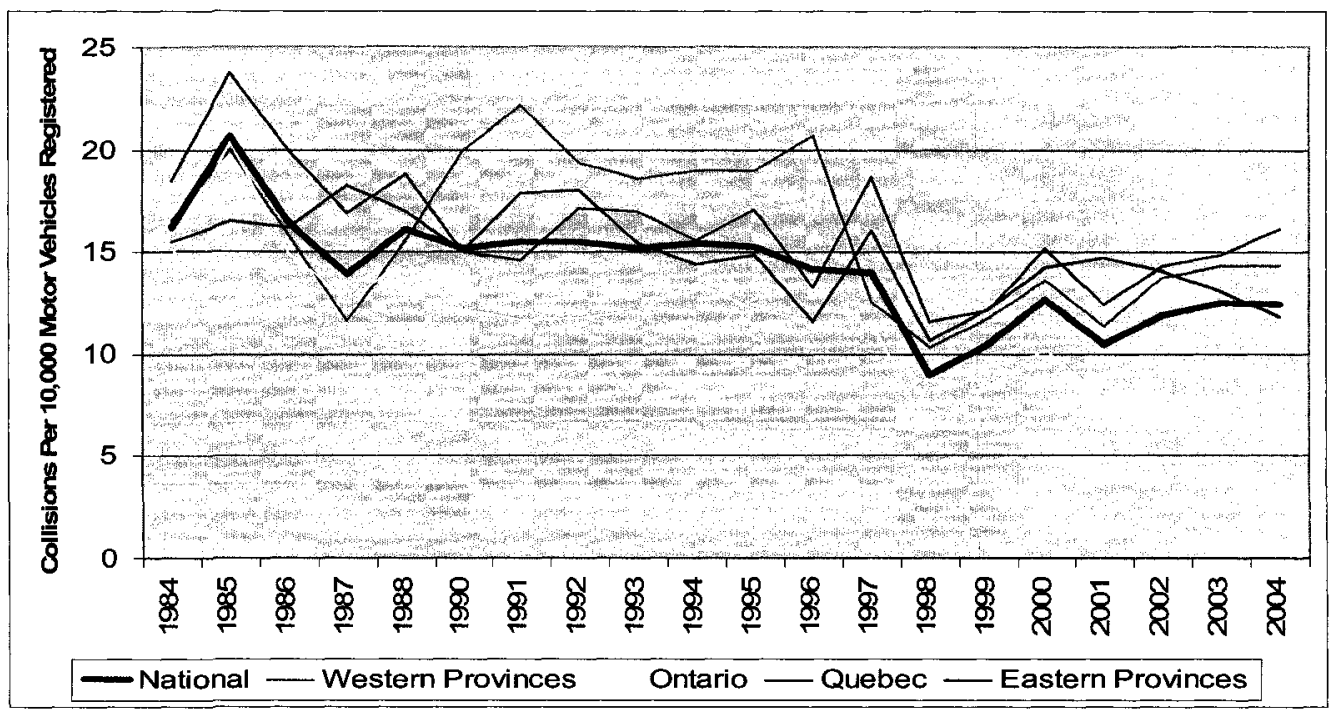

Figure 3.52: Injury Collisions On Winter Condition Roads Per 10,000 Motor Vehicles Registered By Year. 


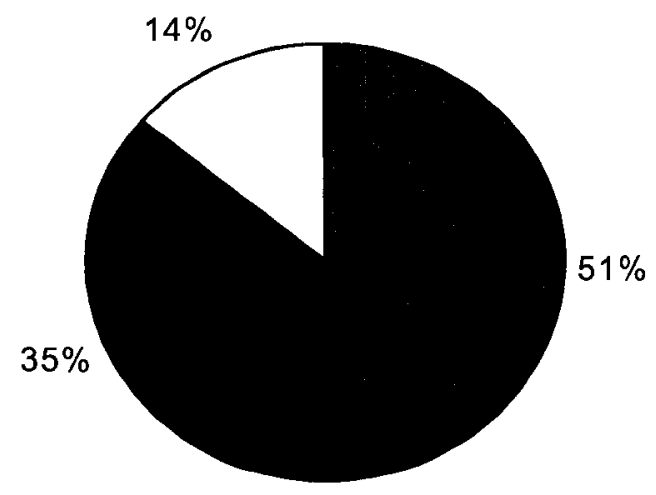

Day Dark 口Other

Figure 3.53: Percentage of Fatal Collisions for Light Condition Values.

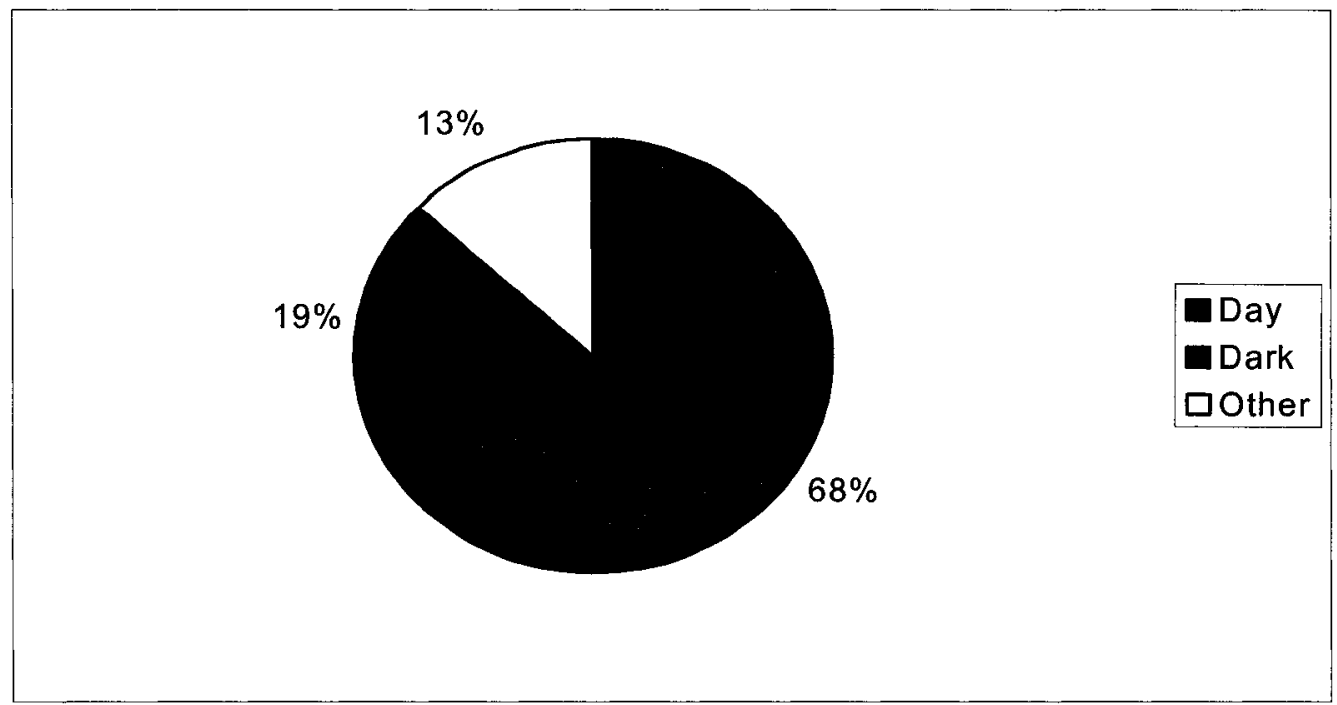

Figure 3.54: Percentage of Injury Collisions for Light Condition Values. 


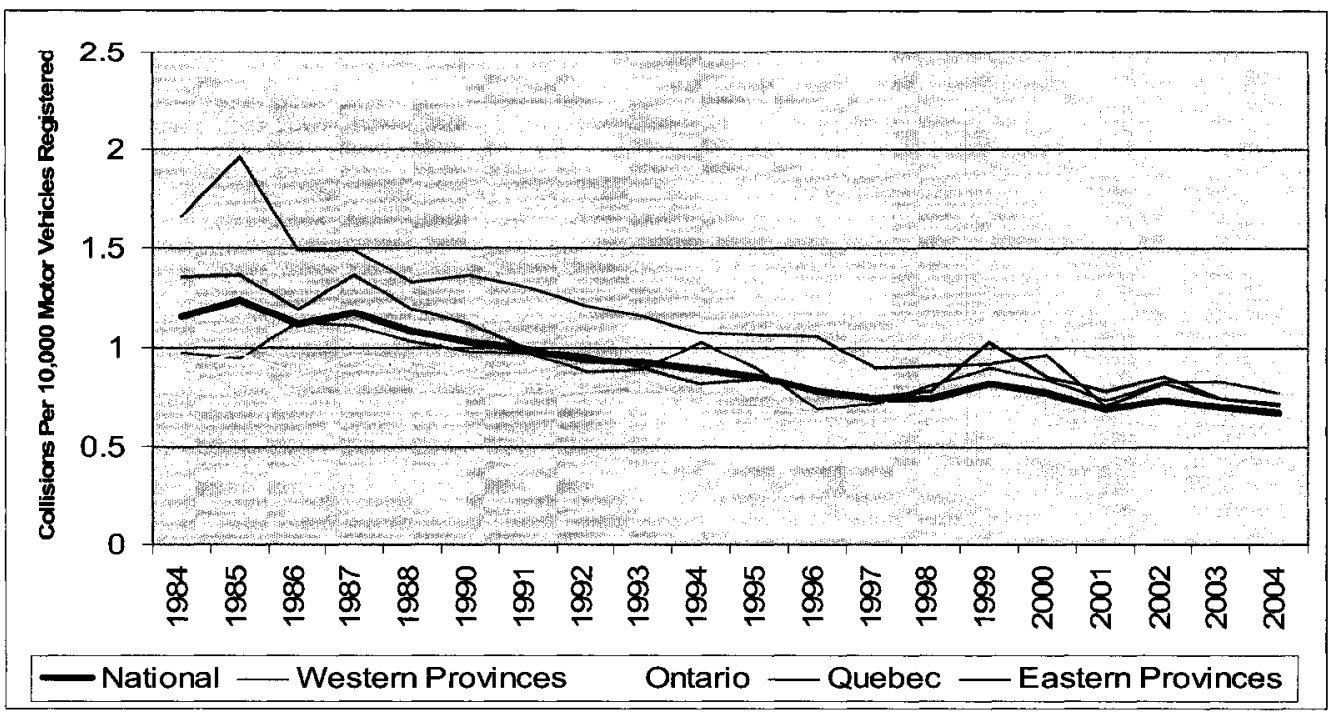

Figure 3.55: Fatal Collisions That Occurred During Daylight Per 10,000 Motor Vehicles Registered By Year.

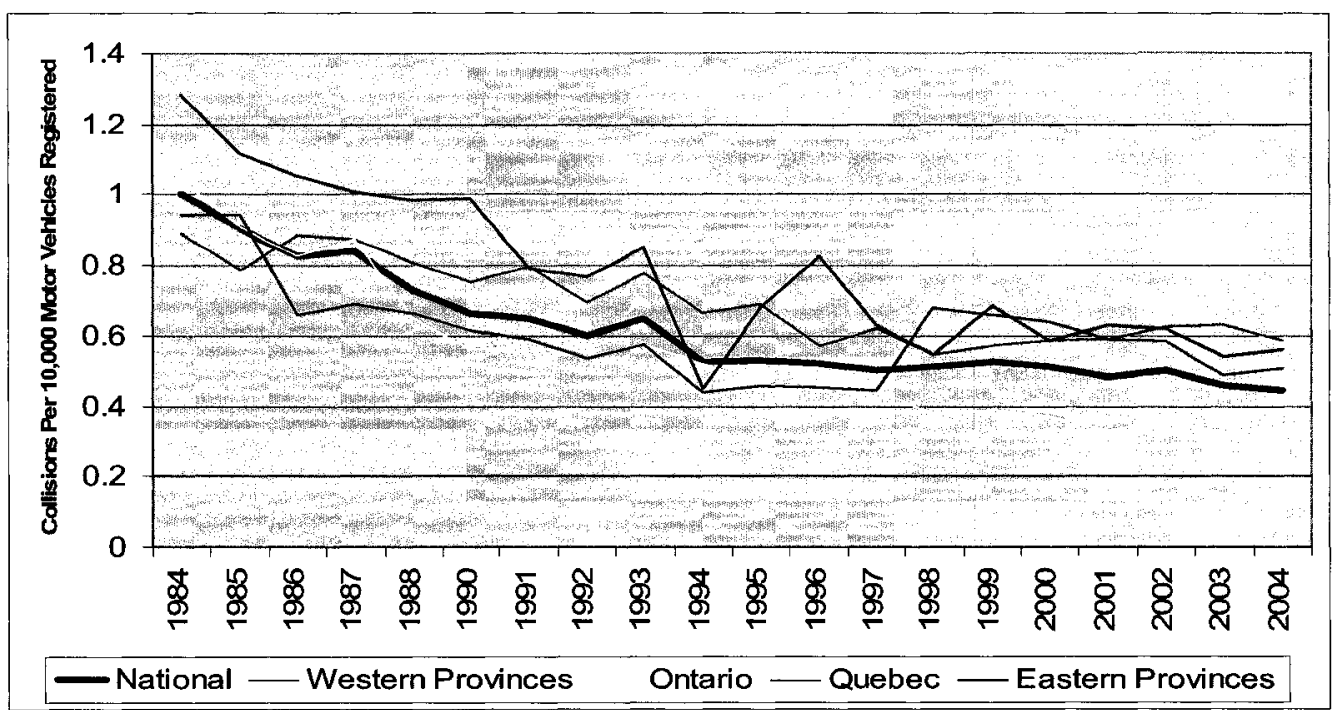

Figure 3.56: Fatal Collisions That Occurred While It Was Dark Per 10,000 Motor Vehicles Registered By Year. 


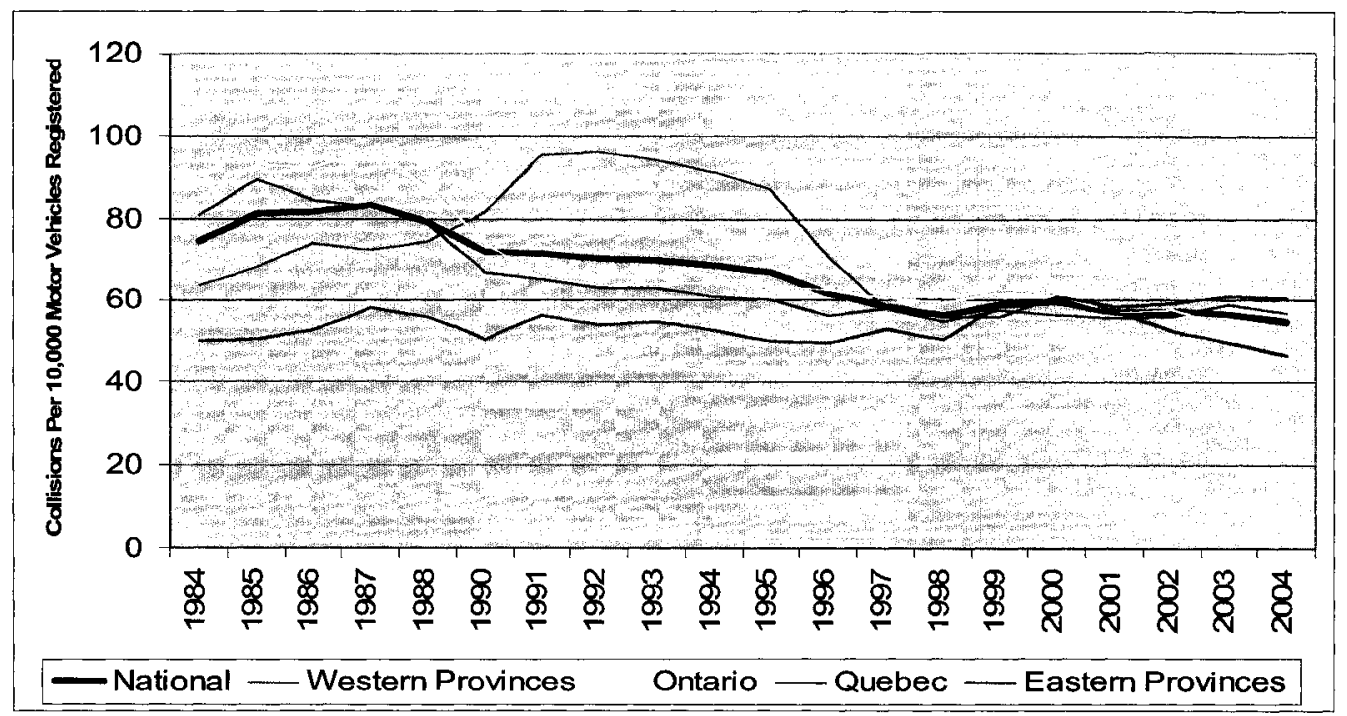

Figure 3.57: Injury Collisions That Occurred During Daylight Per 10,000 Motor Vehicles Registered By Year.

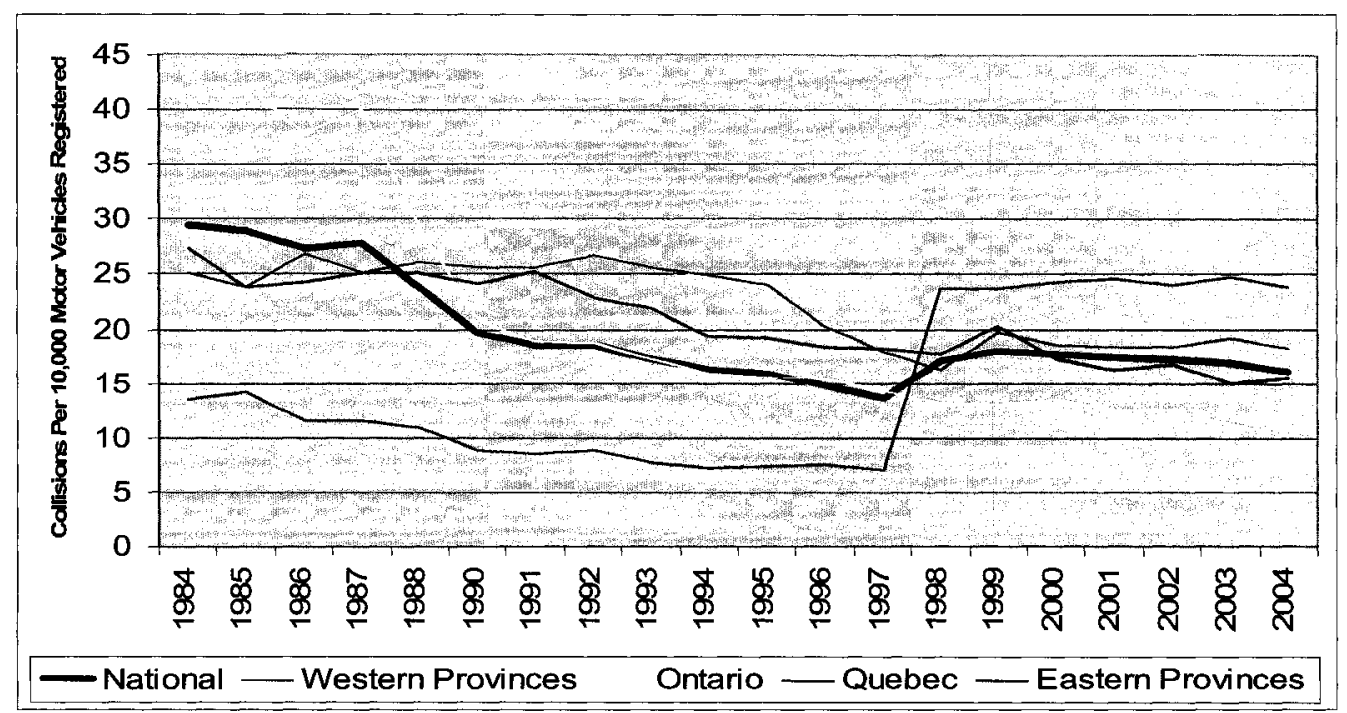

Figure 3.58: Injury Collisions That Occurred While It Was Dark Per 10,000 Motor Vehicles Registered By Year. 


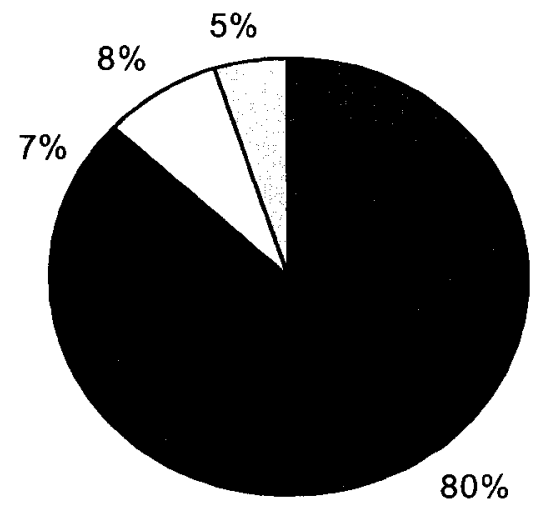

No Control

- Traffic Signals $\square$ Stop Signs 口Other

Figure 3.59: Percentage of Fatal Collisions for Traffic Control Values.

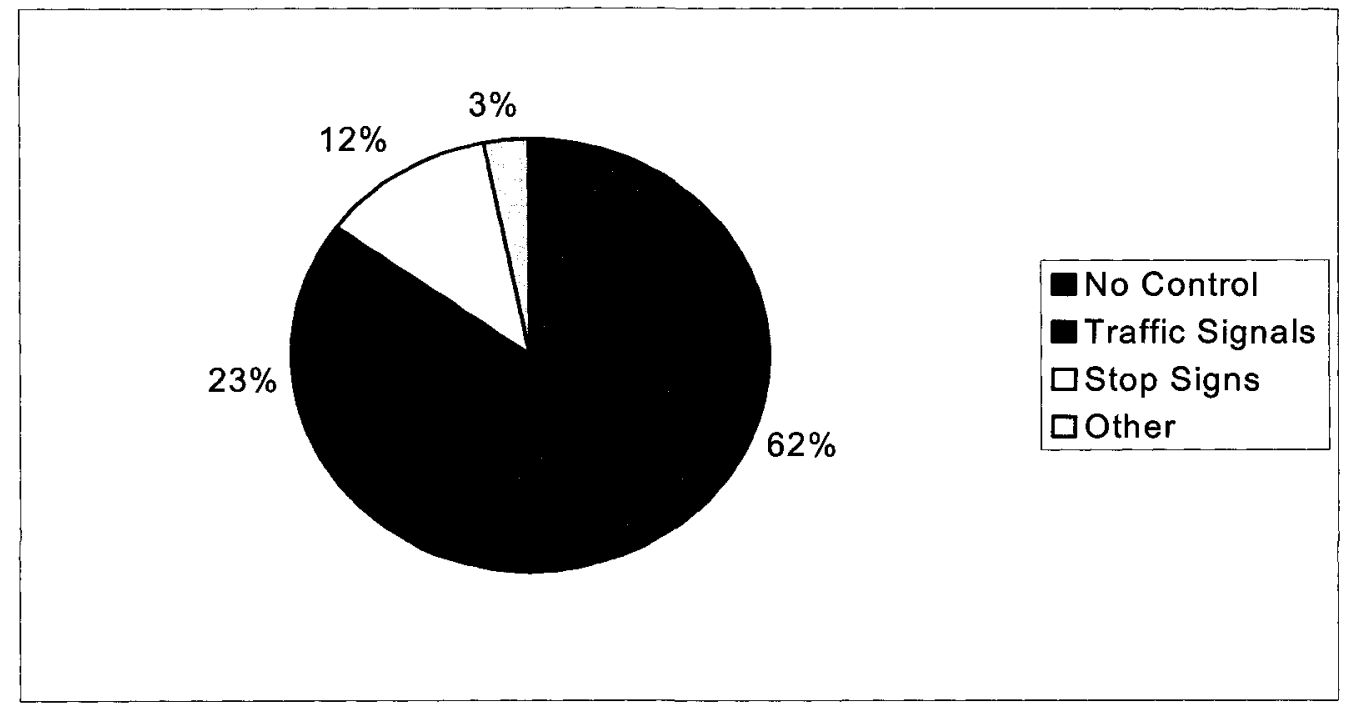

Figure 3.60: Percentage of Injury Collisions for Traffic Control Values. 


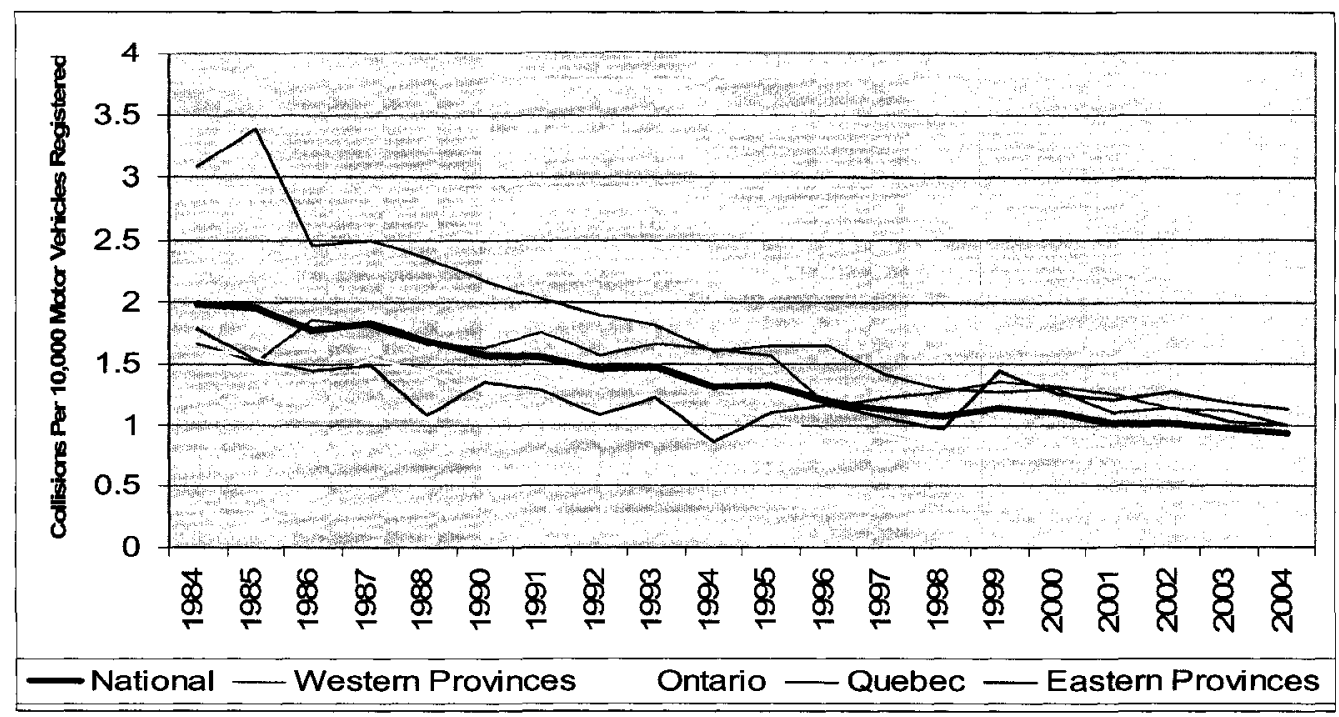

Figure 3.61: Fatal Collisions That Occurred Where There Was No Control Present Per 10,000 Motor Vehicles Registered By Year.

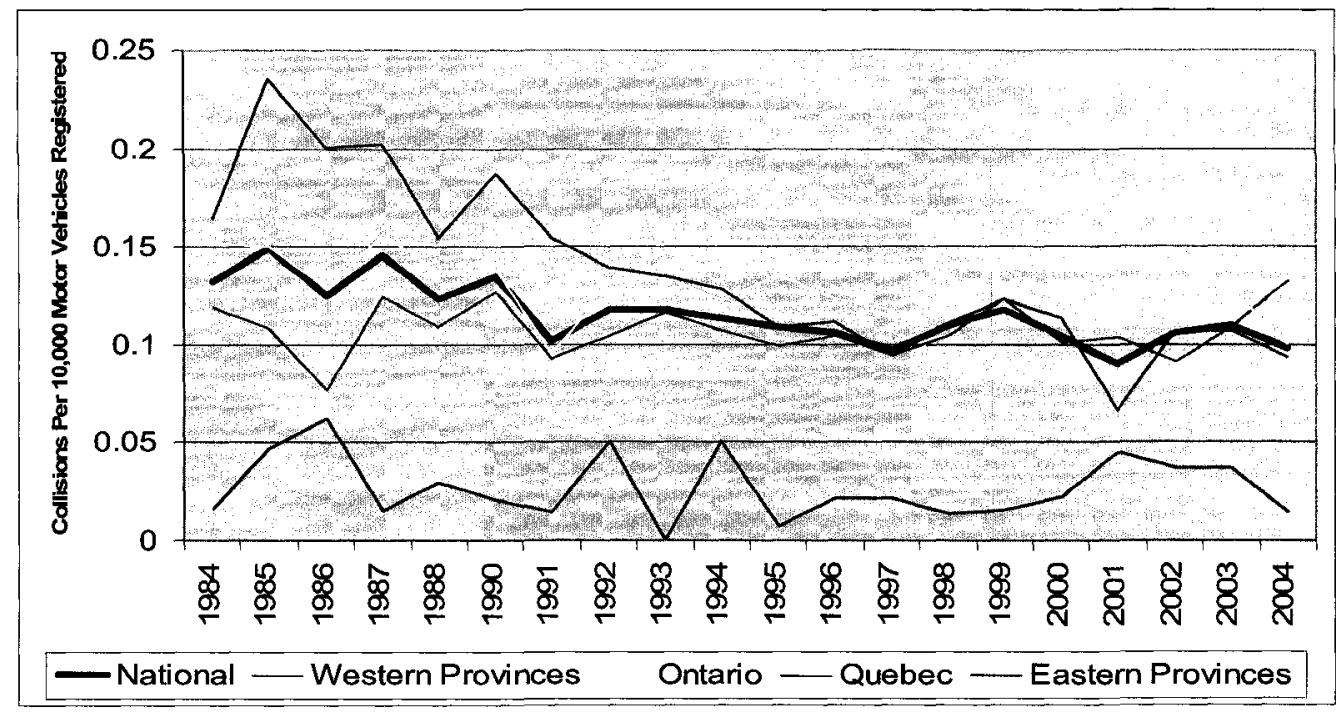

Figure 3.62: Fatal Collisions That Occurred At Traffic Signals Per 10,000 Motor Vehicles Registered By Year. 


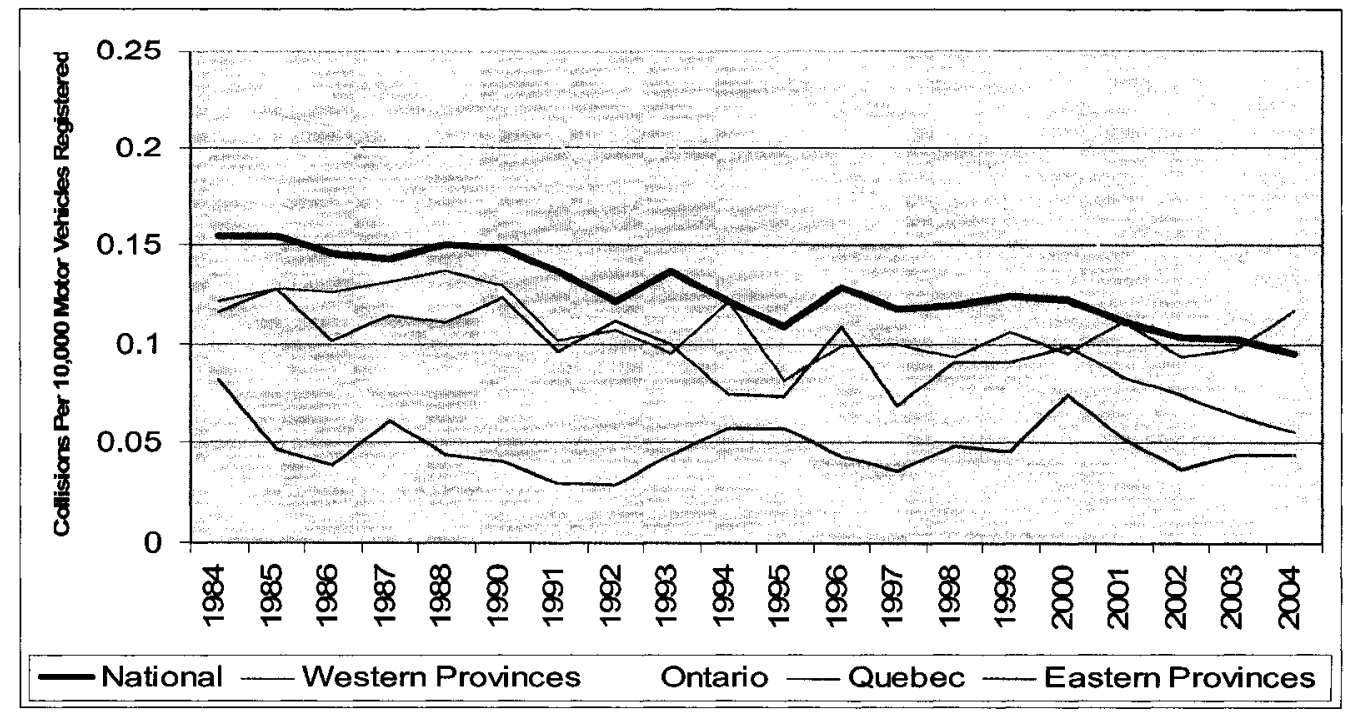

Figure 3.63: Fatal Collisions That Occurred At Stop Signs Per 10,000 Motor Vehicles Registered By Year.

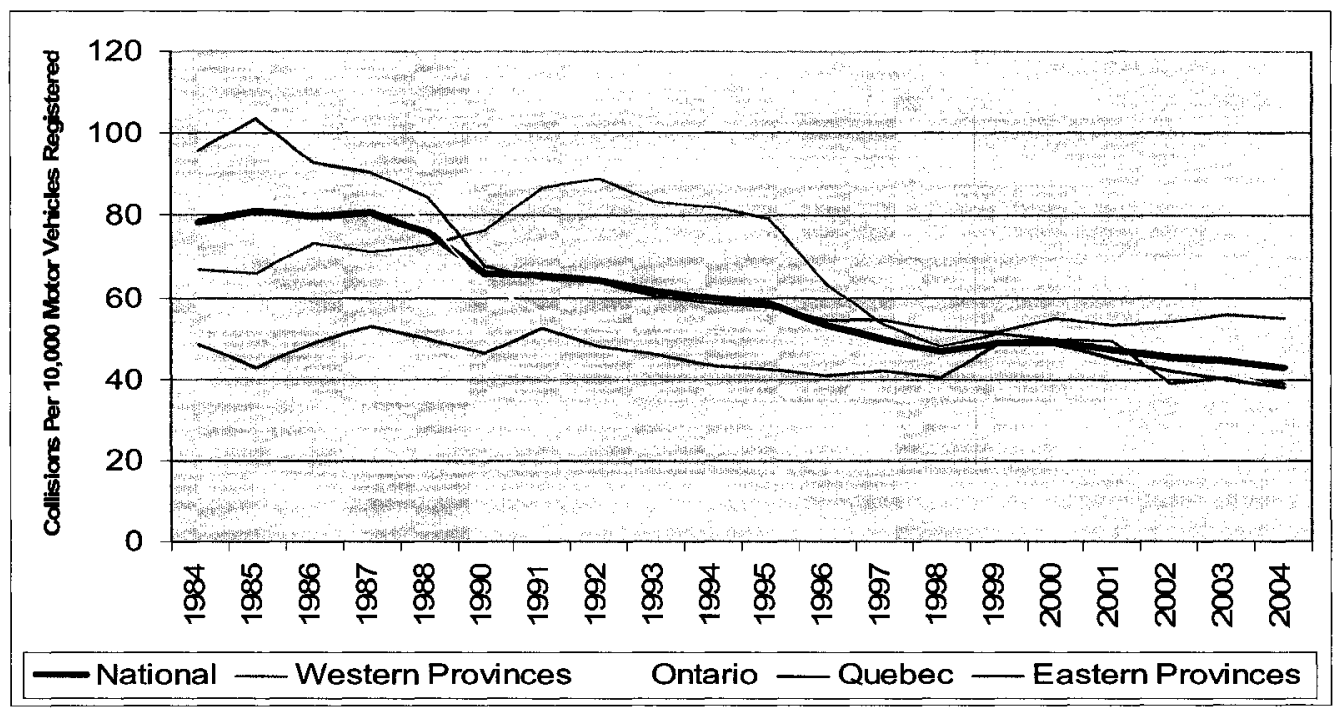

Figure 3.64: Injury Collisions That Occurred Where There Was No Control Present Per 10,000 Motor Vehicles Registered By Year. 


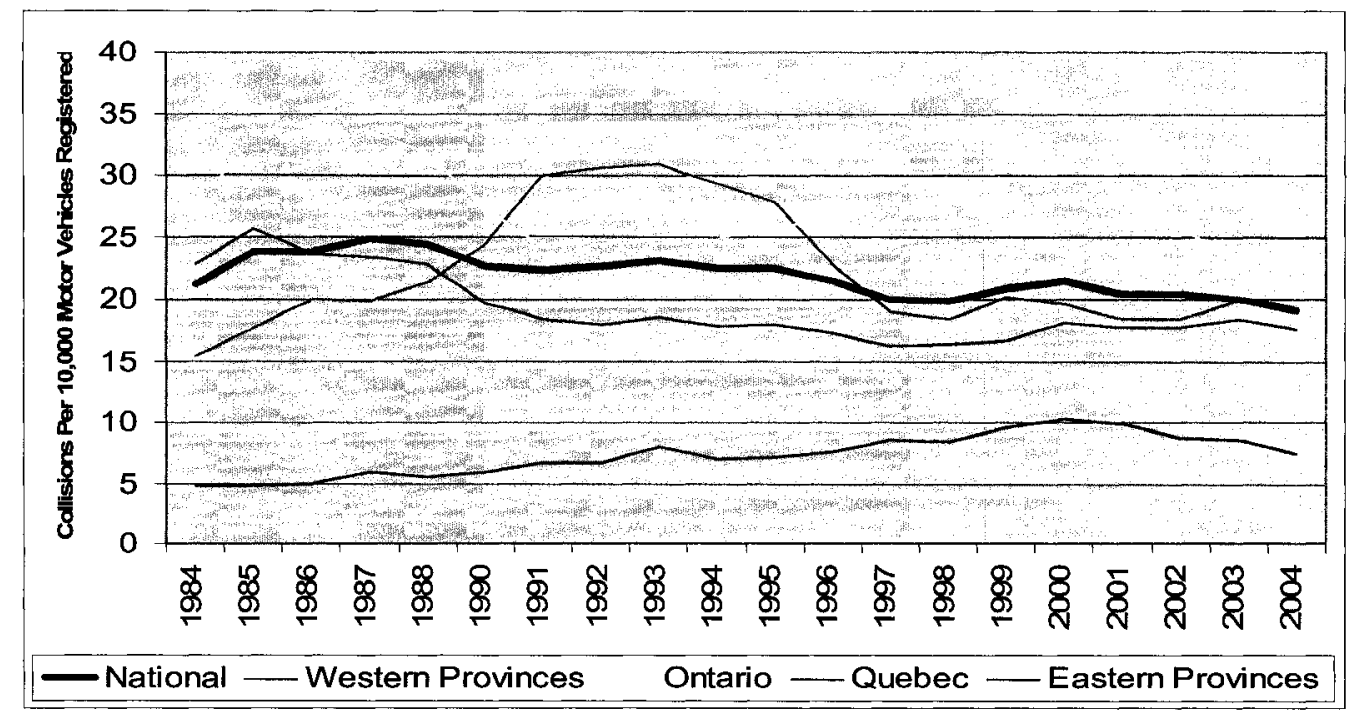

Figure 3.65: Injury Collisions That Occurred At Traffic Signals Per 10,000 Motor Vehicles Registered By Year.

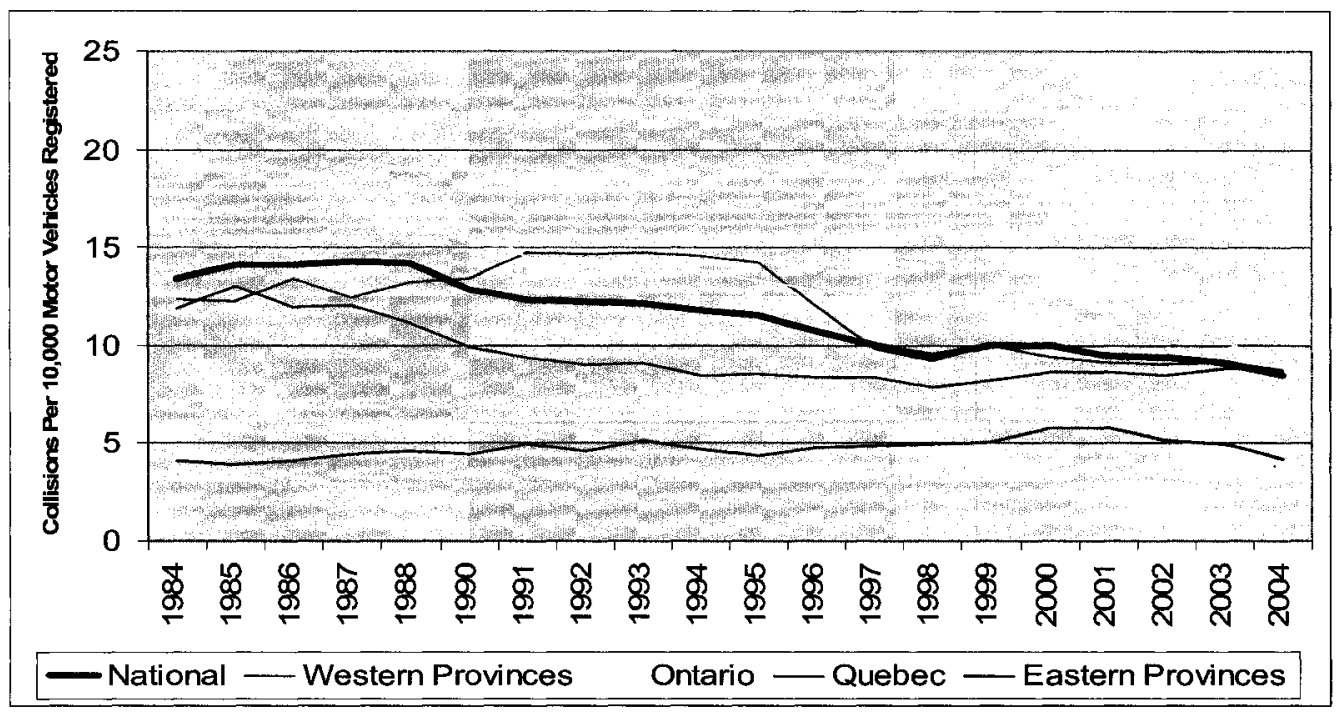

Figure 3.66: Injury Collisions That Occurred At Stop Signs Per 10,000 Motor Vehicles Registered By Year. 


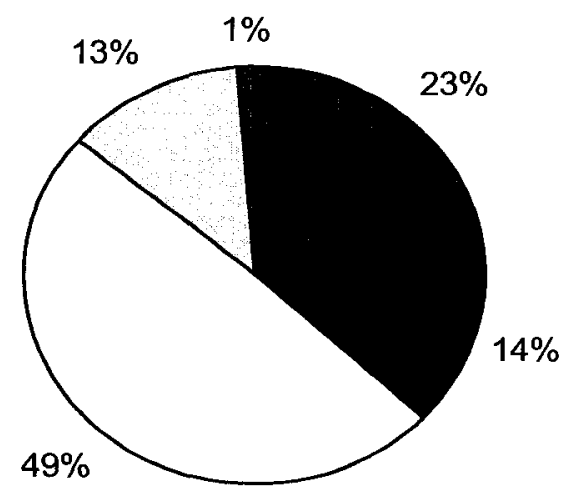

$40850 \mathrm{~km} / \mathrm{h}$ $60870 \mathrm{~km} / \mathrm{h}$ 口 $80 \& 90 \mathrm{~km} / \mathrm{h}$ $\square 100 \& 110 \mathrm{~km} / \mathrm{h}$ - Other

Figure 3.67: Percentage of Fatal Collisions for Speed Limit Values.

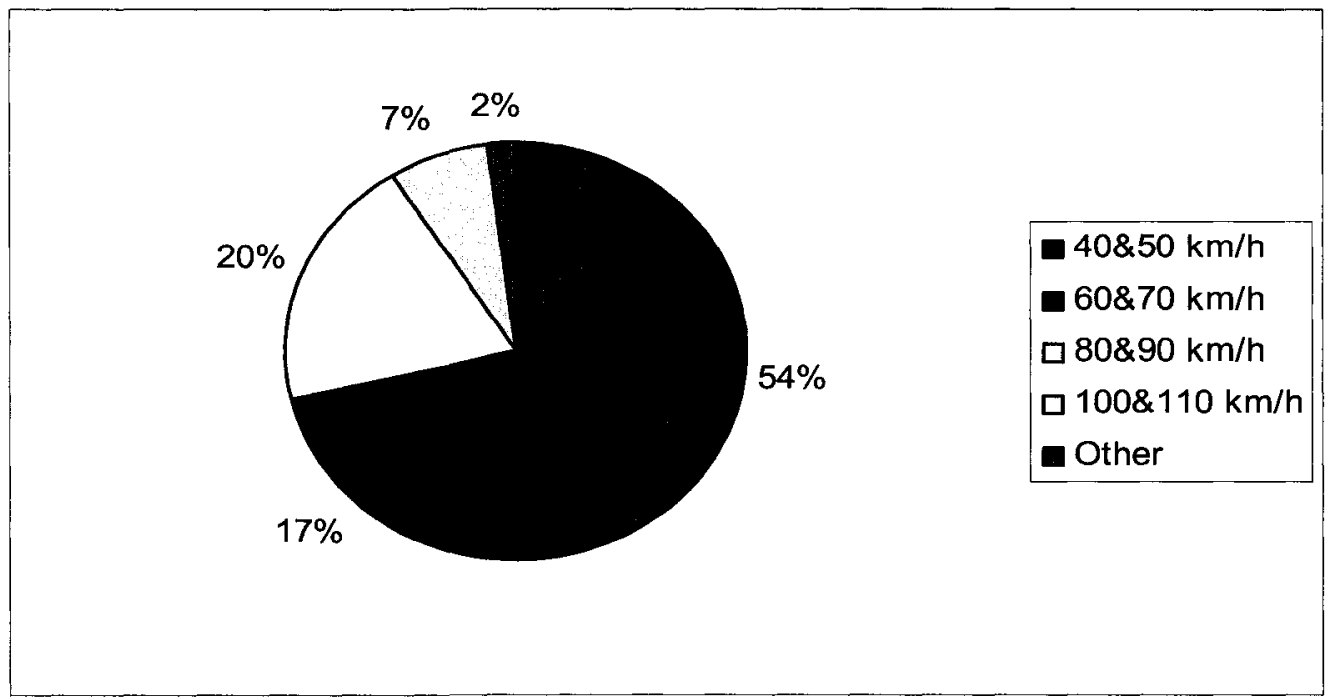

Figure 3.68: Percentage of Injury Collisions for Speed Limit Values. 


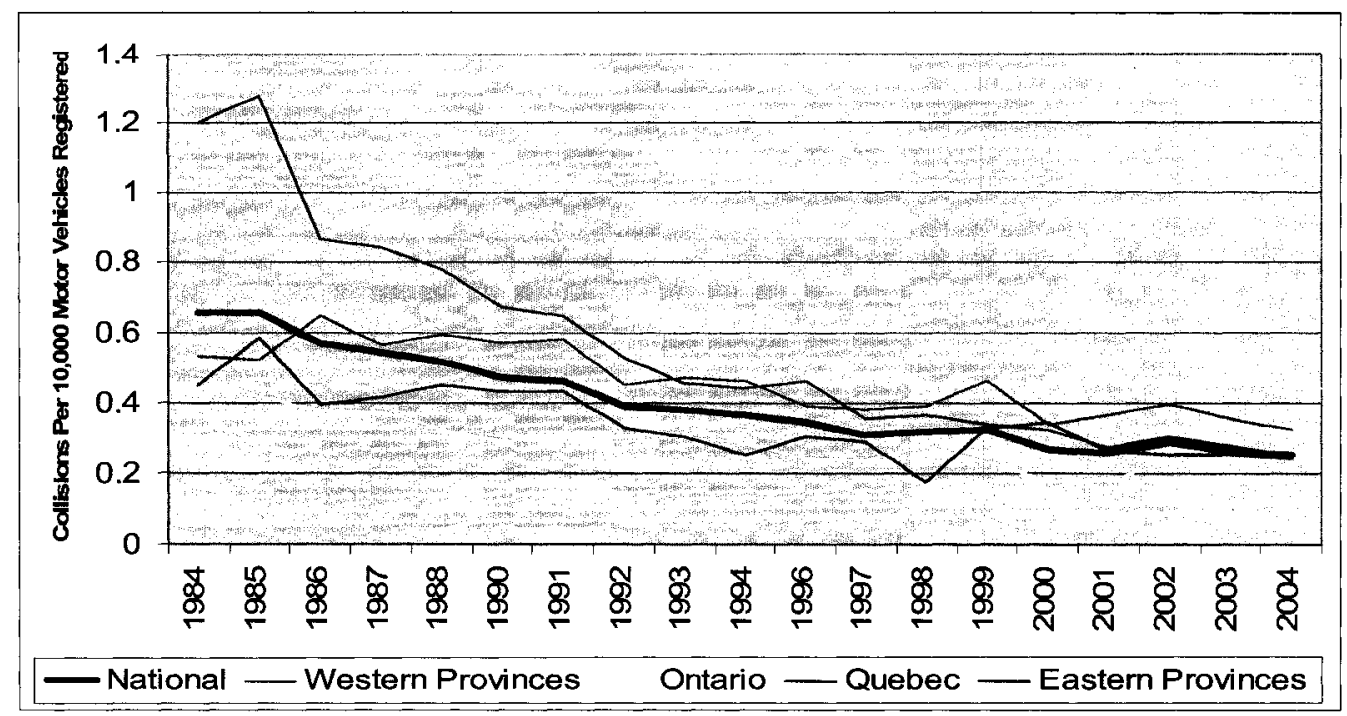

Figure 3.69: Fatal Collisions That Occurred Where the Speed Limit was 40\&50 km/h Per 10,000 Motor Vehicles Registered By Year.

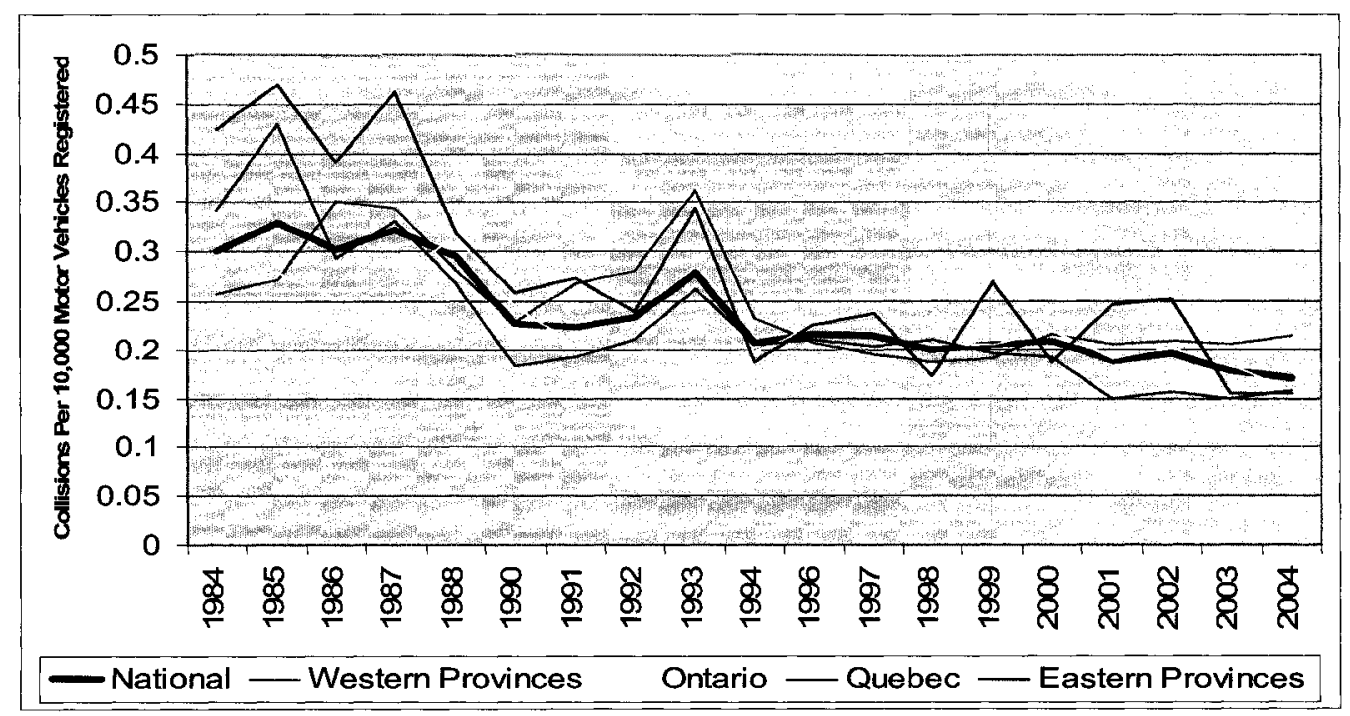

Figure 3.70: Fatal Collisions That Occurred Where the Speed Limit was 60\&70 km/h Per 10,000 Motor Vehicles Registered By Year. 


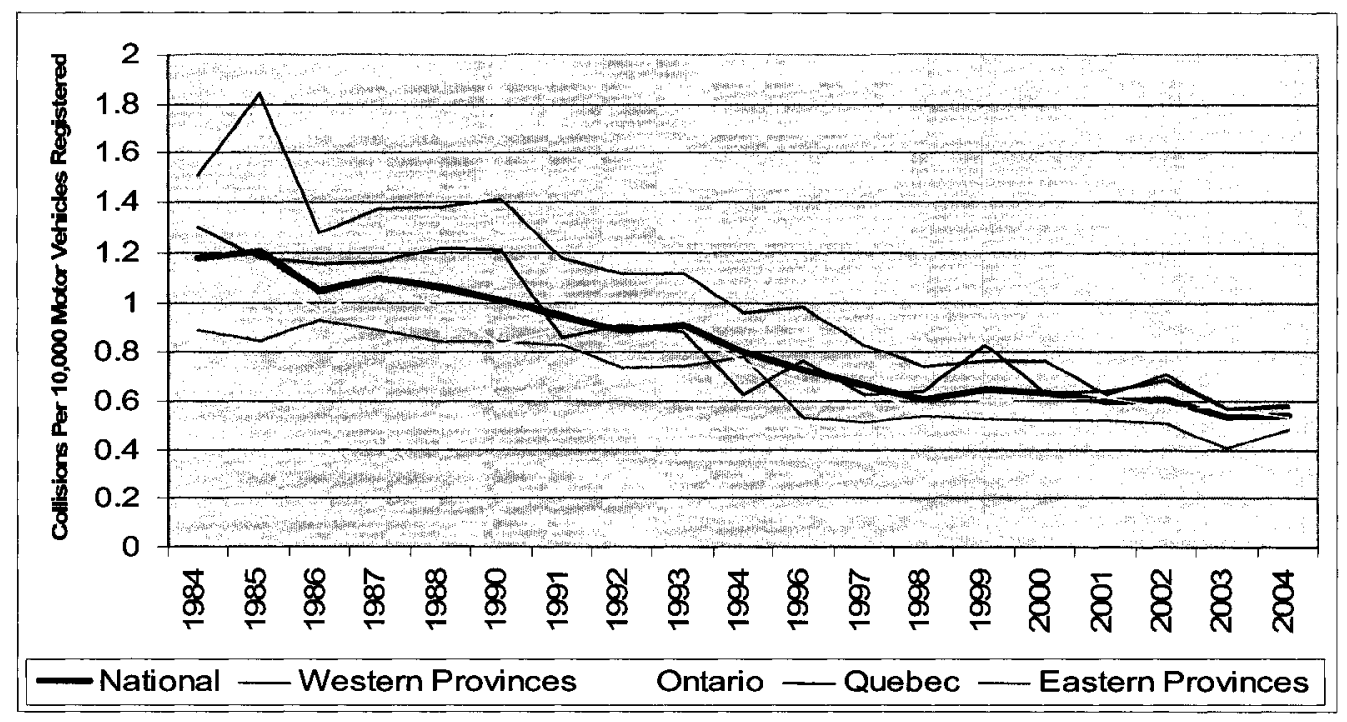

Figure 3.71: Fatal Collisions That Occurred Where the Speed Limit was 80\&90 km/h Per 10,000 Motor Vehicles Registered By Year.

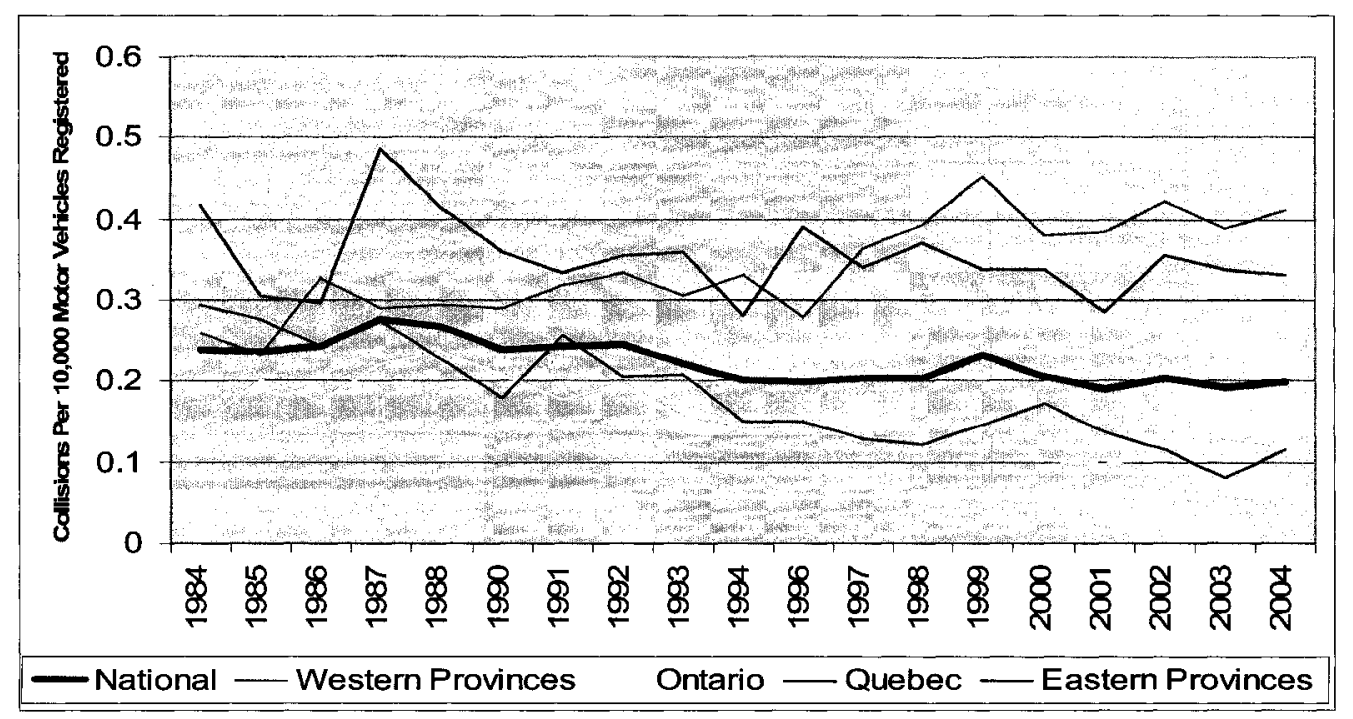

Figure 3.72: Fatal Collisions That Occurred Where the Speed Limit was 100\&110 km/h Per 10,000 Motor Vehicles Registered By Year. 


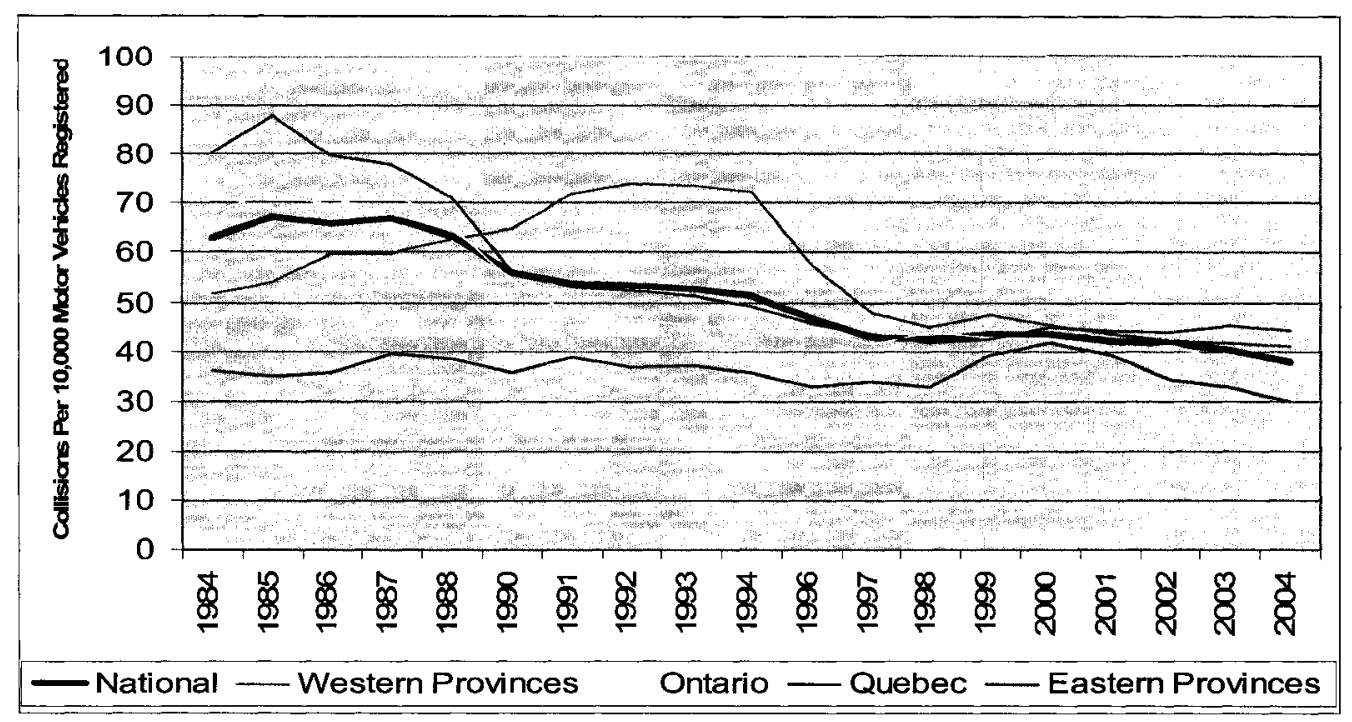

Figure 3.73: Injury Collisions That Occurred Where the Speed Limit was 40\&50 km/h Per 10,000 Motor Vehicles Registered By Year.

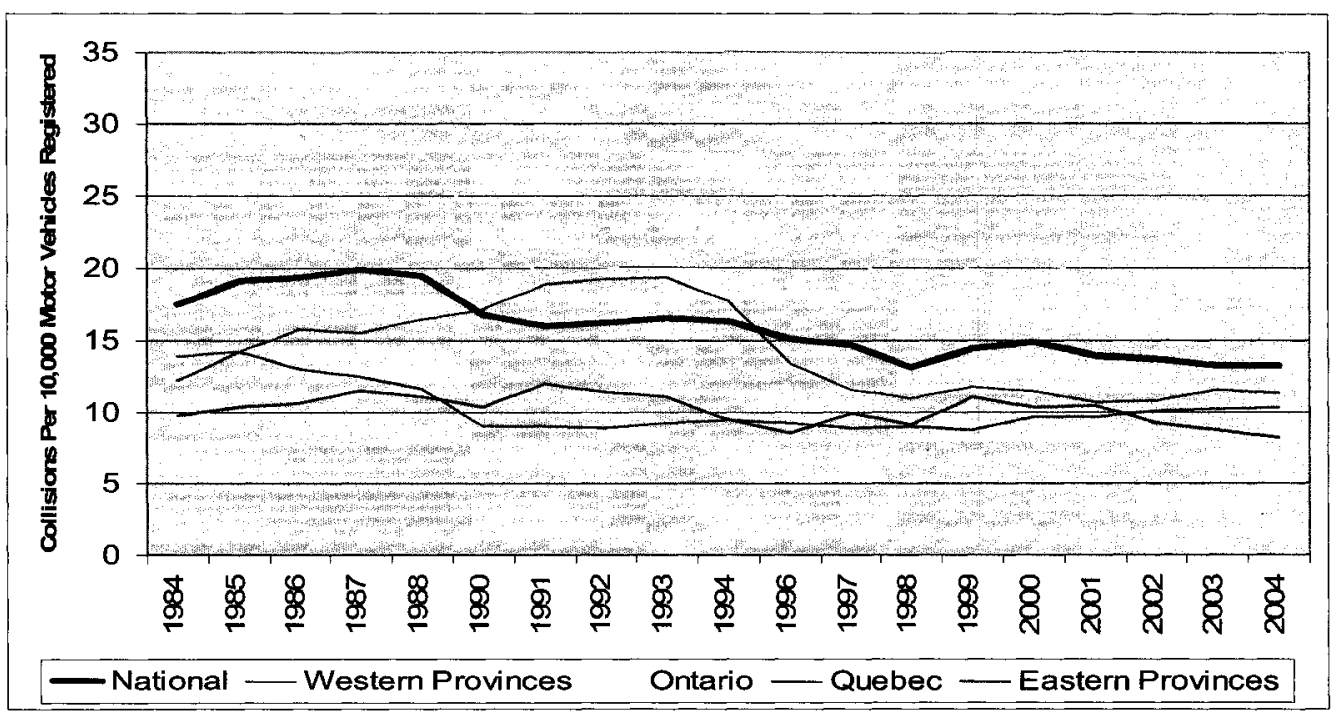

Figure 3.74: Injury Collisions That Occurred Where the Speed Limit was 60\&70 km/h Per 10,000 Motor Vehicles Registered By Year. 


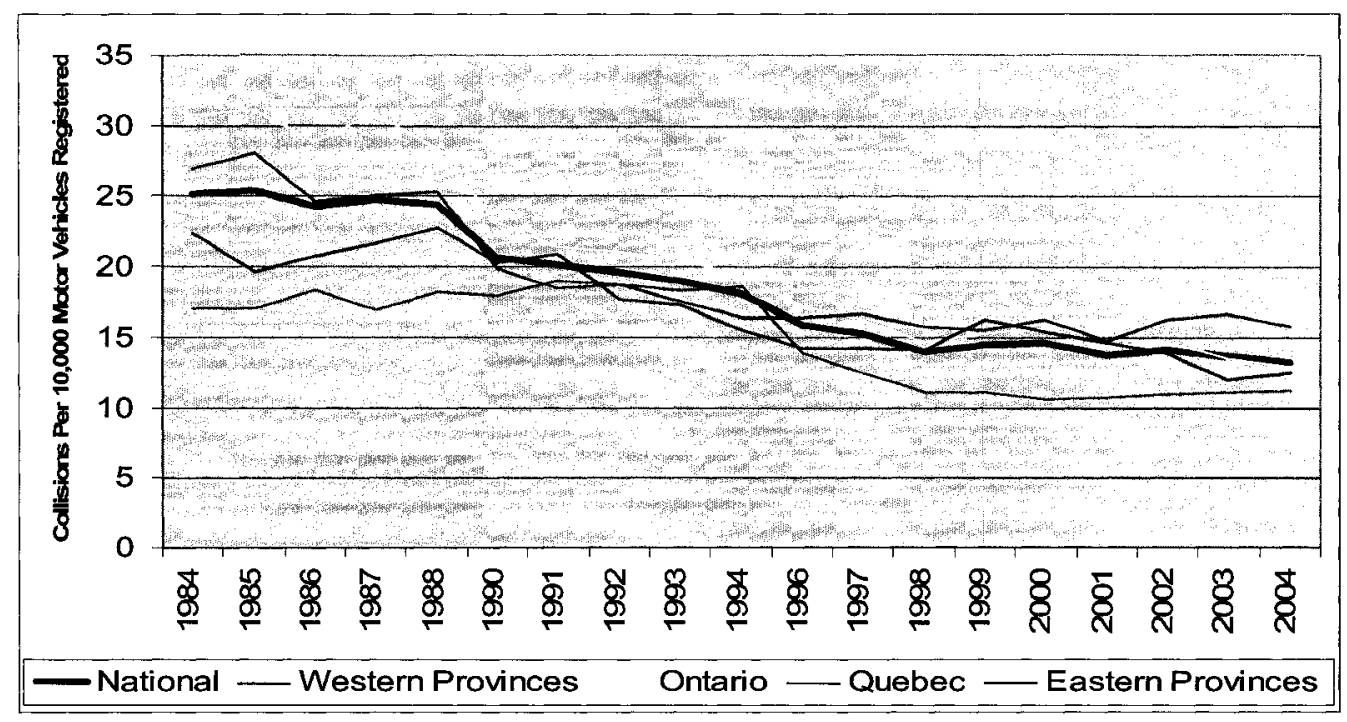

Figure 3.75: Injury Collisions That Occurred Where the Speed Limit was 80\&90 km/h Per 10,000 Motor Vehicles Registered By Year.

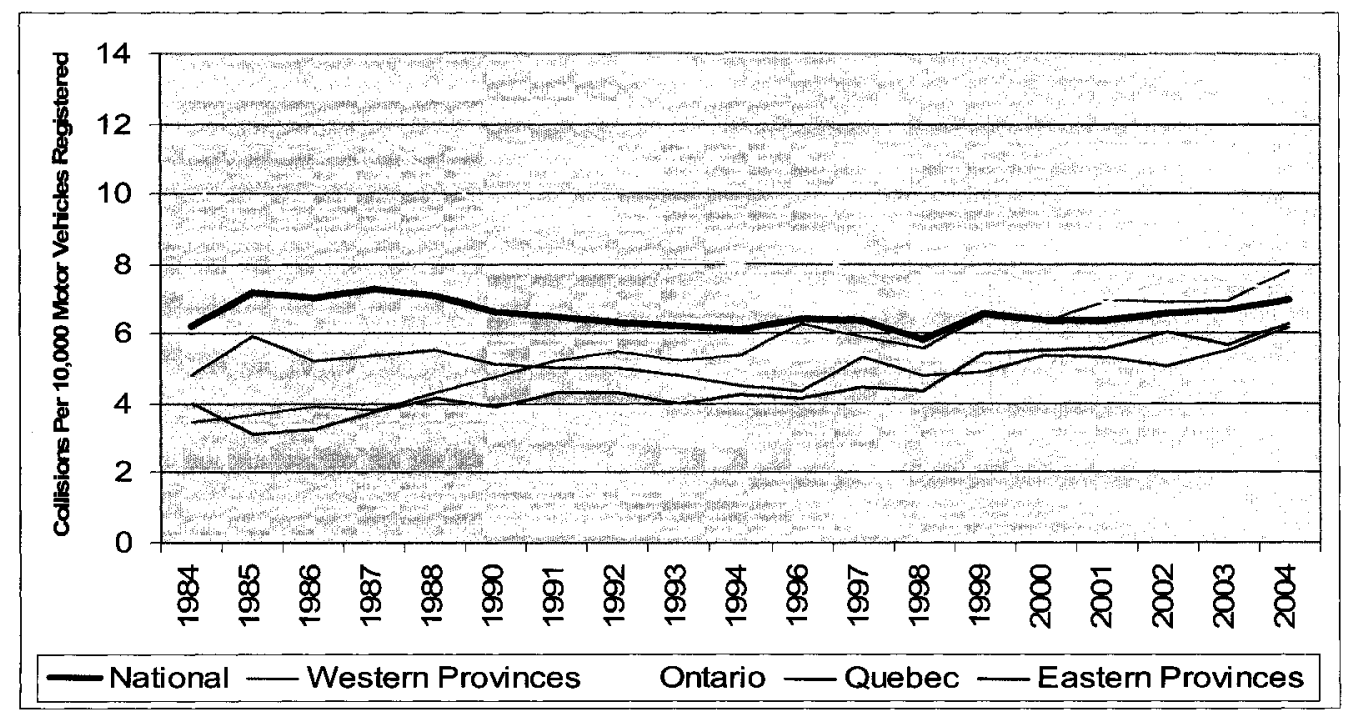

Figure 3.76: Injury Collisions That Occurred Where the Speed Limit was 100\&110 km/h Per 10,000 Motor Vehicles Registered By Year. 


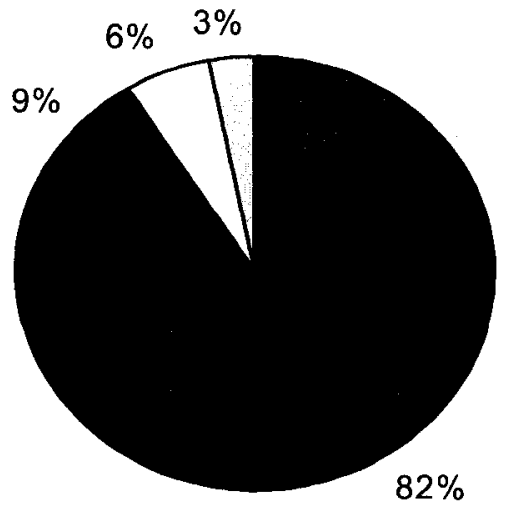

Clear

Raining

$\square$ Snowing $\square$ Other

Figure 3.77: Percentage of Fatal Collisions for Weather Condition Values.

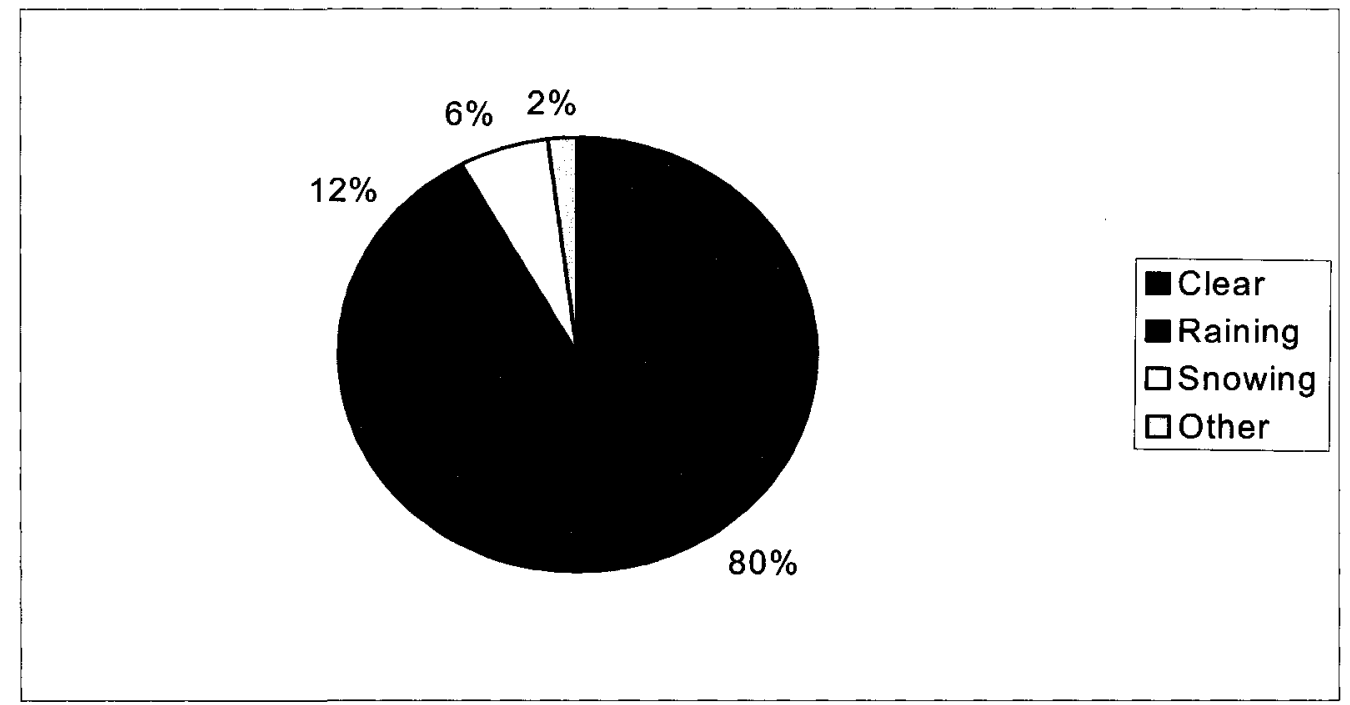

Figure 3.78: Percentage of Injury Collisions for Weather Condition Values. 


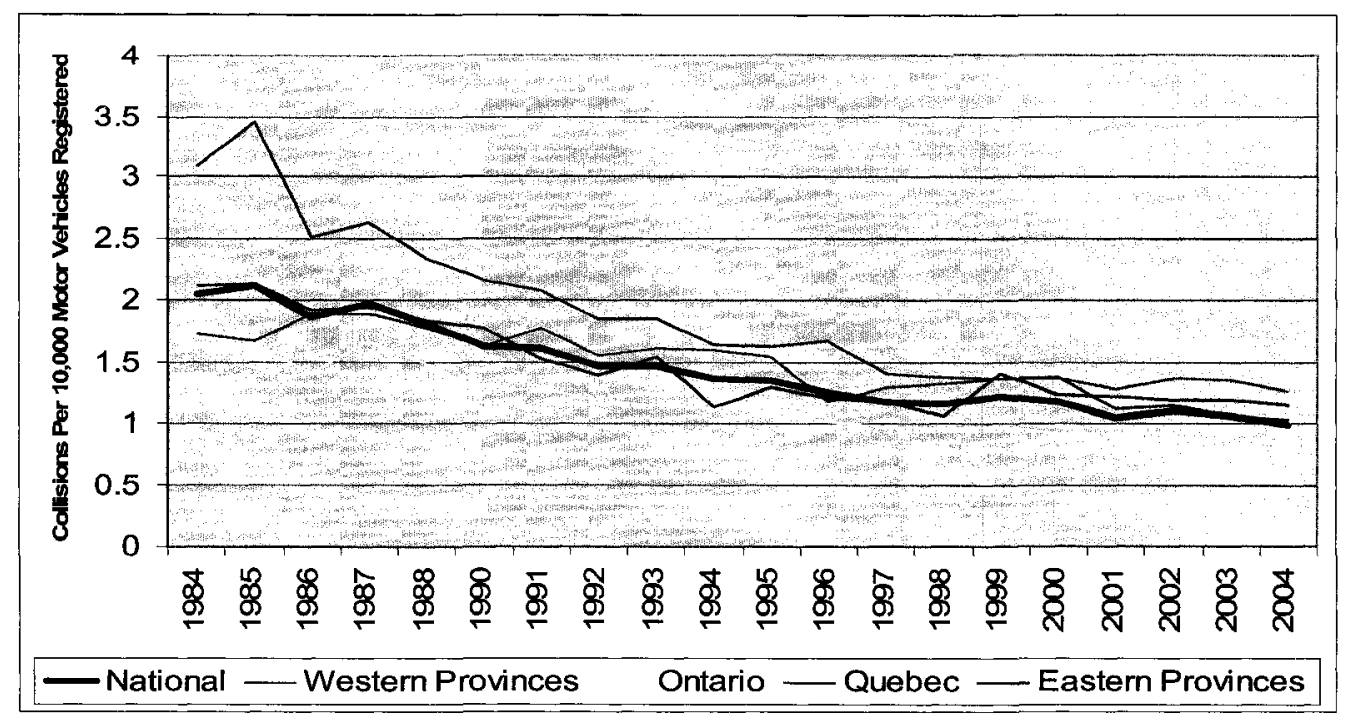

Figure 3.79: Fatal Collisions That Occurred When the Weather was Clear Per 10,000 Motor Vehicles Registered By Year.

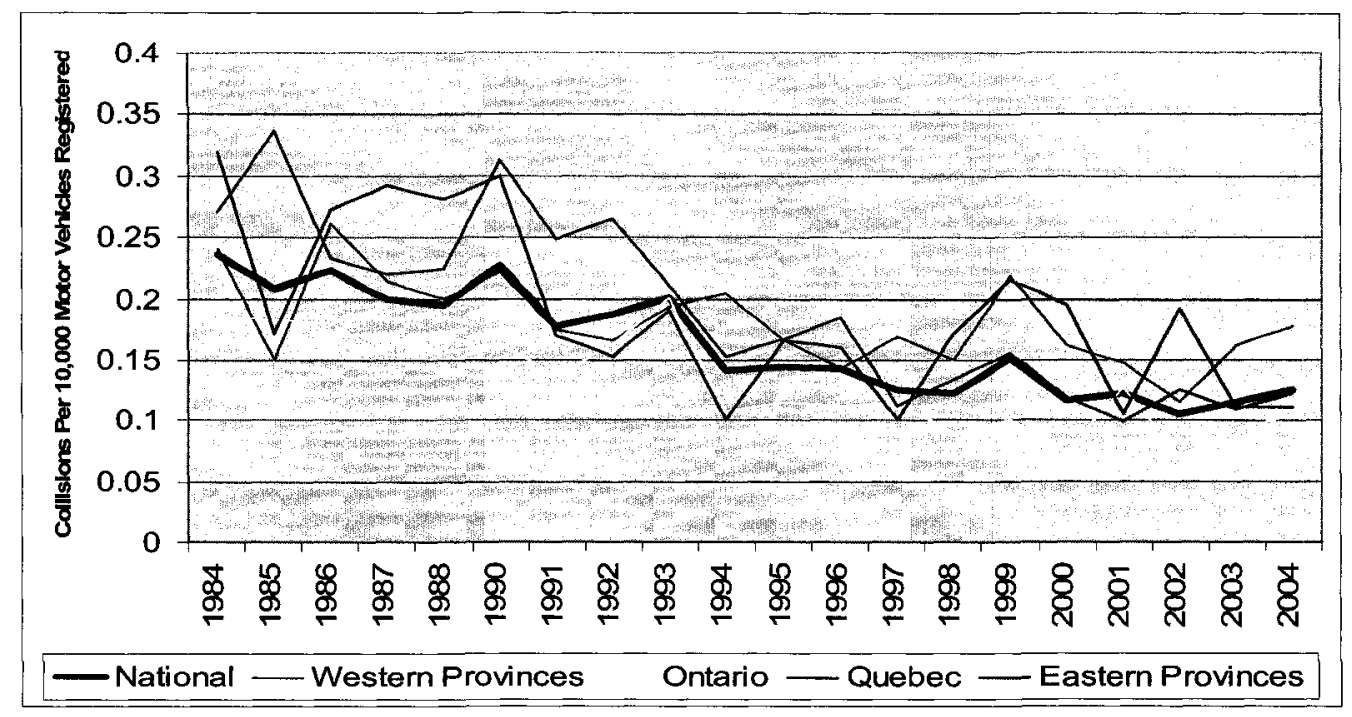

Figure 3.80: Fatal Collisions That Occurred When it was Raining Per 10,000 Motor Vehicles Registered By Year. 


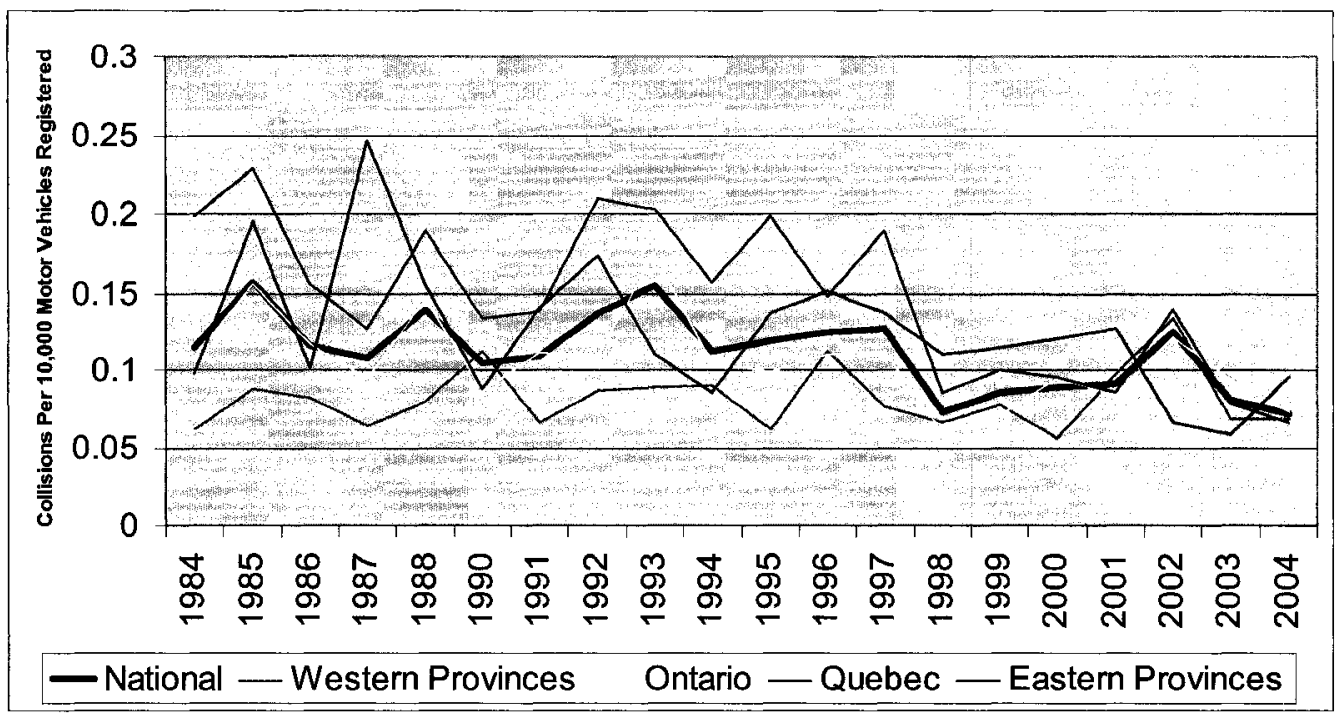

Figure 3.81: Fatal Collisions That Occurred When it was Snowing Per 10,000 Motor Vehicles Registered By Year.

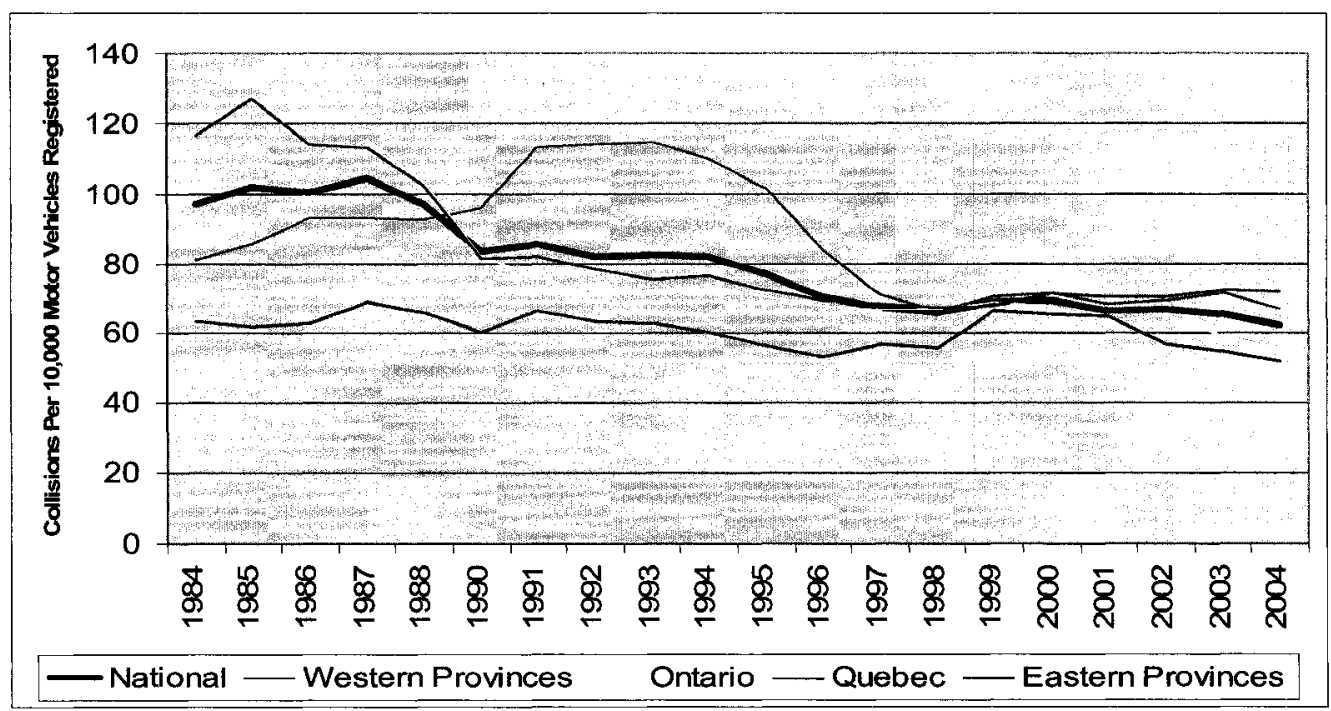

Figure 3.82: Injury Collisions That Occurred When the Weather was Clear Per 10,000 Motor Vehicles Registered By Year. 


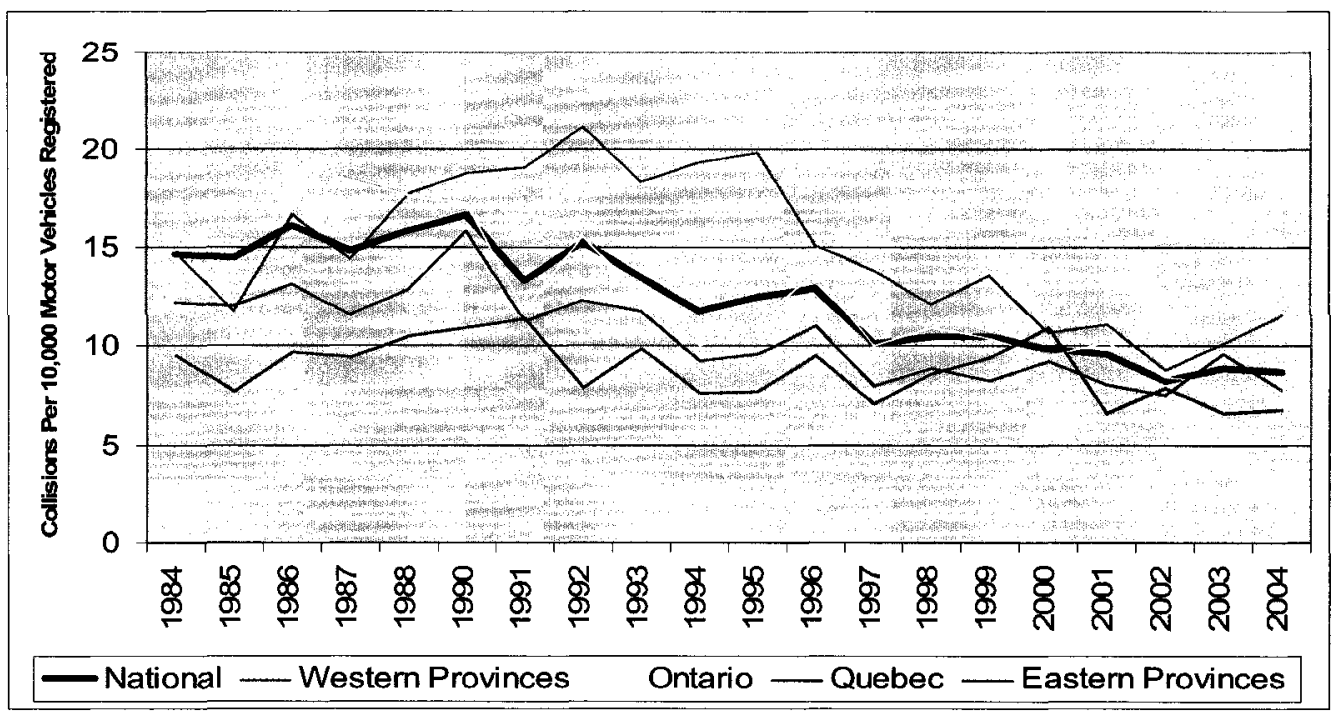

Figure 3.83: Injury Collisions That Occurred When it was Raining Per 10,000 Motor Vehicles Registered By Year.

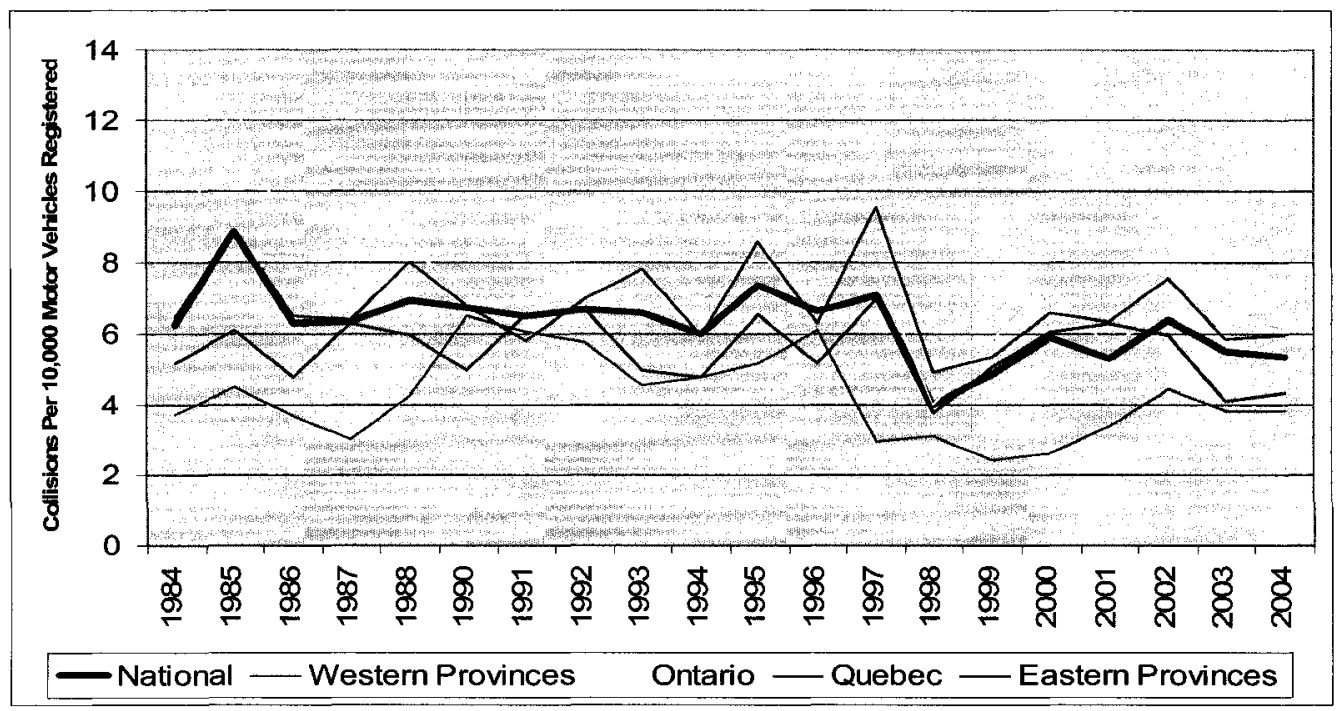

Figure 3.84: Injury Collisions That Occurred When it was Snowing Per 10,000 Motor Vehicles Registered By Year. 


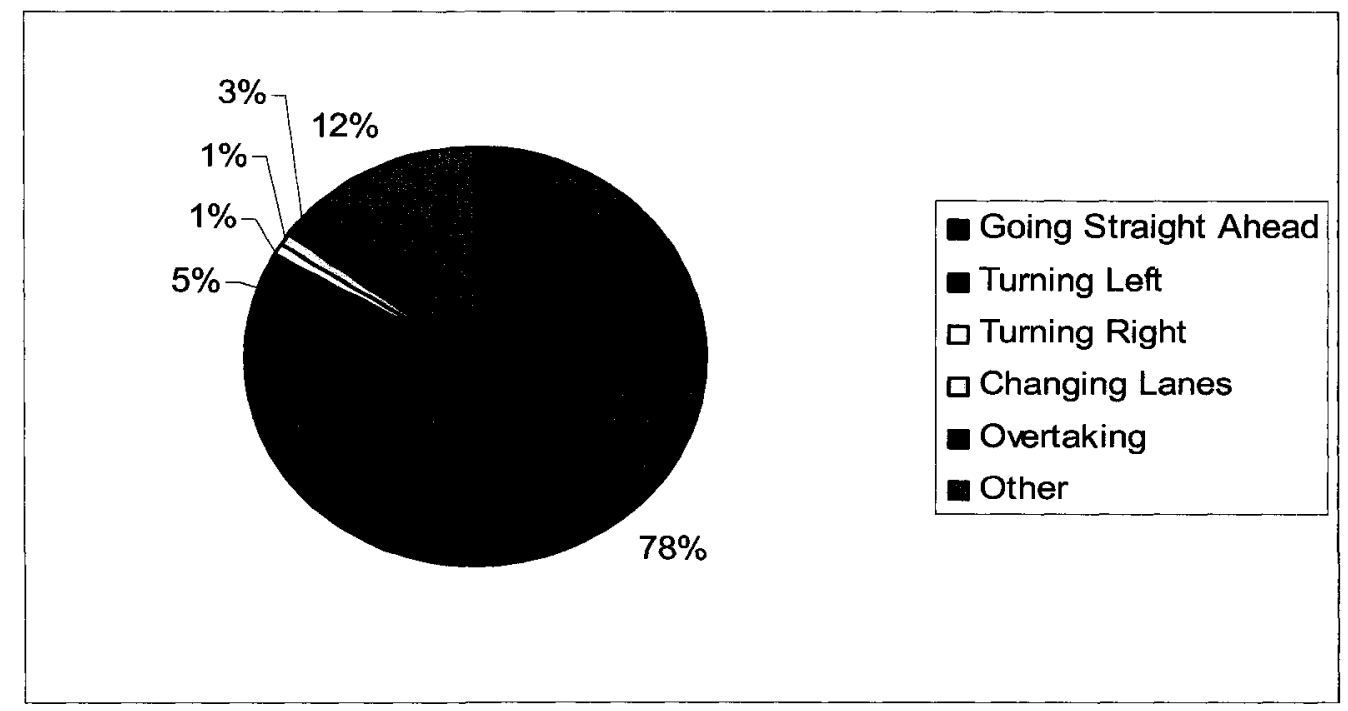

Figure 3.85: Percentage of Vehicles Involved in Fatal Collisions for Vehicle Manoeuvre Values.

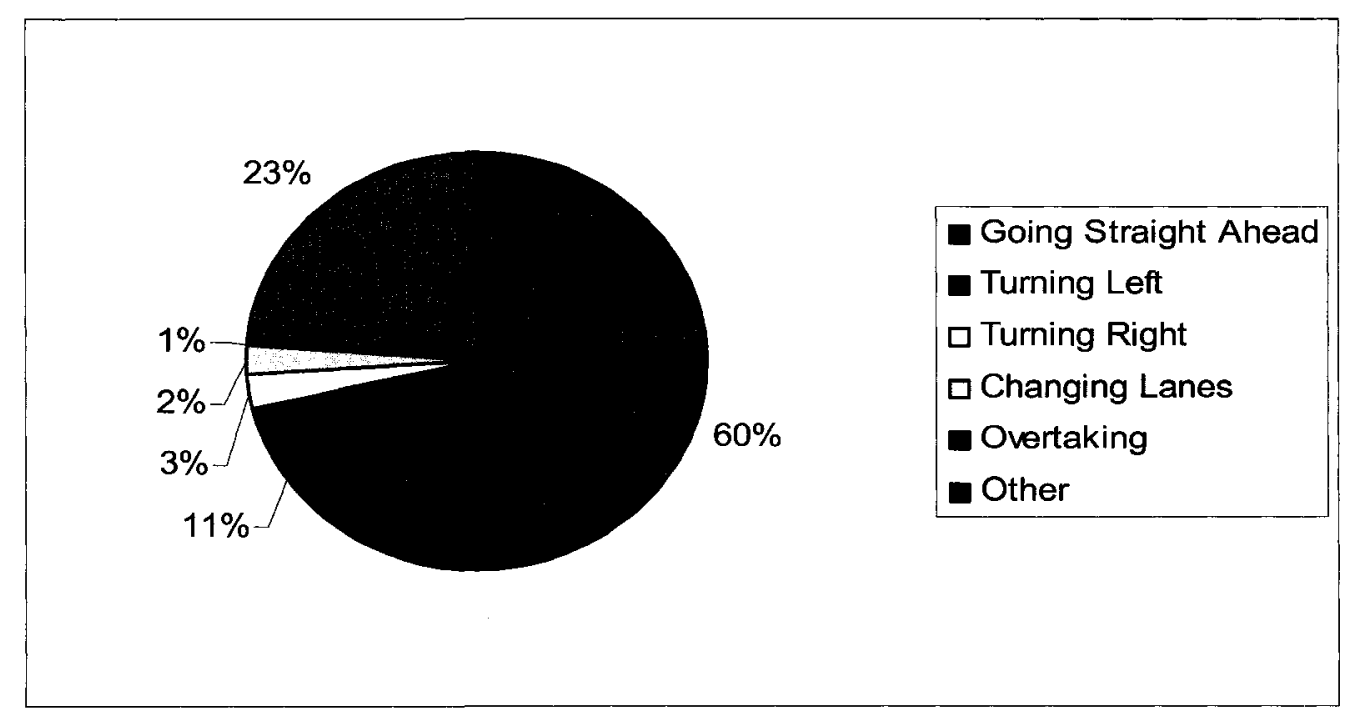

Figure 3.86: Percentage of Vehicles Involved in Injury Collisions for Vehicle Manoeuvre Values. 


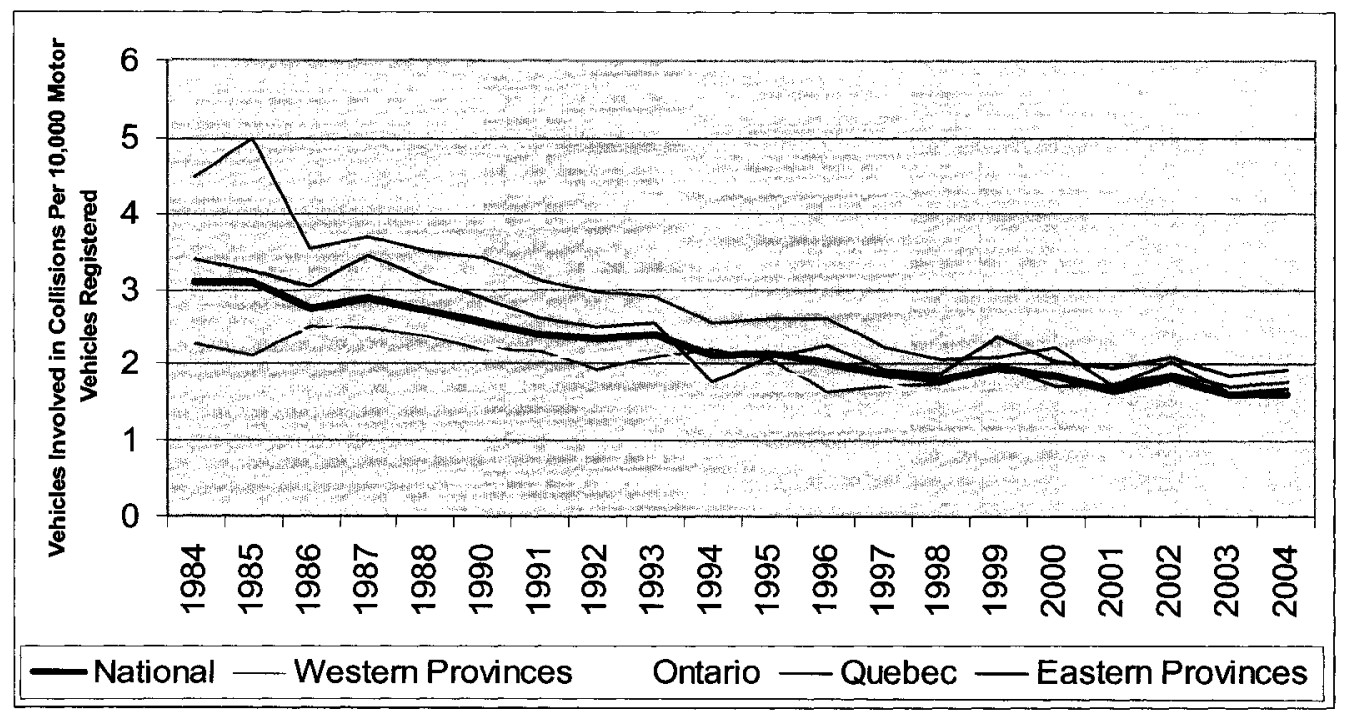

Figure 3.87: Vehicles Involved in Fatal Collisions While They Were Travelling Straight Ahead Per 10,000 Motor Vehicles Registered By Year.

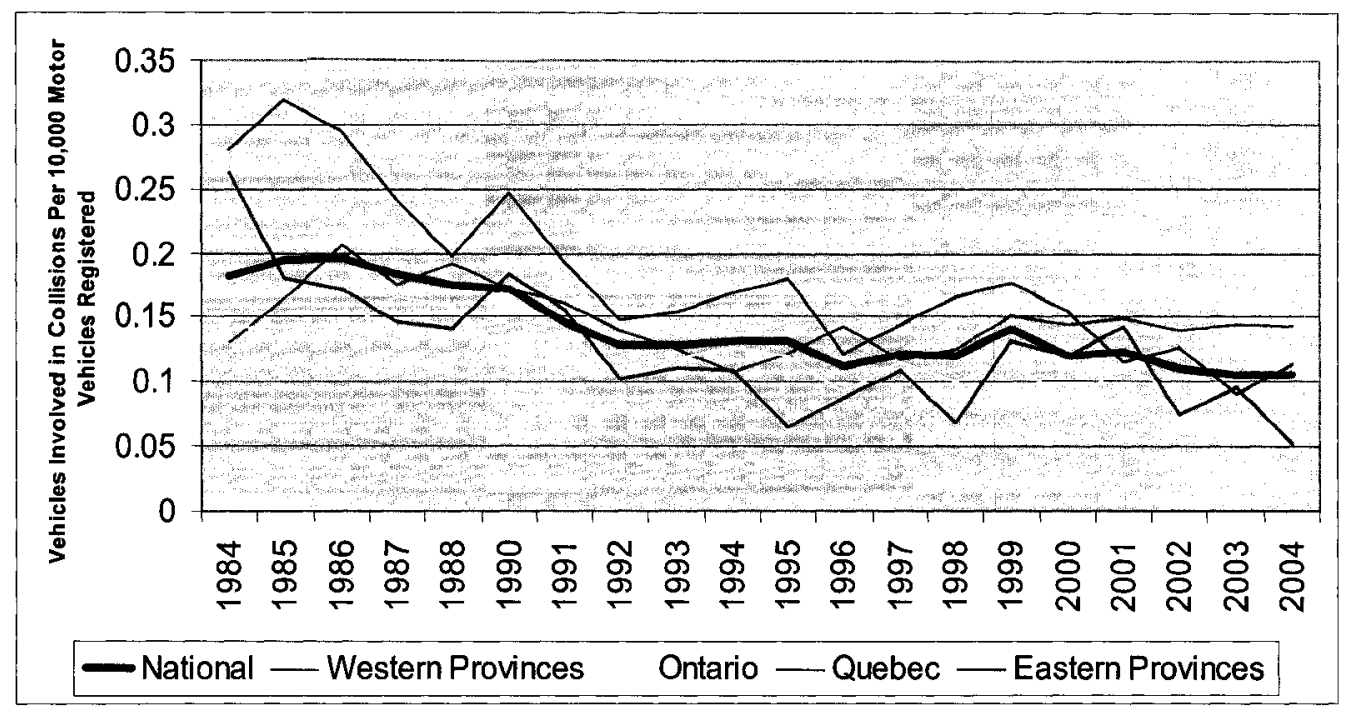

Figure 3.88: Vehicles Involved in Fatal Collisions While They Were Turning Left Per 10,000 Motor Vehicles Registered By Year. 


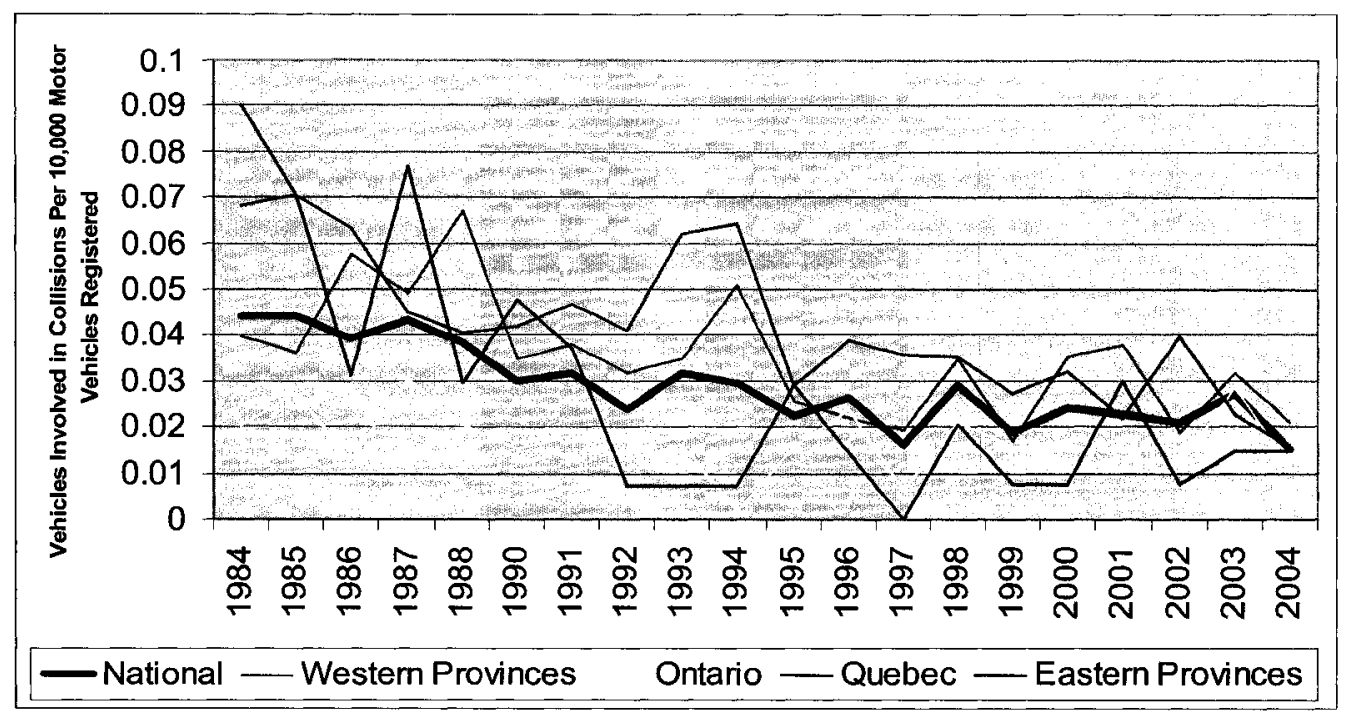

Figure 3.89: Vehicles Involved in Fatal Collisions While They Were Turning Right Per 10,000 Motor Vehicles Registered By Year.

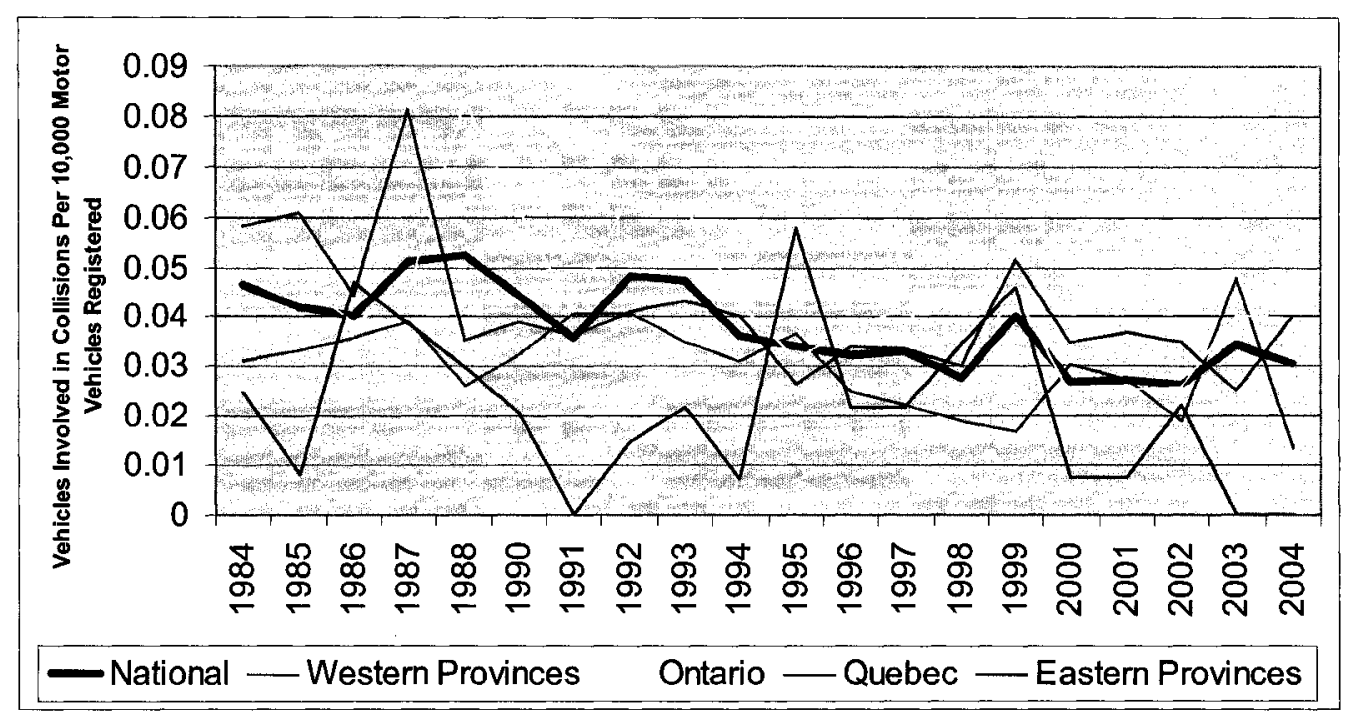

Figure 3.90: Vehicles Involved in Fatal Collisions While They Were Changing Lanes Per 10,000 Motor Vehicles Registered By Year. 


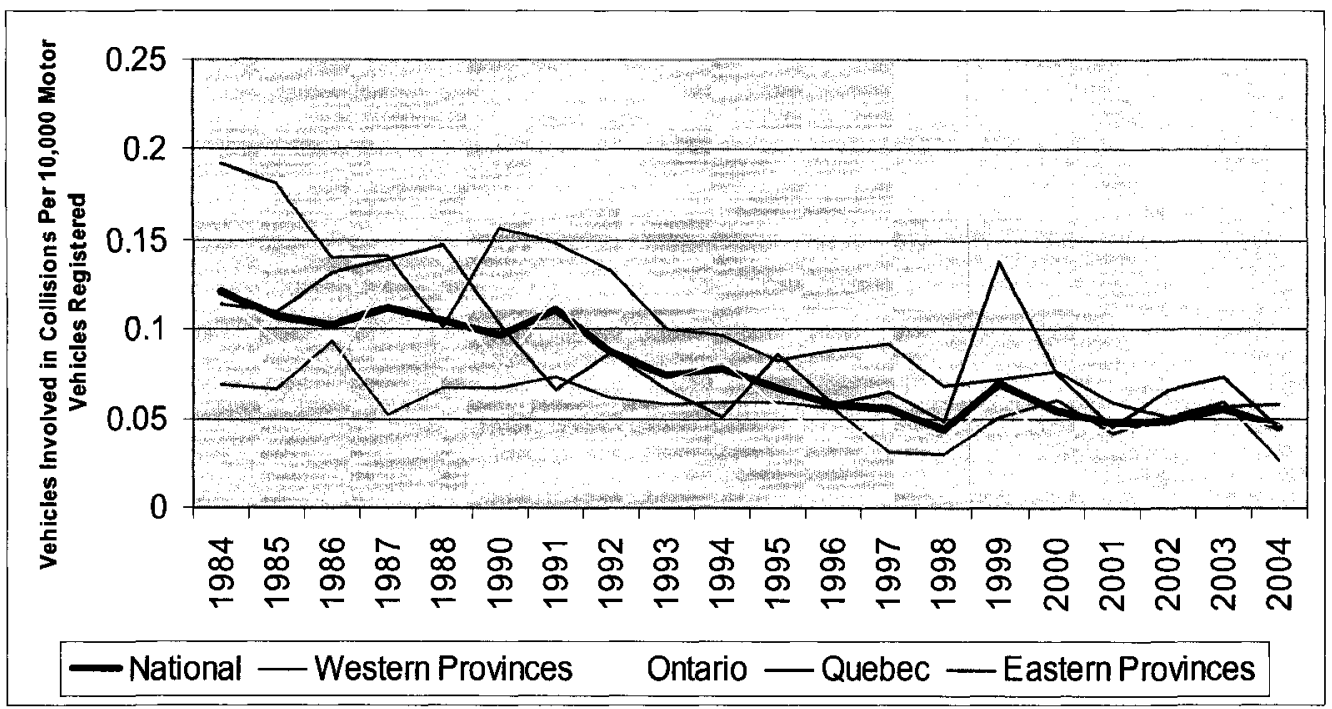

Figure 3.91: Vehicles Involved in Fatal Collisions While They Were Overtaking Another Vehicle Per 10,000 Motor Vehicles Registered By Year.

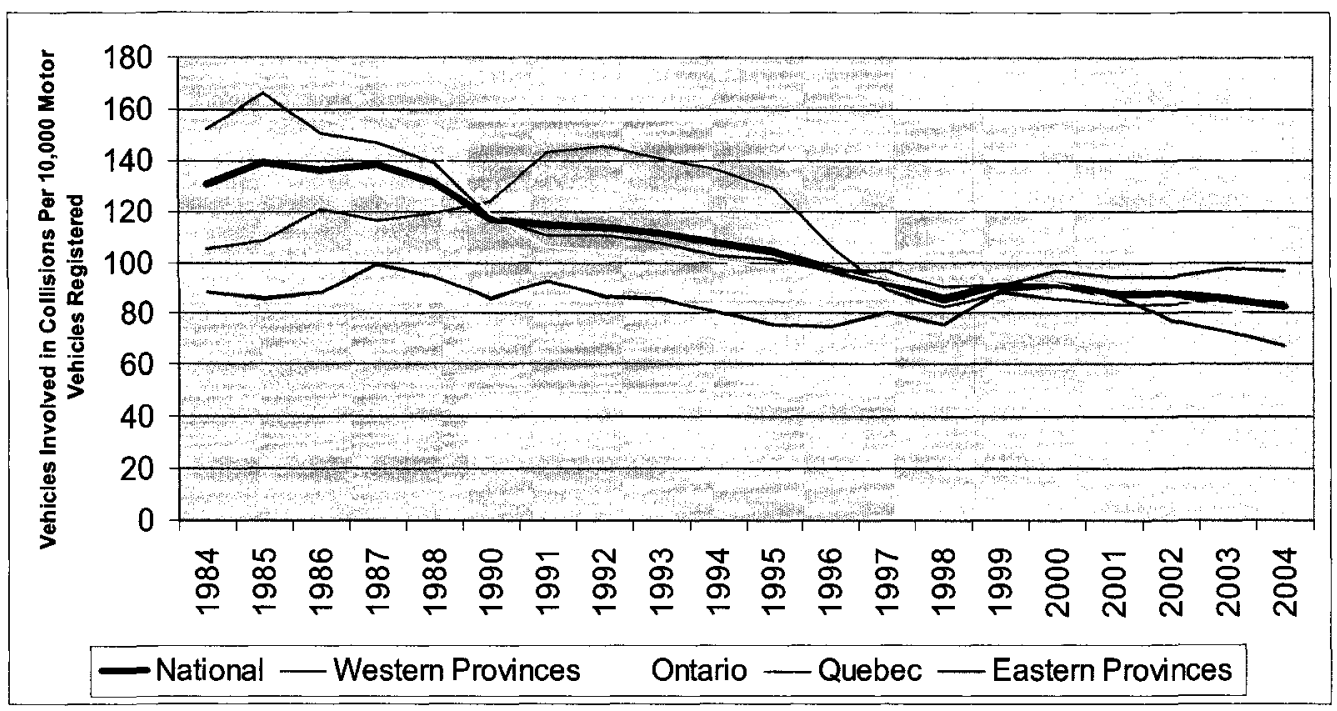

Figure 3.92: Vehicles Involved in Injury Collisions While They Were Travelling Straight Ahead Per 10,000 Motor Vehicles Registered By Year. 


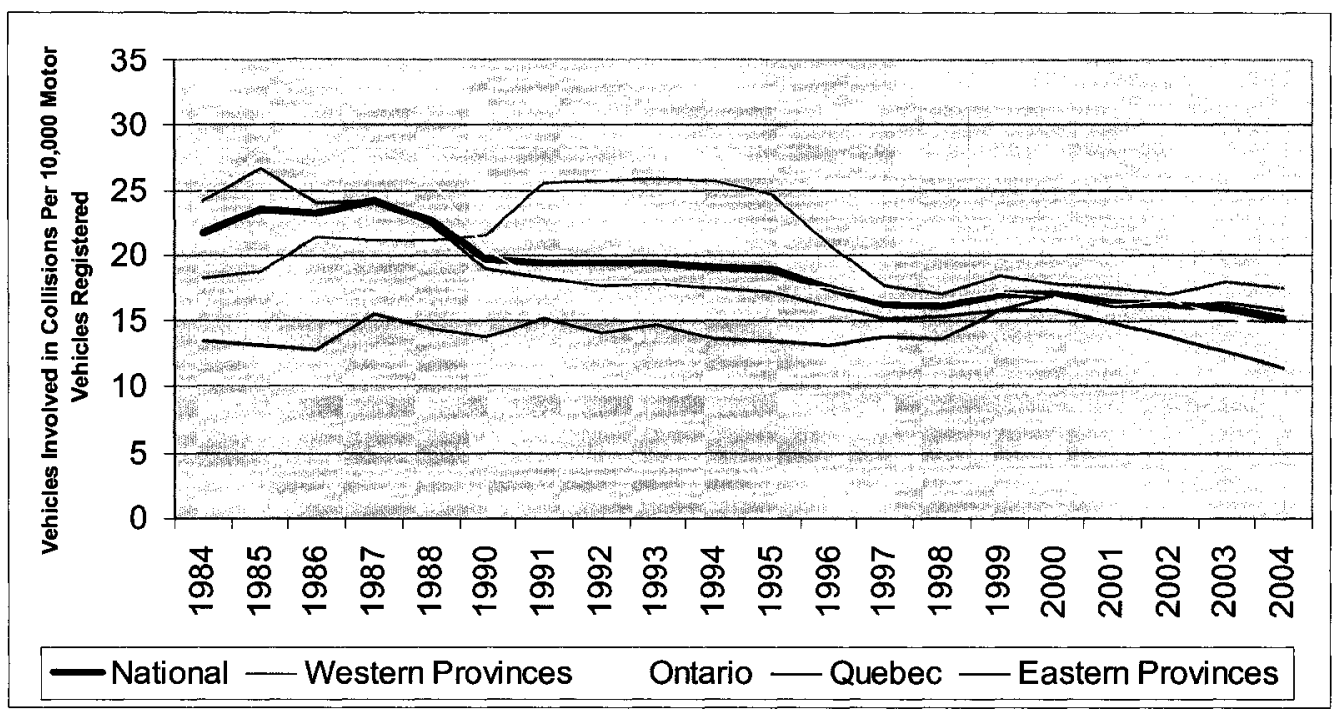

Figure 3.93: Vehicles Involved in Injury Collisions While They Were Turning Left Per 10,000 Motor Vehicles Registered By Year.

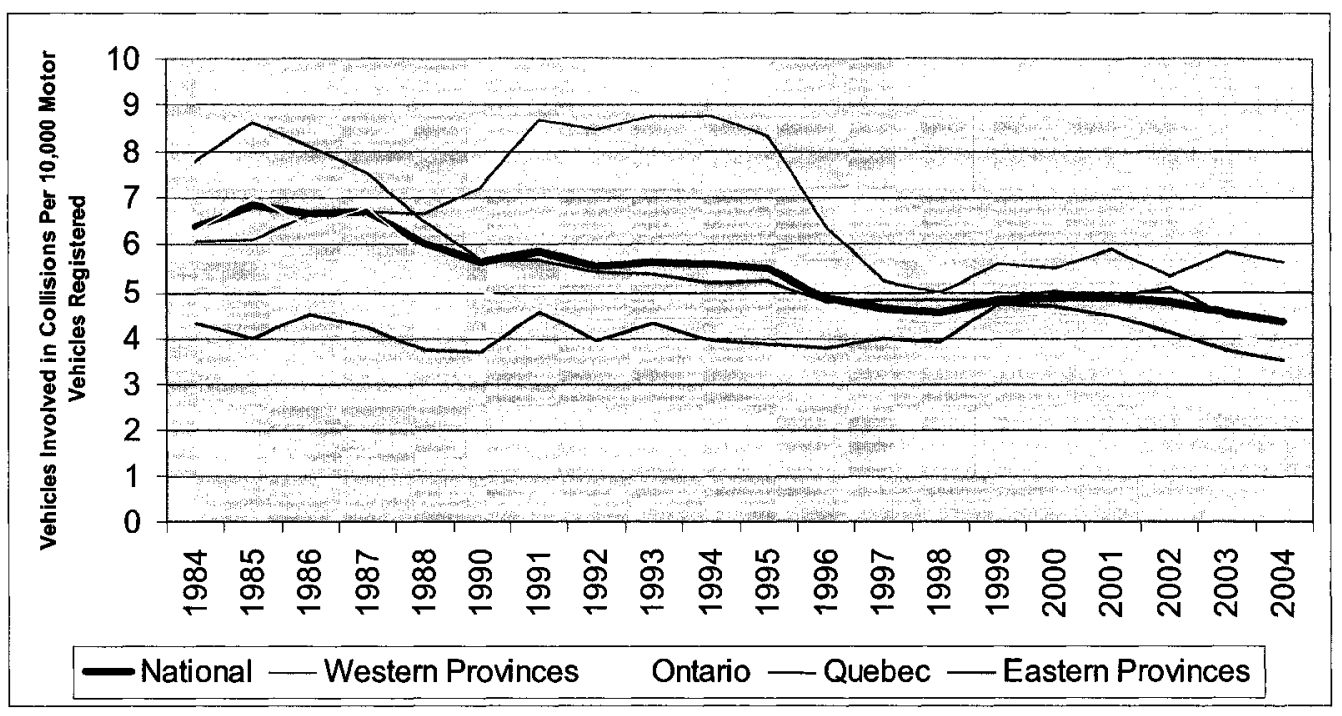

Figure 3.94: Vehicles Involved in Injury Collisions While They Were Turning Right Per 10,000 Motor Vehicles Registered By Year. 


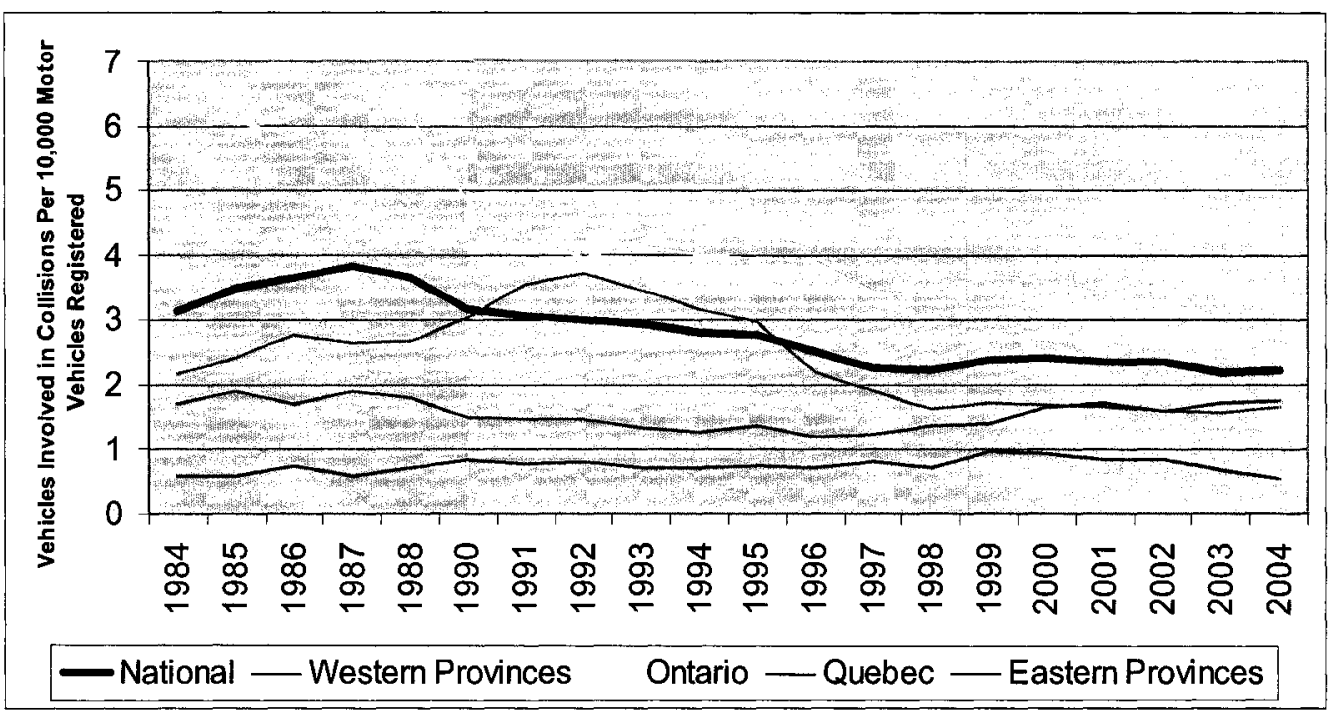

Figure 3.95: Vehicles Involved in Injury Collisions While They Were Changing Lanes Per 10,000 Motor Vehicles Registered By Year.

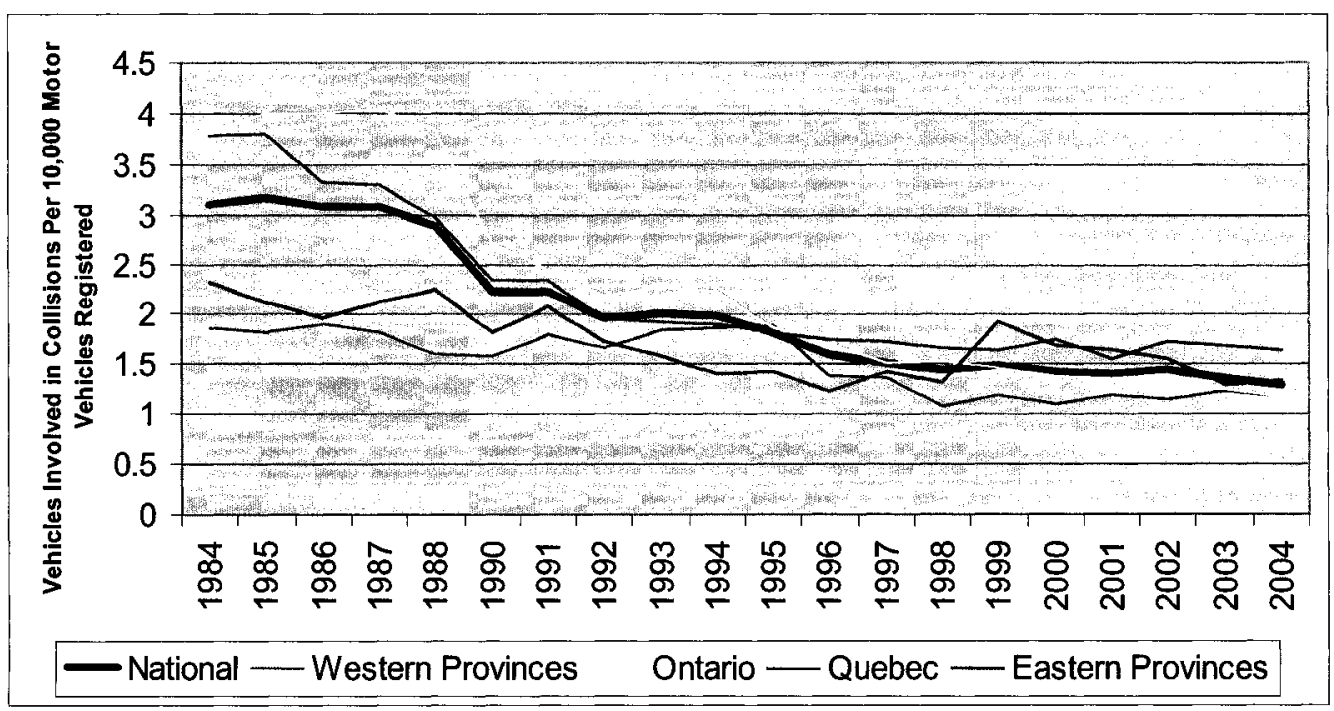

Figure 3.96: Vehicles Involved in Injury Collisions While They Were Overtaking Another Vehicle Per 10,000 Motor Vehicles Registered By Year. 


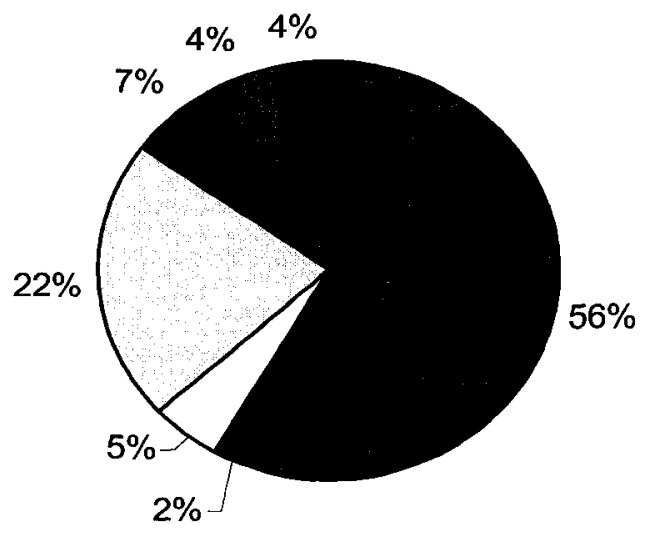

Automobile

Bicycle

$\square$ Motorcycle

口Pickup<4536 kg

- Tractor Trailer

- Truck>4536 kg

ather

Figure 3.97: Percentage of Vehicles Involved in Fatal Collisions for Vehicle Type Values.

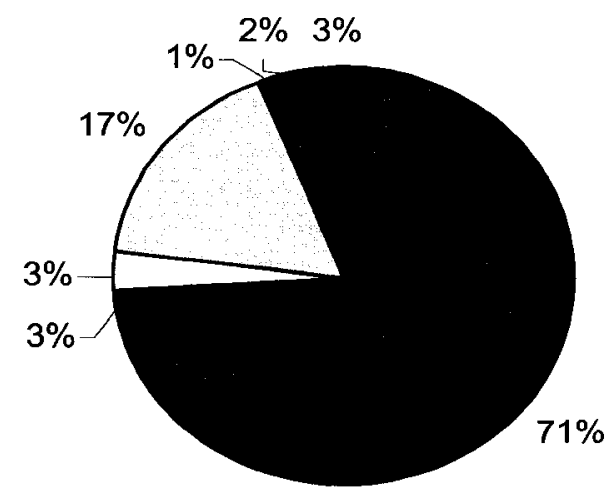

Automobile - Bicycle $\square$ Motorcycle 口 Pickup<4536 kg n Tractor Trailer - Truck>4536 kg - Other

Figure 3.98: Percentage of Vehicles Involved in Injury Collisions for Vehicle Type Values. 


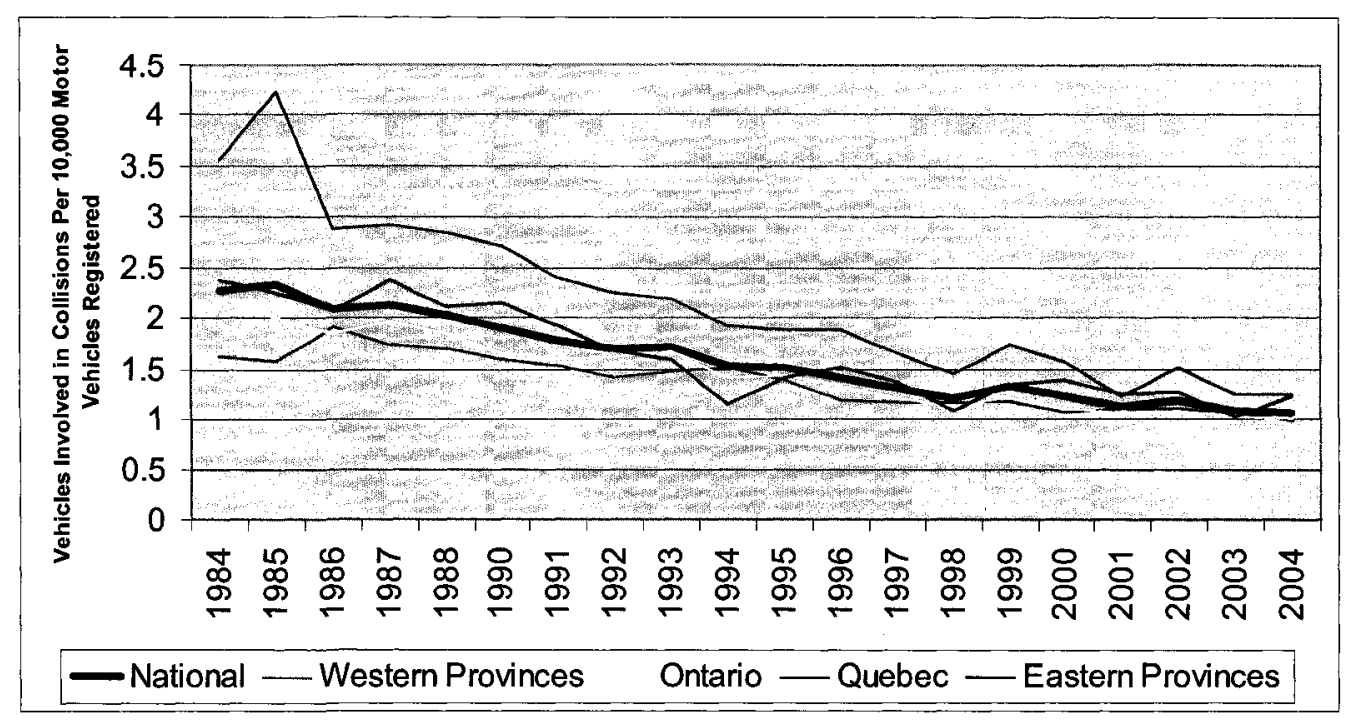

Figure 3.99: Automobiles Involved in Fatal Collisions Per 10,000 Motor Vehicles Registered By Year.

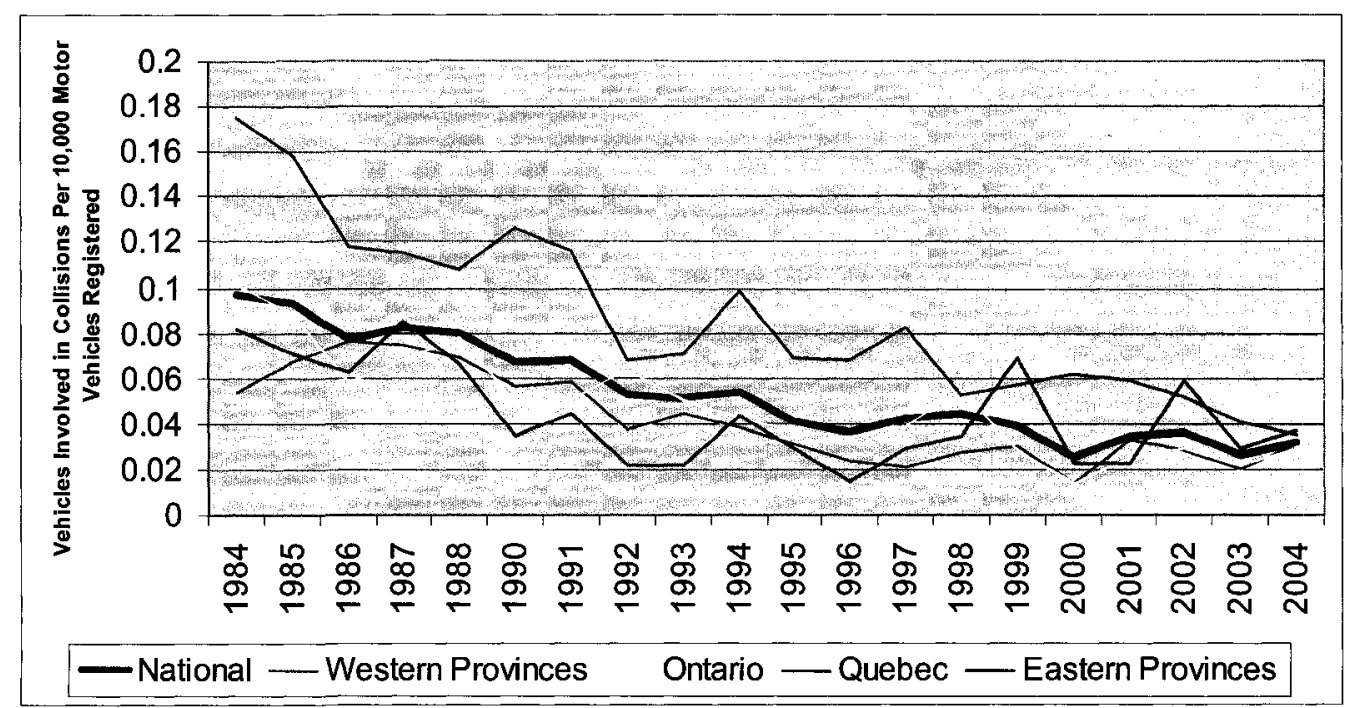

Figure 3.100: Bicycles Involved in Fatal Collisions Per 10,000 Motor Vehicles Registered By Year. 


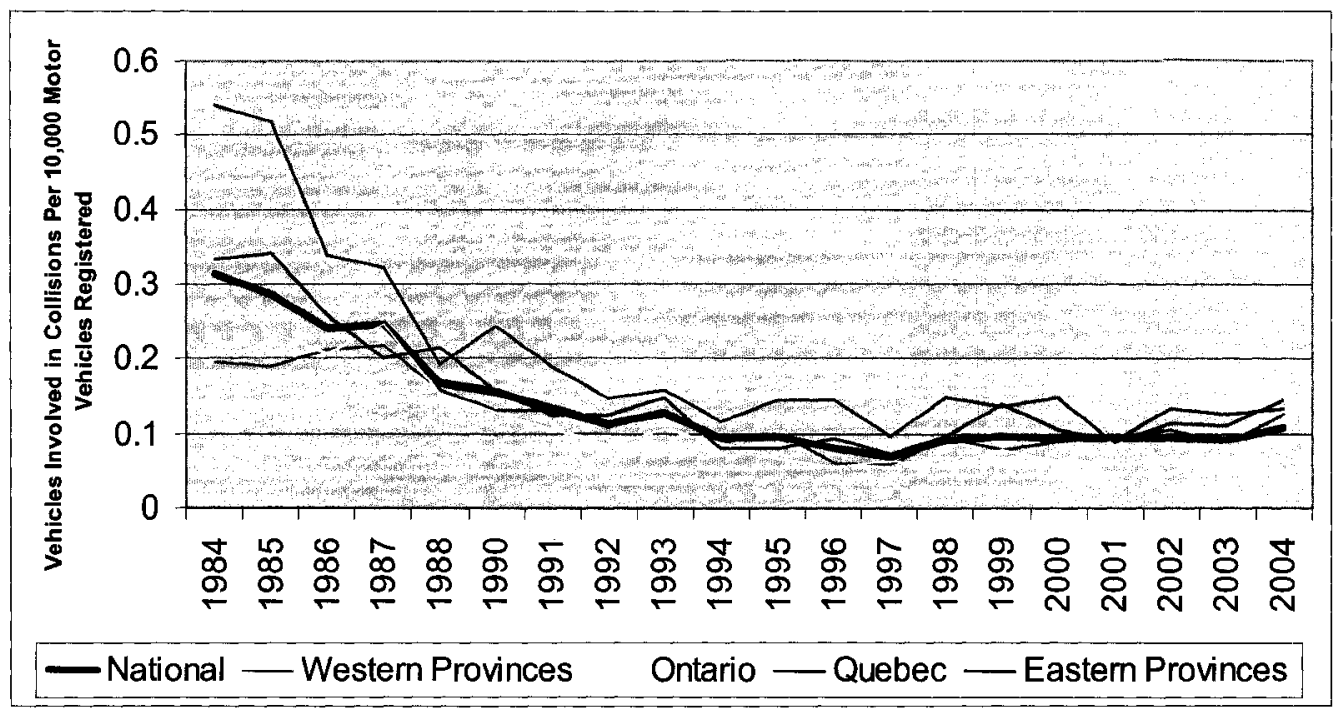

Figure 3.101: Motorcycles Involved in Fatal Collisions Per 10,000 Motor Vehicles Registered By Year.

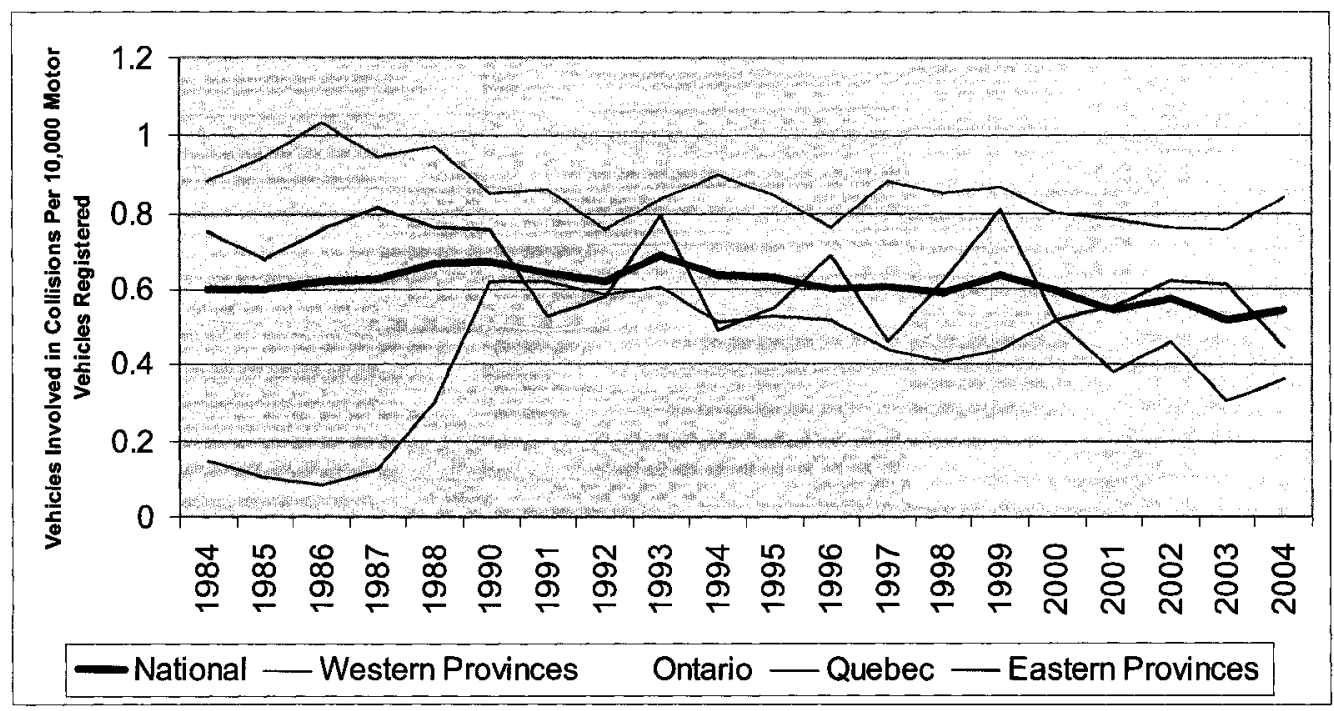

Figure 3.102: Pick-Up Trucks Involved in Fatal Collisions Per 10,000 Motor Vehicles Registered By Year. 


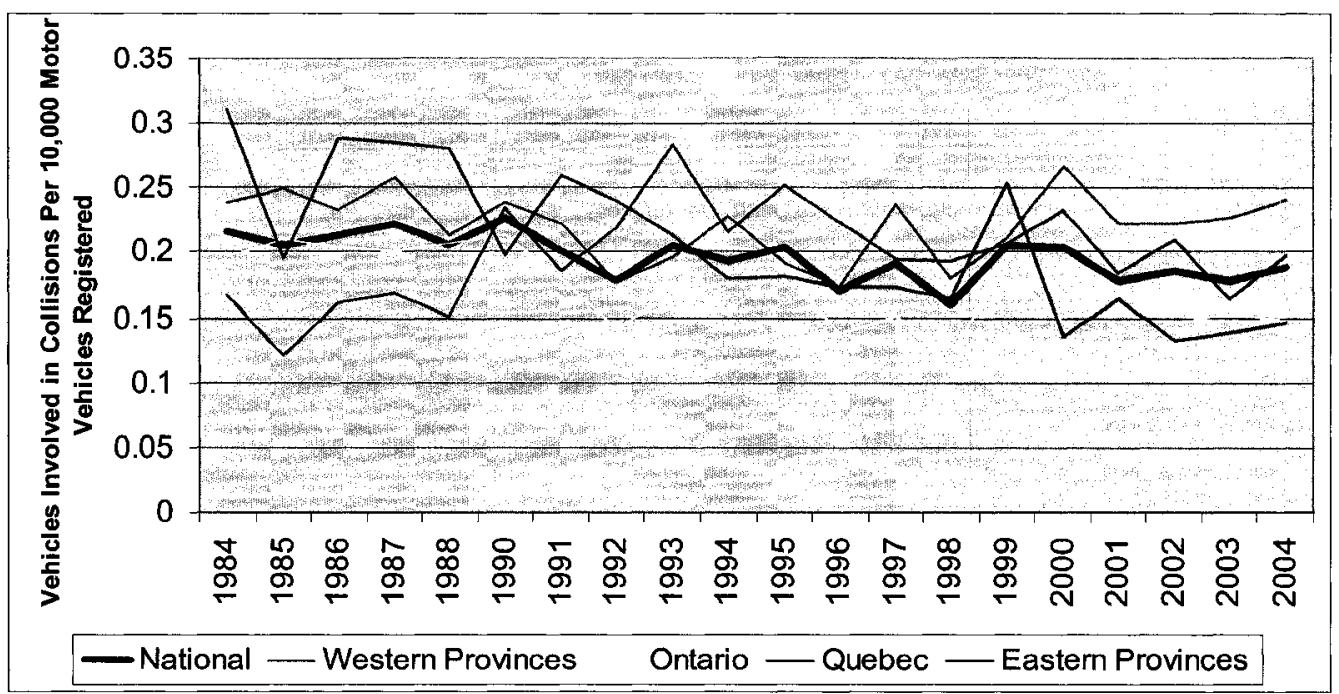

Figure 3.103: Tractor Trailers Involved in Fatal Collisions Per 10,000 Motor Vehicles Registered By Year.

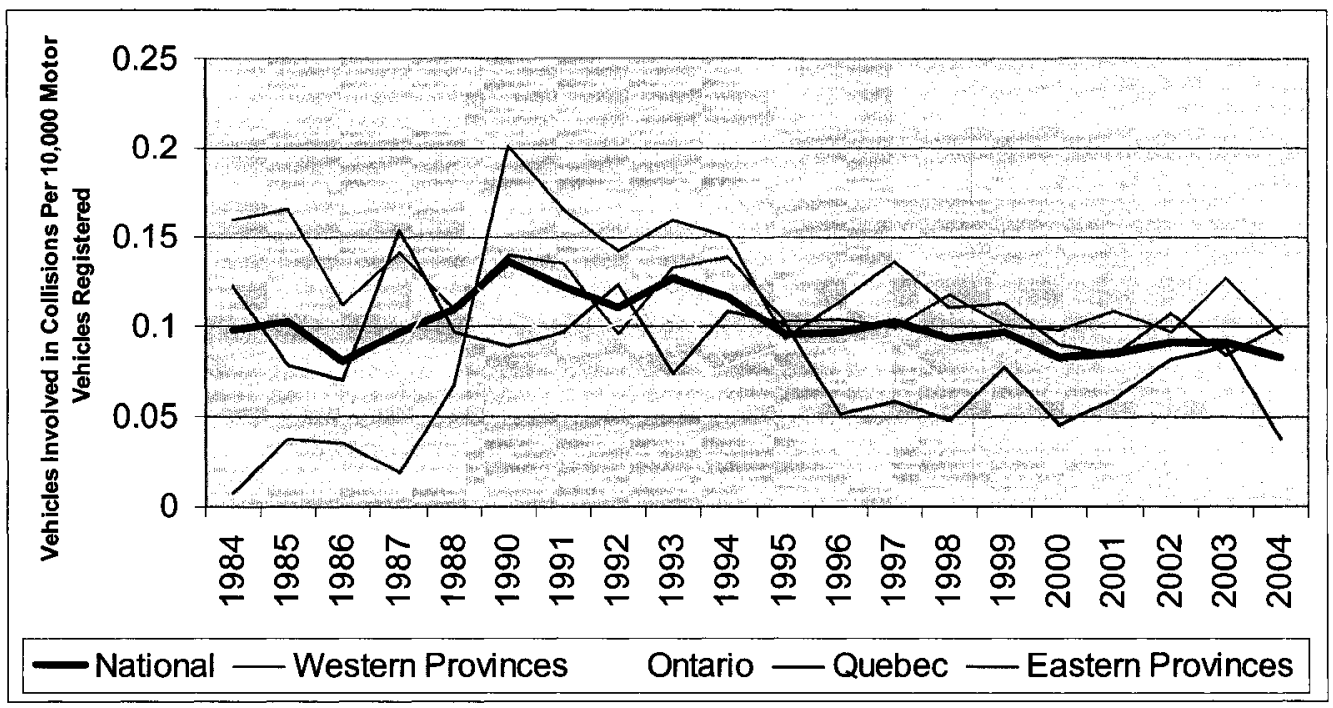

Figure 3.104: Trucks $>4536$ kg Involved in Fatal Collisions Per 10,000 Motor Vehicles Registered By Year. 


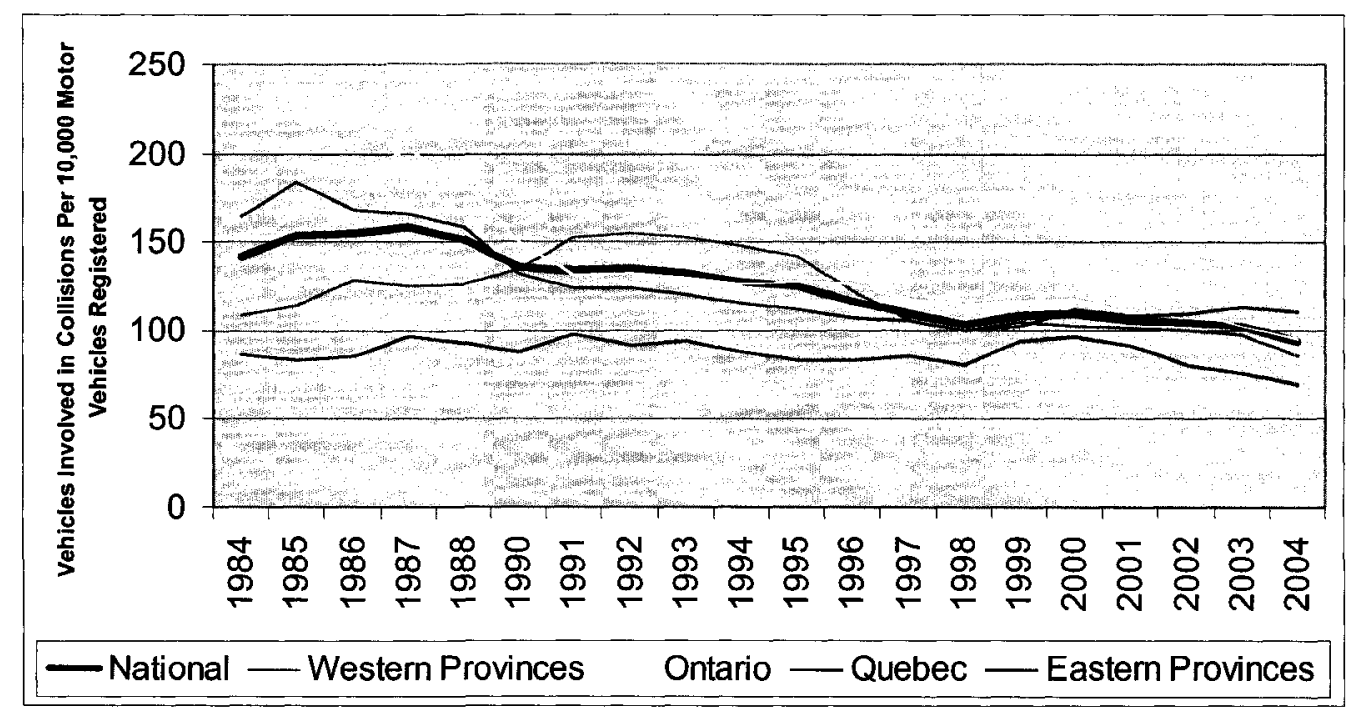

Figure 3.105: Automobiles Involved in Injury Collisions Per 10,000 Motor Vehicles Registered By Year.

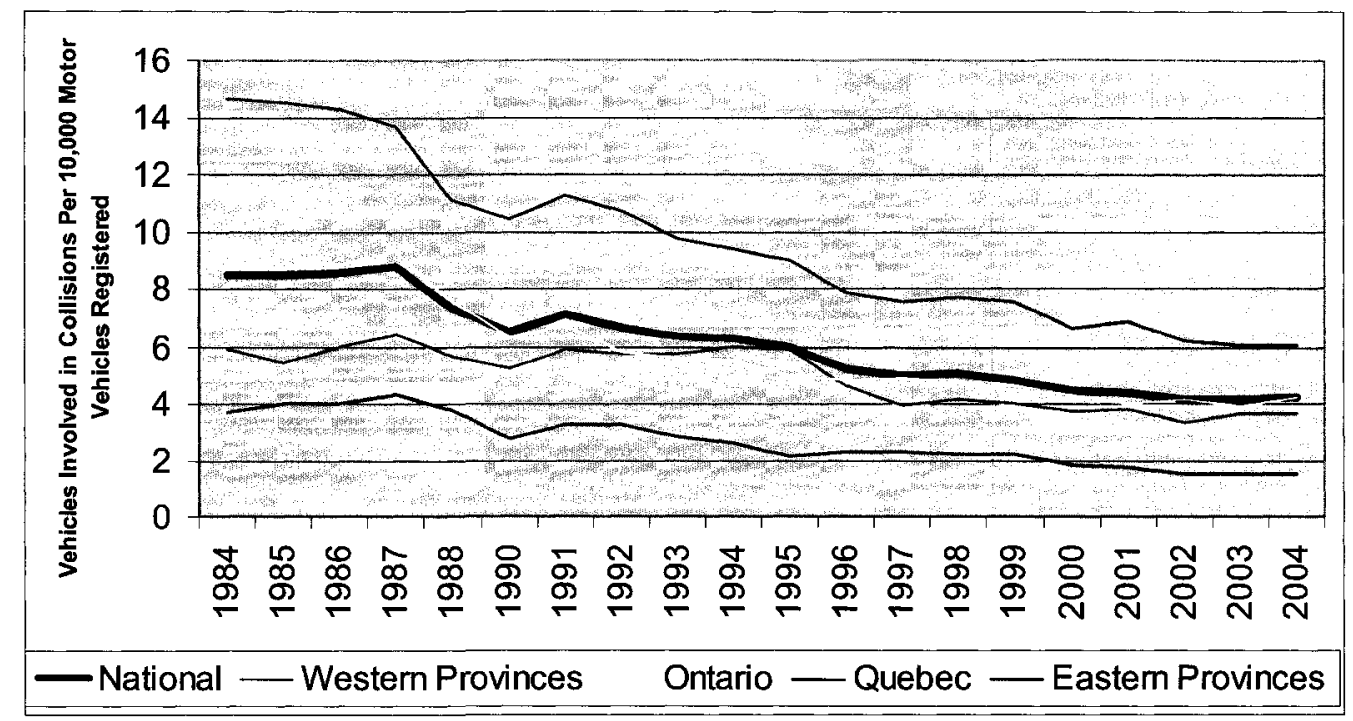

Figure 3.106: Bicycles Involved in Injury Collisions Per 10,000 Motor Vehicles Registered By Year. 


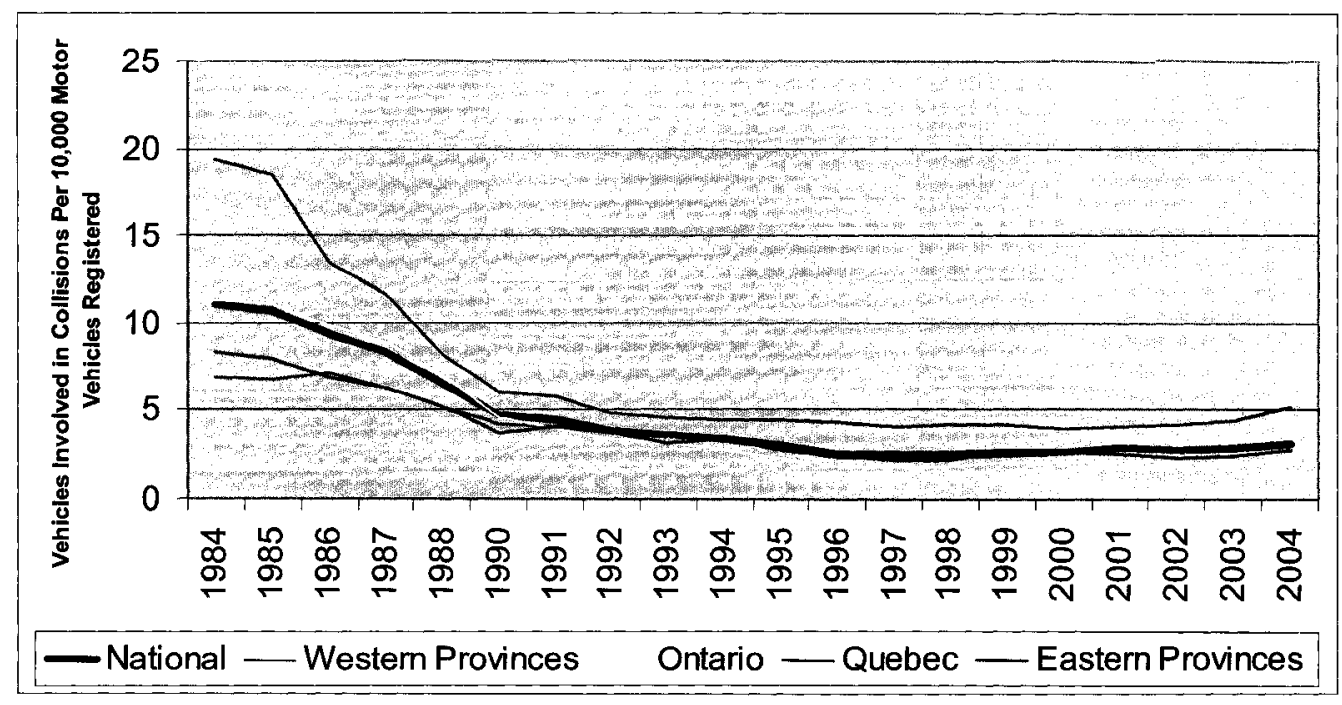

Figure 3.107: Motorcycles Involved in Injury Collisions Per 10,000 Motor Vehicles

\section{Registered By Year.}

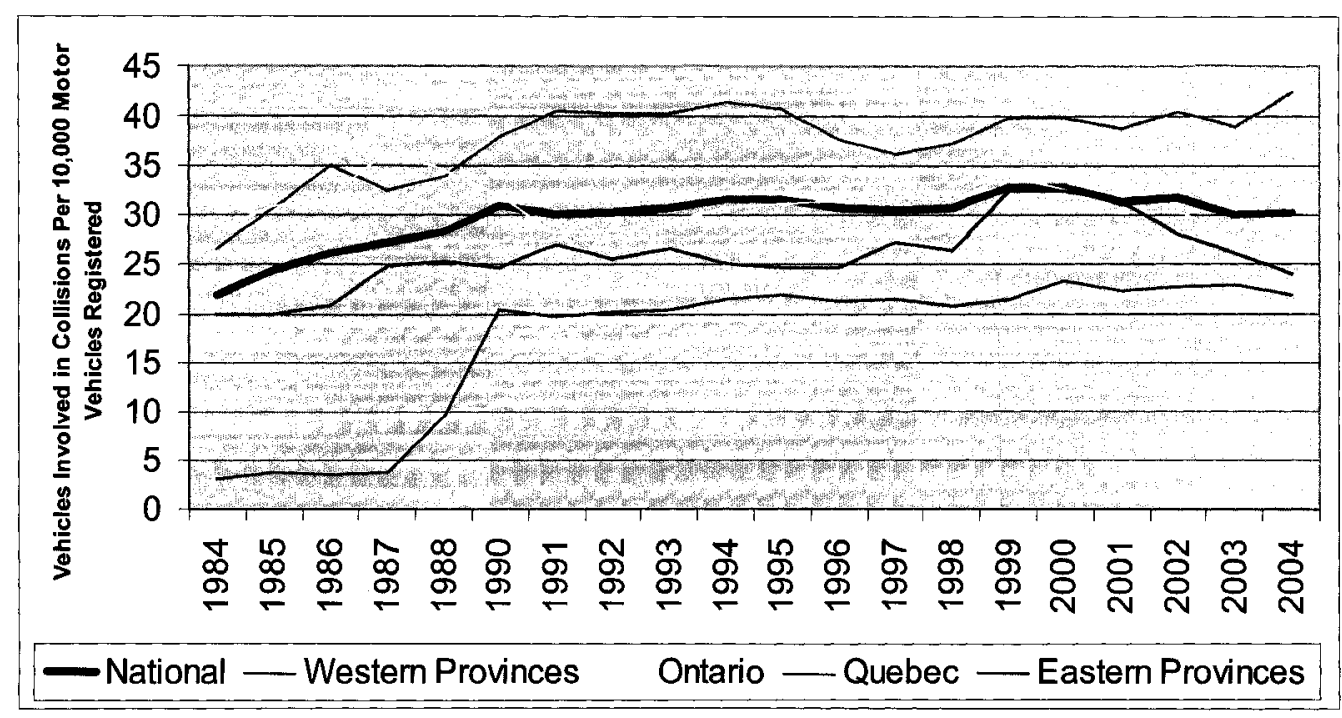

Figure 3.108: Pick-Up Trucks Involved in Injury Collisions Per 10,000 Motor

Vehicles Registered By Year. 


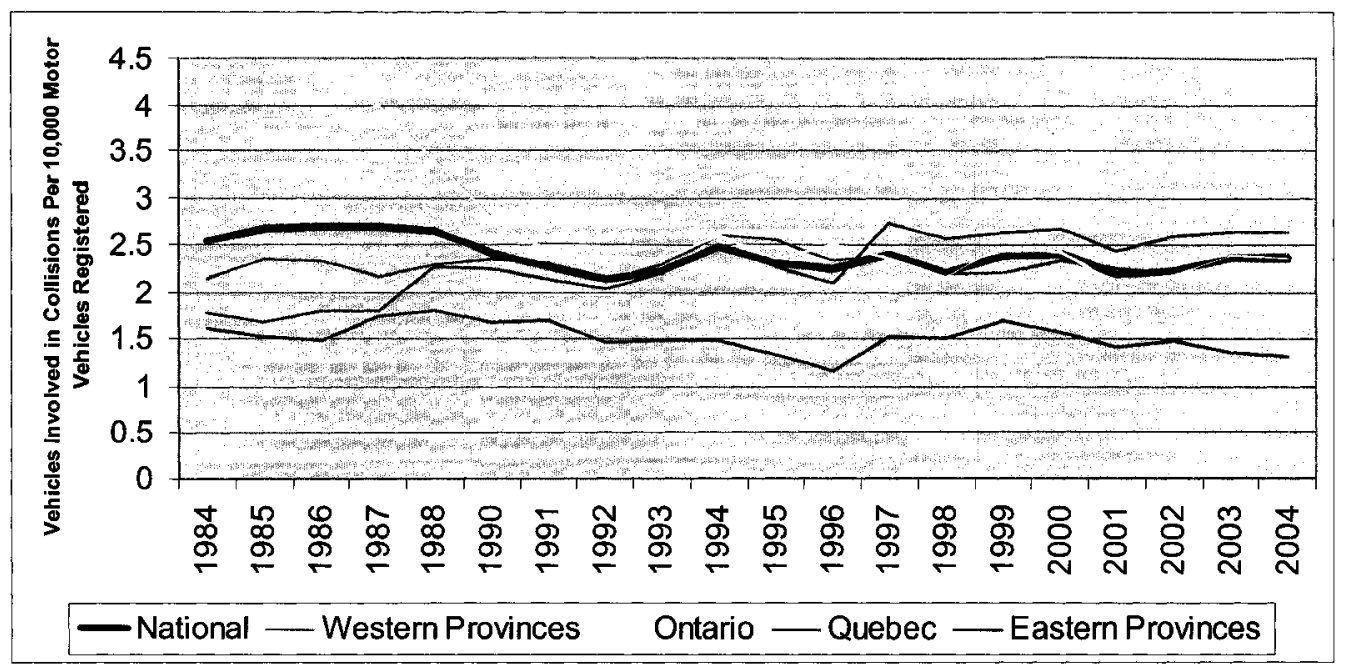

Figure 3.109: Tractor Trailers Involved in Injury Collisions Per 10,000 Motor Vehicles Registered By Year.

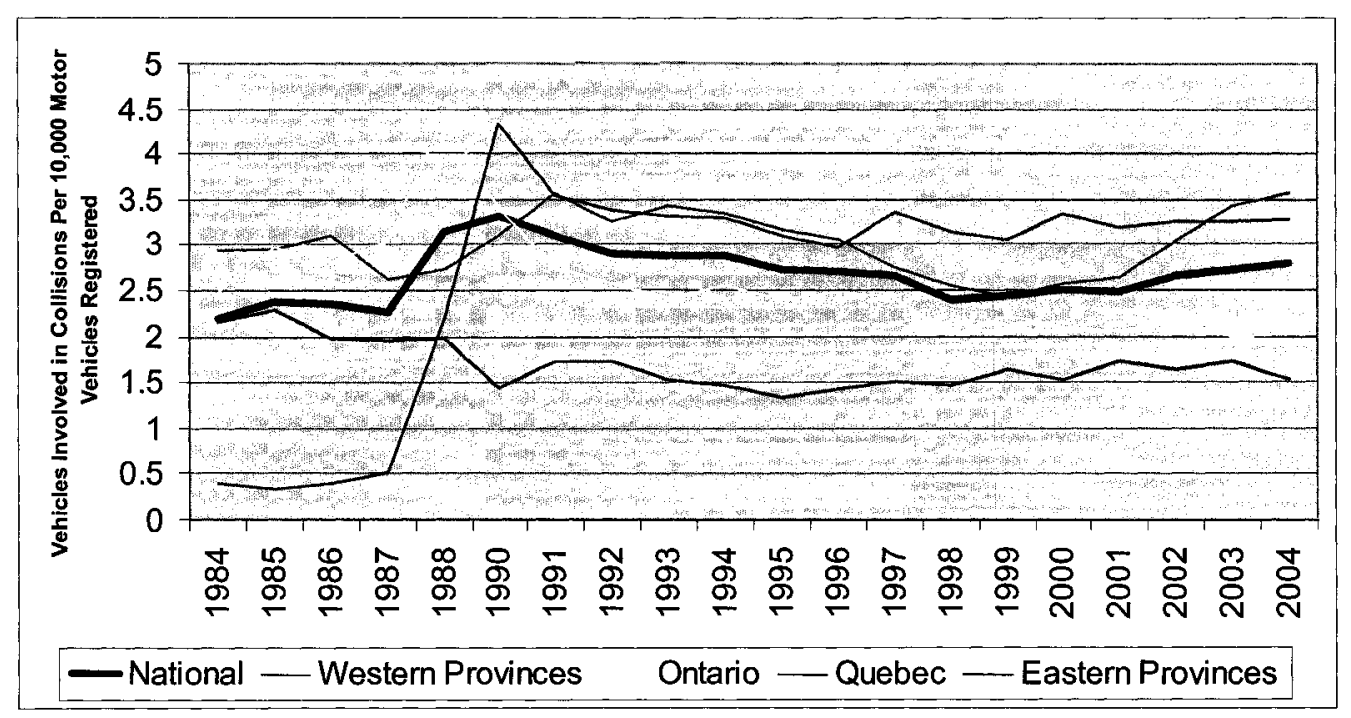

Figure 3.110: Trucks $>4536 \mathrm{~kg}$ Involved in Injury Collisions Per 10,000 Motor Vehicles Registered By Year. 


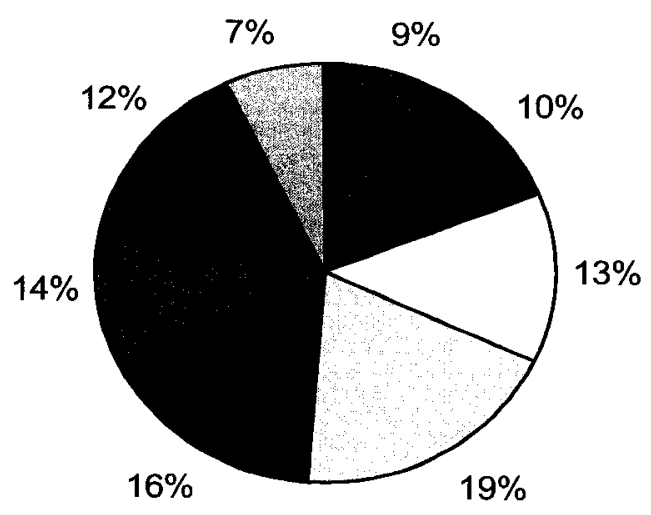

$6: 00$ to $8: 59 \mathrm{am}$ 9:00 to $11: 59 \mathrm{am}$ ㅁ 12:00 to $2: 59 \mathrm{pm}$ 口 3:00 to $5: 59 \mathrm{pm}$ - 6:00 to $8: 59 \mathrm{pm}$ - 9:00 to $11: 59 \mathrm{pm}$ - 12:00 to $2: 59 \mathrm{am}$ 固 3:00 to $5: 59 \mathrm{am}$

Figure 3.111: Percentage of Fatal Collisions for Hour of Collision Values.

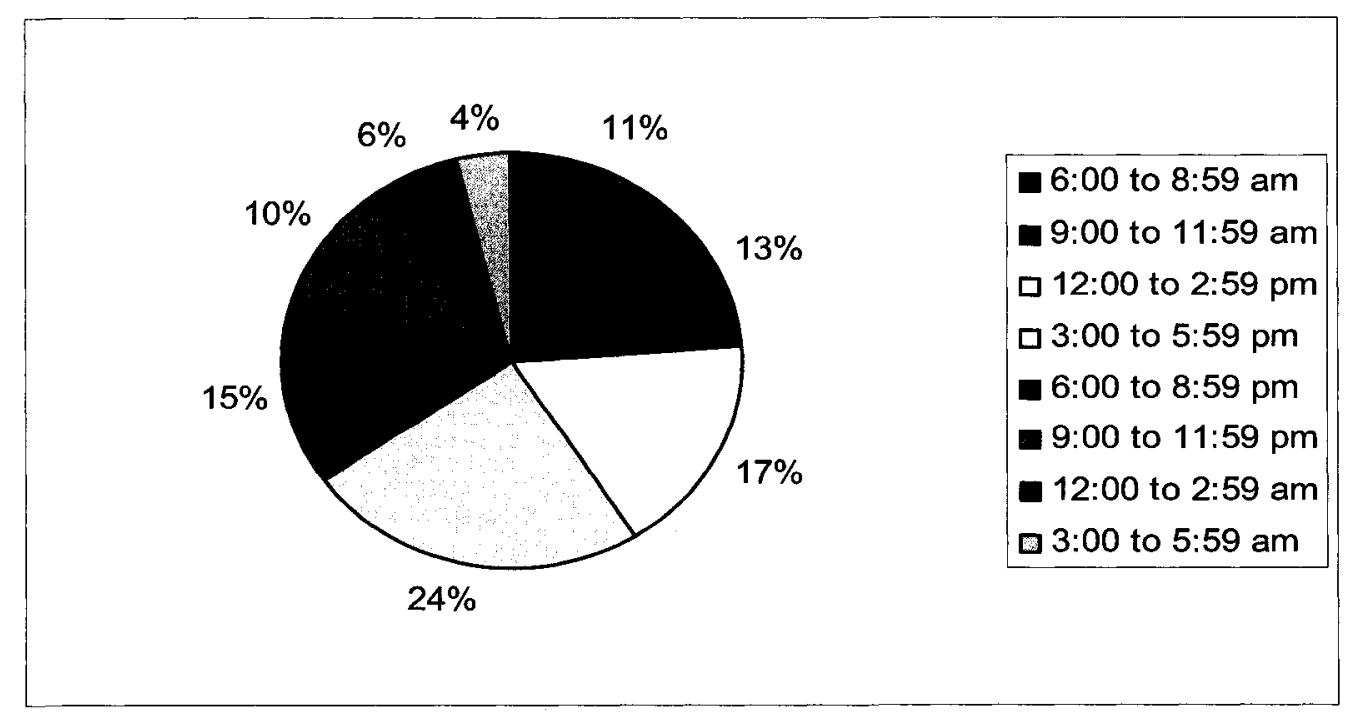

Figure 3.112: Percentage of Injury Collisions for Hour of Collision Values. 


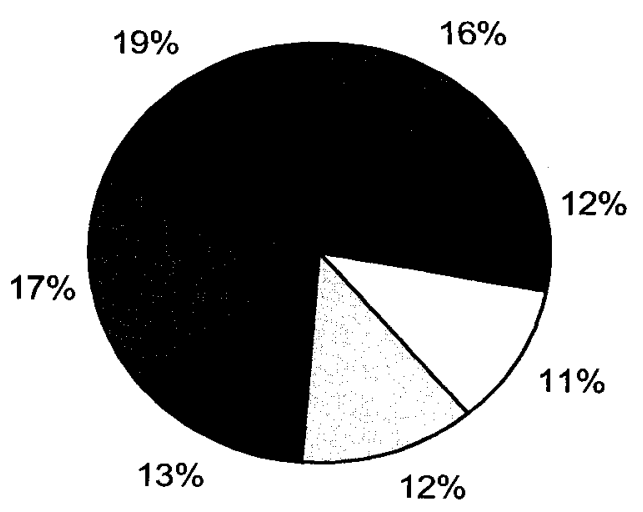

Sunday

Monday

$\square$ Tuesday

$\square$ Wednesday

- Thursday

- Friday

- Saturday

Figure 3.113: Percentage of Fatal Collisions for Day of Week Values.

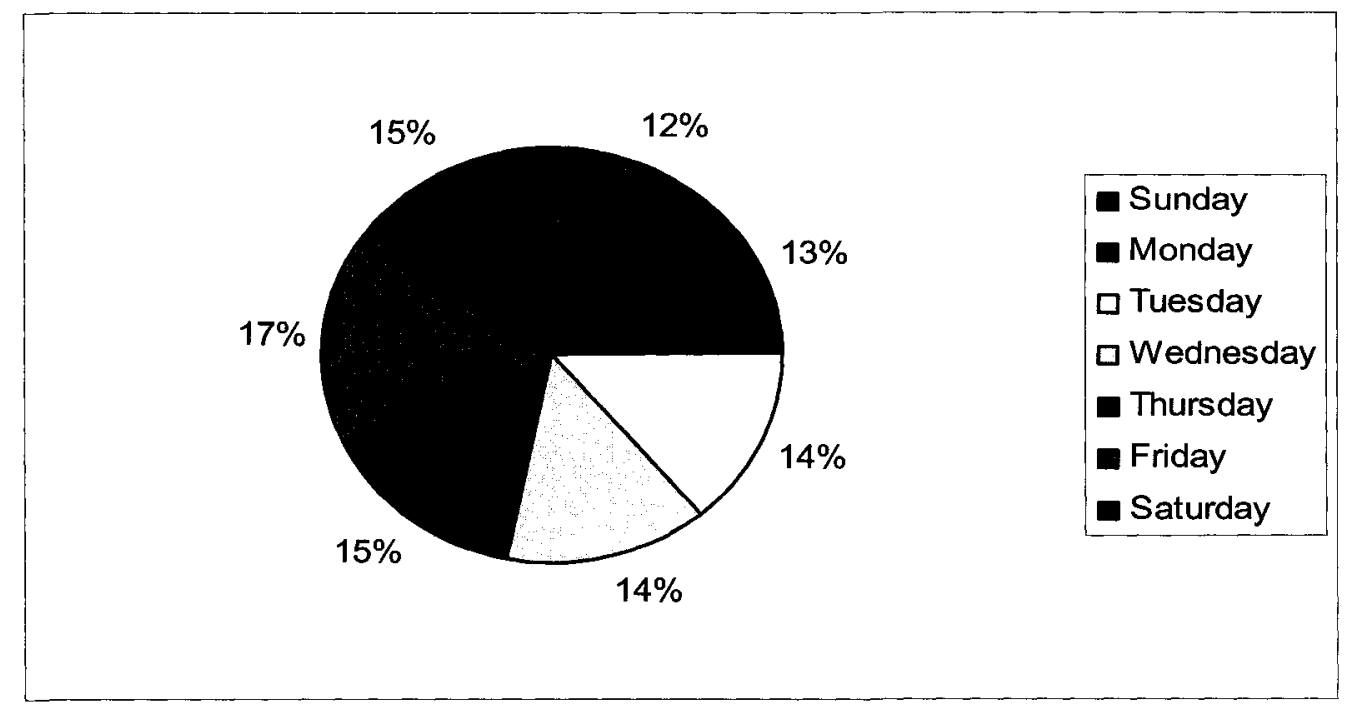

Figure 3.114: Percentage of Injury Collisions for Day of Week Values. 


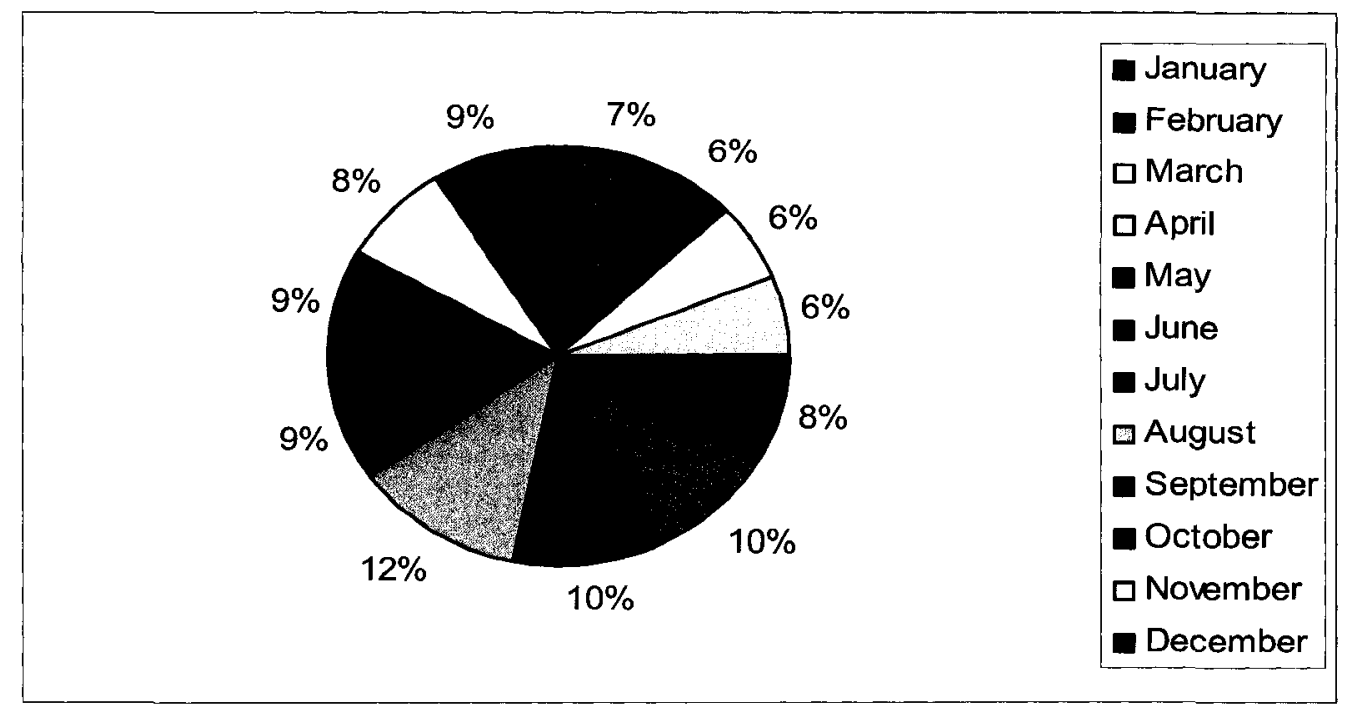

Figure 3.115: Percentage of Fatal Collisions for Month of Collision Values.

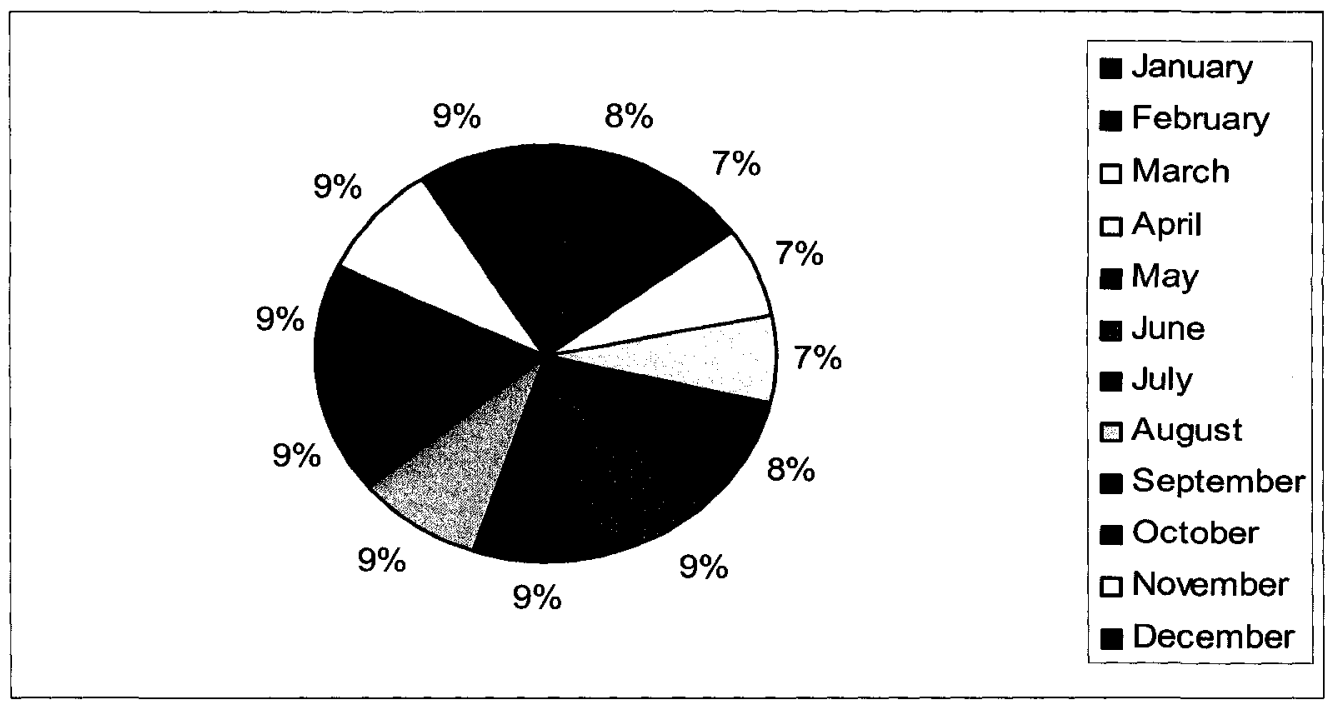

Figure 3.116: Percentage of Injury Collisions for Month of Collision Values. 


\section{Chapter 4: Review of Literature on the Impact of Safety Countermeasures}

In Chapter 2 a review of literature was conducted on road safety trends both in Canada and internationally with an effort to find studies that showed how specific road safety countermeasures have contributed to these trends. However, limited studies were found that provided this link between trends and countermeasures. This chapter attempts to help bridge that gap and presents a review of literature related to road and vehicle engineering countermeasures that have shown to improve road safety after their implementation. The countermeasures investigated were those that were thought to have contributed the most to reducing the number or severity of collisions in Canada in approximately the last 40 years. The countermeasures were then linked to trends in Chapter 3 in order to show what countermeasures may have had an effect on specific collision types. These observations are discussed in Chapter 4. Since limited Canadian studies were available, the review was extended to include those from the U.S. The chapter is organized in five sections which include "Intersections", "Other Roadway Elements", “Roadside Elements", “Medians", and "Vehicle-Related Countermeasures". Each type of countermeasure includes a brief description and a summary of safety studies found.

\subsection{Intersections}

This section contains a review of safety studies related to intersection countermeasures, which include channelization, railway crossing warning devices, roundabouts, and left-turn signal accommodations. 


\subsubsection{Channelization}

Channelization is the act of separating turning movements at intersections by using islands or pavement markings. This design element has shown to increase safety and reduce collisions by eliminating specific conflicts within an intersection and giving drivers a designated lane for making right and left turns separate from the through movement flow of traffic. They started to be implemented in North America around the 1960 's. In the early 1960 's a one-year "after" study was conducted on 43 newly channelized intersections in Austin, Texas (Carson and Marsh 1961, 663). The results found collision reductions of 20 percent compared with three years of "before" data. Then in the mid 1960's an evaluation was completed on a channelization program in the City of Denver, Colorado (Colorado Department of Public Works 1965) that took place from 1962 to 1964 and resulted in the implementation of left turn channelization using traffic paint for a number of their two-way major arterial streets. The results showed a 6 percent decrease in left-turn collisions, a 52 percent decrease in rear-end collisions, a 28 percent decrease in injury collisions, and a 28 percent decrease in total collisions. During that same time, a study was being conducted to analyze the traffic collisions occurring before and after channelization was installed on an arterial street in Northwest Houston, Texas (Rowan, Williams, and Wilson 1966). The study found that non-intersection collisions, rear-end collisions, and collision rates significantly decreased where channelization was introduced but that an increase was observed in fixed object collisions which were all associated with vehicles hitting a "Keep Right" sign on the channelizing island. The study also found that personal injuries were reduced by 25 percent, there were no differences in personal injury rates, and daylight collisions decreased. Overall, 
the study concluded that the introduction of channelization at major intersections reduces collisions and therefore improves road safety. Later in the 1960's a study was conducted in Los Angeles, California to compare the collision experience of 1.14 miles (1.83 kilometres) of arterial roadway before and after paint channelization was implemented (Terry and Kassan 1968, 22). The overall results showed that painted median channelization can be a significant factor in reducing injury collision rates on urban arterial streets.

More recently, in 2002, a before-after evaluation was completed on the safety effects of providing left- and right-turn lanes for at-grade intersections on major-road approaches in various locations in the U.S (Federal Highway Administration 2002). The results showed that by adding left-turn lanes at rural four-leg intersections with the minor road having stop control, the expected reduction in collisions would be 28 percent. For four-leg intersections on rural roads where the traffic control device was a traffic signal, the expected reduction in collisions would be 18 percent. The results also showed that by adding left-turn lanes at urban four-leg intersections with the minor road having stop control, the expected reduction in collisions would be 27 percent. For four-leg urban intersections with traffic signal control, the expected reduction in collisions would be 10 percent. Furthermore, with the installation of right-turn lanes on major road approaches to rural and urban intersections, the expected reduction in collisions was found to be 14 percent where the minor road had a stop control and 4 percent where the minor road had traffic signals. A year later, several studies were referenced in Transport Canada's 
"Synthesis of Safety for Traffic Operations" (Forbes 2003) showing the safety benefits of providing left and right-turn lanes. The following is a summary:

- A study was conducted in the City of Hamilton, Ontario where exclusive left-turn lanes and raised medians were added to signalized intersections on arterial streets. A before-after analysis of 8 locations resulted in collision modification factors (CMFs) ranging from 0.25 to 0.67 . CMFs provide traffic engineers with an estimate of the expected outcome of a safety treatment. If the CMF is less than one, there is a safety benefit. If the CMF is greater than one, there will be an increase in collisions.

- A study was conducted in the City of Indianapolis, Indiana to determine the safety impacts of re-striping intersection approaches with four lanes (two in each direction), to include opposing left-turn lanes. A before-after analysis for 8 sites showed CMFs of $0.41,0.46,0.56$, and 0.43 for left-turn, right-angle, rear-end, and all collisions, respectively.

- A study conducted in Minnesota found that the presence of a right-turn lane on a main rural road at a stop-controlled t-intersection was associated with a CMF of 0.79 . 
- A study was conducted in Connecticut that examined the safety benefits of leftturn lanes at 13 intersections. The results showed CMFs ranging from 0.41 to 0.98 .

- A study was conducted to determine the safety impacts of installing exclusive turning lanes at 8 intersections in Iowa. The results of a before-after analysis showed that right-angle collisions had CMFs between 2.19 to 0.61 , rear-end collisions had CMFs between 1.06 to 0.49 , and left-turn collisions had CMFs between 3.61 to 0.92 .

\subsubsection{Railway Crossing Warning Devices}

Railway crossing warning devices such as gates, traffic signs, bells, and flashing beacons are commonly used at roadway/railway grade crossings to warn drivers to stop in advance of the crossing when a train is passing or about to pass. These devices, when implemented, help reduce the number of collisions that occur at roadway/railway grade crossings by preventing cars from crossing the tracks at an inopportune time and being struck by an oncoming train. Railway crossing warning devices have been implemented in North America since the late 1960's. Since then, studies have been conducted to determine how effective these devices have been in improving road safety. An early study (Schulte 1976, 49) was conducted to determine the effect of automatic warning devices on the frequency of vehicle-train collisions and to examine specific crossing locations to measure the capabilities of automatic warning devices in reducing the number and severity of vehicle-train collisions. To determine the effectiveness of 
automatic warning devices under varying conditions, the before and after collision histories at 1,552 grade crossings in California where automatic devices were installed between 1960 and 1970 were compared on a yearly basis and separated by type of warning device, rural versus urban conditions, and the number of railroad tracks. The results indicated that the installation of automatic gates could be expected to reduce vehicle-train collisions by about 70 percent per year and to reduce related deaths and injuries by 89 and 83 percent per year respectively. Also, the use of automatic gates reduced the severity of collisions since there were 64 percent fewer deaths per collision, 43 fewer injuries per collision, and 36 percent fewer deaths per injury. Collision rates before and after the installation of automatic warning devices were far lower at rural than at urban crossings. The percentage of reduction in all collision and casualty rates was higher at rural crossings. Later another study was conducted (Morrissey 1980) that looked at the effectiveness of active warning devices, flashing lights and flashing lights with gates, in reducing collision potential. The study compared the collision rates at 2,994 roadway/railway crossings throughout the U.S.; both before and after active warning devices had been installed. The results showed that locations that upgraded from passive warning devices to flashing lights reduced collisions by 65 percent, locations that upgraded from passive warning devices to flashing lights with gates reduced collisions by 84 percent, and locations that upgraded from flashing lights to flashing lights with gates reduced collisions by 64 percent.

In the mid-1980's two studies were conducted. The first one (Farr and Hitz 1985) developed estimates of the safety effectiveness of various types of motorist warning 
devices in reducing collisions at roadway/railway crossings throughout the U.S. Results showed that upgrading passive warning devices to flashing lights was 70 percent effective in reducing collisions, upgrading passive warning devices to gates was 83 percent effective in reducing collisions, and upgrading flashing lights to gates was 69 percent effective in reducing collisions. Also, stop signs installed at crossings with passive signs were 35 percent effective in reducing collisions. Flashing light upgrades from passive signs at crossings with a rural location had a significantly higher level of effectiveness than those with an urban location. For crossings with fewer than 25 percent of trains operating during daylight, the effectiveness of upgrades from passive signs to flashing lights and from flashing lights to gates was found to be significantly higher than cases with greater a percentage of day trains. The second study (Eck and Halkias 1985, 94) developed measures of effectiveness for the following roadway/railway grade crossing upgrade situations at locations throughout the U.S.: a) passive systems to flashing lights on a single track, b) passive systems to gates on single and multiple tracks, and c) flashing lights to gates on single and multiple tracks. The results showed that upgrades from passive systems to flashing lights were 69 percent effective in reducing collisions, upgrades from passive systems to gates were 84 percent effective, and upgrades from flashing lights to gates were 72 percent effective. Upgrades on warning devices on a single track had higher effectiveness values than those on multiple tracks.

More recently, evaluations were conducted (Federal Highway Administration 2001) on projects in the U.S. that used Intelligent Transportation Systems (ITS) at roadway/railway grade crossings. The study identified seven projects that tested such 
functions as in-vehicle warning, second train warning, and four quadrant gates with automatic train stop. Evaluation results from these projects indicated that ITS technologies have a positive impact in increasing safety and mobility at highway-rail grade crossings. Tests of second train coming signs in Maryland and California showed a notable reduction in risky behaviour of drivers by 36 percent and a reduction in risky behaviour of pedestrians by 14 percent. Also, videotaped observations of driver behaviour revealed that risky behaviour of drivers decreased significantly following installation of a four-quadrant gate with an automated train stop system in Connecticut. Also, in-vehicle warning systems were found to be helpful in focusing drivers' attention to the presence of an on-coming train.

\subsubsection{Roundabouts}

Roundabouts are fairly new in North America but have been used in Europe and Australia for decades. Roundabouts are circular intersections where motorists travel counter-clockwise around a centre island. They are different from traffic circles, which have been around for quite awhile. Roundabouts have a smaller diameter than most traffic circles, resulting in safer conditions and lower speeds. Vehicles can enter roundabouts much easier than traffic circles due to flared approaches, entry angles, and the fact that vehicles entering roundabouts always yield to circulating traffic. The reason that they are becoming so popular in North America is because they have many safety benefits. Not only are they designed so that motorists decrease their speed of travel when entering the roundabout; they also eliminate opposing left-turn manoeuvres. In addition, 
vehicle-vehicle and vehicle-pedestrian conflict points are significantly reduced at roundabouts compared to signalized intersections as shown in

Figures 4.1 and 4.2 .

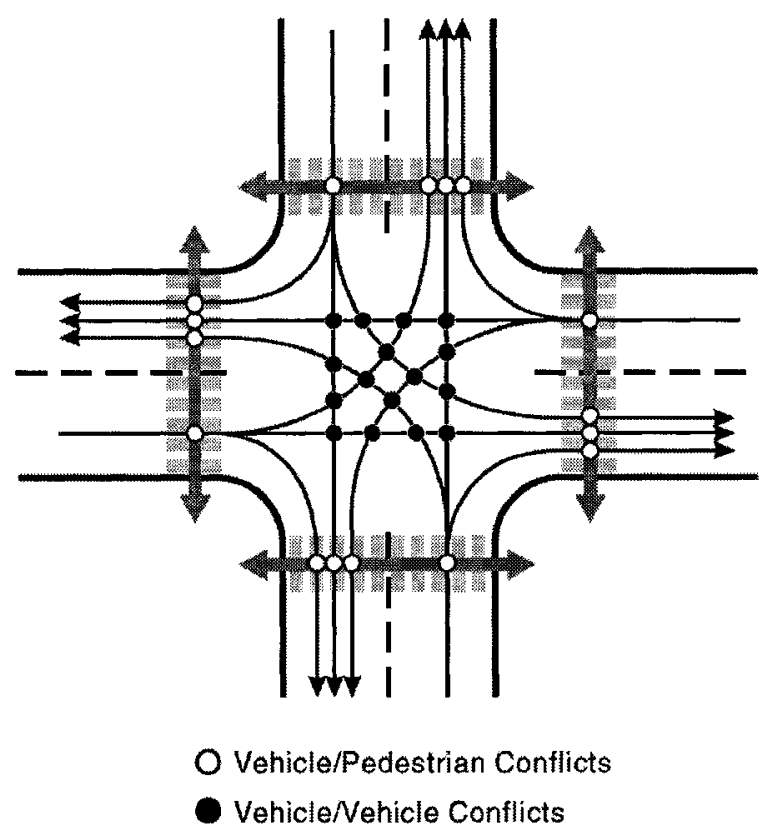

Figure 4.1: Conflicts at Signalized Intersections (Robinson et al. 2000). 


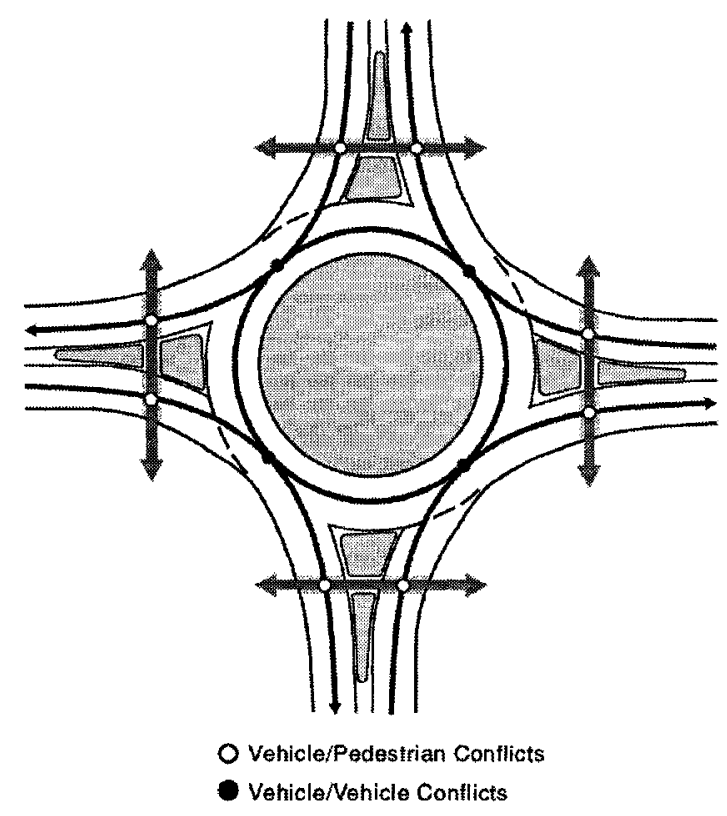

Figure 4.2: Conflicts at Roundabouts (Robinson et al. 2000).

They have been implemented in North America since the late 1990's and have shown to reduce the number of collisions at intersections where they are installed. Since then several studies have been conducted, especially in the U.S to determine just how effective they are in decreasing collisions. One study (Flannery and Elefteriadou 1999) looked at the safety performance of eight single lane roundabouts located in the States of Florida and Maryland and evaluated them through a collision analysis. The analysis included a comparison of collision frequency and collision rates before and after the installation of roundabouts. In addition, injury rates and frequencies were compared before and after the installation of roundabouts. The results showed that all sites with the exception of one located in Palm Beach County, Florida, had a reduction in collision frequency after the installation of single lane roundabouts. Overall, the study sites as a group had a reduction in collision frequency of 3.8 collisions per year. Also, all of the 
sites experienced a reduction in collision rate. Overall the study group had a reduction in injury collisions per year of 1.25 in the after period. Also, injury collision rates per year experienced a reduction at all sites. Another study (Myers 1999) that was conducted during the same time looked at the reduction of collisions from five roundabouts installed in the state of Maryland. Overall, the average collision rate at these five intersections was reduced from an average of 5.56 collisions per year to an average of 2.3 collisions per year, a reduction of 59 percent. Also, injury collisions were reduced by 80 percent. Overall, all of the intersections experienced a reduction.

Later, the Federal Highway Administration Roundabout Informational Guide (Robinson et al. 2000) referenced crash frequencies (average annual crashes per roundabout) experienced at eleven intersections in the U.S. that were converted to roundabouts. As shown in Table 4.1, all sites showed a reduction in both injury and property damage collisions after installation of a roundabout.

Table 4.1: Percent Reduction in Collisions After Installation of Roundabouts, (Robinson et al. 2000).

\begin{tabular}{|l|c|c|c|c|}
\hline & & \multicolumn{3}{|c|}{ Percent Reduction in Collisions } \\
\hline $\begin{array}{l}\text { Type of } \\
\text { Roundabout }\end{array}$ & Sites & Total & Injury & PDO \\
\hline Small/Moderate & 8 & 51 & 73 & 32 \\
\hline Large & 3 & 29 & 31 & 10 \\
\hline Total & 11 & 37 & 51 & 29 \\
\hline
\end{tabular}

During the same time, a study was (Persaud et al. 2000) conducted that evaluated the changes in motor vehicle crashes following conversion of 24 intersections from stop 
sign and traffic signal control to modern roundabouts between 1992 and 1997. Eight states were involved in the study - California, Colorado, Florida, Kansas, Maine, Maryland, South Carolina, and Vermont. Of the 24 intersections, 21 were previously controlled by stop signs, and 3 were controlled by traffic signals. A before-after study was conducted using the empirical Bayes approach, which accounts for regression to the mean. Empirical Bayes is a calculation that combines prior and up-to-date data to estimate for present conditions. In road safety, empirical Bayes is used to estimate the expected crash frequency of a location. Results showed reductions of 39 percent for all crash severities, 76 percent for injury crashes, and 90 percent for fatal crashes.

More recently, a summary of safety statistics was completed (Jacquemart 2004) for 33 roundabouts in the U.S. The crash data were collected as part of a study conducted in 2003 for the New York State Department of Transportation. The study compared the actual numbers of crashes after roundabout conversion to the number of crashes predicted under the empirical Bayes before-after procedure. As shown in Table 4.2, overall the percent reduction of all crashes was 47 percent, the percent reduction of property damage only collisions was 41 percent the percent reduction of injury collisions was 72 percent. 
Table 4.2: Percent Reduction in Crashes After Installation of Roundabouts, (Jacquemart 2004).

\begin{tabular}{|l|c|c|c|c|}
\hline $\begin{array}{l}\text { Roundabout } \\
\text { Characteristics } \\
\text { Before } \\
\text { Condition }\end{array}$ & $\begin{array}{c}\text { Number of } \\
\text { Sites }\end{array}$ & \multicolumn{3}{|c|}{ Percent Reduction in Crashes } \\
\hline & & Total & PDO & Injury \\
\hline $\begin{array}{l}\text { Single Lane, } \\
\text { Urban Stop } \\
\text { Controlled }\end{array}$ & 12 & $69 \%$ & $67 \%$ & $80 \%$ \\
\hline $\begin{array}{l}\text { Single Lane, } \\
\text { Rural Stop } \\
\text { Controlled }\end{array}$ & 9 & $65 \%$ & $63 \%$ & $68 \%$ \\
\hline $\begin{array}{l}\text { Multi Lane, } \\
\text { Urban Stop } \\
\text { Controlled }\end{array}$ & 7 & $8 \%$ & $0 \%$ & $73 \%$ \\
\hline $\begin{array}{l}\text { Urban } \\
\text { Signalized }\end{array}$ & 5 & $37 \%$ & $31 \%$ & $75 \%$ \\
\hline All Sites & 33 & $47 \%$ & $41 \%$ & $72 \%$ \\
\hline
\end{tabular}

The most recent study found on the safety of roundabouts was one that was conducted in the Las Vegas metropolitan area (Nambisan and Parimi 2005). The evaluation consisted of a comparison of traffic crashes in the proximity of roundabouts with those at comparable conventional stop controlled and signalized intersections. Five years of crash data were used for the study. Depending upon the Average Daily Traffic (ADT) levels, the six roundabouts were classified into three categories. The results indicated that roundabouts that had minor and medium levels of traffic volumes were generally safer than the intersections that were stop controlled and signalized. However, high volume intersections with signalized traffic controls appeared to be safer than roundabouts. It was noted that the high volume roundabouts were poorly designed with inadequate markings and signage and that this could have negatively affected the results. The minor intersections, which are controlled by roundabouts, had crash rates per motor 
vehicle travelled between 0.21 and 0.67 while the traditional intersections controlled by stop signs had crash rates per motor vehicle travelled ranging between 0.46 and 1.72 . There was only one medium roundabout available for the analysis, which had a crashes per motor vehicle travelled value of 0.5 . In comparison the stop-controlled intersections had crash rates per motor vehicle travelled varying from 0.48 to 0.80 . At the major roundabout intersections the crash rates per motor vehicle travelled varied from 1.41 to 2.59 and the crash rates per motor vehicle travelled for signalized intersections varied from 0.58 to 1.04 . A comparison of the severity level of all crashes was conducted as well. Zero fatal collisions occurred at the roundabouts, 11.94 percent were injury collisions, and 88.06 percent were property damage only collisions. Zero fatal collisions occurred at conventional intersections, 33.12 percent were injury collisions, and 66.88 percent were property damage only collisions. Overall, the collision severity level at the roundabout locations was a lot lower than at the conventional intersections.

\subsubsection{Left-Turn Accommodations at Signalized Intersections}

Left-turn manoeuvres at any intersection is a potentially dangerous situation. Motorists having to turn in front of opposing traffic and at the same time make sure to give way to pedestrians crossing the street is a manoeuvre that has caused numerous collisions many of which were fatal. That is one of the reasons why protected left-turn phasing came into effect. Protected left-turns at signalized intersections give right-ofway to drivers turning left without having to wait for opposing traffic or pedestrians to cross the roadway. This reduces the number of conflicts within a signalized intersection and therefore the risk of a collision occurring. Protected left-turn phasing was first 
implemented in North America is the late 1970's. Since then, a number of studies have been conducted to evaluate their effectiveness. One study which was conducted in the early 1980's (Michael, Sinha, and Fletcher 1981) analyzed 18 high collision intersections in Indiana using a computer simulation package and recommended countermeasures for reduction of collisions at these sites. One significant finding of the simulation study was that for signalized intersections, the addition of separate left turn phases reduced the number of left-turn conflicts. Then in the mid-1980's, an evaluation was completed (Warren 1985, 121) on two types of left turn control changes: (1) The change from protected-only to protected/permitted, and (2) the introduction of protected/permitted phasing at signalized intersections that previously had no left turn signals. The number of collisions before and after the change to protected/permitted phasing was analyzed and compared to the number of collisions at similar intersections that were not changed. Nine sites were selected from protected/permitted intersections in Prince George and Howard Counties, Maryland. For intersections that went from permitted to protected/permitted, the total number of collisions decreased slightly because of a large drop in rear end collisions. Left turn and injury collisions increased at both the test and control intersections. The percentage increase in injury collisions at the test sites was greater than at the control sites. For the intersections that went from protected-only to protected/permitted, left turn collisions doubled.

Two studies were conducted in the mid 1990's. The first one (Quaye, Leden, and Hauer 1993) developed models to examine two typical schemes for accommodating left turning vehicles and how they influence the number of left turning collisions involving 
pedestrians. These were a semi-protected scheme, where left-turning vehicles faced no opposing traffic but conflict with pedestrians and a permissive scheme, in which left turning vehicles have to find suitable gaps in the opposing traffic. Data from 1977 to 1986 was used for streets in the Regional Municipality of Hamilton-Wentworth. The results showed that semi-protected left turns tended to be safer for pedestrians at low vehicular flows. The opposite was true for high flows of left turning vehicles. The second study (Maze, Henderson, and Sankar 1994) looked at the safety impacts of leftturn treatments at high speed signalized intersections in the state of Iowa. Models were developed which estimated approach collision rates at high-speed signalized intersections. Collision data was obtained from the Iowa Department of Transportation Accident Location and Analysis System. Regression models were developed for two different dependent variables; 1) the ratio of the number of left turn collisions per approach to million left turning vehicles per approach, and 2) the ratio of collisions per approach to million traffic movements per approach. The research indicated that protected left turn phasing had a lower collision potential than protected/permitted or permitted phasing. In addition, the Southeast Michigan Council of Governments Traffic Safety Manual (Southeast Michigan Council of Governments 1997) referenced a study conducted by the Kentucky Transportation Research Program, the Kentucky Transportation Center, and the Texas Department of Transportation that found that the provision of left-turn signals of any type was expected to result in an overall crash reduction of 25 percent. 
More recently, Transport Canada's "Synthesis of Safety For Traffic Operations" (Forbes 2003) referenced two studies. The first one used crash data from several signalized intersection approaches in Arizona and examined the safety performance of five different types of left-turn phasing; permissive, leading exclusive-permissive, lagging exclusive-permissive, leading exclusive only, and lagging exclusive only. The results showed that the exclusive phasing, either leading or lagging, demonstrated a safety benefit over permissive-only phasing. The second study looked at the safety of various left-turn phasing. The study included 54 intersections from Texas and Louisiana, and was conducted on approaches, as phasing varied among approaches, to the same intersection. All of the subject intersections had exclusive left-turn lanes. Three consecutive years of crash data was used in the analysis. The left-turn phasing studied included permissive only, lead protected-permissive, lag protected-permissive, lead protected only, and lag protected only. The following conclusions were reached from the study:

- There was no significant difference between the crash rates of protectedpermissive and permissive only phasing.

- Protected only phasing was safer than protected-permissive phasing.

- There was no significant difference between the crash rates of lead and lag protected only phasing.

- There was no significant difference between the crash rates of lead and lag protected-permissive phasing. 
The most recent study that was found (Davis and Aul 2007) estimated crash modification factors associated with different left-turn phasing schemes at intersections where the major approach speed limit exceeded $40 \mathrm{mph}(64 \mathrm{~km} / \mathrm{h})$. The results showed that for the installation of signals at previously through/stop-controlled intersections, rear-end crashes increased while right-angle crashes decreased. Installation of the signal had no effect on either major or minor approach left turn crashes as long as the protectedonly left turn phasing was used on the major approaches. At one intersection where a signal was originally installed with permitted/protected phasing on the major approaches, an increase in major approach left turn crashes occurred, which vanished when the major approach left-turn treatment was changed to protected-only.

\subsection{Other Roadway Elements}

This section includes safety studies related to access management, divided highways, passing lanes, roadway lighting, and horizontal curve flattening.

\subsubsection{Access Management}

Access management is a way to control motorist access to roadways. Specific examples include longer driveway spacing and median treatments to divide roadways. Different levels of access are usually designated to different road types (ex. local residential roads are allowed full access, while major highways and freeways allow very little). Access management has the potential to improve safety and reduce collisions by limiting conflict situations with opposing lanes of traffic and within intersections. Access management techniques have been implemented in North America since the late 1970's 
however studies on their safety effectiveness were only found starting in the mid 1990's. The first study found (Lall, Huntington, and Eghtedari 1996) was an analysis of collisions that occurred within 29 miles (47 kilometres) of the Oregon Coast Highway 9. The study covered 756 collision records using several years of data. The purpose of this study was to establish a direct relationship between access density and the number of collisions and their severity. The results of the analysis showed that the frequency of collisions and access density were highly related whether considered as total number of collisions or rate per million vehicle miles. An access density of 50 access points per mile ( 31 access points per kilometre) appeared to be critical in both rural and urban areas of the highway. Above 50 driveways per mile ( 31 driveways per kilometre), the collision rate increased at a much steeper rate.

Two studies were found that were conducted in the late 1990's. The first one (Brown and Tarko 1999, 68) used regression models to predict crash frequencies on urban multi-lane arterial road segments based on geometric and access control characteristics. The study found that more frequent access points experienced more crashes, the presence of an outside shoulder led to a reduction in crashes, the presence of signals led to higher crash rates, the presence of a two-way left-turn lane led to a reduction in crashes, and the presence of a median with no openings between signalized intersections led to a reduction in crashes. Overall, the study found that 10 additional access points were associated with a 32 percent increase in the number of crashes. The second study (Levinson and Gluck 1999) performed an analysis of collision information obtained from Delaware, Illinois, Michigan, New Jersey, Oregon, Texas, Virginia, and 
Wisconsin. Overall, 386 roadway segments were analyzed to establish the relationships between access and collisions for various spacing and median types. For urban and suburban areas, the following results were found:

- Collision rates for access densities of over 60 per mile ( 37 per kilometre) was more than 2.5 times higher than the collision rates for access densities of under 20 per mile (12 per kilometre).

- Undivided road sections had 8.59 collisions per million vehicle miles (5.33 collisions per million vehicle kilometres) as compared to 6.88 (4.27) for two-way left-turn lanes and 5.19 (3.22) for non-traversable medians.

- Two-way left-turn lanes had a 20 percent lower collision rate and non-traversable medians had a 40 percent reduction as compared with undivided road sections.

- Collision rates increased as signalized access density increased. The collision rate for more than six signals per mile (more than three signals per kilometre) was more than 2.5 times that for signal densities of two or less per mile ( 1.3 or less per kilometre).

- Non-traversable medians had lower collision rates than the other median treatments for all signal spacing frequencies. 
- Collision frequency increased as unsignalized access density rose.

For rural areas:

- The increase in access density from less than 15 access points to over 30 access points per mile ( 9 access points to over 19 access point per kilometre) resulted in a 65 percent increase in the overall collision rate.

- Two-way left-turn lanes had about a 40 percent lower collision rate and nontraversable medians had a 60 percent lower collision rate than undivided road sections.

Later a study (Transportation Research Board 2000) compared the results of previous access management research and conducted an analysis of Minnesota's access and crash statistics in order to determine if access management was a public safety issue. The results of the research review indicated that crash rate increases as access density increases. The study also looked at the results of two case studies. The first one was in Minnesota which included the conversion of a two and four-lane undivided roadway to a three-lane road, conversion of a four-lane to a five-lane, and the addition of raised medians with protected turning bays to a four-lane undivided roadway. As a result of these projects, crash frequency and crash rates were reduced by an average of more than 40 percent. The second case study was in Iowa where eight roadways were improved by providing systems of left-turn lanes, frontage roads and reducing the number of commercial driveways. The average reduction in the density of access was about 20 
percent and the reduction in the annual crash rate was approximately 40 percent. Soon after, another study was conducted (Dissanayake and Lu 2003) which included a beforeafter analysis where the operational and safety characteristics of a full median opening were compared with those of a directional median opening. A full opening allows turns to be made in both directions whereas a directional opening allows turns to be made in only one direction. An example of a directional median would be one that allows left turns into a driveway but does not allow left turns to be made out. The results showed that the number of conflicts per hour and conflicts per thousand involved vehicles were both significantly reduced due to the change in the median opening type from full to directional. Percentage reductions in conflicts per hour and conflicts per thousand involved vehicles were 49.9 percent and 46.3 percent, respectively. It was also found that the severity of conflicts was less for the after period.

More recently a study was conducted (Wang, $\mathrm{Lu}$, and Xiang 2005, 85) that evaluated the affects of a right-turn followed by a u-turn as an alternative to a direct left-turn in Florida. The study found that right-turn followed by u-turn movements not only reduced the conflict rate but also lessened the conflict severity. The estimated total crash reduction was 17.8 percent and 27.3 percent for injury and fatal crashes respectively. Then a little later, a study (Eisele and Frawley 2005) looked at the safety impacts of access management techniques such as raised medians and driveway consolidation. Safety impacts were investigated along 11 test corridors in Texas and Oklahoma to estimate relationships between crash rates and access point densities, as well as the presence of raised medians or two-way left-turn lanes. The study found that as access 
density increased, there was an increase in crash rates. Also, the relationship was steeper on roadways without raised medians. Where crash data were investigated before and after the raised median installation, a reduction in the crash rate was always found. The percent reduction ranged from 17 to 58 percent, which occurred over a range of access point densities from 20 to 53. Two corridors that went from a two-way left-turn lane to a raised median experienced a 17 and 58 percent reduction, while the two corridors that were previously undivided experienced a 34 to 53 percent reduction. The average of all corridors together showed an average reduction of 31 percent going from either a twoway left-turn lane or undivided roadway to a raised median. And finally, the most recent study found (Schultz and Lewis 2006) looked at the safety impact of several locations where access management techniques such as raised median installation and driveway consolidation had been installed in the state of Utah. The study found that crash rates were not reduced but other safety improvements were observed. The raised medians generally reduced the more serious types of collisions, which resulted in a decrease in the severity of crashes.

\subsubsection{Divided Highways}

A divided highway is a roadway where opposing traffic is separated by either a median barrier or a strip of land. Divided highways significantly influence road safety because they eliminate the potential of dangerous opposing-vehicle head-on collisions. They have been implemented in North America since the mid 1960's, however limited studies were found on their effectiveness. One study (Council and Stewart 2000, 37) used a cross-sectional analysis to develop estimates of the safety effects of converting 
two-lane undivided roads to four-lane divided roads, and to determine whether such effects would be similar across multiple States in the U.S. The results showed that the conversion from a two-lane to a four-lane divided road would result in a crash per kilometre reduction of between 40 to 60 percent. Also, another study (Huang et al. 2001) conducted an analysis of collisions in North Carolina from 1993 to 1997. One of their findings was that in rural settings, multilane undivided highways had a collision rate 68 percent higher than multilane divided highways.

\subsubsection{Passing Lanes}

Two-lane undivided highways put motorists in a vulnerable situation, especially if a passing manoeuvre is being undertaken. Passing manoeuvres require a motorist to enter into the opposing lane of traffic to overtake another vehicle. This puts the motorist at the risk of getting into a head-on collision with opposing traffic. Passing lanes were first introduced in North America in the mid 1970's to allow the opportunity for motorists to overtake other vehicles without encroaching in the opposing lane of traffic. Several studies were found on the safety effectiveness of passing lanes with the first one being from the mid 1980's. The study (Harwood, St. John, and Warren 1985, 31) involved the safety evaluation of the effectiveness of passing lanes and short four-lane sections in a number of U.S States. The results showed that passing lanes had slightly lower collision rates than untreated two-lane highways. The total collision rate of the passing lane sites was on the average, 38 percent less than that for comparable untreated sites and the fatal and injury collision rate was 29 percent less than that for comparable untreated sites. A similar study conducting during that time (Harwood and Saint John 1985) evaluated the 
safety effects of passing lanes using data from 13 states. A comparison was made with the collision rates of passing lane sites before and after installation of passing lanes. Results showed that on average, passing lane installation reduced the total collision rate by 8.7 percent and the fatal and injury collision rate by 17 percent. Also, the passing lane sites were, on average, 38 percent less than the comparable sites in total collision rate and 29 percent less than the comparable sites in fatal and injury collision rate.

More recently, a study was conducted (Persaud 1992) that reviewed previous research on the safety effects of installing passing lanes on highways. The results found that they could reduce severe collision rates by about 20 percent. A little later on, a cross-section analysis was conducted (Mutabazi, Russell, and Stokes 1999) where highways with passing lanes were compared with comparable highways without passing lanes in Kansas State to determine the effect of passing lanes on reducing collisions. The results showed that sections with passing lanes had significantly fewer collisions than the state average rural two-lane roads. Then another study (Potts and Harwood 2004) looked at the safety effects of using passing lanes in Missouri. An evaluation of three existing passing lane sites on Missouri National Highway System routes found that the collision frequency per mile per year within passing lane sections on two-lane highways is 12 to 24 percent lower than for conventional two-lane highway sections.

\subsubsection{Roadway Lighting}

Roadway lighting has been around for a long time but as years progressed, new research and technology helped engineers understand the safety effects of lighting design. 
Improved lighting over the years has helped decrease nighttime collisions making the road more visible to the motorist with reduced glare. Significant lighting improvements have been implemented in North America since the mid 1970's. In the early 1990's, a review of previous research (Persaud 1992) was conducted on the safety effects of intersection lighting and concluded that a 20 percent reduction in nighttime collisions is expected when lighting is introduced to intersections. Research on the safety effects of installing roadway lighting was also reviewed in the same study and it was found that it reduced nighttime collisions from 25 to 30 percent and severe nighttime collisions from 30 to 50 percent. Another summary of research (Ogden 1996) from the U.S. found that lighting improvements reduced fatal collisions by 41 percent and injury collisions by 16 percent.

Later, a case was referenced (Hasson and Lutevick 2002, 32) where in Milwaukee, Wisconsin in 1980 all of Milwaukee's freeway lighting was turned off to save money. Later analysis using data from the previous 3 years for comparison showed that the total number of nighttime crashes increased 6 percent, reportable night crashes were up 14 percent, injury crashes rose 5 percent, and the number of people injured was up 50 percent. A later study (Green et al. 2003) analyzed the safety benefits associated with roadway lighting. A list of intersections where roadway lighting had been installed in the past few years was obtained from one highway district within Kentucky. The list was used to analyze the effect that roadway lighting had on the number of nighttime crashes. Nine intersections were used in the analysis with the number of crashes per year obtained for up to four years prior to the lighting installation and three years after 
installation. The results showed that the average number of nighttime crashes per year was reduced from 1.1 to 0.6 crashes after the lighting installation. This is a reduction of about 45 percent.

More recently, a before-after study was conducted (Isebrands et al. 2006) to evaluate the impact of lighting at 48 intersections in Minnesota. A 13 percent reduction in night-crash frequency and a 36 percent decrease in the ratio of night to day crash rate occurred after lighting was installed. The expected night crash rate before lighting was installed was 59 percent higher than after lighting was installed. A little later, another study was conducted (Sullivan and Flannagan 2007, 638) to determine the potential safety benefit of improved lighting for three pedestrian crash scenarios. For curve lighting, pedestrian crashes on curved roadways were examined; for motorway lighting, crashes associated with high speed roadways were examined; and for cornering light, crashes involving turning vehicles at intersections were examined. While all three scenarios suggested a potential for safety improvement, scenarios related to high-speed roadway environments showed the greatest potential.

\subsubsection{Horizontal Curve Flattening}

Sharp curves along the roadway cause several problems especially if insufficient warning is provided and motorists are not expecting to have to reduce their speed to navigate through them. Sharp curves have led to several loss-of-control and run-of-road collisions and have also resulted in motorists over steering and encroaching in opposing lanes of traffic. In order to fix this problem, engineers have redesigned roadways and 
flattened the curves to make them more gradual with less effort for drivers to navigate through them, reducing the chance of a collision occurring. Curve flattening has been implemented in North America since the mid 1970's. Only one study was found related to the road safety impacts of this countermeasure. The study (Zeeger et al. 1990) was conducted to determine the horizontal curve features, which affect safety and traffic operations, and to quantify the effects on collisions of various curve-related improvements. The primary database developed and analyzed consisted of 10,900 horizontal curves in Washington State. Three existing federal databases on curves were also analyzed. These databases included the cross-section database of nearly 5,000 miles ( 8,000 kilometres) of roadway from 7 states, a surrogate database of vehicle operations on 78 curves in New York State, and 3,277 curve segments from 4 States. Based on statistical analysis and model development, variables found to have a significant effect on collisions included degree of curve, roadway width, curve length, ADT, presence of a spiral, superelevation, and roadside condition. Curve flattening was expected to reduce collisions by up to 80 percent, depending on the amount of flattening.

\subsection{Roadside Elements}

This section presents safety studies related to clear zones, shoulder rumble strips, and energy-absorbing barrier end treatments.

\subsubsection{Clear Zones}

A clear zone may be defined as the total roadside border area, starting at the edge of the travelled way, available for safe use of errant vehicles. Clear zones are effective in 
reducing the risk of injury or fatality when a vehicle runs off the road as it provides a safe recovery area free of objects to hit such as trees or telephone poles. The do not reduce the chance of a vehicle running off the roadway. Clear zones have been incorporated in the geometric design of roads in North America since the mid 1970's. An early study was referenced (Organization for Economic Cooperation and Development 1975) which describes a safety program that was implemented in California called CURE - Clean Up the Roadside Environment. It involved the consideration of fixed objects, which were most commonly involved in fatal collisions such as bridge rail ends, piers and abutments, signs and lampposts. The framework of this program included solutions such as assisting vehicles to stay on the roadway by means of better road alignment, good delineation and better road surfacing, and clearing the road shoulders of dangerous obstacles. It was estimated that the program saved nearly 500 lives within five years. The run-off-road fatal collisions involving a collision with a fixed object declined from 38 to 24 per year and the run-off-road collisions without hitting an object declined from 26 to 22 percent per year. Another study is referenced (Tignor et al. 1982) that calculated the percentage of vehicles getting away without an incident per clear zone width. The study showed that as the clear zone width increased, so did the percentage of departing vehicles that got away without being harmed starting at zero feet (zero metres) with 17.7 percent of vehicles getting away to 100 feet ( 30 metres) and about 47 percent of vehicles getting away.

Later, a study is referenced (Ogden 1996) that looked at the relationship of increased clear zone to collision reductions on straight and curved road sections in the 
U.S. The results are shown in Table 4.3. The results showed that as the amount of roadside recovery distance increased, so did the reduction in related collisions.

Table 4.3: Reduction in Collisions From Increased Clear Zones, (Ogden 1996).

\begin{tabular}{|c|c|c|}
\hline $\begin{array}{c}\text { Amount of increased } \\
\text { roadside recovery distance } \\
\text { in metres }\end{array}$ & Reduction in related collision types (percent) \\
\cline { 2 - 3 } & Straight & Curves \\
\hline 1.5 & & 9 \\
\hline 2.4 & 13 & 14 \\
\hline 3.0 & 21 & 17 \\
\hline 3.6 & 25 & 19 \\
\hline 5.0 & 29 & 23 \\
\hline 6.0 & 35 & 29 \\
\hline
\end{tabular}

\subsubsection{Shoulder Rumble Strips}

Rumble strips are continuous grooves in the pavement that make a sound and vibrate a vehicle when driven over them. Traditionally, they have been installed on the right shoulder of the roadway to alert drivers when they are leaving the right-of-way, preventing the possibility of a run-off the road collision. Rumble strips are most helpful when drivers are inattentive, distracted or fatigued, as they alert the driver that they are leaving the right-of-way and to correct their vehicle position before running of the road and potentially getting into a collision. They have been installed in North America since the mid 1980's. The earliest study found (Moore 1987) evaluated the effectiveness of shoulder rumble strips for 26 roadways in Louisiana between August 1982 and September 1984. A comparison of collision report statistics indicated that, after installation of rumble strips, there was a slight reduction in both the quantity and severity of collisions at potentially hazardous intersections. Collision reports that covered a fouryear period, two years before and two-years after installation, demonstrated that 58.6 
percent of all collisions occurred prior to installation. Analysis of the severity of collisions indicated there were no fatal collisions in the after period, as opposed to 2.6 percent in the before period. While injury collisions remained virtually unchanged, 20.3 percent versus 19.7 percent, collisions involving property damage only dropped from 25.5 percent to 21.7 percent.

Later, two studies related to the safety effects of rumble strips were cited (Harwood 1993, 80). The first one involved an evaluation on the safety effects of continuous rumble strips on asphalt shoulders in California for seven projects representing about 135 miles (217 kilometres) of rural freeway. The safety evaluation focused on the effect of rumble strips on run-off-road collisions. An evaluation of one year of collision data before and one year after installation of the shoulder rumble strips found that the run-off-road collision rate was reduced by 49 percent. Rumble strips on the right shoulder were found to reduce run-off-road collisions by 63 percent, while rumble strips on the left (median) shoulder reduced run-off-road collisions by 18 percent. The second study, which was conducted in 1985 , evaluated the collision experience before and after rumble strip installations at 10 sites located in Arizona, California, Mississippi, Nevada, and North Carolina. The study found that after selected test sites were improved by placing rumble strips on the roadway shoulders, run-off-road collision rates on the test sites decreased by 20 percent, while run-off-road collision rates on comparable control sites increased by 9 percent. 
Then, in the mid 1990's, a study was conducted (Garder and Alexander 1994) that involved a literature review and a survey of the 50 states in the U.S. on the use of continuous shoulder rumble strips (CSRS). The results showed that 34 states used CSRS along at least parts of their freeway systems, with a few states using them along other roads. Results of the literature review indicated that CSRS could reduce run-off-road collisions by 20 percent to 50 percent. In addition around the same time, a study was conducted (Cheng, Gonzalez, and Christensen 1994) to evaluate the difference in collision rate experience between highway segments with and without rumble strips. Three interstate segments were selected for the study in Utah. Collision data was used for the years 1990 to 1992 . The results showed that collision rates for both overall and run-off-road collisions were lower on those sections with rumble strips. For those sections with rumble strips, the collision rates were found to be 0.713 and 0.394 for overall and run-off-the-road collisions, respectively. Highway sections without rumble strips were found to have collision rates of 0.951 (33.4 percent higher) and 0.5 (26.9 percent higher) for overall and run-off-road collisions, respectively. The severity of collisions that occurred on the studied areas was also reviewed. The results showed that the presence of rumble strips is effective in lowering the number of fatal and incapacitating collisions. When rumble strips were present, a rate of 1.58 and 1.26 serious collisions per mile ( 0.98 and 0.78 serious collisions per kilometre) were found for overall and run-off-the road collisions, respectively. The absence of rumble strips attributed to a rate of 2.01 (27.2 percent higher) and 1.37 (8.7 percent higher) for overall and run-offthe-road collisions, respectively. 
Further work (Federal Highway Administration 1999) included a before-after safety evaluation of projects involving the installation of continuous shoulder rumble strips on rural and urban freeways in Illinois and California. Two analyses approaches were used $-\mathbf{a}$ before-after evaluation that compared treated sites within untreated sites; and a before-after evaluation with a comparison group. The results of the Illinois data found that for the first analysis approach, the average safety effect of continuous shoulder rumble strips was estimated to be a reduction of single-vehicle run-off-road collisions by 18.3 percent. The results of the second analysis approach found the average safety effect of continuous shoulder rumble strips to be a reduction of single-vehicle run-off-road collisions by 21.1 percent. For California data, only the second analysis approach was used. The results showed an estimated 7.3 percent reduction in single-vehicle run-offroad collisions with the installation of continuous shoulder rumble strips. Later, another study (Bahar, Wales, and Lontin-Nobel 2001) reviewed before-after studies of the benefit of installing shoulder rumble strips to reduce run-off-road collisions in North America. The study found that the reported reduction in run-off-road collisions from the use of shoulder rumble strips ranged from 18 percent to 65 percent.

A little later, a before-after study was conducted (Chen, Darko, and Richardson 2003,30 ) of collisions where shoulder rumble strips were installed on sections of highway in Virginia. The study used crash data for the years 1994 to 2000 for 12 sites ranging from 8.96 miles (14.34 kilometres) to 47.97 miles ( 76.75 kilometres) in length. The results concluded that the implementation of continuous shoulder rumble strips significantly reduced the frequency of run-off-road crashes by 51.5 percent. Around the 
same time another study (Annino 2003) looked at the safety benefits achieved from rumble strips along roadways in Connecticut by conducting a before-after collision analysis. From the results of the study, the number of single vehicle, fixed object, runoff-road collisions decreased as well as the number of fatal and injury collisions.

More recently, an evaluation was conducted (Nambisan et al 2007) on continuous shoulder rumble strip treatments to reduce run-off-road crashes in Nevada. Crash records involving single-vehicle run-off-road crashes were evaluated on which rumble strips had been installed. The roadways studied included Interstate freeways, U.S. routes, and state routes totaling 306 individual segments corresponding to a total of 1,303 centreline miles (2,097 centreline kilometres) of roadways. Data for the period from 1995 to 2003 was used for the analyses. Overall, for the entire 1,303 centreline miles (2,097 centreline kilometres) of roadways evaluated, there was a 39.7 percent reduction in the crash rate due to the installation of continuous shoulder rumble strips during the "after" period as compared to the "before" period. Around the same time, another study was being conducted (Patel, Council, and Griffith 2007, 205) to estimate the safety benefits of shoulder rumble strips on two lane rural highways in Minnesota. The study involved an empirical Bayes before-after analysis to evaluate the safety effectiveness of continuous shoulder rumble strips on two-lane rural highways in Minnesota. The treatment was installed at 23 treatment sites. The results of the analysis found a 13 percent reduction in all single-vehicle run-off-road crashes and an 18 percent reduction in injury producing single-vehicle run-off-road crashes. 


\subsubsection{Energy-Absorbing Barrier End Treatments}

The performance of barrier end treatments has been a subject of concern to highway engineers for many years. The lack of adequate barrier end treatments have resulted in severe collisions, in some cases where vehicles were cut in half when hitting the barrier end straight on. The implementation of barrier end treatments does not reduce the frequency of collisions but they have been successful in reducing their severity. They have been implemented in North America since the early 1980's. Only two safety studies were found related to energy-absorbing barrier end treatments. The first one (Pigman, Agent, and Creasey 1985,73 ) was an analysis of 50 collisions involving breakawaycable-terminal (BCT) end treatments and 19 collisions involving median-breakawaycable-terminal (MBCT) end treatments as used in Kentucky. Results showed that BCT end treatments performed properly in most collisions ( 60 percent of the time). The wooden posts broke away or the guardrail redirected the vehicle. The MBCT end treatment performed properly only 50 percent of the time. The second study (Elvik 1995, 523) evaluated the effects of crash cushions on the probability and severity of collisions by means of a meta-analysis. Results showed that crash cushions reduced collision rates by 84 percent, fatal collisions by 69 percent and injury collisions by 68 percent.

\subsection{Medians}

This section includes safety studies related to centreline rumble strips, two-way left turn lanes, and median barriers. 


\subsubsection{Centreline Rumble Strips}

Centreline rumble strips are used for the same purpose as shoulder rumble strips except they are targeted to drivers leaving the road right-off way to the left and encroaching on opposing lanes of traffic. They help in reducing the chance of becoming involved in a head-on collision. They have been installed in North America since the late 1990's. A few studies were found related to the safety effectiveness of centreline rumbles strips. The first one (Outcalt 2001) evaluated the effectiveness of centreline rumble strips on a two-lane mountain highway in the state of Colorado. Collision data before and after construction was used to demonstrate the improvement in safety. Collision data was collected comparing similar periods from before construction and after construction. Collision reports from the two periods showed a decrease of 34 percent in head-on collisions, and a 36 percent decrease in sideswipe collisions in spite of a considerable increase in the average daily traffic for the highway.

More recently a study was conducted (Persaud, Retting, and Lyon 2003) to determine the safety effectiveness of the installation of rumble strips along the centrelines of undivided rural two-lane roads. Data were analyzed for approximately 210 miles (338 kilometres) of treated roads in seven states before and after installation of centreline rumble strips. An empirical Bayes before-after procedure was employed to properly account for regression to the mean. Overall, results indicated the motor vehicle crashes at sites treated with centreline rumble strips were reduced by 14 percent, injury crashes were reduced by an estimated 15 percent, frontal and opposing-direction sideswipe crashes were reduced by an estimated 21 percent, and frontal and opposing-direction 
sideswipe crashes involving injuries were reduced by an estimated 25 percent. A little later, a U.S. and Canadian nationwide survey of the safety effectiveness of centreline rumble strips was completed (Russell and Rys 2006). The overall conclusion of the study was that the safety benefits of centreline rumble strips outweigh some non-benefits and that they are a viable, low-cost safety devices for reducing crossover crashes on two-lane highways.

\subsubsection{Two-Way Left Turn Lanes}

Two-way left-turn lanes (2WLTLs) were introduced to accommodate motorists on busy corridors by giving them a chance to move out of the way of the main traffic flow to make a left turn. The lane is shared for left-turning traffic in both directions of travel. Research has found that this reduces the number of rear-end collisions with vehicles that originally had to stop within the main traffic flow in order to make a left turn. They have been implemented in North America since the mid 1970's. Three safety studies related to two-way left turn lanes were conducted in the mid 1980's. For the first one (Thakkar 1984, 27) collision data were collected for 31 roadway sections, 15 fivelane and 16 three-lane sections in the state of Illinois. Two years of before and after data were used. Statistically significant reductions were found in collisions, their rates, and their severity. The second study (Harwood and St. John 1985) involved an evaluation to quantify the effectiveness of 2WLTL sections on rural two-lane highways. Seven 2WLTL sites in rural areas of the U.S. were used in this evaluation, along with four untreated two-lane sites. Results showed that the 2WLTL sites experienced total collision rates and fatal and injury collision rates that were both less than 30 percent of 
the collision rates on the comparable untreated sections. At the four sites for which before and after data were available, the total collision rate was reduced 85 percent and fatal and injury collision rates were reduced 67 percent by 2 WLTL installation. The third study (Nicholas 1988, 1) summarized the effects of 2WLTLs on collisions and total collision rates after installation on a given section of roadway in the six county area of Chicago. The overall effect of the 2 WLTL in the areas was positive. In four out of the five segments analyzed, the collision rate clearly dropped after the 2 WLTL was installed. In the remaining segment, the collision rate peaked during the first eighteen months after the 2WLTL installation, and dropped gradually to below the collision rate prior to its installation.

Transport Canada's "Synthesis of Safety For Traffic Operations" (Forbes 2003) referenced three safety studies related to 2 WLTLs. One study examined the safety effects of constructing 2WLTLs on four four-lane arterial streets in Michigan. The before-after study found that 2WLTLs reduced collisions by about 33 percent where installed. The second study referenced examined the effects of 2 WLTLs on arterial streets in the City of Hamilton, Ontario. All 2WLTLs were constructed on four lane roads, resulting in a five-lane cross-section. A before-after study was used. Three years of before data was compared to one and two years of after periods. The results indicted a collision reduction that averaged 49 percent. The third study referenced looked at the safety impacts of 2WLTLs on jurisdictions across Canada and the U.S. Crash data was supplied for 30 road sections that had been provided with a 2WLTL. A before-after analysis was used to show an overall reduction in collisions by 28 percent. The source 
also referenced a study conducted in the City of San Buenaventura, California where 2WLTLs were introduced to five areas of the city. The before-after analysis found a total reduction of collisions of 58 percent. Finally, another study from the same source referenced a study, which included an examination of the effects of 2WLTLs on crash occurrence in Indiana. The results showed a total reduction of collisions by 53 percent. More recently, a study (Noyce, Talada, and Gates 2006) evaluated the safety characteristics of 2WLTLs compared to four-lane undivided roadways in Minnesota. Nine study sites were selected. Crash data was analyzed before and after the conversion from a four-lane undivided roadway to a three-lane roadway with a 2 WLTL. The percent reduction in total crashes, property damage only crashes and left turn crashes after the conversion were approximately 37 percent, 46 percent and 24 percent, respectively.

\subsubsection{Median Barriers}

Roadside and median barriers are used to protect motorists from leaving the roadway and hitting a roadside object, falling over a cliff, rolling over in a ditch, or encroaching on opposing traffic reducing the severity of a collision. Although there is still the potential for drivers to hit the barrier, barriers have shown to overall reduce collisions where they are installed. They have been implemented in North America since the mid 1970's. The first study found (Elvik 1995, 523) evaluated the effects of median barriers and guardrails along the edge of the road on the probability and severity of collisions. Results showed that the installation of median barriers increased collision rates by 29 percent but decreased fatal collisions by 32 percent and did not affect injury collisions. Guardrails significantly reduced collision rates by 27 percent, fatal collisions 
by 44 percent and injury collisions by 52 percent. A later study (Monsere, Sposito, and Johnston 2003) involved before-after analysis of the safety effectiveness of approximately 21.9 miles ( 35.2 kilometres) of cable median barrier on Interstate 5 in the state of Oregon. The study used three years of before and after computerized crash records. The study found that the cable barrier system was effective in reducing the severity of crashes but resulted in an increase of reportable minor injury and property damage crashes. In the three-year period prior to the installation of the cable barrier, there were 11 crashes ( 2 fatal and 1 injury) as a result of a vehicle crossing the median. The remaining crashes were minor injury or property damage. In the three years after the barrier treatment, there were no reported crashes involving a vehicle crossing over the median.

In more recent years, a study (Shankar et al. 2004) examined the safety impacts of installing median barriers on Washington State highways. A before-after analysis was conducted. Data from 1990 to 1994 containing crash information about vehicle crossovers on non-barriered medians was used. The dataset consisted of 275 nonbarriered highway sections over the entire Washington State highway network totaling a length of nearly 670 centreline miles ( 1,072 centreline kilometres). It was found that a section with two to five grade changes per mile (one to three grade changes per kilometre) and median barriers experienced fewer overall crashes than similar sections without median barriers. Around the same time, another study was conducted (Davis and Pei 2005) that involved the reconstruction of several fatal median-crossing events that occurred where there was no median barrier installed. The study found that for most 
cases, the median encroachment was triggered by loss of control following a steering overcorrection, and by the time the vehicle encroached onto the median, there was a substantial yaw component to the vehicle's motion. Since the drivers never regained control, their vehicles would traverse the median unless they either lacked sufficient kinetic energy or were stopped by an obstacle. The conclusions stated that a wide range of barrier designs could probably have prevented crashes such as these.

\subsection{Vehicle-Related Countermeasures}

This section summarizes safety studies related to daytime running lights, electronic stability control, centre high mounted stop lamps, seat belts, air bags, child restraints, and antilock braking systems.

\subsubsection{Daytime Running Lights}

The introduction of daytime running lights has shown promising results in reducing daytime collisions. The purpose of daytime running lights is to increase visual contrast, making the vehicle more visible to road users during the daytime. Daytime running lights have been a standard in vehicles in Canada since 1989. The first safety study found on daytime running lights included one (Stein 1985, 13) where over 2,000 passenger cars, vans, and pickup trucks in three fleets were modified to operate with daytime running lights. The crash experience of these vehicles was compared to similar but unmodified vehicles in the fleets. Results showed that daytime multiple vehicle crash rates, relevant to daytime running lights was 22 percent lower for the modified vehicles. Also daytime multiple vehicle crashes were a smaller percentage of all of the crashes of 
modified vehicles than of standard vehicles. Right-angle crashes were most affected for passenger cars; and crashes of vehicles travelling in the same direction were most affected for vans and pickups. Nonequipped standard vehicles were also more often struck in multiple vehicle collisions than were daytime running light vehicles.

Later in the early 1990's, a literature review (Streff 1991) was conducted on the safety effects of daytime running lights. The study also applied statistically significant daytime running light effects found in a study of daytime running light implementation in a large Canadian vehicle fleet to data representing the totality of U.S. crash experience for 1989. Based on the analysis, daytime running light implementation was expected to prevent between 200,744 and 380,845 property damage crashes, 98,839 to 209,052 personal injury crashes, 165,673 to 335,630 nonfatal injuries, 42 to 3,129 fatal crashes, and 396 to 4,542 deaths each year in the U.S. Another study (Sparks et al. 1993, 619) was conducted where crashes of vehicles with and without daytime running lights owned by the Central Vehicle Agency of the Province of Saskatchewan were compared to a random selection of crashes drawn from provincial crash files involving vehicles without daytime running lights for the years 1982 through 1989. Daytime two-vehicle crashes involving vehicles approaching from the font or side were reduced by about 28 percent for the daytime running light equipped vehicles.

Later, an evaluation was conducted (Arora et al. 1994) on the effectiveness of legislating the mandatory installation of daytime running lights in new Canadian vehicles. Statistical analysis focused on the reduction of two-vehicle, opposing-direction, daytime 
collisions for vehicle model years before and after the legislation in 1989. The analysis showed that the use of daytime running lights reduced these collisions by 8.3 percent. Also, another evaluation was conducted (Tofflemire and Whitehead 1997, 257) that studied the impact of daytime running light legislation on the incidence of angle and opposing collisions from 1989 cars and 1990 cars in the 1991 calendar year in Canada. The results showed that the combined incidence of the two types of collisions was reduced by 5.3 percent. A little later, a further study (Farmer and Williams 2002, 197) analyzed involvement in multiple-vehicle daylight crashes in nine states in the U.S. over 4 years for a group of passenger cars and light trucks equipped with automatic daytime running lights. On average, these vehicles were involved in 3.2 percent fewer multiplevehicle crashes than vehicles without daytime running lights.

\subsubsection{Electronic Stability Control}

Electronic Stability Control (ESC) is a computerized system designed to improve a vehicle's handling by detecting and preventing skids, helping the driver maintain control of the vehicle and preventing a collision. Although the technology has been around since the late 1980's, ESC is still not available for most vehicle makes and models. The first study found (Farmer 2004, 317) was one conducted in 2004, which estimated the effects of ESC on crash risk. Vehicle models eligible for study were those equipped with ESC as standard equipment in the 2000 or 2001 model year. Information on all police-reported crashes of these vehicles in Florida, Illinois, Kansas, Maryland, Missouri, New Mexico, and Utah during 2001-2002 was extracted from the State Data System maintained by the National Highway Traffic Safety Administration (NHTSA). 
Per vehicle crash involvement rates were compared with identical models with and without ESC systems. ESC was found to affect single-vehicle crashes to a greater extent than multiple-vehicle crashes, and crashes with fatal injuries to a greater extent than less severe crashes. ESC reduced single vehicle crash involvement risk by approximately 41 percent and single-vehicle injury crash involvement risk by 41 percent. There was an estimated 7 percent reduction in overall crash involvement risk and a 9 percent reduction in overall injury crash involvement risk. Based on all fatal crashes in the U.S. over 3 years, ESC was found to have reduced single-vehicle fatal crash involvement risk by 56 percent. This translates to an estimated 34 percent reduction in overall fatal crash involvement risk. The same author conducted another study (Farmer 2006, 319) as a follow-up to the 2004 study with more data, allowing for separate effectiveness estimates for cars and SUVs and a more detailed examination of multiple-vehicle crash types. Crash involvement rates per registered vehicle were compared for otherwise identical vehicle models with and without ESC. The results showed that ESC reduced singlevehicle crash involvement risk by approximately 41 percent. It also showed that ESC reduced single-vehicle crash involvement risk by 49 percent for SUVs and 33 percent for cars. Based on all fatal crashes in the U.S. during four years, ESC was found to have reduced single-vehicle fatal crash involvement risk by 56 percent. Again, effectiveness estimates were higher for SUVs than for cars -59 percent for SUVs and 53 percent for cars. Multiple-vehicle fatal crash involvement risk was reduced by 32 percent to 37 percent for SUVs and 25 percent for cars. 
Another study (Dang 2004) analyzed crash data from U.S. State and Fatality Analysis Reporting System (FARS) databases. Crash data from years 1997 to 2002 from 5 States (Florida, Illinois, Maryland, Missouri, and Utah) were used. The effectiveness of ESC in reducing fatal single vehicle crashes was also evaluated by analyzing FARS data from years 1997 to 2003 . The first set of analyses used multi-vehicle crash involvements as a control group. Linear regression analyses were also performed to look at the singleand multi-vehicle crash involvement rates per 100,000 vehicle registration years, controlling for vehicle age. The results showed that single vehicle crashes were reduced by 35 percent in passenger cars and by 67 percent in Sport Utility Vehicles (SUVs). Similarly, fatal single vehicle crashes are reduced by 30 percent in cars and by 63 percent in SUVs. The second set of analyses also showed reductions in the multi-vehicle crash rates per 100,000 vehicle years with ESC and it also showed reductions in single vehicle crash rates with ESC. The same author (Dang 2007) conducted a statistical analysis of the effectiveness of ESC. Statistical analyses of 1997 to 2004 crash data from FARS and 1997 to 2003 crash data from Washington State data files were used. The results showed overall that ESC reduced fatal run-off-road crashes by 36 percent for passenger cars and 70 percent for light trucks and vans (LTVs), rollover involvements in fatal crashes were decreased by 70 percent in passenger cars and 88 percent in LTVs, and ESC reduced all fatal crashes by 14 percent for passenger cars and 28 percent for LTVs.

More recently, a study was conducted (Green and Woodrooffe 2006, 493) to assess the effects of ESC on loss-of-control type crashes for SUVs. Data was used from the National Automotive Sampling System (NASS) and General Estimates System 
(GES). Overall, the estimated percent reduction in the odds of a loss-of-control crash for SUVs equipped with ESC was 70.3 percent. The positive effects of ESC on roads that were not dry were significantly greater than on roads that were dry. The same authors also analyzed eight years of government vehicle crash statistics for approximately 1,500 fatal car crashes and 500 fatal SUV crashes. They found that ESC systems could reduce the odds of a fatal rollover crash by nearly 73 percent in SUVs and by nearly 40 percent in passenger cars. Nonfatal loss-of-control crash odds were reduced by 70 percent for SUVs and 55 percent for cars, with even more obvious benefits in poor weather conditions. Fatal single-vehicle crashes were 50 percent less likely in SUVs with ESC and 31 percent less likely in cars with ESC.

\subsubsection{Centre High Mounted Stop Lamps}

A Centre High Mounted Stop Lamp (CHMSL) is a central brake lamp on a vehicle that is mounted higher than the vehicle's left and right brake lamps. They provide a deceleration warning to following drivers whose view of the braking vehicle's regular stop lamps are blocked by interceding vehicles. It provides drivers with another mechanism in which to communicate to other motorists behind them, reducing the chance of a rear-end collision. They have been installed in passenger cars in Canada since 1986.

The first study (Kahane 1987) to evaluate its safety effectiveness was conducted in the U.S. The study was based on a census of police reported collisions that occurred at 50 National Collision Sampling System areas between June 1 and September 5, 1986. The involvement rate in rear impacts for model year 1986 cars (all CHMSL equipped) 
was compared to 1985 cars (mostly without the lamps). CHMSLs reduced the likelihood of being struck in the rear while braking by a statistically significant 22 percent. The data also suggested that CHMSLs might be especially useful in preventing chain collisions involving three or more vehicles. The same author (Kahane 1989) later evaluated the effectiveness of CHMSLs based on 1987 data. The effectiveness analysis was based on police reported collision files from 11 States. The study found that CHMSLs equipped cars were 17 percent less likely to be struck in the rear while braking than the cars without CHMSL.

Anther study (Farmer 1996, 2001) was conducted to estimate CHMSL effectiveness over the general population of passenger vehicles in the U.S. by examining automobile property damage liability insurance claims data over 6 years. A comparison focused on model year 1985 versus 1986 passenger cars. The overall effectiveness of CHMSLs in reducing collisions with rear-end damage were estimated to be between 3 and 7 percent. The effectiveness of CHMSLs was found to be highest for midsize cars, between 7 and 12 percent. A further study (Kahane and Hertz 1998) estimated the effectiveness of passenger car CHMSLs in each year from 1986 through 1995. The analysis is based on police-reported crash data from eight States. The study found, that in the long term, passenger car CHMSLs reduced rear impacts by 4.3 percent.

\subsubsection{Seat Belts}

Since the introduction of mandatory seat belt wearing laws in provinces starting in the mid 1970's, seat belt usage has become an important measure in reducing collision 
severity. Vehicles are designed to slow relatively gradually when impacted in a crash. However an unrestrained occupant would move at the vehicle's impact speed until hitting something solid either inside or outside the vehicle. In a crash, seat belts link a person to the vehicle to slow them down to the same rate as the vehicle, decreasing the chance of a fatality or severe injury. Another major benefit of wearing seat belts is simply preventing occupants from being ejected from the vehicle in the event of a crash.

Only one study was found on the safety effectiveness of seat belts. This study (Fujita, Yamazaki, and Shimamura 2005, 5) looked at the tendency of front seat occupants to sustain severe injuries due to forward movement of passengers in rear seats at the moment of frontal collisions, and evaluated the effectiveness of rear passengers' wearing seat belts in reducing injuries of front seat occupants. Results showed that the number of killed or seriously injured drivers is estimated to decrease by around 25 percent if rear seat occupants came to wear seat belts. Also, the number of killed or seriously injured passengers in front seats is estimated to decrease by 28 percent if unbelted rear seat occupants were to wear seat belts.

\subsubsection{Air Bags}

Although air bags have been available as an optional feature on new vehicles since the late 1970s, it wasn't until the 1990's when they became a common feature. Air bags are connected to sensors that detect sudden deceleration. When activated, the sensor sends an electrical signal that ignites a chemical propellant, and when ignited, this propellant produces nitrogen gas, which inflates the air bag. This process occurs in about 
one-twentieth of a second. Sensors deploy air bags only when deceleration exceeds a minimum threshold. Frontal air bags protect the head and upper body in frontal crashes and are not designed to open in rear-end collisions, side impacts, or rollovers. Sidemounted air bags protect drivers and passengers in certain side-impact collisions (Transport Canada 1996). Air bags do not reduce the number of collisions, just the severity of them. The earliest study found that evaluated the effectiveness of air bags was conducted in the mid 1970's. The study (Mohan et al. 1976) compared three groups of real-world frontal crashes: those in which front-seat occupants were using no restraints, those in which they were wearing lap/shoulder belts, and those in which they were automatically restrained by air bags. The results showed that both air bags and lap/shoulder belts (when worn) substantially reduce the likelihood of death and serious injury to front seat occupants of full-size and luxury cars involved in frontal crashes. The results also showed that as the severity of the crashes increased, the role of the restraint became very important. The average injury severities were reduced by 66 percent for the air bag restrained occupants and 55 percent for the lap/shoulder belted occupants in the more severe frontal crashes. The corresponding reductions in the likelihood of death in such crashes were 79 percent and 72 percent.

In later years a study (Kahane 1996) was conducted where the fatality risk of front-seat occupants of passenger cars and light trucks equipped with air bags was compared to the corresponding risk in similar vehicles without air bags, based on statistical analyses of FARS data from 1986 through early 1996. The main conclusion was that driver air bags save lives. The fatality reduction benefit of air bags for all 
drivers was an estimated 11 percent. The study also found that passenger air bags save lives of right-front passengers aged 13 or older and that driver air bags provide a significant supplemental life saving benefit for the driver who wears a seat belt. However, data showed a higher fatality risk for child passengers aged 0 to 12 in cars with current dual air bags than in cars without a passenger air bag. Another study (Barry, Ginpil, and O'Neill 1999, 781) evaluated the effectiveness of air bags by analyzing data from the U.S FARS database of fatal crashes. The study found that both the driver and passenger side air bag devices were shown to significantly reduce the probability of death in direct frontal collisions, but the effect calculated was small compared to the effect of the use of air bags and seat belts together.

More recently, a study (Berkowitz 2000) analyzed the effectiveness of light truck driver air bags to reduce the risk of severe injury. The analysis of data from The New Car Assessment Program for multi-tested vehicle models for the period 1979 through 2000 indicated a significant reduction of 56 percent for light trucks in the risk of severe trauma for drivers in air bag equipped vehicles. A further study by Transport Canada (Transport Canada 2001) evaluated the effectiveness of air bags and seat belts on saving lives. The study was a follow-up to a previous study from 1998, which estimated the number of front occupant lives saved by both seat belts and air bags in light-duty vehicles involved in collisions over the eight-year period of 1990 to 1997 . The aim of this study was to extend the analysis to the year 2000. Input parameters for each of the years 1997 to 2000 were obtained from Transport Canada's Traffic Accident Information Database. As well, the results from the National Annual Seat Belt Survey for each of the years 1997 
to 2000 were used as input parameters for the model. The results showed that 11,690 front light-duty vehicle occupant lives were saved by seat belts over the eleven-year period of 1990 to 2000 . The number of front light-duty vehicle occupant lives saved by air bags over the same eleven-year period was 313 .

\subsubsection{Child Restraints Laws}

Mandatory infant and child restraint usage along with the introduction of the Lower Universal Anchorage System (LUAS) have helped to increase the safety of children in motor vehicles and reduce the severity of collisions. All new Canadian vehicles, manufactured on or after September 1, 2002, are equipped with lower universal anchorage bars, as required by Canadian regulation. These lower anchorage bars make it easier to install infant and child seats in the rear seat of a vehicle. An early study was conducted (New York State Department of Motor Vehicles 1986) to determine the effects of motor vehicle occupant safety restraint laws in New York State on the collision experiences of children 0 to 6 years of age. Mandatory restraint laws were found to have been the major influence in increasing overall restraint usage by study children from under 30 percent to nearly 90 percent. Use of the restraints resulted in significant reductions in rates of total injuries and the severity of injuries especially among the younger children. Restraints had the most effect in preventing head injuries, which constituted over 80 percent of all injuries to children involved in collisions. Also, ejection had been greatly reduced by the increased use of restraints. 
A more recent study (Arbogast et al. 2004, 585) was conducted to determine the effectiveness of forward facing child restraint systems in preventing serious injury and hospitalization in children 12 to 47 months of age compared with similar age children in seat belts. Data were obtained from a cross-sectional study of children aged 12 to 47 months in crashes of insured vehicles in 15 U.S. States, with data collected using insurance claims records and a telephone survey. Serious injuries occurred to 0.47 percent of all 12 to 47 month olds studied, including 1.72 percent of those in seat belts and 0.39 percent of those in child restraint systems. The risk of serious injury was 78 percent lower for children in front facing child restraint systems than in seat belts. The risk of hospitalization was 79 percent lower for children in front facing child restraint systems than in seat belts. There was no difference between the restraint types in preventing minor injuries.

\subsubsection{Antilock Braking Systems}

Anti-lock braking systems (ABS) were introduced to vehicles in the mid 1980s to help the driver maintain steering ability and avoid skidding while braking. ABS uses wheel speed sensors to determine if one or more wheels are trying to lock up during braking. If a wheel tries to lock up, a series of hydraulic valves limit or reduce the braking on that wheel. This prevents skidding and allows you to maintain steering control (Transport Canada 1997). This is beneficial on slippery, wet or snowy roads. Drivers would be able to still steer his/her vehicle when braking in order to avoid colliding with another car or object near the roadway. Overall, ABS has shown to reduce the number and severity of collisions. 
Two studies were conducted in the mid 1990's on the effectiveness of ABS. The first one (Hertz, Hilton, and Johnson 1995) involved an analysis of the crash experience of passenger cars (PC) and light trucks and vans (LTV) equipped with ABS. Separate analyses were conducted for PCs and LTVs. Data from NHTSA's Fatal Accident Reporting System (FARS) were used to analyze the crash experience of ABS-equipped and non-ABS-equipped vehicles in both analyses. In the PC analysis, state crash files for Florida, Maryland, Missouri, and Pennsylvania were also used. In the LTV analysis, data from Florida, Maryland, Michigan, and Missouri were used in addition to the FARS data. For PCs, it was found that a significant reduction in non-fatal frontal impacts with another motor vehicle in transport crashes was associated with the presence of ABS, significant increases in non-fatal frontal impacts with parked vehicles or fixed objects and in non-fatal side impacts with parked vehicles or fixed objects were associated with the presence of ABS, and significant increases in fatal rollover crashes and in fatal side impacts with parked vehicles or fixed objects were also associated with the presence of ABS. For LTVs, it was found that significant reductions in non-fatal rollover crashes and side impacts with fixed objects/parked vehicles were associated with the presence of rearwheel antilock systems (RWAL). A significant reduction in non-fatal rollover crashes was associated with the presence of all-wheel antilock systems (AWAL). The reductions in non-fatal crashes did not extend to fatal crashes, in which no significant reductions associated with the RWAL or AWAL were found. Also, significant increases in nonfatal and fatal frontal crashes with another vehicle in transport were found associated with the presence of RWAL. The second study (Padmanaban and Lau 1996) looked the effect of ABS on collision and injury risk. Police-reported data from Florida, 
Pennsylvania, and North Carolina and FARS were examined. Collision rates were normalized using vehicle registration data. The examination of over 60,000 collisions showed that with the presence of ABS there were 9 to 11 percent reductions in overall collision rates, 16 to 17 percent reductions in collisions on wet roads, 6 to 9 percent reductions in collisions on dry roads, and 7 to 16 percent reductions in injury rates under all road conditions. There was no measurable difference in fatal collision rates between $\mathrm{ABS}$ and non-ABS vehicles. ABS seemed especially effective in reducing multi-vehicle crashes.

A later study (Forkenbrock, Flick, and Garrott 1999) evaluated the braking performance of passenger vehicles in 18 stop situations. These situations were comprised of various road surfaces, driver steering actions, and vehicle speeds. Testing was performed with lightly and heavily laden vehicles, with the ABS active and disabled, and used two brake pedal application techniques. The selected vehicles included at least one ABS from each of the eight major manufacturers. The study found that for most stopping manoeuvres on most surfaces, ABS-assisted full pedal brake application stops were shorter than those made with the ABS disabled. The one systematic exception was on loose gravel where stopping distances increased by an average of 27.2 percent overall. Also, the vehicular stability during testing was almost always superior with the assistance of ABS. For the cases in which instability was observed, ABS was not deemed responsible for its occurrence. 
During that same time period, a study (Mazzae et al. 1999) was conducted which examined driver crash avoidance behaviour and the effects of ABS on drivers' ability to avoid a collision in a crash-imminent situation. The study was conducted on a test track under dry and wet pavement conditions to examine the effects of ABS versus conventional brakes. The study found that drivers tend to brake and steer in realistic crash avoidance situations and that excessive steering can occur. However, a significant number of road departures did not result from this behaviour for either pavement condition. ABS was found to reduce crashes significantly on wet pavement as compared to conventional brakes. That same year, another study was conducted (Mazzae, Baldwin, and McGehee 1999) that examined driver crash avoidance behaviour and the effects of ABS on drivers' ability to avoid a collision in a crash-imminent situation. The study was conducted on the Iowa Driving Simulator and examined the effects of ABS versus conventional brakes, speed limit, ABS instruction, and time-to-intersection on driver behaviour and crash avoidance performance. This study found that average, alert drivers tend to brake and steer in realistic crash avoidance situations and that excessive steering can occur. However, this behaviour did not result in a significant number of road departures.

A further study was conducted (Forkenbrock, Flick, and Garrott 1999) where braking performance of nine passenger vehicles was observed over a number of driving conditions. The results showed that for most manoeuvres, on most surfaces, ABSassisted stops yielded distances shorter than those made with the ABS disabled. The one exception was on loose gravel where stopping distances increased by an average of 27.2 
percent overall. Also, the vehicular stability observed during testing was almost always superior with ABS. For the cases in which instability was observed, ABS was not deemed responsible for its occurrence. Finally, an additional study (Hertz 2000) analyzed the crash experience of vehicles equipped with ABS. Results found that ABS had a beneficial effect in preventing rollovers, run-off-road, frontal impacts and pedestrian involved crashes but not in preventing side impact crashes. 


\section{Chapter 5: Discussion}

This chapter provides a link between the road safety trends in Canada and the road safety countermeasures presented in Chapter 4. A timeline of factors influencing road safety are compared with the national trend lines of fatal and injury rates with explanations on how each measure has affected their overall decrease. This chapter also discusses the results of the collision analysis from Chapter 3 divided into 7 topic areas; General, Intersections, Rural Roads, Roadside and Median, Urban Roads, Environmental and Temporal, and Vehicle Type. The differences of trends between regions are compared, and where possible explanations are provided on observations.

\subsection{Countermeasures Affecting National Road Safety Trends}

Road safety is a complex issue and is affected directly and indirectly by many factors. Contributing factors that may affect a drivers' ability include such things as fatigue, inattention, inexperience, impatience, aggression, age, medical problems, drugs, and alcohol. Economic factors such as wars, recessions, inflation, and the price of gas all have an impact on safety as well as it could have an effect on whether people can afford a vehicle or not, resulting either in an increase or decrease in motor vehicle registrations and motor vehicle use. The more cars on the road, the more chances of a conflict occurring. Although society tries to control some of these factors by enforcing stricter penalties for drinking and driving, illegalizing drugs such as marijuana and cocaine, restricting in-vehicle cell phone use, and developing mandatory graduated licensing 
programs, it is still impossible to control how people feel, how they react to situations, what they do on a day to day basis, and what substances they intake. What we can control is the way we build our road infrastructure and design our vehicles so that if a conflict does occur, road users are protected well enough to not be seriously hurt. Anyone can drive and decide to run a red light but they will not be able to buy a new car without daytime running lights.

Vehicle engineering has progressed substantially in the last two decades. As shown in Chapter 3, some of the major vehicle-related safety countermeasures such as antilock braking systems, centre high mounted stop lamps, daytime running lights, airbags, and electronic stability control have contributed to a reduction in collisions and collision severity. Sometimes it takes years for these types of measures to become a standard for all new cars so the safety benefits are gradual from when they are introduced. The same goes for road infrastructure countermeasures. In some cases, a certain countermeasure may only be implemented in one jurisdiction before they catch on across the country. An example would be roundabouts. Roundabouts are fairly new in Canada but there are specific provinces that have taken the lead in installing them. Quebec was the first to start in 1998 and British Columbia was not far behind. However, in the past few years, more and more jurisdictions are starting to incorporate them into their road network. It is impossible to standardize road infrastructure across Canada because there are no road design standards. The Transportation Association of Canada (TAC) has a set of geometric design guidelines (Transportation Association of Canada 1999) and although most jurisdictions use them, they are not obligated to. In recent years 
however, safety information has been added to the guide to provide practitioners with more information in which to base their design decisions. This set the stage for incorporating safety into design and becoming more proactive in saving lives. TAC is also developing a road safety engineering guide which would be an additional source for road designers and planners to use to learn how to incorporate safety into the work that they do. The whole science of road safety design is a fairly new concept to North America and is still emerging. As more studies are conducted on the effectiveness of specific road engineering countermeasures, the more practitioners will understand just how important they are in saving lives.

Figure 5.1 is a time line that shows the major multidisciplinary factors that have contributed to road safety from 1960 to the present and Figures 5.2 and 5.3 illustrate the trend lines of fatalities and injuries per 10,000 motor vehicles registered from 1960 to 2006. This high level data was retrieved from Transport Canada's old and new collision statistic brochures (Transport Canada 2007). TRAID only had data from 1984. The extra years shown in the graphs below provides a better perspective of how certain road engineering safety countermeasures have contributed to the decreasing trend since several of them were initially implemented before 1984 . 


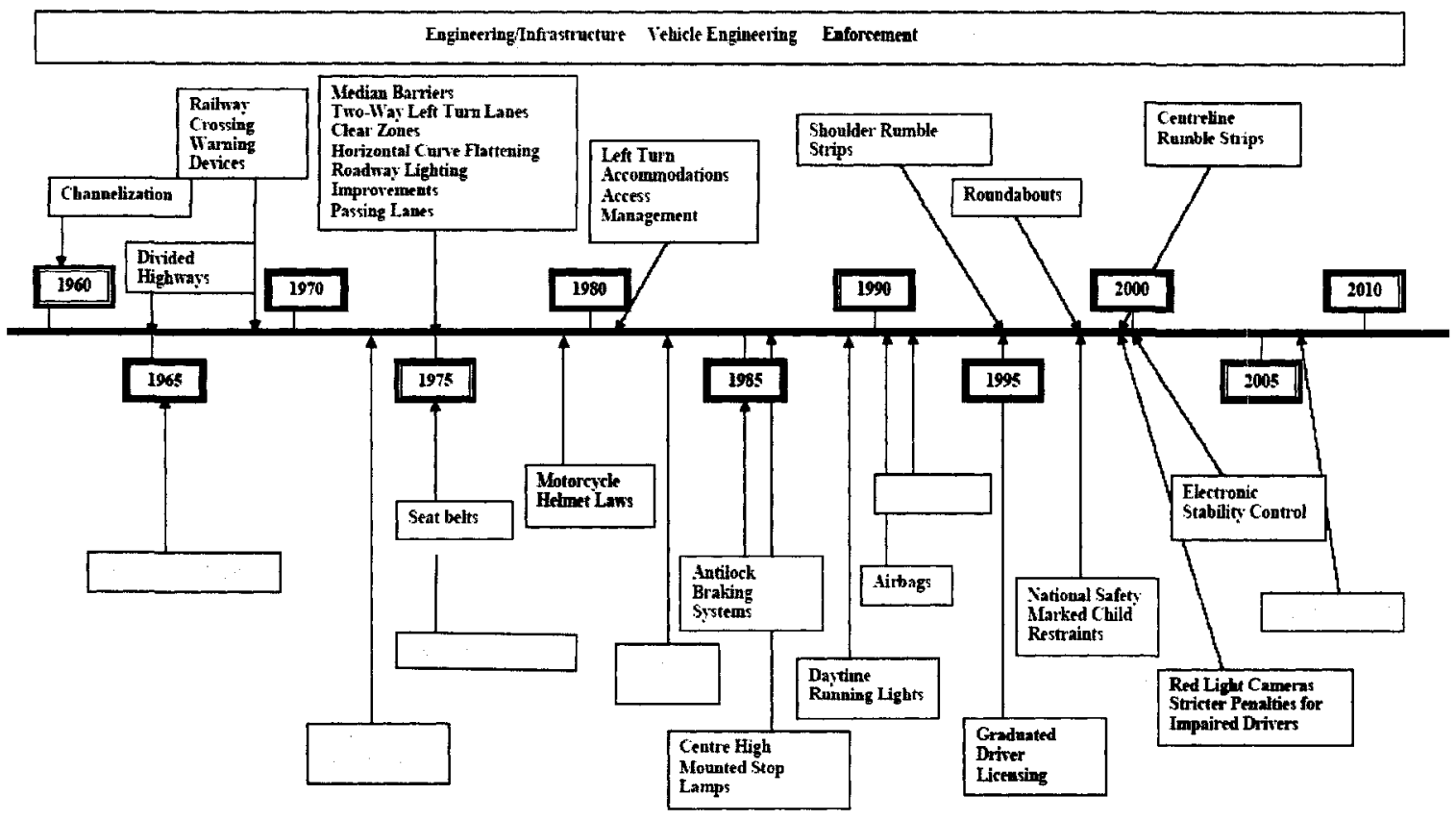

Figure 5.1: Road Safety Countermeasure Timeline.

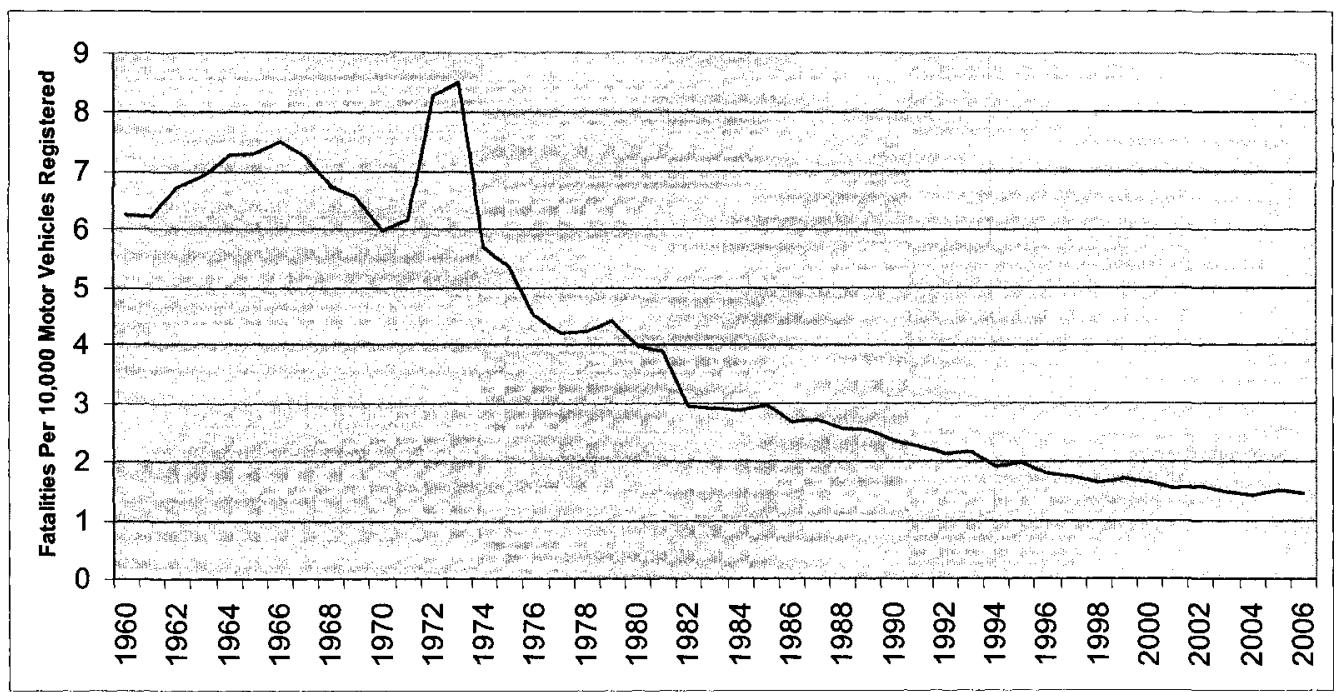

Figure 5.2: Fatalities Per 10,000 Motor Vehicles Registered By Year. 


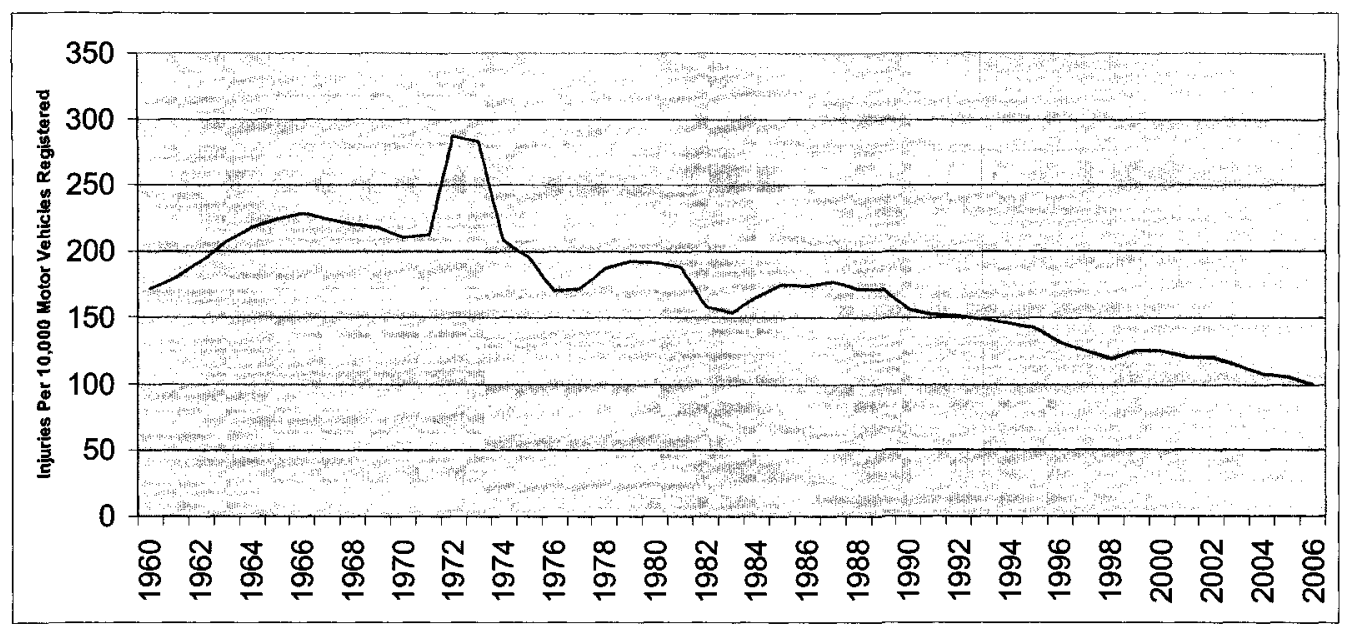

Figure 5.3: Injuries Per 10,000 Motor Vehicles Registered By Year.

It is interesting to note that both graphs look very similar. Fatal and injury rates peaked at an all time high in 1972 and 1973. However, the drastic decline in collisions between 1973 and 1979 was most likely due to a combined effect of the Oil Embargo of 1974, the Vietnam war, mandatory seat belt laws, motorcycle helmet laws, and the introduction to a variety of road safety engineering measures such as median barriers, clear zones, roadway lighting improvements, and passing lanes. From about 1979 to 1983, the rates started to climb again. The Vietnam War was over and the economy was in better shape. The increasing trend did not last long though. Around 1983, Canada experienced an economic recession, which shows up as a decrease in fatality and injury rates until around 1985. However, other factors that may have attributed to this decrease were the introduction of access management techniques and left turn accommodations at intersections. From 1985 to 1988 , injury rates increased while fatality rates decreased. This is most likely not a result of the economy since it would be expected to affect both fatality and injury rates together, but an accumulation of road engineering safety 
measures that had started to be implemented in Canada since the 1960s and were becoming more prevalent in jurisdictions across the country. The enforcement of seat belts and motorcycle helmets most likely also contributed to the decline in fatalities. Wearing seat belts and motorcycle helmets would not reduce collisions from occurring but would reduce the severity of them. Also during that time period, antilock braking systems and centre high mounted stop lamps were being introduced to the vehicle fleet. Although the effects of these measures would not show up nationally until years later when they became more common in the fleet, they would have provided some safety benefits right from the start. Both of these measures would most likely reduce the chance of a collision from occurring rather than just reducing the severity of it. From about 1988 to 2000 fatality and injury rates decreased. The major countermeasures introduced during this timeframe were daytime running lights, air bags, shoulder rumble strips, graduated licensing, and roundabouts. Although these would have definitely contributed to the decline, the accumulation of past measures mentioned would have played a larger part. Daytime running lights, shoulder rumble strips, graduated licensing, and roundabouts would have contributed to not only a decrease of collision severity but the elimination of a collision altogether. Air bags would not have contributed to a decrease in collisions but just a decrease in the severity level of the crash. From 2000 on, injury rates were still decreasing whereas fatality rates were levelling off. This may be an indication that the accumulation of road safety countermeasures that had been introduced in Canada was reaching its peak and were being used and implemented nationally. Without new and innovative countermeasures to introduce to our road system, it may be difficult to reduce the fatality rates further. Year after year, the vehicle fleet changes and 
soon most cars on the road will have the standard safety features, which have been implemented over the years. Road Safety Vision 2010 stresses the need for enforcement and education measures to help reach Canada's target. While these are important measures in any road safety program, perhaps it is necessary to look abroad for fresh new ideas and measures in order to reach our national road safety target. The fact that injury rates are still declining shows that past countermeasures are still having an effect on these collisions and those new countermeasures such as red light cameras and electronic stability control could also be starting to contribute to the decline.

\subsection{Regional Trend Discussion Based on Analysis}

\subsubsection{General}

Overall, throughout the study years, as shown in Table 3.1, all regions had fatal collisions that represented 0.4 percent of all collisions except for the Eastern Provinces, who had a slightly higher percentage of fatal collisions. It is also interesting to note that Ontario had the highest percentage of injury collisions compared to the other regions. In general, as shown in Figures 3.1 and 3.2, both fatal and injury collisions per 10,000 motor vehicles registered in Canada had been gradually decreasing from 1984 to 2004, with fatal collision rates having the higher reduction both nationally and regionally. The fact that fatal collisions had been decreasing at a faster pace than injury collisions is an indication that some countermeasures being implemented may specifically have had an effect on the severity of collisions but not actually reduce the number of collisions occurring. A countermeasure such as a median barrier is a good example of this. Median barriers reduce the risk of cars crossing the centreline and getting involved in a head-on 
collision, however, there is still the possibility of vehicles hitting the barrier. Hitting the barrier is not usually as severe of a collision as hitting a moving vehicle in the opposing lane. Therefore, as the driver may get injured from hitting a median barrier, the collision would not normally result in a fatality.

The highest fatal collision rate reduction was in Quebec. As shown in Figure 3.1, Quebec had a much higher fatal collision rate than the other regions from 1984 to 1996. From then on, their rate merged very close to the national average. In fact, by 2004, most regions were very close to the national average fatality rate. This may be an indication that programs that caught on nationally such as graduated licensing, vehicle engineering components which were standard on most vehicles within the fleet such as daytime running lights, and road infrastructure improvements which were constantly ongoing such as the conversion of undivided highways to divided highways have had the same effect within all regions in Canada and are all finally catching up with each other. It is also interesting to see something similar occur with injury collision rate reductions throughout the regions. In 1984, as shown in Figure 3.2, the regional injury collision rates were spread out but they eventually merged together to one point in 2000. At that point, all regions had about the same injury rate. However from then on, the trend lines started to gradually spread out again, indicating that some regions are succeeding more than others in maintaining their injury rate reduction.

Most collisions appear to take place on straight and level roads where vehicles were travelling straight ahead and there is no traffic control. These are quite typical 
scenarios in Canada given our vast road network and the long distances we travel from one city to another. For the analysis of non-intersection collisions, only data from the Western Provinces and Ontario were available. Their percentage of fatal and injury nonintersection collisions is virtually the same. It in interesting to note that their fatal collision percentages were a lot higher than their injury collision percentages as shown in Table 3.9, indicating that more fatal collisions occur at non-intersections than injury collisions. Also, as shown in Figures 3.34 and 3.36, non-intersection fatal and injury collisions in Ontario are decreasing at a faster rate than in the Western Provinces.

As shown in Table 3.11, a high number of fatal and injury collisions occurred on straight and level road. This is not surprising since these types of roads represent the majority of Canada's road network. Similar to the fatal collision rate reduction, Quebec had the highest reduction in fatal collision rates on straight and level roads. By 2004, all regions were quite similar in their fatal collision rates. For injury collision rates on straight and level roads, as shown in Figure 3.42, the Western Provinces and the Eastern Provinces stood out as being a lot lower than Ontario and Quebec. It is also interesting to note that Ontario and Quebec follow very similar trend lines throughout the study years for collisions that occurred on straight and level roads. It is also apparent that most collisions occurred on road segments where there was no control, which included nonintersections and intersections where no control was present such as those in rural areas with low traffic volumes. Again, the trend line graph for fatal collision rates, where there was no control present as shown and Figure 3.61 is quite similar to the general fatal collision rate trend line graph in Figure 3.1 since these fatal collision types represent the 
majority of the fatal collisions. The same goes for the comparison of the injury collision rate trend line graph where there was no control present as shown in Figure 3.64 and the general injury trend line graph for all injury collisions as shown in Figure 3.2. In both cases, by 2004, all regions were quite close in collision rates. However, one interesting fact is that the fatal and injury collision rates had not decreased as much in the Eastern Provinces then in the other regions but by 2004, their rates were close to the national average. This shows that originally, from 2004, they had been doing a lot better in terms of fatal and injury collision rates where there was no control present compared to the rest of the country, however throughout the years, the other regions had caught up with them. It is quite possible that without more new and innovative countermeasures, their rates will remain leveled off. Going straight ahead is the manoeuvre that occurs most often when fatal and injury collisions occur as shown in Figures 3.85 and 3.86. Again, the trend lines for both vehicles involved in fatal collisions and vehicles involved in injury collisions when a vehicle was going straight ahead are very similar to the general fatal and injury collision rate trend lines since they represent such a large number of collisions.

\subsubsection{Intersections}

Intersections are a unique situation because of the many manoeuvres that occur at them and their many conflict points. Intersections are usually either stop controlled (twoway or four-way) or signalized unless they are located in areas with very low volumes in which case they may be uncontrolled. Dangers occur when drivers disobey traffic control devices either intentionally or unintentionally. Having the right of way through a stop controlled intersection or having a green light at a signalized intersection gives drivers a 
sense of security that can turn out to be a false one. When drivers run a red light or drive through a stop sign, the system at the intersection fails and other road users may be confronted with a dangerous situation. Intersections are also usually designed in a way to allow drivers who are proceeding straight through to be able to maintain their speed. Often drivers speed up through intersections in order to make the green light before it turns to amber and red. If a collision does occur in this case, it would be more severe with the increased speed. Drivers also often tend to come to a quick stop at intersections when realizing that they will not be able to make the green light. This increases the risk of rear-end collisions. Left turns are one of the more dangerous manoeuvres at an intersection especially if it is an unprotected left turn where drivers have to give way to other cars and vulnerable road users and judge whether there is a large enough gap to complete the manoeuvre. Right turn manoeuvres are often associated with vulnerable road user collisions. While drivers usually look to the left to find a gap in traffic to make a right turn on a red light, a pedestrian may be attempting to cross in front of them from their right. If a gap in traffic is found to the left, the driver proceeds to find himself/herself in contact with a pedestrian. The following paragraphs discuss observations from the collision trend analysis and possible reasons for the trends.

As shown in Figures 3.31 and 3.32, throughout the years, there were a higher percentage of injury collisions than fatal collisions at intersections. This could be explained by the fact that there is more traffic exposure at intersections within urban areas where speed limits are lower and the majority of collisions are less severe. are more intersections within urban areas where the speed limit is lower and the traffic 
volumes are higher. It is interesting to see, as shown in Figure 3.33 that the Western Provinces and Ontario had a very similar trend line for fatal collision rates at intersections. This could be an indication that road safety countermeasures that have been implemented nationally are having the same effect from jurisdiction to jurisdiction. Their injury collision rates at intersections on the other hand varied throughout the years but eventually became the same by 2004 as shown in Figure 3.35 .

As shown in Figure 3.8, left turn fatal collision rates were quite sporadic in the Eastern Provinces. The reason for this is that their left turn fatal collisions represent a low percentage of their total collisions. This is also true for the Western Provinces but their trend line is a little smoother since they have a larger sample size overall. Left turn injury collision rates in the Eastern Provinces were a lot lower than the Western Provinces throughout the study years as shown in Figure 3.15. It is also interesting to note that left turn injury collisions in the Western Provinces have been increasing while they have remained quite constant in the Eastern Provinces. Also, left turn injury collisions in the Western Provinces were at an all time high between 1992 and 1995. The above results may be compared with the value "Turning Left" within the data element "Vehicle Manoeuvre". This value is represented by more regions and is more useful for comparison purposes. As shown in Figure 3.88, for vehicles involved in fatal collisions when turning left, the Western Provinces do not show much improvement over the study years. This is true for vehicles involved in injury collisions when turning left. Also, the Eastern Provinces again had the lowest rate for vehicles involved in fatal and injury collisions when turning left. Overall, the percentage of vehicles involved in fatal and 
injury collisions when turning left were higher than the percentage of left turn collisions throughout the regions. This may be an indication that more than one vehicle is usually involved in a left turn collision.

As shown in Figures 3.7 and 3.14, throughout the years, the Eastern provinces had a lot lower right turn fatal and injury collision rate than the Western Provinces. It was also interesting to see that the fatal and injury collision percentages for right turn collisions were a considerable amount more than fatal and injury collision percentages for left turn collisions. This was a surprising discovery since left turn collisions are usually perceived as being more dangerous and severe. One explanation could be that on average there may be more frequent right turn manoeuvres at intersections than left turn manoeuvres and more chances of exposure to conflicts with vehicles and pedestrians. When we look at the value "Turning Right" in the Vehicle Manoeuvre data element, it shows in Table 3.23 that the percentages of vehicles involved in turning right manoeuvres for fatal and injury collisions are a lot lower than the percentages of vehicles involved in turning left manoeuvres. This is opposite to the results from the "right turn" and "left turn" values mentioned above. This could indicate that more pedestrians are involved in right turn collisions than left turn collisions. It is also interesting to note that throughout the study years, Ontario had a lower rate of vehicles involved in fatal collisions where a vehicle was turning right than the rest of the regions.

Throughout the study years, as shown in Table 3.17, the percentage of fatal collisions that occurred at traffic signals was less than the percentage of collisions that 
occurred at stops signs in every region except for Quebec. The opposite occurred for the percentage of injury collisions, where more occurred at traffic signals. The Eastern Provinces had a considerably lower fatal collision rate at traffic signals throughout the study years compared to the other regions as shown in Figure 3.62. The Western Provinces and Ontario seem to have remained quite constant in their fatal traffic signal collisions and by 2004; the Western Provinces, Ontario and Quebec had very similar fatal collision rates at traffic signals. The Eastern Provinces also had a lot lower rate of injury collisions at traffic signals throughout the study years, where, on average, Ontario had the highest as shown in Figure 3.65. Also, as shown in Figure 3.63, the Eastern Provinces had the lowest rate of fatal collisions at stop signs throughout the study years where Ontario had the highest. Injury collision rates at stop signs showed similar results as shown in Figure 3.66.

Overall, throughout the study years, the average trend shows that fatal and injury intersection collisions have gradually decreased. The major road engineering safety countermeasures that have contributed to these decreases are channelization, left turn accommodations, access management, railway warning devices, and roundabouts. Other large contributors would be roadway lighting, mandatory seat belts, centre high mounted stop lamps, daytime running lights, airbags, and child restraints. Other measures that may have also contributed are red light cameras, larger street signs, advanced warning and intersection flashers, improved intersection sight distance, transverse rumble strips or pavement markings to alert drivers that they are approaching an intersection and to slow down, pedestrian countdown signals, signal progression and coordination, pavement 
marking guide lines, restriction of turning movements, larger signal displays, additional signal displays, yellow backplates for signal heads, restrictions of right turn on red, pedestrian grade separation, the increased use of bicycle helmets, education, and enforcement measures.

\subsubsection{Rural Roads}

Rural roads pose a higher safety risk as opposed to urban roads for one main reason, the fact that speed limits are higher on rural roads. The higher the speed of the vehicle in a crash, the higher the chance of a fatality occurring. Other geometric features that contribute to risks on rural roads include the lack of median treatments and the potential for vehicles to cross the centreline and get hit by opposing traffic, limited passing opportunities leading to driver frustration and illegal overtaking manoeuvres, and an insufficient forgiving roadside to allow vehicles recovery time if they run off the road. Also, in most rural areas in Canada it is common to encounter wildlife crossing the roadway. Animals such as moose, deer, and elk are large and heavy enough to smash through a windshield if hit and cause fatal damage. The following paragraphs discuss observations from the collision trend analysis and possible reasons for the trends.

Throughout the regions, fatal collisions are a lot more common on rural roads than urban roads. As shown in Figure 3.22, rural fatal collision rates have been gradually decreasing over the years and regional rates are very close to the national average. Rural fatal collisions in the Western Provinces have decreased the least over the study years and in 2004 they had one of the highest regional fatal collision rates. Rural injury collisions 
are less common than urban injury collisions as shown in Table 3.5. Figure 3.24 shows that all regions experienced a decrease in rural injury collision rates over the study years and by 2004 all regions had similar rates.

Within all regions, a considerably higher percentage of fatal and injury collisions occurred on roads where the speed limit was 80 and $90 \mathrm{~km} / \mathrm{h}$ than where the speed limit was 100 and $110 \mathrm{~km} / \mathrm{h}$. The reason for this is that roads where the speed limit is 80 or 90 $\mathrm{km} / \mathrm{h}$ are usually undivided and do not have as many enhanced geometric features than higher speed roadways. Roads designated as 100 or $110 \mathrm{~km} / \mathrm{h}$ are usually divided highways, which are designed at a higher standard and contain controlled features such as median treatments and wider roadside clear zones that decrease the chance of a severe collision. As shown in Figure 3.71, fatal collision rates where the speed limit was 80 and $90 \mathrm{~km} / \mathrm{h}$ decreased in every region throughout the study years and by 2004 , the rates were very similar throughout the regions. The trend lines for fatal collision rates where the speed limit was 100 and $110 \mathrm{~km} / \mathrm{h}$, as shown in Figure 3.72 indicates a different trend. These collision rates seem to be branching out and differing wider between regions. The Western Provinces even experienced an increase in these collision rates. This could be a result of there being several undivided highways which speed limits of 80 and $90 \mathrm{~km} / \mathrm{h}$ that have been converted to divided highways with a speed limit of 100 or $110 \mathrm{~km} / \mathrm{h}$. This is resulting in less exposure of vehicles on 80 and $90 \mathrm{~km} / \mathrm{h}$ roads and more exposure on 100 and $110 \mathrm{~km} / \mathrm{h}$ roads. Divided highways reduce the chance of head-on collisions and usually have at least two lanes in each direction, providing passing opportunities without have to cross over to the opposing lane of traffic. Therefore, the collisions that 
were occurring on the undivided highways have either been eliminated or the severity of them has been reduced on the now divided highways.

For injury collision rates where the speed limit was 80 and $90 \mathrm{~km} / \mathrm{h}$, the trend line is quite similar to the fatal collision rate trend line at the same speed limit where all regions were showing a decrease and by 2004 all regions had similar fatal collision rates as shown in Figure 3.75. However, for injury collisions rates where the speed limit was 100 and $110 \mathrm{~km} / \mathrm{h}$, as shown in Figure 3.76, all regions experienced in increasing trend over the study years except for Ontario. Again, this could be a result of there being increasingly more 100 and $110 \mathrm{~km} / \mathrm{h}$ roads throughout all regions. Vehicles involved in fatal and injury collisions where an overtaking manoeuvre was involved does not represent a large percentage of vehicles involved in collisions overall, however, the trend lines in Figure 3.91 and 3.96 show a decreasing trend throughout the regions. These decreases may be due to an increased number of passing lanes on undivided highways and the conversion of undivided highways to divided highways.

The major road engineering safety countermeasures that have contributed to an overall decrease in rural collisions include access management, conversion of undivided highways to divided highways, more passing lanes, improved roadway lighting, horizontal curve flattening, clear zone widening, shoulder and centreline rumble strips, and median barriers. Other large contributors include daytime running lights, electronic stability control, centre high mounted stop lamps, seat belts, air bags, child restraints, and antilock braking systems. Other measures such as improved signs and pavement 
markings, wider lanes and shoulders, breakaway devices, improved sight distance, improved skid resistance, improved roadway alignment, enforcement, and education measures may also have contributed.

\subsubsection{Roadside and Median}

Run off road collisions are quite common especially on rural roads. Driving long distances without taking breaks on monotonous straight sections of road could lead to road hypnosis or fatigue and result in motorists running off the road. Other situations such as inattention, driving too fast for conditions, under- or overestimating a curve, or losing control on slippery road conditions could also result in a run off the road collision. If a vehicle runs off the road to the right or left, ideally there is enough clear zone distance for the vehicle to come to a complete recovery instead of hitting a roadside object or rolling over in a ditch. One factor that could contribute to a vehicle getting involved in a run off the road collision would be the pavement edge drop-off type, height, and slope. An errant vehicle that has departed the paved surface can experience difficulty reentering the travel way if the tires traverse a vertical edge. It may cause a sudden and steep-angled reentry of the vehicle onto the travel way. This can lead to over steering and on undivided highways, head-on collisions. The following paragraphs discuss observations from the collision trend analysis and possible reasons for the trends.

In the Western and Eastern Provinces, running off the right shoulder in fatal and injury collisions were more common than running off the left shoulder. Although on separate sides of the country, these two regions had similar percentages of these types of 
collisions, overall throughout the years as shown in Table 3.3. Also, for both run off left shoulder and run off right shoulder fatal and injury collision rates, the two regions had decreasing trends. For run off right shoulder fatal collision rates throughout the years as shown in Figure 3.11, it is interesting to see how similar the trend lines are for the Western Provinces and the Eastern Provinces.

The percentage of fatal and injury collisions that occurred on a curve were quite similar throughout the regions and are also quite common compared to total collisions overall. All regions also experienced decreases in collision rates for these types of collisions. It is interesting to note that Ontario had the lowest collision rate for fatal collisions on curves throughout the study years compared to all of the other regions as shown in Figure 3.40. This is the same for injury collision rates that occurred on a curve as shown in Figure 3.43. For collisions that occurred on a gradient, again, all regions had similar percentages for both fatal and injury collisions. They also all experienced a collision rate decrease over the study years. Once again, Ontario had a noticeably lower collision rate throughout the study years for fatal collisions that occurred on a gradient compared to all other regions as shown in Figure 3.41. For injury collision rates that occurred on a gradient, Ontario had the lowest rate from around 1995 to 2004 as shown in Figure 3.44.

When comparing collisions on undivided roads to collisions on divided roads, it is clear that divided roads are safer and represent a noticeably lower percentage of fatal and injury collisions. It is clear that undivided roads put motorists in a more vulnerable 
situation leaving them open to come in contact with opposing traffic. Throughout the study years, both fatal and injury collision rates for divided and undivided roads experienced decreases. For fatal collision rates on divided and undivided roads the trend lines were quite similar for the Western Provinces and Ontario as shown in Figures 3.27 and 3.28. However for injury collision rates on divided and undivided roads, there appears to be an increase that occurred in the Western Provinces between 1990 and 1995 as shown in Figures 3.29 and 3.30. Also, from 1997 to 2004, these collisions seem to be leveling off and not decreasing any further. This is an indication that the road safety countermeasures are doing a better job at reducing the severity of the collisions but not actually the number of them. The percentage of fatal head-on collisions in the Western and Eastern Provinces are a lot higher than injury head-on collisions. This indicates that more head on collisions result in a fatality rather than just an injury. For both the Western and Eastern Provinces, head on fatal and injury collision rates decreased throughout the study years as shown in Figures 3.6 and 3.13.

The major road engineering safety countermeasures that have contributed to the reduction in run off roadway and head-on collisions throughout the study years include divided highways, median barriers, clear zones, shoulder rumble strips, and horizontal curve flattening. A newer countermeasure that has been implemented in more recent years is the centreline rumble strip. As this countermeasure becomes more prevalent within jurisdictions, it is expected that it will contribute to run off left shoulder collisions. Other major countermeasures that would have contributed to these decreases would be mandatory seat belt wearing, antilock braking systems, air bags, and electronic stability 
control. Additional countermeasures that may have contributed include improved pavement edges, improved skid resistance, improved superelevation, positive guidance around curves by providing advance warning signs with recommended reduced speed limits and installing chevrons around the curve to help guide drivers and increase driver expectancy, wider lane widths, improved shoulder widths, the provision of paved shoulders, improved guardrails, enforcement, and education measures.

\subsubsection{Urban Roads}

Urban areas are known for their low speed limits, high traffic volumes, and high numbers of pedestrians and bicyclists on the road. All of these conditions have an impact on road safety. The fact that speed limits are lower makes it more difficult overall for a fatal collision to occur unless vehicles are disobeying the speed limit or vulnerable road users are involved. High traffic volumes and in some cases congestion leads to more exposure for a conflict to occur and may also result in driver frustration, aggressive driving, and road rage. Actions such as following too close behind the car in front, excessive speeding, and red light running are just a few examples of aggressive driving. Pedestrians and bicyclists are vulnerable in urban areas especially if there is no dedicated bike lane or sidewalk for their accommodation. Vulnerable road users hit by a vehicle often results in a fatal collision because of their lack of protection. Urban areas also contain more intersections as compared to rural areas with more vehicle manoeuvres occurring, increasing the risk of a conflict. The following paragraphs discuss observations from the collision trend analysis and possible reasons for the trends. 
Overall, throughout the study years, in all regions, injury collisions were more common on urban roads than on rural roads. Fatal collisions in urban areas, although not as common as injury collisions, still represented a considerable amount. Overall throughout the study years, Quebec had the highest percentage of fatal and injury urban collisions compared to the other regions as shown in Table 3.5. By 2004, as shown in Figure 3.21, urban fatal collision rates were quite similar for all regions. For urban injury collision rates, as shown in Figure 3.23, by 2004, all regions appeared similar except for the Eastern Provinces who has had a considerable lower urban injury collision rate throughout the study years.

Based on the percentages in Table 3.19, it is more common for injury collisions to occur at 40 and $50 \mathrm{~km} / \mathrm{h}$ speed limits than fatal collisions. Fatal collision rates at 40 and $50 \mathrm{~km} / \mathrm{h}$ speed limits have decreased in all regions throughout the study years and by 2004, all regions had similar rates close to the national average as shown in Figure 3.69. The same goes for injury collisions at 40 and $50 \mathrm{~km} / \mathrm{h}$ with the Eastern Provinces again coming out with the lowest collision rate overall as shown in Figure 3.73. Fatal and injury collisions were not as common where the speed limit was 60 and $70 \mathrm{~km} / \mathrm{h}$ as compared to where the speed limit was 40 and $50 \mathrm{~km} / \mathrm{h}$. A reason for this could be that there may be more exposure to traffic on 40 and $50 \mathrm{~km} / \mathrm{h}$ roads than 60 and $70 \mathrm{~km} / \mathrm{h}$ roads. Fatal and injury collision rates on 60 and $70 \mathrm{~km} / \mathrm{h}$ roads decreased throughout the study years in all regions. By 2004, as shown in Figure 3.70, regional fatal collision rates on 60 and $70 \mathrm{~km} / \mathrm{h}$ roads were quite similar and close to the national average. This is not the case for injury collision rates on 60 and $70 \mathrm{~km} / \mathrm{h}$ roads. Ontario stands out as having 
the highest injury collision rates and Quebec and the Eastern Provinces having the lowest, overall throughout the study years. Also, as shown in Figure 3.74, although overall, all regions experienced a decrease in these collision rates from 1984 to 2004 , their trend lines appear to be quite constant.

As shown in Table 3.3, rear end collisions more commonly resulted in an injury rather than a fatality. It is difficult to compare the trends for fatal rear-end collisions in the Western and Eastern Provinces because the percentage of these collisions in the Eastern Provinces are quite small. However, as shown in Figure 3.9, overall it appears that these collisions are more prevalent in the Western Provinces. It is also interesting to note that the Eastern Provinces experienced an increase in injury rear-end collisions throughout the study years as shown in Table 3.4. Table 3.3 shows that hit object/person collisions more commonly resulted in a fatal collision than an injury collision. This is not surprising given the size and weight of vehicles compared to pedestrians on impact. Vehicles hitting solid objects that are not breakaway such as light posts or trees could often result in a fatal collision rather than an injury collision if travelling at high speeds. It is also interesting to note that fatal and injury hit object/person collision rates were noticeably higher in the Eastern Provinces than in the Western Provinces throughout the study years. The vehicle manoeuvre "changing lanes" was difficult to compare overall because they do not represent a large percentage of fatal or injury collisions. However, for their vehicles involved in injury collision rates, as shown in Figure 3.95, it appears that Ontario's rate is quite a bit higher than the rate in Quebec and the Eastern Provinces throughout the study years. 
The major road engineering safety countermeasures that have contributed to decreases in urban collisions are channelization, two-way left turn lanes, roadway lighting improvements, and left turn accommodations. Other major countermeasures that would have had an effect include centre high mounted stop lamps, daytime running lights, airbags, seat belts, and child restraints. Additional measures may include improved signing and pavement marking, traffic calming measures such as speed humps and chicanes, parking restrictions, the improvement of sight distances, breakaway devices which reduce the impact when vehicles hit a solid object, installation of bike lanes and sidewalks, dedicated pedestrian crosswalks with signals, enforcement, and education measures. The provision of adequate transit options and bicycle and pedestrian accommodation also encourages road users to take other modes of transportation, decreasing the number of vehicles on the roadway and reducing potential conflicts.

\subsubsection{Environmental and Temporal}

Weather and environmental conditions play a part in road safety because they affect the condition of the roads and the visibility of potential hazards. It may be difficult for drivers to judge how much to reduce their speed when these types of occasions occur. Slippery or wet roads could end up resulting in losing control, hydroplaning, or running off the road and hitting another vehicle. Not judging the correct distance of an opposing traffic gap because of visibility constraints when making a left turn may result in a side impact collision. Also, the time of day, day of the week and the month of the year show specific trends when the highest percentage of collisions occurred. The following 
paragraphs discuss observations from the collision trend analysis and possible reasons for the trends.

As shown in Table 3.12, most fatal and injury collisions occurred on dry normal roads throughout the regions. This also is the same for collisions that occurred when the weather was clear. Dry, normal roads represent the majority of collisions because this is the most common condition in which motorists drive. Also, all regions experienced a decrease in these collisions throughout the study years. The percentage of fatal collisions and injury collisions that occurred on wet roads throughout the years were quite similar but injury collision percentages were a little higher overall in each region. All regions also experienced a decrease in collision rates for these collisions. Overall, as shown in Figure 3.51, the Western Provinces had the highest percentage of injury collisions on wet roads which is not surprising since British Columbia makes up a large proportion of the these collisions and have a reputation of getting a lot of rain on an annual basis. For example, based on a report from Environment Canada (Environment Canada 2006), between 1971 and 2000, the average annual precipitation in Vancouver was 1,199 $\mathrm{mm}$ as compared to Toronto who had $793 \mathrm{~mm}$. For fatal and injury collisions when it was raining, a slightly higher percentage represented injury collisions rather than fatal collisions. Again, all regions experiences a decrease in fatal and injury collision rates throughout the study years and the Western Provinces had the higher rate of injury collisions when it was raining as shown in Figure 3.83. 
Fatal and injury collision percentages for winter condition roads were lower than wet roads. Both fatal and injury collision percentages were quite similar throughout the regions over the study years as shown in Table 3.13. All of the regions also experienced a decrease in collision rates. It is interesting to note that Ontario appears to be the region that had the lowest collision rates for fatal and injury collisions on winter roads, as shown in Figures 3.49 and 3.52. Fatal and injury collisions that occurred when it was snowing had similar percentages within all regions over the study years. The Western Provinces appear to have the lowest fatal and injury collision rates when it was snowing overall throughout the years as shown in Figures 3.81 and 3.84. This could be the result of collisions in British Columbia making up a large sample size of the Western Provinces and little snowfall occurring in the southern portion of the province. For example, Environment Canada reports that from 1971 to 2000 Vancouver got an average $48 \mathrm{~cm}$ of snowfall per year whereas the city of Quebec got $316 \mathrm{~cm}$ (Environment Canada 2006).

As shown in Table 3.14 a larger percentage of collisions occurred during daylight than when it was dark. Fatal and injury collisions that occurred during daylight experienced decreases over the study years in all regions. Collisions that occurred during the dark experience a considerable percentage of collisions as well. It is interesting to note that for all regions, a higher percentage of fatal collisions occurred in the dark than injury collisions. All of the regions experienced decreases in fatal and injury collision rates for collisions that occurred when it was dark except for Quebec who experienced an increase in injury collision rates as shown in Figure 3.58. Quebec is also showing a large increase in these types of collisions from 1997 to 1998. By 2004, Ontario had the lowest 
fatal and injury collision rates for collisions that occurred when it was dark compared to all of the other regions as shown in Figures 3.56 and 3.58.

The major road engineering safety countermeasure that contributed to the overall decrease in the above mentioned collisions include improved roadway lighting. Other major countermeasures that had an effect throughout the study years include antilock braking systems, centre high mounted stop lamps, seat belts, airbags, child restraints, and daytime running lights. Additional countermeasures include warning signs indicating trouble spots where it is exceptionally slippery when wet, variable message signs encouraging drivers to reduce speed for road conditions, improved skid resistance on pavements, road weather information systems indicating to road maintenance crews when it is necessary to salt roads, high retroreflective signs and pavement markings, reflective backplates on signal heads, increased use of winter tires, traveler information systems showing on a map the road surface conditions on roads in real time so that drivers can make informed decisions on whether to use the road or not, enforcement, and education measures.

Other observations found that collisions occurred more often during the 3:00 to 5:59 pm rush hour period. The after work rush hour period often causes congestion and driver frustration. It may be that drivers are either in more of a hurry or are more agitated during after work rush hour than before work rush hour. The most common day for fatal collisions is on Saturday. The weekend appears to be a problem spot, which can indicate that people are out more for entertainment reasons, which may involve alcohol and result 
in drunk driving. According to Mothers Against Drunk Driving (Mothers Against Drunk Driving 2008), an estimated 1,210 people were killed in drinking and driving collisions in 2005 and 71,413 were injured. The most common month of fatal collisions was August and the most common months for injury collisions were from June to December. There does not seem to be a real trend for injury collisions, but the fact that August was the month with the most fatal collisions could be the result of several factors. It may be that families are taking summer vacations in August resulting in more long distance travel on higher speed roads.

\subsubsection{Vehicle Type}

Automobiles are the most common type of vehicle involved in collisions followed by pick-up trucks. Based on the 2007 Canadian Vehicle Survey (Statistics Canada 2007), these two types of vehicles make up 70 percent of the vehicle fleet in Canada. Throughout all regions, the rate of automobiles involved in fatal and injury collisions have decreased over the study years. For automobiles involved in injury collisions, the Eastern provinces had the lowest rate overall throughout the study years as shown in Figure 3.105. The Western Provinces had the highest rate of pick-up trucks involved in fatal and injury vehicles involved in collisions as shown in Figures 3.102 and 3.108. Quebec appears to have the lowest rate overall throughout the study years but also shows a drastic increase from 1987 to 1990 . This could be a result of differing reporting methods between these years. 
Bicycles involved in fatal and injury collisions did not represent a large percentage overall throughout the regions but each region experienced a decrease of this type of vehicle involved in collisions as shown in Figures 3.100 and 3.106. Quebec experienced the largest decrease of fatal and injury collision rates involving bicycles but still remained the region with the highest rate of bicycles involved in collisions. The lowest rate of bicycles involved in collisions was in the Eastern Provinces. This may be an indication of the amount of bicycle use within these regions. Motorcycles involved in fatal and injury collisions also do not represent a high amount, however it is interesting to note that all regions experienced large decreases in motorcycles involved in fatal and injury collisions over the study years. Drastic decreases across all regions appear to have occurred between 1984 and 1990 as shown in Figures 3.101 and 3.107. Since this decrease occurred on a national level, it could be a direct result of motorcycle helmet laws that came into effect in 1979.

Trucks greater than $4536 \mathrm{~kg}$ and Tractor Trailers do not represent a large percentage of vehicles involved in fatal and injury collisions either, however, there were some interesting observations with their trend lines. It appears that in most regions, these types of vehicles involved in collisions are not decreasing but remaining quite constant throughout the study years. For injury collisions involving these types of vehicles, the Eastern Provinces have a noticeably lower rate than the other regions throughout the study years as shown in Figures 3.109 and 3.110. 


\section{Chapter 6: Recommendation and Conclusions}

This chapter concludes the thesis with some recommendations including 10 priority areas to address in order to progress road safety in Canada along with conclusions and future research needs.

\subsection{Recommendations}

In order to make recommendations on how to further road safety in Canada, it is important to make sense of all of the information provided in this thesis and identify areas that require the most attention. This thesis represents the first attempt to compare regional collision trends over a time period of more than 20 years. Recommendations that come out of this thesis should consider how road safety may be improved on a national level but also consider regional needs that require special attention. Just because a specific type of collision represents a large percentage of collisions overall nationally or does not represent a large decreasing trend, it doesn't mean that every region is experiencing the same results. The following ten priority areas identified in order to advance road safety in Canada were determined based on a weighted average of 2004 collision rates assuming that fatal collisions were worth 50 percent more than injury collisions. The 50 percent factor was used based on the assumption that fatal collisions cost 50 times more than the average injury collision. For example, a fatal collision could $\operatorname{cost} \$ 2,500,000$ to the economy whereas an injury collision would cost $\$ 50,000$. The ten collision types that ended up weighing the highest were identified as the priority areas. 
However, collision rate decreases for the specific collision types over the study years were also taken into consideration. The areas are listed below are in order of priority.

The first priority observation that stands out is the high proportion of fatal and injury collisions that occurred on undivided roads as compared to divided roads. Even through only the Western Provinces and Ontario had enough data available for the trend analysis, it is still evident that undivided roads present a serious safety issue, especially on roads with higher speed limits. An estimated 52,560 fatal collisions and 2,753,083 injury collisions took place on undivided roads throughout the study years. Rural undivided roads should be given priority when trying to decrease the number of fatal and injury collisions in Canada. Specific countermeasures that would directly reduce these collisions include the installation of median barriers, centreline rumble strips, and converting more undivided highways to divided highways. These would also decrease the chance of head-on collisions and are recommended for more implementation throughout Canada.

The second priority item is the need to address fatal and injury collisions that occur on rural roads where the speed limit is 80 or $90 \mathrm{~km} / \mathrm{h}$. These represent a high percentage of collisions overall in all regions. An estimated 39,262 fatal collisions and 940,927 injury collisions took place on rural roads throughout the study years. Although the collision rates for these collisions have experienced a decrease in all regions throughout the study years, the trend lines seem to be leveling off and not showing improvements in more recent years. This issue is related to the safety problem of 
undivided roads as described above since most roads that have a speed limit of 80 or 90 $\mathrm{km} / \mathrm{h}$ are rural undivided roads. Therefore, the countermeasures described above in the first priority area would address both priority topics. It is possible that without the introduction of new and innovative countermeasures, it will be difficult to address these collisions. Perhaps it is necessary to consider countermeasures that are being used abroad such as the installation of $2+1$ roads consisting of two lanes in one direction and one lane in the other, alternating every few kilometres, and separated usually with a steel cable barrier. These roads provide more passing opportunities and eliminate the possibility of crossing over the centreline in the opposing lane of traffic. It is recommended that this countermeasure be explored further to determine its feasibility of implementation in Canada.

The third priority item is run off the road collisions. An estimated 22,164 fatal collisions and 662,134 injury collisions were a result of a vehicle running off the road throughout the study years. Only the Western and Eastern Provinces were available for the analysis of these types of collisions but when you combine running off the road to the right collisions with running off the road to the left, overall these collisions represent a high percentage of fatal collisions as well as injury collisions. In recent years, shoulder and centreline rumble strips have helped eliminate some of these collisions by alerting drivers that they are leaving their travelling right-of-way. It is recommended that these countermeasures be considered on roads that are being planned for repaving in all areas in Canada. Additional countermeasures that are recommended to decrease run of the road collisions include improvements to pavement edge drop-offs and wider clear zones. 
The fourth priority area is collisions that occur on urban roads with a speed limit of 40 or $50 \mathrm{~km} / \mathrm{h}$. Although it is more common for injury collisions to occur on these roads than fatal collisions, they still represented a large percentage of both fatal and injury collisions overall. An estimated 22,164 fatal collisions and 2,474,290 injury collisions occurred on urban roads throughout the study years. The Eastern Provinces stand out as having the best record for injury collision rates on urban roads. The main concern in urban areas is the level of exposure to vehicles and vulnerable road users in a condensed area. It is difficult to solve this issue as population centres become denser every year. The main recommendation for urban areas is to provide more sufficient transportation choices for road users. Convenient and reliable transit services, the installation of more bicycle lanes and paths, and a more pedestrian friendly environment will encourage less people to drive and more to take advantage of the other facilities provided.

The fifth priority item is collisions that occur in the dark. An estimated 22,164 fatal collisions and 662,134 injury collisions occurred in the dark throughout the study years. All regions experienced a noticeably high percentage of fatal collisions when it was dark. Also, Quebec experienced an increase in injury collision rates that occurred in the dark. Improvements in roadway lighting have helped reduce these types of collisions overall, over the years, however, they still appear to be a problem and their trend lines have been leveling off in more recent years. It is recommended that more lighting improvements be considered on a national level and that other measures such as highly 
reflective pavement markings and signs and reflective backplates on traffic signal heads be considered for more wide spread implementation.

The sixth priority area is collisions at intersections, more specifically signalized intersections. Even though only data from the Western Provinces and Ontario were available for this type of collision, it was evident that they represented a high number of fatal and injury collisions. An estimated 20,264 fatal collisions and 2,056,100 injury collisions took place at intersections throughout the study years. Decreases were experienced over the years but there is a lot of room for additional improvement. Major contributors to the decreases over the years included channelization and left turn priority accommodations. More recently roundabouts have been given special attention at reducing fatal collisions at intersections by up to 90 percent. This countermeasure has a lot of promise and it is recommended that they be installed wherever feasible at intersections across Canada.

The seventh and eighth priority areas are collisions that occur on a curved section of road and collisions that occurred on a gradient. An estimated 18, 364 fatal collisions and 522,737 injury collisions occurred on curved sections of roadway and an estimated 17,098 fatal collisions 662,134 injury collisions occurred on a gradient throughout the study years. With the exception of Ontario, these types of collisions have experienced high collision rates over the years. Injury collision rates for these types of collisions appear to still be declining however fatal collision rates are leveling off. Curve flattening has directly contributed to this decline over the years. However, this can be costly 
because it involves realigning the roadway. More recently, the concept of design consistency has emerged and had been incorporated in the Geometric Design Guide for Canadian Roads (Transportation Association of Canada 1999). This concept takes driver expectancy into consideration when roads are being designed and attempts to eliminate roadway features that would catch drivers off guard such as a sharp curve on a roadway that has mainly curves with larger radii or unexpected steep grades. It is recommended that design consistency be considered in all new roads that are being constructed. Where applicable this should be incorporated into road safety audits. It is also recommended that in-service road safety reviews be conducted on existing roads to find out where driver expectancy is being compromised. Recommended measures to be implemented on existing roads to increase driver expectancy of curves are transverse pavement markings, chevron signs, and increased delineation during the night.

The ninth priority area was found to be collisions that occurred when the road was wet. An estimated 10,765 fatal collisions and 766,681 injury collisions occurred on wet roads throughout the study years. All provinces appear to have a decreasing trend for fatal and injury collisions that occurred on wet roads but they still represent a large proportion of collisions overall. Antilock braking systems have contributed to the decrease by providing drivers a means of keeping control of their vehicle. Electronic stability control is also showing promise in more recent years. On the infrastructure side, it is recommended that improved skid resistance be applied to all newly paved roads. 
The tenth priority area is rear-end collisions. Only data from the Western and Eastern Provinces were available for this value as well. An estimated 2,533 fatal collisions and 940,927 injury collisions were rear-end collisions throughout the study years. It is more common for rear-end collisions to result in an injury collision rather than a fatal collision, however, they still represented a large percentage of collisions overall. Rear-end injury collision rates in the Eastern Provinces actually increased over the study years. The major countermeasures that have contributed to helping decrease these collisions directly included two-way left-turn lanes, intersection channelization, and centre high mounted stop lamps. Centre high mounted stop lamps are standard on all new vehicles in Canada now. Therefore, it is recommended that more two-way left turn lanes and intersection channelization installations be implemented in urban areas, especially in the Eastern Provinces.

The ten priority areas discussed above would apply mostly on a national level. The following additional areas, which stood out on the trend lines from overall national trends in the collision analysis are recommended for more research at the regional level. The Western Provinces should consider their left-turn collisions and collisions that are occurring on roads where the speed limit is 100 and $110 \mathrm{~km} / \mathrm{h}$. Ontario should research on their intersection collisions (collisions that involved traffic signals and stop signs), collisions that occur on roads where the speed limit is 60 and $70 \mathrm{~km} / \mathrm{h}$, and vehicles involved in collisions when they were changing lanes. Quebec should consider their collisions that occur in the dark, and collisions involving vulnerable road users (bicyclists 
and motorcyclists). The Eastern Provinces should consider their hit/object person collisions and rear-end collisions.

\subsection{Conclusions}

The objective of this thesis was to analyze fatal and injury national collision data from 1984 to 2004, find trends nationally and within regions, and recommend specific countermeasures that would help further road safety in Canada. This is the first time in Canada where trends between regions have been compared for different collision types based on data spanning over 20 years. One of the major challenges of this thesis was data quality and consistency across the country because all provinces and territories have their own collision report form with differing data elements. However, the data quality has been improving in recent years and developments have been made in coming up with a uniform collision report form that may be used by all jurisdictions in Canada.

In the collision analysis it was encouraging to find that the majority of collision types showed a decreasing trend. Higher decreases were associated with fatal collisions rather than injury collisions. It was also interesting to find that for many of the collision types, collision rates differed considerably in 1984 then gradually merged together by 2004 so that all regions were experiencing similar collision rates. This is most likely the result of vehicle features such as daytime running lights, air bags, and centre high mounted stop lamps becoming more standard in the Canadian vehicle fleet, enforcement measures that have been implemented on a national basis such as mandatory seat belt wearing laws, stricter penalties for drinking and driving, and national safety marked child 
restraints, and road engineering safety countermeasures becoming more commonly implemented across the country such as passing lanes, access management, and divided highways.

The review of research related to road infrastructure/engineering countermeasures showed promising studies of measures that have been implemented in Canada over the years and that have helped improve road safety. The sub-targets within Canada's Road Safety Vision 2010, especially those associated with rural roads and intersections would benefit from the promotion of these types of countermeasures on a national level. However, many of the trend lines appear to be leveling off in more recent years which may be an indication that without new and innovative road safety countermeasures, it will be difficult for overall collision rates to decrease to Canada's road safety target.

The top ten areas that were identified as priority to address in order to advance road safety nationally are collisions on undivided roads, collisions on rural roads with speed limits of 80 or $90 \mathrm{~km} / \mathrm{h}$, run off the road collisions, collisions that occur on urban roads with speed limits of 40 or $50 \mathrm{~km} / \mathrm{h}$, collisions that occur in the dark, collisions at intersections, collisions that occur on a curve, collisions that occur on a gradient, collisions that occur on wet roads, and rear-end collisions. The major measures recommended to address these collisions include median barriers, shoulder and centreline rumble strips, highly reflective signs and pavement markings especially for curved sections of roadway, improved lighting, roundabouts, two-way left turn lanes, skid resistant pavements, and more accommodation for vulnerable road users in urban areas. 
Two countermeasures mentioned above, centreline rumble strips and roundabouts are fairly new to Canada and have not been implemented as widely as the others. These measures have been showing promising results in decreasing intersection collisions and head-on collisions respectively and have the potential to continue the decreasing trend of fatal and injury collisions.

The collision analysis also found differing results within regions and that specific collision types should get more attention depending on the trends observed throughout the years. By improving road safety on a national level, it is important to observe trends regionally so that there is a better understanding of where the needs are. This is what national road safety targets should be based on. This will bring Canada one step closer in achieving its goal of having the safest roads in the world and reducing the stress and trauma on families of crash victims.

\subsection{Further Research}

It is recommended that further research be conducted in the area of collision trends for Canada. Once more recent data is available, the trend lines may be extended in order to identify further progress made in road safety. Further analysis, cross-referencing values within data elements would help narrow down the areas requiring more attention. For example, it would be useful to know whether more fatal collisions occur at rural intersections or urban intersections. It would also be useful to compare Canadian trend lines with trend lines from other countries. From those countries that are progressing faster than Canada in terms of road safety, it would be useful to know if they have 
implemented different countermeasures, what they are, and whether or not they would apply in the Canadian context.

During the review of literature on road engineering safety countermeasures, it was more difficult to find Canadian studies as compared to U.S. studies. Although the U.S. produces more research than Canada because of their higher level of resources, it would still be useful to have a database of road safety studies conducted in jurisdictions across Canada, which may be used by researchers. Ideally, this would lead to an inventory of road engineering safety countermeasures that have been implemented in specific jurisdictions in Canada linked with their safety benefits. 


\section{References}

Alberta. 2007. Alberta Traffic Collision Statistics 2006. Edmonton, Alberta, Canada: Alberta.

Anielski Management Incorporated. 2004. Alberta Traffic Safety Progress Report: Key Indicators and Trends. Alberta, Alberta Motor Association.

Annino, J. M. 2003. Rumble Strips in Connecticut: A Before/After Analysis of Safety Benefits. Washington, District of Columbia, U.S.: Federal Highway Administration.

Arbogast, K. B., D. R. Durbin, R. A. Cornejo, M. J. Kallan, and F. K. Winston. 2004. An Evaluation of the Effectiveness of Forward Facing Child Restraint Systems. Accident Analysis \& Prevention 36(4): 585-589.

Arora, H., D. Collar, G. Robbins, E. R. Welbourne, and J. G. White. 1994. Effectiveness of Daytime Running Lights in Canada. Ottawa, Ontario, Canada: Transport Canada. 
Australian Transport Safety Bureau. 2007. Road Deaths Australia 2006 Statistical Summary. Civic Square, Australian Capital Territory, Australia: Australian Transport Safety Bureau.

Austroads Incorporated. 2005. RoadFacts 2005: An Overview of the Australian and New Zealand Road Systems. Sydney, New South Wales, Australia: Austroads Incorporated.

Bahar Geni, Jennifer Wales, and Lori Longtin-Nobel. 2001. Best Practices for the Implementation of Shoulder and Centreline Rumble Strips. Ottawa, Ontario, Canada: Transportation Association of Canada.

Barry, S., S. Ginpil, and T. J. O’Neill. 1999. The Effectiveness of Air Bags. Accident Analysis \& Prevention 31(6): 781-787.

Berkowitz, A. 2000. Evaluation of the Effect of Air Bags in Multi-Year NCAP Tests. Washington, District of Columbia, U.S.: National Highway Traffic Safety Administration.

British Columbia. 2006. Traffic Collision Statistics: Police-attended Injury and Fatal Collisions. Victoria, British Columbia, Canada: British Columbia. 
Brown, H. C., and A.P Tarko. 1999. Effects of Access Control On Safety On Urban Arterial Streets. Transportation Research Record 1665: 68-74.

Burgess, Marilouise. 2005. Contrasting Rural and Urban Fatal Crashes 1994-2003. Washington, District of Columbia, U.S.: National Center for Statistics and Analysis.

Canadian Council of Motor Transport Administrators and Transport Canada. 2006. Road Safety Vision 2010: 2005 Annual Report, Making Canada's Roads the Safest in the World. Ottawa, Ontario Canada: Government of Canada.

Carson and Marsh. 1961. Gains from Channelization. Traffic Engineering and Control 2(11): $663-665$.

Chen, C., E. O. Darko, and T. N. Richardson. 2003. Optimal Continuous Shoulder Rumble Strips and the Effects on Highway and the Economy. ITE Journal 73(5): $30-41$.

Cheng E. Y-C., E. Gonzalez, and M. O. Christensen. 1994. Application and Evaluation of Rumble Strips on Highways. Paper presented at the $64^{\text {th }}$ ITE Annual Meeting, October 16-19, in Dallas, Texas, U.S. 
Colorado Department of Public Works. 1965. Channelization and Accidents Federal Boulevard, Denver Colorado 1965. Colorado: Colorado Department of Public Works.

Council, F. M., and J. R. Stewart. 2000. Safety Effects of the Conversion of Rural TwoLane Roadways to Four-Lane Roadways. ITE Journal 70(4): 37-42.

Dang, Jennifer N. 2007. Statistical Analysis of the Effectiveness of Electronic Stability Control (ESC) Systems Final Report. Washington, District of Columbia, United States: National Highway Traffic Administration.

Dang, Jennifer N. 2004. Preliminary Results Analyzing the Effectiveness of Electronic Stability Control (ESC) Systems. Washington, District of Columbia, United States: National Highway Traffic Safety Administration.

Davis, Gary A., and Jianping Pei. 2005. Bayesian Reconstruction of Median-Crossing Crashes and Potential Effectiveness of Cable Barriers. Transportation Research Record 1908: 141-147.

Davis, Gary A., and Nathan Aul. 2007. Safety Effects of Left-Turn Phasing Schemes at High-Speed Intersections. St. Paul, Minnesota, U.S. Minnesota Department of Transportation. 
Dissanayake, S., and J. Lu. 2003. Access Management Techniques to Improve Traffic Operations and Safety: A Case Study of a Full Vs. Directional Median. Paper presented at the Mid-Continent Transportation Research Symposium, August 2122, Ames, Iowa, U.S.

Eck, Ronald W., and John A. Halkias. 1985. Further Investigation of the Effectiveness of Warning Devices at Rail-Highway Grade Crossings. Transportation Research Record 1010: 94-101.

Eisele, William L., and William E. Frawley. 2005. Safety and Operational Analyses of Access Management Treatments: Results of Managing Driveway Density and Installing Raised Medians. Paper presented at the $3^{\text {rd }}$ International Symposium on Highway Geometric Design, June 29-July 1, in Chicago, Illinois, U.S.

Elvik, R. 1995. The safety Value of Guardrails and Crash Cushions: A Meta-Analysis of Evidence from Evaluation Studies. Accident Analysis \& Prevention 27(4): 523549.

England Department of Transport. 2007. Road Casualties in Great Britain Main Results: 2006. Transport Statistics Bulletin 7(18).

Environment Canada. 2006. Climate Normals 1971 to 2000. Ottawa, Ontario Canada: Environment Canada. 
Farmer, Charles M. 2006. Effects of Electronic Stability Control: An Update. Traffic Injury Prevention 7(4): 319-324.

Farmer, Charles M. 2004. Effect of Electronic Stability Control On Automobile Crash Risk. Traffic Injury Prevention 5(4): 317-325.

Farmer, Charles M. 1996. Effectiveness Estimates For Center High Mounted Stop Lamps: A Six-Year Study. Accident Analysis \& Prevention 28(2): 201-208.

Farmer, C. M., and A. F. Williams. 2002. Effects of Daytime Running Lights on Multiple-Vehicle Daylight Crashes in the U.S.. Accident Analysis \& Prevention 34 (2): 197-203.

Farr, E. H. and J. S. Hitz. 1985. Effectiveness of Motorist Warning Devices at RailHighway Crossings. Cambridge, Massachusetts, U.S.: Transportation Systems Center.

Federal Highway Administration. 2002. Safety Effectiveness of Intersection Left- and Right-Turn Lanes. McLean, Virginia, U.S.: Federal Highway Administration. 
Federal Highway Administration. 2001. Intelligent Transportation Systems at HighwayRail Intersections: A Cross Cutting Study, Improving Safety and Mobility at Highway-Rail Grade Crossings. Washington, District of Columbia, U.S.: Federal Highway Administration.

Federal Highway Administration. 1999. Safety Evaluation of Rolled-In Continuous Shoulder Rumble Strips Installed on Freeways. McLean, Virginia, U.S.: Federal Highway Administration.

Flannery, A., and L. Elefteriadou. 1999. A Review of Roundabout Safety Performance in the U.S. Paper presented at the Enhancing Transportation Safety in the $21^{\text {st }}$ Century ITE International Conference, March 28-March 31, in Kissimee, Florida, U.S.

Forbes, G. 2003. Synthesis of Safety for Traffic Operations. Ottawa, Ontario, Canada: Transport Canada.

Forkenbrock, G. J., M. Flick, W. R. Garrott. 1999. NHTSA Light Vehicle Antilock Brake System Research Program Task 4: A Test Track Study of Light Vehicle ABS Performance Over a Broad Range of Surfaces and Manoeuvres. East Liberty, Ohio, U.S.: National Highway Traffic Safety Administration. 
Forkenbrock, Garrick, Mark Flick, and W. Riley Garrott. 1999. A Comprehensive Light Vehicle Antilock Brake System Test Track Performance Evaluation: Society of Automotive Engineers.

Fujita, G., M. Yamazaki, and M. Shimamura. 2005. Method to Evaluate the Effect of Safety Belt Use By Rear Seat Passengers on the Injury Severity of Front Seat Occupants. Accident Analysis \& Prevention 37(1): 5-17.

Garder P., and J. Alexander. 1994. Shoulder Rumble Strips For Improving Safety On Rural Interstates: Year One Final Report. Augusta, Maine, U.S.: Maine Department of Transportation.

Green, Paul E., and John Woodrooffe. 2006. The Estimated Reduction in the Odds of Loss-of-Control Type Crashes for Sport Utility Vehicles Equipped with Electronic Stability Control. Journal of Safety Research 37(5): 493-499.

Green, E. R. and K. R. Agent, M. L. Barrett, and J. G. Pigman. 2003. Roadway Lighting and Driver Safety. Washington, District of Columbia, U.S.: Federal Highway Administration.

Green, Paul E, and John Woodrooffe. 2006. The Effectiveness of Electronic Stability Control on Motor Vehicle Crash Prevention. Ann Arbor, Michigan, United States: University of Michigan Transportation Research Institute. 
Harwood, D. W. 1993. Use of Rumble Strips to Enhance Safety. NCHRP Synthesis of Highway Practice 191: 80.

Harwood, D. W., and A. D. Saint John. 1985. Passing Lanes and Other Operational Improvement on Two-Lane Highways: Phase I Technical Report. McLean, Virginia, U.S.: Federal Highway Administration.

Harwood, D. W., A. D. Saint John, and D. L. Warren. 1985. Operational and Safety Effectiveness of Passing Lanes on Two-lane Highways. Transportation Research Record 1026: 31-39.

Hasson, P., and P. Lutkevick. 2002. Roadway Lighting Revisted. Public Roads 65(6): 3236.

Hertz, E. 2000. Analysis of the Crash Experience of Vehicles Equipped with All Wheel Antilock Braking Systems (ABS): A Second Update Including Vehicles with Optional ABS. Washington, District of Columbia, U.S.: National Highway Traffic Safety Administration.

Hertz, E., J. Hilton, and D. M. Johnson. 1995. An Analysis of the Crash Experience of Light Trucks Equipped with Antilock Braking Systems: NHTSA Technical Report. Washington, District of Columbia, U.S.: National Highway Traffic Safety Administration. 
Hertz, E., J. Hilton, and D. M. Johnson. 1995. An Analysis of the Crash Experience of Passsenger Cars Equipped with Antilock Braking Systems: NHTSA Technical Report. Washington, District of Columbia, U.S.: National Highway Traffic Safety Administration.

Huang, H. F., R. J. Schneider, C. V. Zegeer, A. J. Khattak, V. J. Amerlynck, J. K. Lacy. 2001. Identification of Severe Crash Factors and Countermeasures in North Carolina. Washington, District of Columbia, U.S.: Federal Highway Administration.

Isebrands, Hillary N., Shauna Hallmark, Zach Hans, Tom McDonald, Howard Preston, and Richard Storm. 2006. Safety Impacts of Street Lighting At Isolated Rural Intersections: Part II. St. Paul Minnesota: Minnesota Department of Transportation.

Jacquemart, G. G. 2004. Toolbox on Intersection Safety and Design: Designing and Operating Safer Roundabouts. Paper presented at the Intersection Safety: Achieving Solutions Though Partnerships, March 28-31, in Irvine, California, U.S.

Johnson, Mavis, and Eric Howard. 2007. Road Safety Vision 2010: Mid-Term Review. Ottawa, Ontario, Canada: Canadian Council of Motor Transport Administrators. 
Kahane, C. J. 1996. Fatality Reduction by Air Bags: Analyses of Accident Data Through Early 1996: NHTSA Technical Report. Washington, District of Columbia, United States: National Highway Traffic Safety Administration.

Kahane, C. J. 1989. An Evaluation of Center High Mounted Stop Lamps Based on 1987 Data. Washington, District of Columbia, U.S.: U.S. National Highway Traffic Safety Administration.

Kahane, C. J. 1987. Effectiveness of Center High Mounted Stop Lamps: A Preliminary Evaluation. Washington, District of Columbia, U.S.: National Highway Traffic Safety Administration.

Kahane, C. J., and E. Hertz. 1998. The Long-Term Effectiveness of Center High Mounted Stop Lamps in Passenger Cars and Light Trucks. Washington, District of Columbia, U.S.: National Highway Traffic Safety Administration.

Lall, B. K., D. Huntington, and A. Eghtedari. Access Management and Traffic Safety. 1996. Paper presented at the Second National Access Management Conference, August 11-14, in Vail, Colorado, U.S.

Land Transport New Zealand. 2007. Reported Injury Crashes 2006. Wellington, New Zealand: Land Transport New Zealand. 
Levinson, H. S., and J. S. Gluck. 1999. Access Management - Does It Improve Safety? Paper presented at the Enhancing Transportation Safety in the $21^{\text {st }}$ Century ITE International Conference, March 28-31, in Kissimmee, Florida, U.S.

Maze, T. H., J. L. Henderson, and R. Sankar. 1994. Impact on Safety of Left-Turn Treatment at High Speed Signalized Intersections. Ames, Iowa, U.S.: Iowa Department of Transportation.

Mazzae, Elizabeth N., G. H. Scott Baldwin, and Daniel V. McGehee. 1999. Driver Crash Avoidance Behavior with ABS in an Intersection Incursion Scenario on the Iowa Driving Simulator: Society of Automotive Engineers.

Mazzae, Elizabeth N., Frank Barickman, G. H. Scott Baldwin, and Garrik Forkenbrock. 1999. Driver Crash Avoidance Behavior with ABS in an Intersection Incursion Scenario on Dry Versus Wet Pavement: Society of Automotive Engineers.

Michael, H. L., K. C. Sinha, and J. A. Fletcher. 1981. Evaluation of Design and Control Alternatives to Improve Safety of Intersections of Multi-lane Highways with Other Highways. Washington, District of Columbia, U.S.: Federal Highway Administration. 
Mohan D., P. Zador, B. O'Neill, and M. Ginsburg. 1976. Air Bags and Lap/Shoulder Belts: A Comparison of their Effectiveness in Real World, Frontal Crashes. Paper presented at the $20^{\text {th }}$ Annual Conference of the American Association for Automotive Medicine, November 1-3, in U.S.

Monsere, C. M., B. Sposito, and S. Johnston. 2003. Safety Effectiveness and Operating Performance of a Three-Cable Median Barrier On Interstate 5 in Oregon. Paper presented at the ITE 2003 Annual Meeting and Exhibit, August 24-27, in Seattle, Washington, U.S.

Moore, A. F. 1987. Evaluation of Experimental Rumble Strips: Final Report. Washington, District of Columbia, U.S.: Federal Highway Administration.

Morrissey, J. 1980. The Effectiveness of Flashing Lights and Flashing Lights with Gates in Reducing Accident Frequency at Public Rail-Highway Crossings: 1975-1978. Washington, District of Columbia, U.S.: Federal Highway Administration.

Mothers Against Drunk Driving. 2008. The Magnitude of the Alcohol/Drug-Related Crash Problem in Canada Overview. In Canada-wide Statistics. http://madd.ca/english/research/magnitudememo.html (accessed August 27, 2008). 
Mutabazi, M. E. R. Russell, R. W. Stokes. 1999. Review of the Effectiveness, Location, Design, and Safety of Passing Lanes in Kansas. Topeka, Kansas, U.S.: Kansas Department of Transportation.

Myers, E. J. 1999. Accident Reduction with Roundabouts. Paper presented at the $69^{\text {th }}$ Annual Meeting of the Institute of Transportation Engineers, August 1-4, in Las Vegas, Nevada, U.S.

Nambisan, Shashi S., and Venu Parimi. 2005. A Comparative Evaluation of the Safety Performance of Roundabouts and Traditional Intersection Controls. Paper presented at the ITE 2005 Annual Meeting and Exhibit, August 7-August 10, in Melbourne, Australia.

Nambisam, Shashi, Vinay Vanapalli, Mukund Dangeti, and Srinivas S. Pulugurtha. 2007. Evaluating the Effectiveness of Continuous Shoulder Rumble Strips in Reducing Ran-off-Roadway Single-Vehicle Crashes. Carson City, Nevada, U.S.: Nevada Department of Transportation.

National Center for Statistics and Analysis. 2008. Traffic Safety Facts 2006 Data: Overview. Washington, District of Columbia, U.S.: National Center for Statistics and Analysis. 
New York State Department of Motor Vehicles. 1986. Child Safety Restraint Study: A Study of the Effects of Child Safety Restraint Legislation on the Incidence and Severity of Motor Vehicle Accident Injuries to Children Six Years of Age and Younger (Based on 1980-1982 and 1984-1985 Accidents). Albany, New York, U.S.: New York State Department of Motor Vehicles.

Nicholas, A. C. 1988. The Effect of the Two-Way Left-Turn Lane On Accidents in the Six County Area. Operations Review 6(1): 1-8.

Noyce, David A., Vijay Talada, and Tim J. Gates. 2006. Safety and Operational Characteristics of Two-Way Left-Turn Lanes. St. Paul, Minnesota, U.S.: Minnesota Department of Transportation.

Ogden, K. W. 1996. Safer Roads: A Guide to Road Safety Engineering. Hampshire, England: Avebury Technical.

Ontario. 2006. Ontario Road Safety Annual Report 2005. Toronto, Ontario, Canada: Ontario.

Organization for Economic Cooperation and Development. 1975. Roadside Obstacles: Their Effects on the Frequency and Severity of Accidents: Development and Evaluation of Countermeasures. Paris, France: Organization for Economic Cooperation and Development. 
Outcalt, W. 2001. Centerline Rumble Strips. Washington, District of Columbia, United States: Federal Highway Administration.

Padmanaban J. and E. Lau. 1996. Accident Experience of Passenger Vehicles with FourWheel Antilock Braking Systems. Paper presented at the Association for the Advancement of Automotive Medicine $40^{\text {th }}$ Annual Conference, October 7-9, in Vancouver, British Columbia, Canada.

Patel, Rushi B., Forrest M. Council, and Michael S. Griffith. 2007. Estimating Safety Benefits of Shoulder Rumble Strips on Two-Lane Rural Highways in Minnesota: Empirical Bayes Observational Before-and-After Study. Transportation Research Record 2019: 205-211.

Persaud, B. N. 1992. Roadway Safety: A Review of the Ontario Experience and Relevant Work Elsewhere. Toronto, Ontario, Canada: Ontario Ministry of Transportation.

Persaud, B. N., R. A. Retting, and C. Lyon. 2003. Crash Reduction Following Installation of Centerline Rumble Strips on Rural Two-Lane Roads. Arlington Virginia, U.S.: Insurance Institute for Highway Safety.

Persaud, B. N., R. A. Retting, P. E. Garder, and D. Lord. 2000. Crash Reductions Following Installation of Roundabouts in the U.S.. Arlington, Virginia, U.S.: Insurance Institute for Highway Safety. 
Pigman, J. G., K. R. Agent, and T. Creasey. 1985. Analysis of Accidents Involving Breakaway-Cable-Terminal End Treatments. Transportation Research Record 1024: 73-80.

Potts, I. B., and D. W. Harwood. 2004. Benefits and Design/Location Criteria for Passing Lanes. Jefferson City, Missouri: Missouri Department of Transportation.

Quaye, K. L. Leden, and E. Hauer. 1993. Pedestrian Accidents and Left-Turning Traffic At Signalized Intersections. Washington, District of Columbia, U.S.: AAA Foundation for Traffic Safety.

Robinson, B. W., Lee Rodegerdts, W. Scarborough, W. Kittelson, R. Troutbeck, W. Brilon, L. Bondzio, K. Courage, M. Kyte, J. Mason. A. Flannery, E. Myers, J. Bunker, G. Jacquemart. 2000. Roundabouts: An Informational Guide. Mclean, Virginia, U.S.: Federal Highway Administration.

Rowan, N. J., T. G. Williams, and T. G. Wilson. 1966. Channelization. Arlington, Texas, United States: Texas Transportation Institute.

Russell, Eugene R., and Margaret J. Rys. 2006. Reducing Crossover Accidents on Kansas Highways Using Milled Centerline Rumble Strips. Topeka, Kansas, U.S.: Kansas Department of Transportation. 
Schulte, W. R. 1976. Effectiveness of Automatic Warning Devices in Reducing Accidents at Grade Crossings. Transportation Research Record 611: 49-57.

Schultz, Grant G., Jeff S. Lewis. 2006. Assessing the Safety Benefits of Access Management Techniques. Salt Lake City, Utah, U.S.: Utah Department of Transportation.

Shankar, V., S. Chayanan, S. Sittkariya, M-B. Shyu, G. Ulfarsson, and N. K. Juvva. 2004. Median Crossover Accident Analyses and the Effectiveness of Median Barriers. Washington, District of Columbia, U.S.: Federal Highway Administration.

Southeast Michigan Council of Governments. 1997. SEMCOG Traffic Safety Manual. Detroit Michigan: Southeast Michigan Council of Governments.

Sparks, G. A., R. D. Neudorf, A. E. Smith, K. R. Wapman, and P. L. Zador. 1993. The Effect of Daytime Running Lights on Crashes Between Two Vehicles in Saskatchewan: A Study of a Government Fleet. Accident Analysis \& Prevention 25(5): 619-625.

Statistics Canada. 2007. Canadian Vehicle Survey: Annual. Ottawa, Ontario Canada: Statistics Canada. 
Streff, F. M. 1991. The Effectiveness of Daytime Running Lights to Reduce Crashes and Crash Injuries: Final Report. Ann Arbor, Michigan, U.S.: University of Michigan Transportation Research Institute.

Stein, H. 1985. Fleet Experience with Daytime Running Lights in the U.S.. SAE Technical Paper Series: 13.

Sullivan, John M., and Michael J. Flannagan. 2007. Determining the Potential Safety Benefits of Improved Lighting in Three Pedestrian Crash Scenarios. Accident Analysis \& Prevention 39(3): 638-647.

Terry, D. S., A. L. Kassan. 1968. Effects of Paint Channelization on Accidents. Traffic Engineering: 22-26.

Thakkar, J. S. 1984. Study of the Effect of Two-Way Left-Turn Lanes on Traffic Accidents. Transportation Research Record 960: 27-33.

Tignor, Samual C., Charles P. Brinkman, John M. Mason, and John M. Mounce. 1982. Synthesis of Safety Research Related to Traffic Control and Roadway Elements Vol. 1: Washington, District of Columbia, U.S.: Federal Highway Administration. 
Tofflemire, T. C., and P. C. Whitehead. 1997. An Evaluation of the Impact of Daytime Running Lights On Traffic Safety in Canada. Journal of Safety Research 28(4): 257-272.

Transport Canada. 2007. Canadian Motor Vehicle Traffic Collision Statistics. Ottawa, Ontario, Canada: Transport Canada.

Transport Canada. 2001. Trends in Motor Vehicle Traffic Collision Statistics 1988 to 1997. Ottawa, Ontario Canada: Government of Canada.

Transport Canada. 2001. Evaluation of the Effectiveness of Air Bags and Seat Belts: Estimates of Lives Saved Among Front Seat Occupants of Light-Duty Vehicles Involved in Collisions Attributable to the Use of Seat Belts and Air Bags in Canada. Ottawa, Ontario, Canada: Government of Canada.

Transport Canada. 1997. What you should know about anti-lick braking. In Transport Canada Road Safety. http://www.tc.gc.ca/roadsafety/tp/tp13082/absind e.htm (accessed June 16, 2008).

Transport Canada. 1996. Safety Issues for Canadians: Air Bags. In Transport Canada Road Safety. http://www.tc.gc.ca/roadsafety/absg/airboce.htm (accessed June 16, 2008). 
Transport Canada. 1995. Traffic Accident Information Database User's Guide. Ottawa, Ontario, Canada: Transport Canada.

Transportation Association of Canada. 1999. Geometric Design Guide for Canadian Roads. Ottawa, Ontario, Canada: Transportation Association of Canada.

Transportation Research Board. 2000. Statistical Relationship Between Vehicular Crashes and Highway Access. Paper presented at the Fourth National Access Management Conference, August 13-16, Portland, Oregon, U.S.

Wang, Z., J. J. Lu, and Q. Xiang. 2005. Safety and Operational Impacts of Access Management Techniques. Advances in Transportation Studies A\&B (6): 85-95.

Warren, D. L. 1985. Accident Analysis of Left Turn Phasing. Public Roads 48(4): $121-127$.

Zegeer, C., R. Stewart, D. Reinfurt, F. Council, T. Neuman, E. Hamilton, T. Miller, W. Hunter. 1990. Cost Effective Geometric Improvements for Safety Upgrading of Horizontal Curves, Volume I, Final Report. McLean Virginia: Federal Highway Administration.

Zein, Sany, and Jeannette Montufar. 2003. Roadway Safety Benchmarks Over Time. Ottawa, Ontario, Canada: Transport Canada. 